
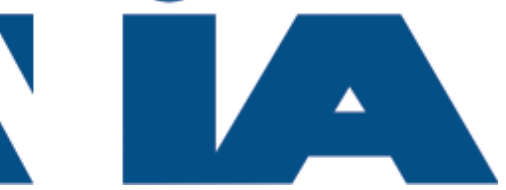

INSTITUTO NACIONAL DE INVESTIGACIÓN AGROPECUARIA

URUGUAY

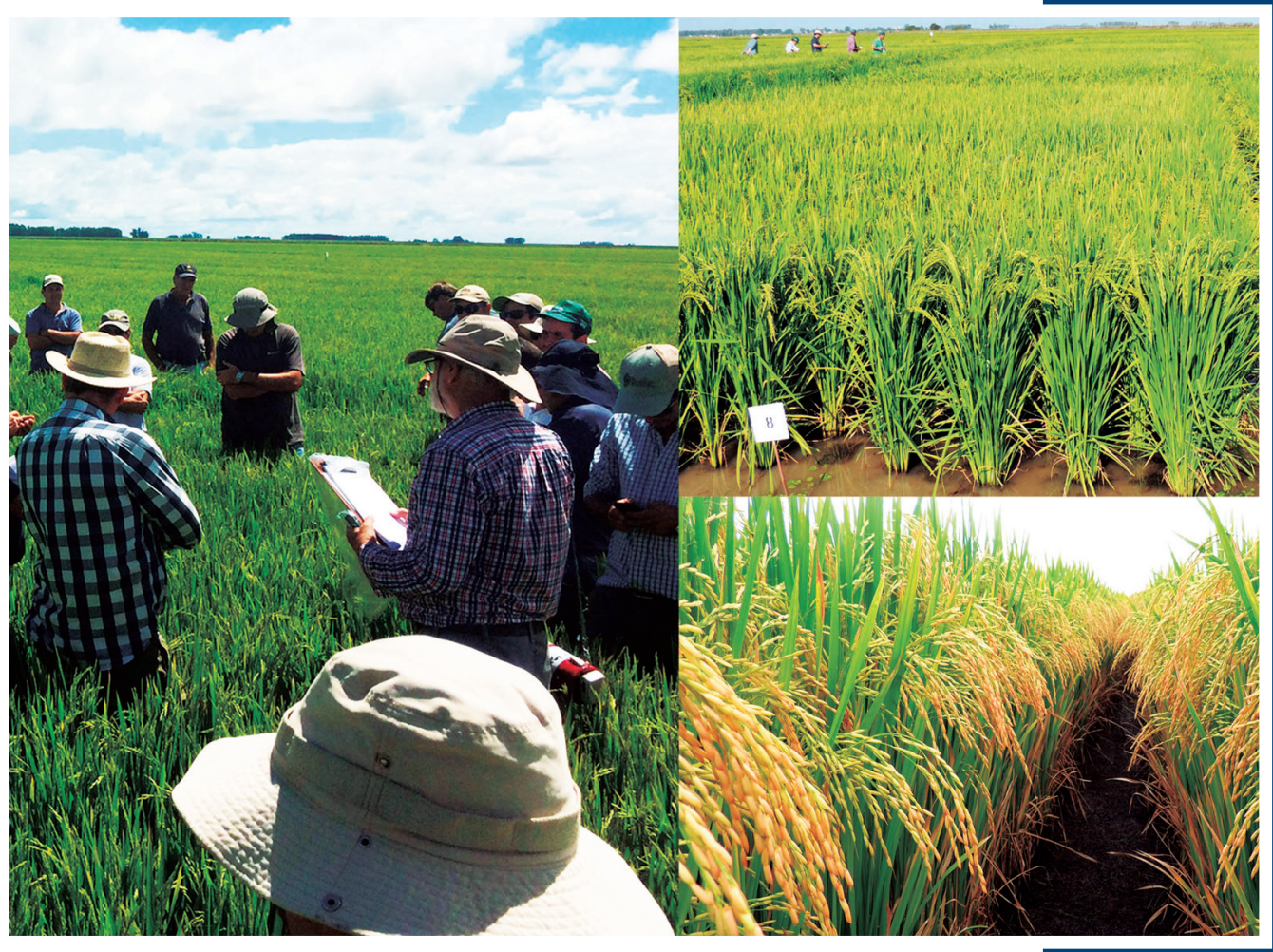

\title{
ROMPIENDO EL
}

TECHO DE

RENDIMIENTO

DEL CULTIVO DE

ARROZ

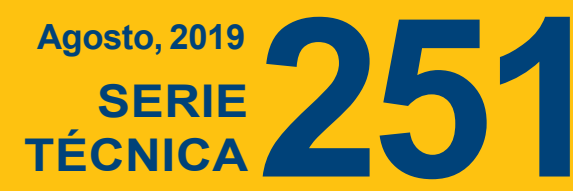

INIA 


\section{ROMPIENDO EL TECHO DE RENDIMIENTO DEL CULTIVO DE ARROZ}

Autores: Enrique Deambrosi ${ }^{1}$, Gonzalo Zorrilla ${ }^{2}$, Mathías Lauz ${ }^{3}$, Pedro Blanco ${ }^{4}$, José Terra ${ }^{5}$

\footnotetext{
${ }^{1}$ M.Sc Coordinador técnico y supervisor de actividades del proyecto
}

${ }^{2}$ M.Sc. Coordinador general del proyecto

${ }^{3}$ Asistente técnico, Contratado por el proyecto ANII 3507

${ }^{4}$ M.Sc. Investigador de INIA hasta marzo 2018

${ }^{5}$ Ph.D. Investigador, Director Programa Nacional de Investigación en Producción de Arroz, INIA 
Título: ROMPIENDO EL TECHO DE RENDIMIENTO DEL CULTIVO DE ARROZ

Autores: E. Deambrosi, G. Zorrilla, M. Lauz, P. Blanco, J. Terra

Serie Técnica $N^{\circ} 251$

(C) 2019, INIA

doi: http://doi.org/10.35676/INIA/ST.251

ISBN: 978-9974-38-432-3

e-ISBN:978-9974-38-431-6

Editado por la Unidad de Comunicación y Transferencia de Tecnología del INIA Andes 1365, Piso 12. Montevideo - Uruguay

http://www.inia.uy

Quedan reservados todos los derechos de la presente edición. Esta publicación no se podrá reproducir total o parcialmente sin expreso consentimiento del INIA. 


\section{Instituto Nacional de Investigación Agropecuaria}

\section{Integración de la Junta Directiva}

D.M.T.V., Ph.D. José Luis Repetto - Presidente

Ing. Agr., Mag. Mariana Hill - Vicepresidenta

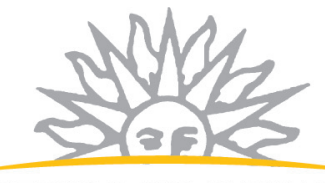

MINISTERIO DE GANADERÍA

AGRICULTURA Y PESCA

REPUBLICA ORIENTAL DEL URUGUAY

Ing. Agr. Rafael Secco
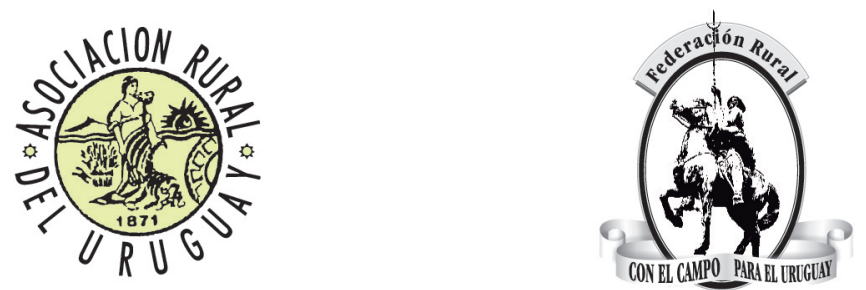

Ing. Agr. Alberto Bozzo

Ing. Agr. Alejandro Henry
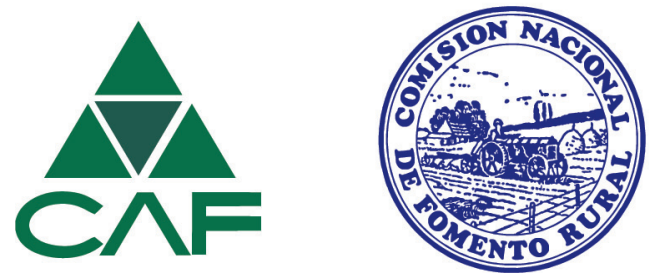



\section{CONTENIDO}

Página

1. INTRODUCCIÓN....................................................................................... 1

2. MATERIALES Y MÉTODOS...................................................................... 3

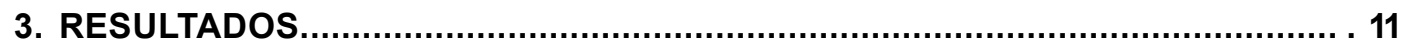

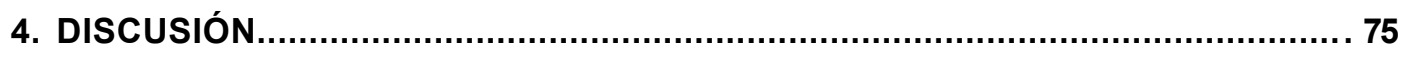

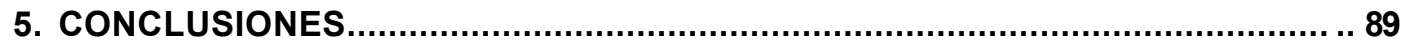

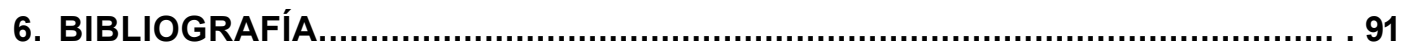

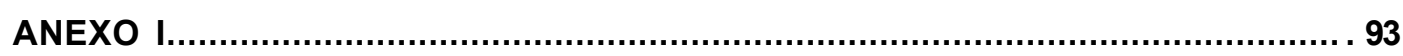

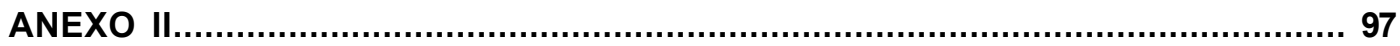





\section{ÍNDICE DE FIGURAS}

Página

Figura 1. Rendimiento promedio de arroz en Uruguay (2000 a 2013) .......................... 1

Figura 2. Edad de los entrevistados, según grupo de productores ............................ 11

Figura 3. Nivel de educación, según grupo de productores ..................................... 12

Figura 4.Tamaño de las chacras (ha), según grupo de productores .......................... 12

Figura 5. Utilización del laboreo de verano (LV) según grupo de productores .............. 14

Figura 6. Aplicación de glifosato pre-siembra según grupo de productores ................ 15

Figura 7. Cultivares sembrados según grupo de productores (aparecen solamente cultivares con más de $25 \%$ de menciones) ...................................................... 16

Figura 8. Épocas de siembra preferidas, según grupo de productores ...................... 16

Figura 9. Densidad de siembra utilizada, según grupo de productores (el porcentaje de menciones no debe necesariamente sumar 100, pues pueden corresponder a situaciones y/o años diferentes)

Figura 10. Aplicación de fertilizante anticipado a la siembra según grupo de productores 18

Figura 11. Tipo de fertilizante aplicado en la siembra según grupo de productores (el porcentaje de menciones no debe necesariamente sumar 100 , pues pueden corresponder a situaciones y/o años diferentes)

Figura 12. Fuentes de $\mathrm{N}$ utilizadas en coberturas según grupo de productores (el porcentaje de menciones no debe necesariamente sumar 100, pues pueden corresponder a situaciones y/o años diferentes)

Figura 13. Épocas de aplicación de $\mathrm{N}$ en cobertura según grupo de productores (el porcentaje de menciones no debe necesariamente sumar 100, pues pueden corresponder a situaciones y/o años diferentes)

Figura 14. Forma de aplicación de la primera cobertura nitrogenada según grupo de productores (el porcentaje de menciones no debe necesariamente sumar 100 , pues pueden corresponder a situaciones y/o años diferentes)

Figura 15. Total de $\mathrm{N} \mathrm{kg/ha} \mathrm{aplicado} \mathrm{en} \mathrm{cobertura} \mathrm{según} \mathrm{grupo} \mathrm{de} \mathrm{productores} \mathrm{(el}$ porcentaje de menciones no debe necesariamente sumar 100 , pues corresponde a situaciones y/o años diferentes) 
Figura 16. Prácticas que modificarían los productores para incrementar los rendimientos: a) ingresar antes a los campos; b) acceder a una rotación; c) más laboreos de verano o anticipados; d) mayor sistematización; e) más drenajes; f) fechas de siembra; g) fertilización; h) sembrar por encima de las taipas; i) reducir la altura de las taipas; j) manejo del riego, y dentro de él un subconjunto referido específicamente a la velocidad; $k$ ) ajustes entre cosecha y recibo del arroz producido; I) variedades

Figura 17. Rendimientos secos y limpios (SL) y sanos, secos y limpios (SSL) obtenidos en Rincón de Ramírez, zafra 2014-2015 37

Figura 18. Rendimientos secos y limpios (SL) y sanos, secos y limpios (SSL) obtenidos en $7^{\text {a }}$ Sección de Treinta y Tres, zafra 2014-2015 40

Figura 19. Rendimientos secos y limpios (SL) y sanos, secos y limpios (SSL) obtenidos en Cebollatí, zafra 2014-2015 42

Figura 20. Rendimientos secos y limpios (SL) y sanos, secos y limpios (SSL) obtenidos en India Muerta. 2014-2015 45

Figura 21. Rendimientos secos y limpios (SL) y sanos, secos y limpios (SSL) obtenidos en Rincón de Ramírez, zafra 2015-2016 48

Figura 22. Rendimientos secos y limpios (SL) y sanos, secos y limpios (SSL) obtenidos en Costas de San Francisco, zafra 2015-2016

Figura 23. Rendimientos secos y limpios (SL) y sanos, secos y limpios (SSL) obtenidos en Cebollatí, zafra 2015-2016 53

Figura 24. Rendimientos secos y limpios (SL) y sanos, secos y limpios (SSL) obtenidos en India Muerta, zafra 2015-2016 55

Figura 25. Análisis estadístico de rendimientos SSL Rincón de Ramírez, zafras 2014-2015 y 2015- 2016, según el método del «árbol» 57

Figura 26. Análisis estadístico de rendimientos SSL $7^{\text {a }}$ S. de Treinta y Tres - C. de San Francisco, zafras 2014-2015 y 2015- 2016, según el método del «árbol»

Figura 27. Análisis estadístico de rendimientos. Cebollatí, zafras 2014-2015 y 2015-2016, según el método del «árbol» 60

Figura 28. Análisis estadístico de rendimientos. India Muerta, zafras 2014-2015 2015- 2016, según el método del «árbol»

Figura 29. Radiaciones solares registradas en Paso de la Laguna en las zafras 2014-2015, 2015-2016 y 2016-2017 


\section{ÍNDICE DE CUADROS}

Página

Cuadro 1. Tasas (\%) y cantidades adicionales de reposición de P y K de acuerdo a los contenidos de nutrientes detectados en los análisis de suelos ...................... 4

Cuadro 2. Conformación de los 12 tratamientos en base a niveles tecnológicos .......... 5

Cuadro 3. Fechas de siembra de los experimentos según año y localización. ............. 6

Cuadro 4. Análisis de suelos de muestras $(0-15 \mathrm{~cm})$ extraídas en 4 localizaciones

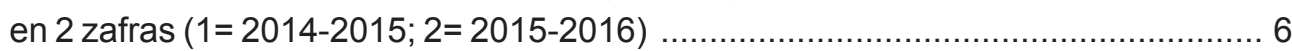

Cuadro 5. Tecnologías testigo vs alternativa (tratamientos $\mathrm{N}^{0} 1$ y 7 respectivamente) en las 4 localidades*. Zafra 2014-2015 ........................................................ 7

Cuadro 6. Fechas de instalación y cosecha de los sitios de validación 2016-2017 ....... 9

Cuadro 7. Análisis de suelos $(0-15 \mathrm{~cm})$ de muestras extraídas en 6 sitios de

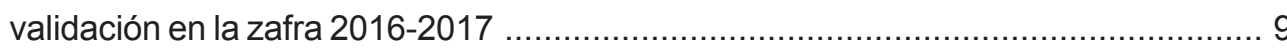

Cuadro 8. Tecnologías testigo (tratamiento $\mathrm{N}^{\circ} 1$ ) y alternativas (tratamientos $\mathrm{N}^{\circ} 9$ en Rincón de Ramírez, Costas de San Francisco, $7^{\text {a }}$ Sección de Treinta y Tres, Vuelta Grande e India Muerta y № 12 en Cebollatí). Validaciones, zafra 2016-2017 ... 10

Cuadro 9. Distribución de edades de los productores según fajas etarias de cada 10 años .. 11

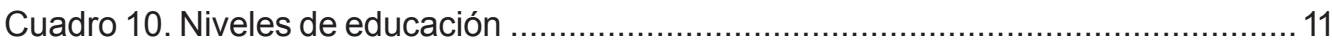

Cuadro 11. Tamaño de chacras sembradas en los últimos 3-4 años ......................... 12

Cuadro 12. Épocas y cantidad de aplicaciones de glifosato realizadas antes de la

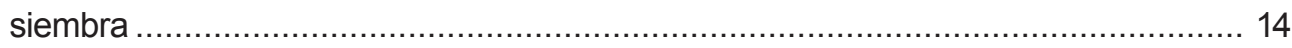

Cuadro 13. Cultivares sembrados. Número de menciones y porcentaje de encuestados 15

Cuadro 14. Períodos en que desearía ubicar la siembra de los cultivos ..................... 16

Cuadro 15. Fertilizantes utilizados en aplicaciones basales .................................. 19

Cuadro 16. Formas de aplicación de la $1^{\mathrm{a}}$ cobertura nitrogenada y su relación con el riego . 21

Cuadro 17. Razones para dividir o no el nitrógeno en diferentes proporciones yépocas ......... 22

Cuadro 18. Herbicidas utilizados en el control de malezas ..................................... 24

Cuadro 19. Productos y/o mezclas de productos (ingredientes activos) utilizados

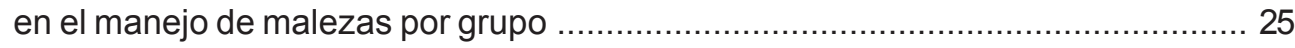


Cuadro 20. Intervalos verticales utilizados para la construcción de taipas 26

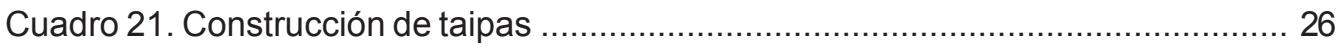

Cuadro 22. Épocas de inundación de los cultivos ................................................... 27

Cuadro 23. Niveles de riego utilizados dentro de los cuadros ................................. 27

Cuadro 24. Prácticas que contribuyen a prevenir problemas serios con enfermedades ........ 28

Cuadro 25. Estrategias de uso de los fungicidas para el manejo de las enfermedades .......... 29

Cuadro 26. Fungicidas utilizados en el manejo de enfermedades ........................... 29

Cuadro 27. Productos y/o mezclas de productos (ingredientes activos) utilizados en el manejo de enfermedades por grupo .......................................................... 29

Cuadro 28. Momentos y condiciones del día preferidos para realizar aplicaciones de fungicidas

Cuadro 29. Volúmenes de solución total utilizados en las aplicaciones aéreas de

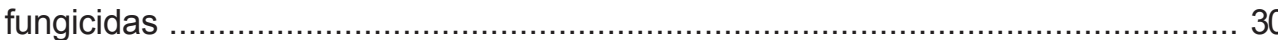

Cuadro 30. Tratamientos de control de insectos en la etapa reproductiva .................. 30

Cuadro 31. Manejo del riego para realizar la cosecha ........................................... 31

Cuadro 32. Rango de variabilidad de los rendimientos de un productor dentro de una zafra ..... 31

Cuadro 33. Factores que contribuyen al logro de una productividad alta .................... 34

Cuadro 34. Testigos tecnológicos de las 3 zonas ................................................ 35

Cuadro 35. Tratamientos aplicados y resultados en rendimiento de arroz sano, seco y limpio (SSL). Rincón de Ramírez, 2014-2015 .............................................. 36

Cuadro 36. Contrastes ortogonales de factores y/o sub-factores. Rincón, 2014-2015 ..... 37

Cuadro 37. Tratamientos aplicados y resultados en rendimiento de arroz sano, seco y limpio (SSL). $7^{\text {a }}$ Sección de Treinta y Tres, 2014-2015 ..................................... 39

Cuadro 38. Contrastes ortogonales de factores y/o sub-factores. $7^{\text {a }}$ Sección de Treinta y Tres. 2014-2015

Cuadro 39. Tratamientos aplicados y resultados en rendimiento de arroz sano, seco y limpio (SSL). Cebollatí. 2014-2015 .............................................................. 42

Cuadro 40. Contrastes ortogonales de factores y/o sub-factores. Cebollatí. 2014-2015 .... 43

Cuadro 41. Tratamientos aplicados y resultados en rendimiento de arroz sano, seco y limpio (SSL). India Muerta. 2014-2015 
Cuadro 42. Contrastes ortogonales de factores y/o sub-factores. India Muerta. 2014-2015 46

Cuadro 43. Tratamientos aplicados y resultados en rendimiento de arroz sano, seco y limpio (SSL). Rincón de Ramírez. 2015-2016 ....

Cuadro 44. Contrastes ortogonales de factores y/o sub-factores. Rincón. 2015-2016 49

Cuadro 45. Tratamientos aplicados y resultados en rendimiento de arroz sano, seco y limpio (SSL). Costas de San Francisco. 2015-2016 49

Cuadro 46. Radiación solar diaria promedio (MJ/m²/día) por décadas. Años 2015, 2016 . 50

Cuadro 47. Contrastes ortogonales de factores y/o sub-factores. Costas de San Francisco. 2015-2016

Cuadro 48. Tratamientos aplicados y resultados en rendimiento de arroz sano, seco y limpio (SSL). Cebollatí 2015-2016 52

Cuadro 49. Contrastes ortogonales de factores y/o sub-factores. Cebollatí. 2015-2016 53

Cuadro 50. Tratamientos aplicados y resultados en rendimiento de arroz sano, seco y limpio (SSL). India Muerta. 2015-2016 55

Cuadro 51. Contrastes ortogonales de factores y/o sub-factores. India Muerta. 2015-2016 56

Cuadro 52. Rincón de Ramírez. Resultados del análisis conjunto de rendimientos SSL, zafras 2014-2015 y 2015-2016

Cuadro 53. $7^{\mathrm{a}} \mathrm{S}$. de Treinta y Tres - C. de San Francisco. Resultados del análisis de rendimientos SSL, zafras 2014-2015 y 2015-2016 58

Cuadro 54. Cebollatí. Resultados del análisis conjunto de rendimientos SSL, zafras 2014-2015 y 2015-2016 39

Cuadro 55. India Muerta. Resultados del análisis conjunto de rendimientos SSL, zafras 2014-2015 y 2015-2016 60

Cuadro 56. Tratamientos seleccionados para la etapa de validación ..... 61

Cuadro 57. Resumen de prácticas de manejo según tratamientos y resultados obtenidos en la validación. Rincón de Ramírez, zafra 2016-2017 62

Cuadro 58. Resumen de prácticas de manejo según tratamientos y resultados obtenidos en la validación. Costas de San Francisco, zafra 2016-2017 64

Cuadro 59. Resumen de prácticas de manejo según tratamientos y resultados obtenidos en la validación. $7^{a}$ Sección de Treinta y Tres, zafra 2016-2017 66 
Cuadro 60. Resumen de prácticas de manejo según tratamientos y resultados obtenidos en la validación. Cebollatí, zafra 2016-2017

Cuadro 61. Análisis de muestras de suelos en área con afección de plantas de arroz. Validación Cebollatí, zafra 2016-2017

Cuadro 62. Algunas características de suelos comparativas de las localizaciones Cebollatí, Vuelta Grande, India Muerta. Validaciones, zafra 2015-2016 70

Cuadro 63. Resumen de prácticas de manejo según tratamientos y resultados obtenidos en la validación. Vuelta Grande, zafra 2016-2017

Cuadro 64. Resumen de prácticas de manejo según tratamientos y resultados obtenidos en la validación. India Muerta, zafra 2016-2017

Cuadro 65. Trabajos de validación 2016-2017. Resultados Rendimientos SL y SSL ... 74

Cuadro 66. Rendimientos SL y SSL obtenidos en 14 ambientes en las zafras 2014-2015, 2015-2016 (investigación parcelaria) y 2016-2017 (validaciones) 82

Cuadro 67. Relaciones entre resultados obtenidos en rendimiento SL y SSL entre la investigación parcelaria y la validación y entre las tecnologías testigo y alternativa

Cuadro 68. Componentes del rendimiento promedio en tratamientos de alta productividad en 4 localizaciones, zafras 2014-2015 y 2015-2016

Cuadro 69. Componentes del rendimiento promedio en parcelas de las validaciones, zafra 2016-2017 84

Cuadro 70. Registros promedio de componentes del rendimiento en tratamientos seleccionados por alta productividad en la etapa de investigación y de las 2 tecnologías en las validaciones

Cuadro 71. Contenidos promedio de nitrógeno, fósforo y potasio en grano y paja en tratamientos seleccionados por alta productividad en la etapa de investigación y de las 2 tecnologías en las validaciones

Cuadro 72. Cantidad de nutrientes (N-P-K) movilizados por tonelada de grano en distintos sistemas de producción

Cuadro 73. Productividad parcial y eficiencia interna de nitrógeno obtenidas en las validaciones 2016-2017 en comparación con otro sistema de producción 


\section{Resultados del proyecto financiado por la Agencia Nacional de Investigación e Innovación (ANII_ALI_1_2012_1_3507) y ejecutado por la Alianza para la Innovación conformada a tal efecto por el Instituto Nacional de Investigación Agropecuaria (INIA), la Asociación de Cultivadores de Arroz (ACA) y la industria (Gremial de Molinos Arroceros y Coopar)}

La gestión del proyecto estuvo a cargo de un comité técnico integrado por representantes de las instituciones desde su formulación, desarrollo, análisis de resultados y conclusiones.

\section{Comité técnico}

Por INIA: Blanco, P., Castillo, J., Macedo, I., Méndez, R., Pérez de Vida F.

Por Asociación Cultivadores de Arroz: Zorrilla, H., Stirling, E.

Por Gremial de Molinos Arroceros y Coopar: Uraga, R., Marella, M., Gonnet, D., Rovira,G.

El proyecto se desarrolló en su totalidad en campos de productores arroceros, a quienes se agradece su colaboración, así como a los 39 productores de punta que participaron de la encuesta sobre manejo del cultivo

Productores y empresas colaboradores

Alex Chagas y Edison Gomes Chagas (Labrustar), Martín Gigena y Federico Gigena (Agropecuaria EI Tero), Leonardo Olivera, Raúl Ferreira (Agropecuaria del Este), Guillermo Young (Campo Rojo), Gustavo Bachino, Edgart Martínez y María Noel Martínez (Anabella Olascoaga) 



\section{PRÓLOGO}

En 2012 se conformó un equipo de trabajo interinstitucional INIA-ACA-GMA con el fin de buscar respuestas a la preocupante tendencia a estabilización de los rendimientos nacionales del arroz, en el entorno de los 8 t/ha, que hacía presumir una aproximación al techo productivo. De esta iniciativa surgió un proyecto cofinanciado por ANII, INIA, GMA, COOPAR y ACA en el modelo de Alianza para la Innovación, que permitió desarrollar dos años de experimentos en campos de productores y un tercer año de validación de los resultados iniciales, en áreas comerciales manejadas por los propios productores. Al término de estos tres años de trabajo, se pudo comprobar que aún existe una brecha de rendimientos potenciales alcanzables a explorar por los productores uruguayos, a pesar de estar hoy entre los más altos del mundo. En un período en el cual el sector arrocero ha sufrido reducciones continuas de área sembrada por dificultades económicas asociadas a variables que en general no están al alcance del productor, éste es un mensaje fuerte y positivo, que sugiere que todavía hay espacio en los sistemas de producción para aplicar conocimientos y tecnologías de manejo que pueden contribuir a una mejora de los resultados productivos y los ingresos. 



\section{1 - INTRODUCCIÓN}

En los últimos 20 años el rendimiento promedio del cultivo de arroz se ha incrementado a una tasa de $160 \mathrm{~kg} / \mathrm{ha} / \mathrm{año}$, alcanzando un promedio de 7,9 t/ha, el cual está al nivel de los más altos internacionalmente.

Sin embargo, la productividad máxima que obtienen los productores de mayores rendimientos muestra un estancamiento en aproximadamente $12 \mathrm{t} / \mathrm{ha}$, el cual es similar al obtenido a nivel experimental. Esto resulta en una paulatina reducción de la brecha entre el rendimiento potencial alcanzable en nuestras condiciones y el obtenido por la generalidad de los productores (Figura 1).

En el Grupo de Trabajo Arroz de INIA, integrado por productores y técnicos del sector productivo e industrial, en más de una oportunidad se ha planteado la necesidad de estudiar métodos o prácticas alternativas de manejo del cultivo, que permitan superar el techo de rendimientos existente. El incremento de los costos de producción registrado en los últimos años hace que los márgenes económicos de los cultivos sean cada vez menores y en muchos casos negativos, lo que hace mucho más crítica la necesidad de incrementar este potencial.

Con el fin de analizar alternativas tecnológicas para explorar un mayor potencial de rendimiento en la zona este del país, se creó una Alianza para la Innovación entre el Instituto Nacional de Investigación Agropecuaria (INIA), la Asociación de Cultivadores de Arroz (ACA) y la industria (Gremial de Molinos Arroceros y Coopar), la cual se presentó a la ANII y obtuvo la financiación para el desarrollo del proyecto «Rompiendo el techo de rendimiento del cultivo del arroz» (ANII_ALI_1_2012_1_3507), del cual se presentan los resultados principales en esta publicación.

Internacionalmente se considera que la productividad del arroz irrigado se ha estabilizado en rendimientos máximos teóricos de $10 \mathrm{t} / \mathrm{ha}$ en regiones tropicales, a 13-15 t/ha en regiones templadas (Yoshida, 1981; Kropff et al., 1994; Mitchel et al., 1998). Estos rendimientos potenciales fueron estimados utilizando diversos modelos, en base a la radiación fotosintéticamente activa (PAR) y a la eficiencia de conversión de radiación solar a biomasa. En condiciones tropicales, se menciona que la PAR varía entre un promedio de 7,8, en la estación húmeda, a 9,1 $\mathrm{MJ} / \mathrm{m}^{2} / \mathrm{d}$, en la estación seca, mientras que en las regiones templadas varía entre 7,8 y 12,6 MJ/m²/d (Mitchel et al., 1998).

En nuestras condiciones, se estimó que la PAR promedio para el período de crecimiento, en base a datos climáticos de la serie histórica de 1971 a 2011 (Paso de la

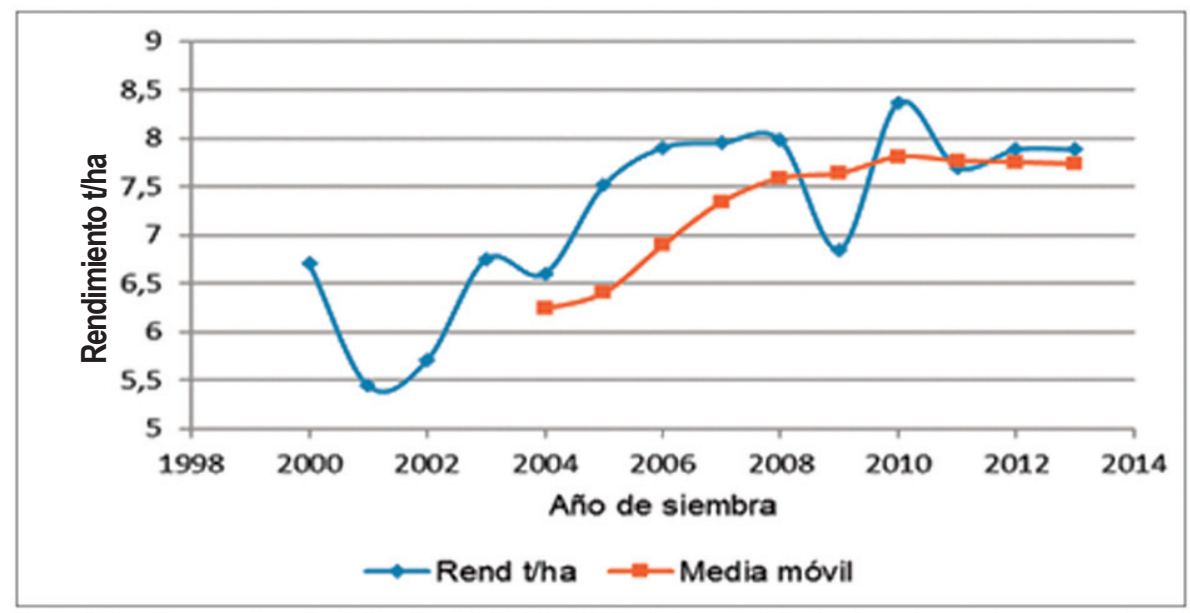

Figura 1. Rendimiento promedio de arroz en Uruguay (2000 a 2013). 
Laguna, Treinta y Tres), es de $9,1 \mathrm{MJ} / \mathrm{m}^{2} /$ día, a la cual corresponde un rendimiento estimado de 10-11 t/ha (Pérez de Vida, 2011). A nivel experimental, en años con buenas condiciones de radiación y temperatura, se han alcanzado rendimientos máximos de 12-13 t/ha. En un estudio de la evolución del rendimiento de los productores de arroz en los últimos 40 años, los datos fueron agrupados en cuantiles, $10 \%, 25 \%$, mediana, $75 \%, 90 \%$ y máximo, para períodos de 5 años en cada década (Blanco et al., 2010). Se observó que el rendimiento máximo alcanzado, en los últimos 20 años, se ha nivelado en aproximadamente $12 \mathrm{t} / \mathrm{ha}$, mientras que el rendimiento del cuartil superior (90\%) pasó de 7,9 t/ha a 9,5 t/ha, de 19951999 a 2005-2009. Esto permite afirmar que los productores de mayor productividad están obteniendo rendimientos similares a los máximos estimados para nuestras condiciones y a los alcanzados a nivel experimental, resultando en la anulación de la brecha entre el rendimiento potencial y alcanzable. En el mismo período, el rendimiento de la mediana de los productores tendía a reducirse. En otros estudios sobre la brecha de rendimiento, se concluyó que la principal variable en determinar las diferencias de rendimiento entre productores era su capacidad de gestión (Uraga et al., 2011).

El mencionado plateau en los rendimientos potenciales de arroz se registra también a nivel internacional y la situación se repite en otros cultivos, como trigo, soja y maíz (Cassman, 1999; Laborte et al., 2012; Aggarwal et al., 2008; Below y Gentry, 2011).
El objetivo general de este proyecto formulado en 2012 y 2013 fue generar tecnologías y prácticas de manejo integrado del cultivo que permitan incrementar al menos $10 \%$ la productividad respecto a la obtenida con la tecnología utilizada por los productores del quintil superior de rendimiento en la zona Este del país.

Sus objetivos específicos fueron:

1) identificar las tecnologías y prácticas de manejo asociadas a los grupos de productores pertenecientes al quintil superior de rendimiento;

2) conceptualizar tecnologías y prácticas de manejo integrado del cultivo para superar el rendimiento de los productores pertenecientes al quintil superior de la zona Este en por lo menos un 10\%;

3) generar una propuesta económicamente viable del cultivo de arroz para aumentar la productividad respecto a la obtenida por los productores del quintil superior;

4) validar a escala productiva y transferir a la generalidad de productores la propuesta de manejo integrado del cultivo para alta productividad.

Esta publicación resume los resultados y conclusiones a nivel de rendimientos físicos y de la posibilidad de incrementarlos por encima de los que alcanzan actualmente los productores de punta del este del país. Se publicarán más adelante el análisis económico de las distintas alternativas de manejo planteadas en el proyecto y un artículo técnico sobre los aspectos fisiológicos y de eficiencia de uso de nutrientes relacionados con la obtención de altos rendimientos. 


\section{2 - MATERIALES Y MÉTODOS}

\subsection{Prácticas de manejo utilizadas por los productores del quintil superior de rendimientos}

Para detectar cuáles eran los factores o prácticas más importantes que contribuyen al logro de la máxima productividad regional, los molinos Saman, Coopar y Casarone, identificaron listas de sus productores remitentes en la zona este que hayan integrado en al menos 3 de los últimos 4 años anteriores (2008-2012) el quintil superior de rendimientos de sus industrias. En base a las mismas, en agosto-setiembre de 2013 se entrevistó en forma personal a 39 empresas arroceras seleccionadas (a sus titulares y/ó técnicos asesores delegados por sus titulares). El rendimiento medio de estas empresas en los últimos 3 años fue de 9 t/ha, un $13,6 \%$ por encima de la media de la región. Se manejó un cuestionario guía para recabar y posteriormente procesar información según diferentes aspectos tratando de cubrir en su conjunto el manejo general del cultivo (Anexo I).

En base a su localización y características ambientales, entre los encuestados se definieron 3 grupos de productores, identificados como Treinta y Tres, Cebollatí e India Muerta, respectivamente. En el primer grupo se integraron 15 productores que siembran en las zonas de Rincón de Ramírez, La Charqueada y $7^{\text {a }}$ Sección del Departamento de Treinta y Tres. En un segundo grupo, denominado Cebollatí, se integraron 14 productores que siembran en alrededores de Cebollatí, Lascano y norte de Lavalleja. En el tercero, India Muerta, se agruparon productores del departamento de Rocha, que siembran en las zonas de India Muerta, San Luis y San Miguel.

Del análisis de las entrevistas realizadas, el comité técnico integrado por representantes de INIA, ACA, GMA y Coopar seleccionó dentro de cada grupo las opciones más utilizadas dentro de 20 tecnologías de manejo integrado del cultivo de arroz.
En diciembre de 2013 se organizó un taller con los productores encuestados, donde se presentó la información procesada, la conformación de los grupos y las prácticas seleccionadas en cada uno de ellos. De la discusión e intercambio de ideas surgió un set definitivo de técnicas de manejo asociadas a los productores de mayores rendimientos en cada subregión.

\subsection{Propuestas tecnológicas para superar los rendimientos de los productores del quintil superior}

\subsubsection{Factores tecnológicos alternativos}

En una segunda etapa el comité técnico buscó conceptualizar propuestas tecnológicas alternativas que permitan superar ese nivel de rendimiento (objetivo específico 2). Se intercambiaron ideas sobre posibles opciones, tratando de manejar prácticas realizables, minimizando el riesgo de perder las evaluaciones o parte de ellas, ya sea por operativa y/o falta de recursos humanos.

Se seleccionaron cuatro factores, para manejar prácticas alternativas: 1) cultivar, en base a productividad y resistencia a Brusone; 2) instalación del cultivo, considerando tratamientos de semilla y el número de plantas a instalar por unidad de superficie; 3$)$ manejos de la fertilización, a la siembra y posteriores en cobertura (incluyendo macro y micronutrientes); 4) protección de enfermedades (número de aplicaciones de fungicida / agregados de fosfito de potasio y silicio).

En el Factor 1 «cultivar», el testigo tecnológico (TT) que era El Paso 144 se cambió por CH-Quebracho en Rincón de Ramírez en los 2 años. En la $7^{\text {a }}$ Sección de Treinta y Tres en la zafra 2014-2015 y en Costas de San Francisco en la zafra 2015-2016 El Paso 144 fue sustituida por INIA Merín. En el Departamento de Rocha en los 2 años se utilizó la variedad Parao en lugar de EI Paso 
144 en Cebollatí, y de INIA Tacuarí en India Muerta, respectivamente.

En el Factor 2 «instalación», como alternativa a la práctica habitual de sembrar una cantidad fija de semilla ( $\mathrm{kg} / \mathrm{ha}$ ) tratada previamente con fungicida e insecticida, se utilizaron las cantidades de semilla estimadas para lograr una implantación de 180 plantas $/ \mathrm{m}^{2}$, tratadas con fungicida, insecticida y zinc, e inoculada con la endobacteria Herbaspirillum, teniendo en cuenta el peso de granos, viabilidad de la semilla y considerando porcentajes de recuperación de plantas de 50 y $40 \%$ para Treinta y Tres y Rocha, respectivamente.

En el Factor 3 «fertilización», se propusieron dos subfactores: Fertilización 1 y Fertilización Plus.

En Fertilización 1, se ajustó la dosis según los resultados de análisis de suelos en contenidos de fósforo (según el método de ácido cítrico), potasio (según el método de acetato de amonio) y nitrógeno aplicado al macollaje (por potencial de mineralización). En caso de encontrarse valores menores a los niveles críticos establecidos en la zona este, 7 ppm de $\mathrm{P}, 0,20$ meq de $\mathrm{K} /(100 \mathrm{~g}$ de suelo), 53,6 g/ $/ \mathrm{kg} \mathrm{NH}_{4}$ se calcularon las correcciones necesarias para alcanzar los mismos. En forma adicional, se consideraron distintos niveles de reposición de $\mathrm{P}$ y $\mathrm{K}$ al suelo, de acuerdo con el contenido de dichos nutrientes relevado en los análisis, y la probable extracción de un cultivo de arroz que rinda $12 \mathrm{t} /$ ha. Según IPNI con dicha productividad se estima una remoción de 2,9 $\mathrm{kg}$ de $\mathrm{P}$ y $2,9 \mathrm{~kg}$ de $\mathrm{K}$ por tonelada de grano producido, o sea $34,8 \mathrm{~kg}$ de $P$ equivalentes a $79,69 \mathrm{~kg} / \mathrm{ha}$ de $\mathrm{P}_{2} \mathrm{O}_{5 y} 34,8 \mathrm{~kg}$ de $\mathrm{K}$ equivalentes a $41,76 \mathrm{~kg} / \mathrm{ha}$ de $\mathrm{K}_{2} \mathrm{O}$. En el cuadro 1 se detallan los criterios utilizados para la reposición; considerándose 3 rangos de contenidos de $\mathrm{P}(7-10 ; 10-13 ; 13-16 \mathrm{ppm})$ y 3 de $\mathrm{K}(0,20-0,25 ; 0,25-0,30 ; 0,30-0,35$ meq/ (100 $\mathrm{g}$ de suelo)), reponiéndose $75 \%$ de la remoción en los primeros casos, $50 \%$ en los intermedios y $25 \%$ en los de mayor contenido. En las fertilizaciones nitrogenadas realizadas en la opción alternativa, en el macollaje se usó una fuente de urea con un inhibidor de la ureasa, para prevenir pérdidas de $\mathrm{N}$; en la segunda cobertura, realizada en forma previa a la formación del primordio floral, se aplicaron $50 \mathrm{~kg} / \mathrm{ha}$ de urea en las variedades $\mathrm{CH}$ Quebracho e INIA Merín y $100 \mathrm{~kg} / \mathrm{ha}$ en el caso de Parao.

En el sub-factor «Fertilización-Plus», se realizaron aplicaciones de azufre, silicio (en 2 oportunidades: macollaje y comienzo de floración), y micronutrientes (macollaje). El azufre fue aplicado en la fertilización basal,

Cuadro 1. Tasas (\%) y cantidades adicionales de reposición de $\mathrm{P}$ y $\mathrm{K}$ de acuerdo a los contenidos de nutrientes detectados en los análisis de suelos.

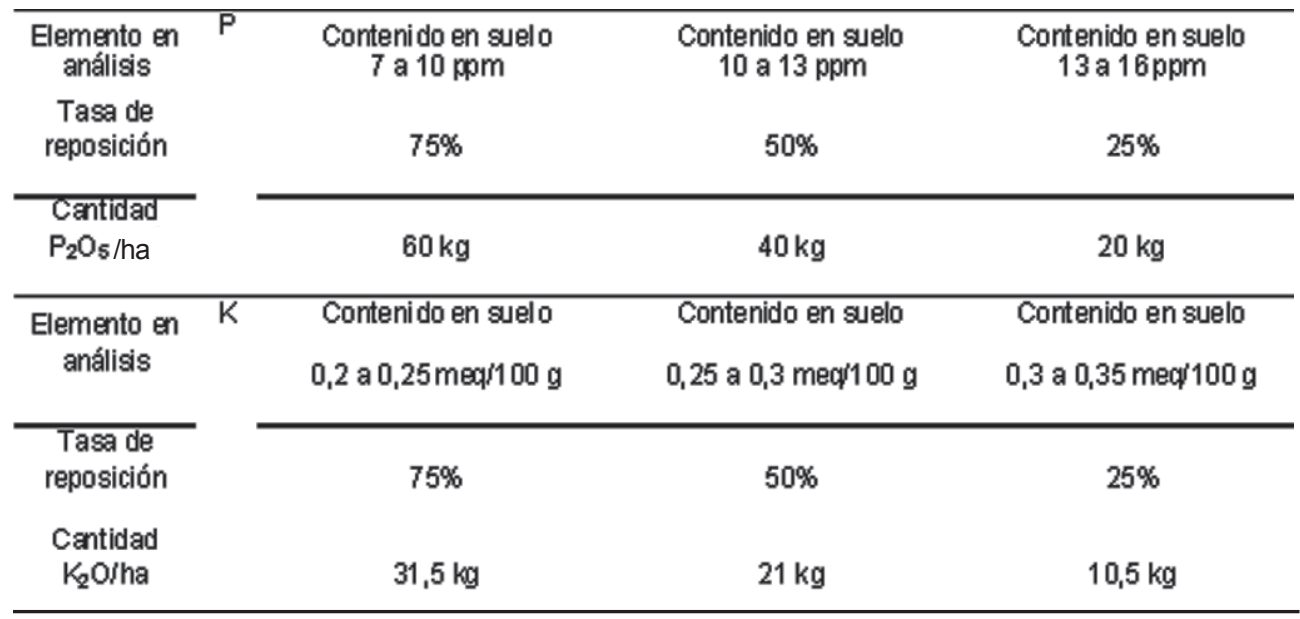

Según IPNI (2012) un cultivo de arroz que produce $12 \mathrm{t} /$ ha remueve $80 \mathrm{~kg} / \mathrm{ha}$ de $\mathrm{P}_{2} \mathrm{O}_{5}$ y $42 \mathrm{~kg} / \mathrm{ha}$ de $\mathrm{K}_{2} \mathrm{O}$. 
en general en una fuente compuesta junto al $P$, y en alguna oportunidad suministrado como complemento como sulfato de amonio. El silicio fue aplicado por aspersión en una forma soluble. El fertilizante foliar (micronutrientes) es un producto a base de aminoácidos y extractos vegetales; además de $\mathrm{N}, \mathrm{P}, \mathrm{K}$, contiene S $(0,75 \%), \mathrm{B}(0,5 \%)$, $\mathrm{Mn}(0,5 \%)$ y $\mathrm{Zn}(1 \%)$.

Como se sugiere la siembra de cultivares con resistencia (total o moderada) al ataque de Pyricularia oryzae, en el Factor 4 «protección de enfermedades», en lugar de la doble aplicación de fungicidas utilizada por los

Cuadro 2. Conformación de los 12 tratamientos en base a niveles tecnológicos*.

\begin{tabular}{|c|c|c|c|c|c|c|}
\hline \multirow{3}{*}{$\begin{array}{l}\text { Trat. } \\
N^{P} . *\end{array}$} & \multirow{3}{*}{$\begin{array}{c}\text { Nivel } \\
\text { texnológico }\end{array}$} & \multicolumn{5}{|c|}{ F actores } \\
\hline & & \multirow{2}{*}{ Cultivar } & \multirow{2}{*}{$\begin{array}{l}\text { Instal ación } \\
\text { del cultivo }\end{array}$} & \multicolumn{2}{|c|}{ Sub-factor } & \multirow{2}{*}{$\begin{array}{l}\text { Protección de } \\
\text { enfermedades }\end{array}$} \\
\hline & & & & F extilización 1 & $\begin{array}{l}\text { F ertilización } \\
\text { Plus }\end{array}$ & \\
\hline 1 & $\begin{array}{c}\text { TT } \\
\text { (Tesigo } \\
\text { Tecnológico) }\end{array}$ & $\pi$ & TT & TT & TT & TT \\
\hline 2 & $\begin{array}{c}\text { TT con } \\
\text { Cultivar PA }\end{array}$ & Alternativa & TT & TT & TT & $\pi$ \\
\hline 3 & $\begin{array}{c}\text { TT con } \\
\text { Instalación } \mathrm{PA}\end{array}$ & $\pi$ & Alternativa & TT & TT & $\pi$ \\
\hline 4 & $\begin{array}{c}\text { TT con } \\
\text { Fert ilización } 1 \\
\text { PA }\end{array}$ & $\pi$ & TT & Alt exnativa & TT & $\pi$ \\
\hline 5 & $\begin{array}{l}\text { TT con } \\
\text { Fertilización } \\
\text { PlusPA }\end{array}$ & $\pi$ & TT & TT & Alt ernativa & TT \\
\hline 6 & $\begin{array}{l}\text { TT conProt. } \\
\text { Enfermedades } \\
\text { PA }\end{array}$ & $\pi$ & TT & TT & TT & Alternativa \\
\hline & $\overline{P A}$ & & & & & \\
\hline 7 & $\begin{array}{l}\text { (Propuesta } \\
\text { Alternativa) }\end{array}$ & Altemativa & Altemaiva & Alternativa & Altem điva & Altemativa \\
\hline 8 & $\begin{array}{l}\text { PA con } \\
\text { Cultivar TT }\end{array}$ & $\pi$ & Altemaiva & Alternativa & Altemaiva & Altemativa \\
\hline 9 & $\begin{array}{c}\text { PA con } \\
\text { Instalación } \Pi \pi\end{array}$ & Altemativa & TT & Aternativa & Altemaiva & Altemativa \\
\hline 10 & $\begin{array}{c}\text { PA con } \\
\text { Fert ilización } 1 \\
\pi T\end{array}$ & Altemativa & Altemaiva & TT & Altemativa & Altemativa \\
\hline 11 & $\begin{array}{l}\text { PA con } \\
\text { Fertilización } \\
\text { PlusTT }\end{array}$ & Altemativa & Altemaiva & Alternativa & TT & Altemativa \\
\hline 12 & $\begin{array}{l}\text { PA con Prot. } \\
\text { Enfemedades } \\
\pi\end{array}$ & Altemativa & Altemaiva & Alternativa & Altemativa & $\pi$ \\
\hline
\end{tabular}

* TT = Testigo Tecnológico - prácticas correspondiente a productores del quintil superior; PA

$=$ Propuesta Alternativa; ${ }^{* *}$ Trat. №. . número de tratamiento; Prot. = Protección. 
productores del quintil superior.de rendimientos, considerando el control de enfermedades de los tallos se propuso una sola aplicación de fungicidas a inicios de floración, acompañada con el agregado de fosfito de potasio y de sílice (ya mencionado).

\subsubsection{Trabajos experimentales}

Identificadas las propuestas de mejoras tecnológicas para intentar incrementar los rendimientos, en las zafras 2014-2015 y 20152016 se instaló una serie de experimentos en predios de productores en las distintas zonas seleccionadas en la región este.

Se usó un diseño estadístico de bloques dispuestos completamente al azar con 3 repeticiones utilizando un total de 12 tratamientos, según la metodología de parcelas de omisión (Below y Gentry, 2011).

En todos los casos, el primer tratamiento (1) corresponde a la utilización de prácticas de manejo definidas según la tecnología base (o testigo) de los productores pertenecientes al quintil superior de rendimientos para cada subregión; en los tratamientos 2 al 6 , se sustituyó alguno de los factores por el uso de su práctica alternativa. En forma similar pero contraria, el tratamiento 7 corresponde al manejo en el que en todos los factores se utilizaron las prácticas alternativas a las utilizadas en el tratamiento 1; luego en los tratamientos 8 al 12, se sustituyó la práctica correspondiente a algún factor, por la usada en el testigo 1. En el cuadro 2 se presenta en forma esquemática el criterio utilizado en la conformación de los tratamientos.

Los experimentos conducidos durante las zafras 2014-2015 y 2015-2016 fueron instalados en:

- Rincón de Ramírez (coordenadas geográficas: $32^{\circ} 47^{\prime}$ Sur $-53^{\circ} 51$ Oeste en el primer año; $32^{\circ} 48^{\prime}$ Sur - $53^{\circ} 47^{\prime}$ Oeste en el segundo);

- Cebollatí $\left(33^{\circ} 23^{\prime}\right.$ Sur - $53^{\circ} 36$ Oeste en el primer año; $33^{\circ} 23^{\prime}$ Sur - $53^{\circ} 37$ Oeste en el segundo);

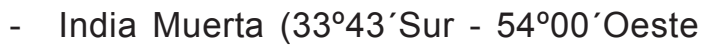
el primer año; $33^{\circ} 47^{\prime}$ Sur - $53^{\circ} 56^{\prime}$ Oeste en el segundo);

- en la $7^{a}$ Sección de Treinta y Tres en

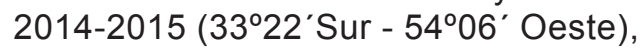
y en Costas de San Francisco en 2015-

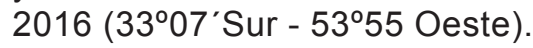

En el cuadro 3 se presentan las fechas de siembra de los experimentos en las 2

Cuadro 3. Fechas de siembra de los experimentos según año y localización.

\begin{tabular}{|c|c|c|c|c|}
\hline \multirow[b]{2}{*}{ Zafra } & \multicolumn{4}{|c|}{ Localización } \\
\hline & $\begin{array}{l}\text { Rinoón de } \\
\text { Ramírez }\end{array}$ & $\begin{array}{l}7^{\mathrm{a}} \text { S. de Treinta y Tres } / \\
\text { Costas de San Francisco }\end{array}$ & Cebollatí & India Muerta \\
\hline $2014-2015$ & 24 oct 2014 & 17 nov 2014 & 28 oct 2014 & 10 nov 2014 \\
\hline $2015-2016$ & 27 oct 2015 & 4 nov 2015 & 6 now 2015 & 7 nov 2015 \\
\hline
\end{tabular}

Cuadro 4. Análisis de suelos de muestras $(0-15 \mathrm{~cm})$ extraídas en 4 localizaciones en 2 zafras $(1=2014-2015 ; 2=2015-2016)^{*}$.

\begin{tabular}{lcccccccccccc}
\hline Loc & $\mathrm{pH}$ & PMN & CO & P cit & $\mathrm{K}$ & $\mathrm{Ca}$ & $\mathrm{Mg}$ & $\mathrm{Na}$ & $\mathrm{Zn}$ & $\mathrm{CIC}$ & $\mathrm{SB}$ & Textura \\
& & $\mathrm{mg} / \mathrm{kg}$ & $\%$ & $\mathrm{ppm}$ & $\mathrm{meq}$ & $\mathrm{meq}$ & $\mathrm{meq}$ & $\mathrm{meq}$ & $\mathrm{Mg} / \mathrm{kg}$ & $\mathrm{meq}$ & $\%$ & Ar-Li-Arc \\
RR1 & 5,5 & 18 & 2,1 & 6,7 & 0,16 & 4,4 & 1,7 & 0,11 & 0,6 & 9,8 & 65,0 & $37-41-21$ \\
RR2 & 5,2 & 46 & 1,1 & 4,3 & 0,18 & 2,7 & 1,1 & 0,25 & 0,80 & 7,8 & 53,3 & $38-39-23$ \\
\hline 7TT1 & 5,9 & 27 & 1,5 & 6,2 & 0,26 & 6,7 & 2,6 & 0,13 & 0,71 & 13,0 & 74,6 & $17-49-34$ \\
CSF2 & 5,3 & 23 & 1,9 & 5,3 & 0,32 & 5,6 & 2,0 & 0,29 & 1,17 & 11,1 & 74,2 & $28-46-26$ \\
\hline CE1 & 6,5 & 30 & 2,0 & 6,7 & 0,33 & 7,4 & 4,3 & 0,57 & 0,91 & 14,5 & 88,9 & $30-44-26$ \\
CE2 & 62 & 33 & 2,0 & 4,3 & 0,32 & 5,4 & 3,7 & 0,85 & 0,91 & 13,2 & 78,2 & $14-61-25$ \\
IM1 & 5,6 & 74 & 1,9 & 17,7 & 0,38 & 8,8 & 4,9 & 0,17 & 1,56 & 21,1 & 68,2 & $15-47-38$ \\
IM2 & 5,9 & 22 & 1,6 & 10,7 & 0,19 & 3,9 & 2,2 & 0,55 & 1,54 & 9,6 & 71,8 & $16-57-27$ \\
\hline
\end{tabular}

*Loc= localización; RR= Rincón de Ramírez; 7TT= 7a Sección de Treinta y Tres; CSF= Costas de San Francisco; $C E=$ Cebollatí; IM= India Muerta; $P M N=$ potencial de mineralización; $\mathrm{CO}=$ carbono orgánico; $\mathrm{P}$ cit= fósforo según el método de ácido cítrico; $\mathrm{K}, \mathrm{Ca}, \mathrm{Mg}, \mathrm{Na}$, $\mathrm{CIC}$ en meq/(100 g de suelo); SB = saturación en bases; $\mathrm{Ar}=\%$ arena, $\mathrm{Li}=\%$ limo, $\mathrm{Arc}=\%$ arcilla. 
zafras y en el cuadro 4 se observan en forma conjunta los resultados de análisis de muestras de suelos extraídas previa a la siembra en los sitios experimentales. Los análisis fueron realizados en el Laboratorio de Suelos, Plantas y Agua de INIA La Estanzuela. Los mismos aparecen ordenados de norte a sur por localización y zafra; en los casos RR2 (Rincón de Ramírez 2015-2016) e IM1 (India Muerta 2014-2015) las evaluaciones fueron realizadas sobre suelos con uso previo de praderas artificiales.
Como ejemplo de conformación de los tratamientos, en el cuadro 5 se presentan los tratamientos $\mathrm{N}^{0} 1$ y 7 de las 4 localidades, para la zafra 2014-2015, que constituyen el máximo contraste entre las tecnologías testigo y alternativa, respectivamente.

Se usaron parcelas de 6,12 $\mathrm{m}$ de ancho por 20 m de largo; las mismas fueron sembradas con una máquina Semeato de siembra directa de 9 hileras con una separación de $0,17 \mathrm{~m}$ entre sí.

Las fertilizaciones basales y de urea en cobertura fueron realizadas a mano; las

Cuadro 5. Tecnologías testigo vs alternativa (tratamientos $N^{0} 1$ y 7 respectivamente) en las 4 localidades*. Zafra 2014-2015.

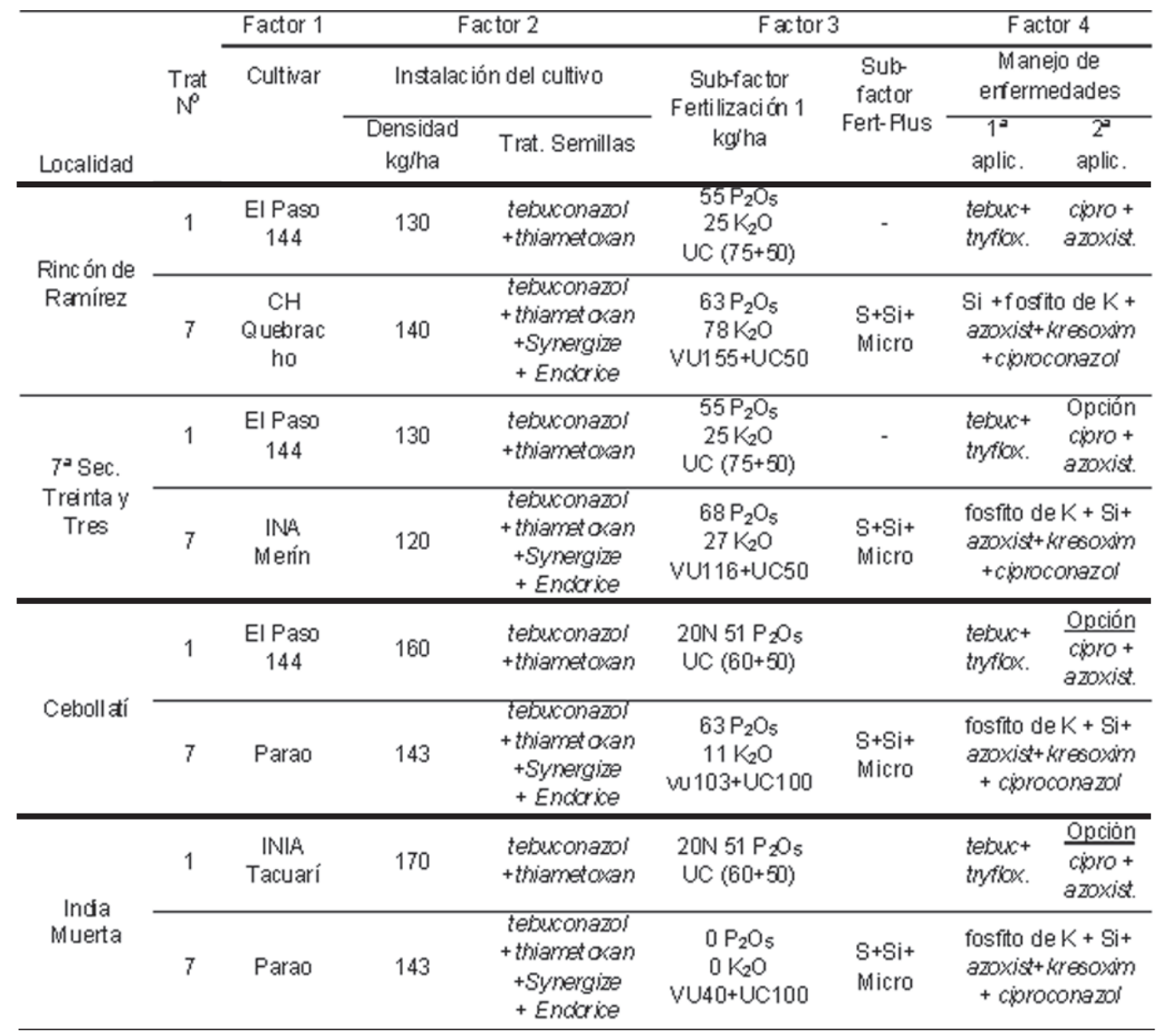

* $\mathrm{N}=$ nitrógeno; $\mathrm{P}_{2} \mathrm{O}_{5}=$ unidades de fósforo; $\mathrm{K}_{2} \mathrm{O}=$ unidades de potasio; tebuc= tebuconazol; tryflox= trifloxystrobin; cipro= ciproconazol; Azoxist= azoxistrobin; $\mathrm{S}=$ azufre; $\mathrm{Si}=$ silicio; UC= Urea común; VU= Verde urea; Micro= producto con micronutrientes, contiene $\mathrm{N}, \mathrm{P}, \mathrm{K}, \mathrm{S}, \mathrm{B}, \mathrm{Mn}, \mathrm{Zn}$ y extracto de algas Ascophyllum nodosum; Synergize $=$ producto que contiene zinc $(290 \mathrm{~g} \mathrm{ZnO})$; Endorice $=$ producto comercial que contiene Herbaspirillum; El producto comercial Tenaz con el que se aplicó silicio $(0,64 \%)$, contiene también $\mathrm{N}$ y K / «Manejo de enfermedades» tratamientos 1 se realiza la $1^{\text {a }}$ aplicación a inicios de floración; la $2^{\mathrm{a}}$ se hace, si aparecen síntomas de Brusone a los 15-20 días después, salvo en Rincón de Ramírez donde se aplicó siempre en esa época. En tratamientos 7, sólo 1 aplicación a inicios de floración. 
primeras se hicieron en forma previa a la siembra y el fertilizante no fue incorporado al suelo. Las aplicaciones de fertilizantes foliares, de silicio, de fosfito de potasio y de fungicidas fueron realizadas a pie, utilizando un equipo accionado por una batería eléctrica con una barra de $6 \mathrm{~m}$ de largo provista de 12 picos pulverizadores, que fue transportada por 2 operarios que transitaron externamente a lo largo de la parcela. La aplicación de fosfito de potasio y la segunda aplicación de silicio, se hicieron en forma conjunta con el fungicida (mezcla de tanque).

El rendimiento en grano fue determinado en los centros de las parcelas $\left(59,84 \mathrm{~m}^{2}\right)$, habiéndose realizado desbordes tanto en los frentes como en los laterales de las mismas. La cosecha fue realizada con una máquina automotriz Fotón de un ancho de corte de $2 \mathrm{~m}$. Los pesos obtenidos fueron corregidos a una base de $13 \%$ de humedad y por las bases de calidad de grano utilizadas en el país (rendimiento sano, seco y limpio, resultante de los valores obtenidos por correcciones en porcentajes de blanco, entero, yesado y mancha). Simultáneamente se extrajeron al azar muestras de $0,6 \times 0,17 \mathrm{~m}^{2}$ para analizar componentes del rendimiento, producción de materia seca, índice de cosecha y contenido de nutrientes. Se midió la altura de 12 plantas por parcela, elegidas al azar.

En la zafra 2015-2016 las épocas de cosecha de los ensayos se vieron afectadas por las condiciones climáticas existentes en el otoño, que impidieron en algunos casos poder realizarlas en las mejores situaciones. En Rincón de Ramírez se levantó el experimento en su totalidad antes del inicio de las lluvias. En Costas de San Francisco se cortaron las parcelas correspondientes al cultivar EI Paso 144 en buenas condiciones y las del cultivar INIA Merín después de una semana de comenzadas las lluvias. De forma similar, se cosechó INIA Tacuarí en India Muerta antes de las precipitaciones y el cultivar Parao 27 días después. En Cebollatí recién se pudo cortar ambas variedades a comienzos del mes de mayo.

En todas las situaciones (localizaciones y zafras) se dispuso de la colaboración de los productores, quienes realizaron el manejo de suelos y general del cultivo (con excepción de los tratamientos). Los análisis de rendimiento y calidad industrial del grano fueron realizados por las industrias, a las que remiten su producción los respectivos productores colaboradores.

Se instalaron estaciones agroclimáticas en la mayoría de los sitios, aunque por diversas razones no se dispuso de un registro uniforme de las distintas situaciones manejadas, tanto entre zafras como en localizaciones. En las figuras 1 a 5 del Anexo Il se presenta información relativa al tema.

\subsubsection{Validación a escala de chacra de las alternativas seleccionadas}

De acuerdo con lo establecido en el componente 4 de la estrategia del proyecto, el comité técnico analizó la información generada en los 8 experimentos conducidos, ya sea en forma individual como conjunta (2 por localidad). En cada zona se seleccionó un tratamiento como el mejor entre los 11 evaluados, para ser incluido junto al testigo tecnológico en las validaciones respectivas.

En 3 de las 4 localidades (Rincón de Ramírez, $7^{\text {a }}$ Sección de Treinta y Tres/Costas de San Francisco e India Muerta) se seleccionó el tratamiento 9, que incluye todas las prácticas alternativas al testigo tecnológico, excepto el factor «instalación del cultivo». En dichos casos, como variedad alternativa se utilizó CH Quebracho en Rincón, INIA Merín en Costas de San Francisco y $7^{\text {a }}$ Sección de Treinta y Tres en lugar de EI Paso 144 y Parao en lugar de INIA Tacuarí en India Muerta. En Cebollatí se seleccionó el tratamiento 12 , en el que se consideran todas las alternativas al testigo tecnológico con la excepción del «manejo de enfermedades», el que demostró en esta localización la mayor productividad en el promedio de los años anteriores. Allí se sembró el cultivar Parao en lugar de EI Paso 144.

Se instalaron 6 sitios de validación: 3 en el Departamento de Treinta y Tres (Rincón de Ramírez, Costas de San Francisco y $7^{a}$ Sección) y 3 en el Departamento de Rocha 
(Cebollatí, India Muerta y Vuelta Grande). Se consideró Vuelta Grande un ambiente más cercano a las condiciones de India Muerta que a las de Cebollatí.

La ejecución de los trabajos en las chacras fue realizada por los productores, en superficies de 8-10 ha divididas al medio según los 2 manejos contrastantes (tratamiento $\mathrm{N}^{0} 1$ = testigo tecnológico vs tratamiento alternativo 9 o 12), con supervisión de los técnicos del proyecto. La evaluación de la producción de arroz (cantidad y calidad industrial) fue realizada por parte de la industria molinera a la que remite el productor involucrado.

Previo a la cosecha se extrajeron al azar 2 muestras de $0,3 \times 0,17 \mathrm{~m}^{2}$ en 5 lugares de cada macroparcela; se analizaron componentes del rendimiento, por un lado y producción de materia seca, índice de cosecha y contenido de nutrientes por otro.

En el cuadro 6 se presentan las ubicaciones, fechas de siembra y de cosecha de los 6 sitios de validación conducidos en la zafra 2016-2017.

En el cuadro 7 se presentan los resultados de análisis de muestras de suelos extraídas en los sitios de validación (en general 1 mes antes de la siembra). De acuerdo con los mismos se establecieron los tratamientos de «fertilización» correspondientes y en el cuadro 8 se presenta un resumen de las tecnologías testigo y alternativas validadas en Rincón de Ramírez, Costas de San

Cuadro 6. Fechas de instalación y cosecha de los sitios de validación 2016-2017.

\begin{tabular}{|c|c|c|c|c|c|}
\hline Localización & Departamento & $\begin{array}{l}\text { Coordenadas } \\
\text { geográficas }\end{array}$ & Cultivar & $\begin{array}{c}\text { Fecha de } \\
\text { sembra }\end{array}$ & $\begin{array}{c}\text { Fecha de } \\
\text { cosecha }\end{array}$ \\
\hline $\begin{array}{l}\text { Rincón de } \\
\text { Ramírez }\end{array}$ & Treinta y Tres & $\begin{array}{l}32^{\circ} 47^{\prime} \mathrm{S} \\
5351^{\prime} 0\end{array}$ & $\begin{array}{c}\text { EP 144 } \\
\mathrm{CH} \text { Quebracho }\end{array}$ & 27 set & $17 \mathrm{mar}$ \\
\hline $\begin{array}{l}\text { C. de San } \\
\text { Francisco }\end{array}$ & Treinta y Tres & $\begin{array}{l}33^{\circ} 07^{\prime} \mathrm{S} \\
5355^{\prime} 0\end{array}$ & $\begin{array}{c}\text { EP 144 } \\
\text { INIA Merín }\end{array}$ & 14-15 oct & $7 \mathrm{abr}$ \\
\hline $\begin{array}{l}7^{\text {a Sec. de }} \\
\text { Tr. y Tres }\end{array}$ & Treinta y Tres & $\begin{array}{l}33^{\circ} 17^{\prime} S \\
54^{\circ} 23^{\prime} 0\end{array}$ & $\begin{array}{c}\text { EP 144 } \\
\text { INIA Merín }\end{array}$ & 8 now & 12-13 abr \\
\hline Cebollatí & Rocha & $\begin{array}{l}33^{\circ} 21^{\prime} \mathrm{S} \\
538^{\circ} 0\end{array}$ & $\begin{array}{l}\text { EP 144 } \\
\text { Parao }\end{array}$ & 14-15 nov & $\begin{array}{c}17-18 \mathrm{abr} \\
30 \mathrm{abr}\end{array}$ \\
\hline $\begin{array}{l}\text { Vuelta } \\
\text { Grande }\end{array}$ & Rocha & $\begin{array}{l}33^{\circ} 32^{\prime} \mathrm{S} \\
54909^{\prime} 0\end{array}$ & $\begin{array}{l}\text { INIA Tacuarí } \\
\text { Parao }\end{array}$ & $5-6$ nov & $15-18 \mathrm{abr}$ \\
\hline India Muerta & Rocha & $\begin{array}{l}33^{\circ} 45^{\prime} \mathrm{S} \\
54900^{\prime} 0\end{array}$ & $\begin{array}{l}\text { INIA Tacuarí } \\
\text { Parao }\end{array}$ & $9-11$ nov & $12-13 \mathrm{abr}$ \\
\hline
\end{tabular}

Cuadro 7. Análisis de suelos $(0-15 \mathrm{~cm})$ de muestras extraídas en 6 sitios de validación en la zafra 2016-2017*.

\begin{tabular}{ccccccccccccc}
\hline Loc & $\mathrm{pH}$ & $\begin{array}{c}\text { PMN } \\
\mathrm{mg} / \mathrm{kg}\end{array}$ & $\begin{array}{c}\mathrm{CO} \\
\%\end{array}$ & $\begin{array}{c}\mathrm{P} \text { cit } \\
\mathrm{ppm}\end{array}$ & $\begin{array}{c}\mathrm{K} \\
\mathrm{me} \\
\mathrm{q}\end{array}$ & $\begin{array}{c}\mathrm{Ca} \\
\mathrm{meq}\end{array}$ & $\begin{array}{c}\mathrm{Mg} \\
\mathrm{meq}\end{array}$ & $\begin{array}{c}\mathrm{Na} \\
\mathrm{meq}\end{array}$ & $\begin{array}{c}\mathrm{Zn} \\
\mathrm{mg} / \mathrm{kg}\end{array}$ & $\begin{array}{c}\mathrm{CIC} \\
\text { meq }\end{array}$ & $\begin{array}{c}\text { SB } \\
\%\end{array}$ & $\begin{array}{c}\text { Textura } \\
\text { Ar-LifArc }\end{array}$ \\
\hline RR & 5,6 & 16 & 1,1 & 7,0 & 0,11 & 3,47 & 1,07 & 0,15 & 0,31 & 7,7 & 59,7 & $54-22-24$ \\
\hline $\mathrm{CSF}$ & 5,8 & 15 & 1,3 & 3,5 & 0,14 & 4,1 & 1,5 & 0,49 & 0,21 & 9,2 & 67,8 & $30-45-24$ \\
\hline $7 T T$ & 6,8 & 15,8 & 2,2 & 10,7 & 0,23 & 11,5 & 3,5 & 1,32 & 0,40 & 18,9 & 87,6 & $13-54-33$ \\
\hline CE & 65 & 22 & 1,8 & 3,8 & 0,27 & 7,2 & 3,8 & 1,26 & 0,29 & 15 & 82,3 & $33-36-31$ \\
\hline VG & 5,7 & 29 & 1,9 & 6,5 & 0,29 & 11,7 & 3,1 & 0,46 & 0,66 & 19,7 & 77,8 & $23-40-37$ \\
\hline IM & 5,6 & 44 & 4,7 & 18,7 & 0,45 & 18,2 & 7,3 & 0,54 & 3,12 & 35 & 75,7 & $9-40-51$ \\
\hline
\end{tabular}

*Loc= localización; RR= Rincón de Ramírez; 7TT= $7^{\text {a }}$ Sección de Treinta y Tres; CSF= Costas de San Francisco; $\mathrm{CE}=$ Cebollatí; $\mathrm{G}=$ Vuelta Grande; $\mathrm{IM}=$ India Muerta; $\mathrm{PMN}=$ potencial de mineralización; $\mathrm{CO}=$ carbono orgánico; $\mathrm{P}$ cit= fósforo según el método de ácido cítrico; $\mathrm{K}, \mathrm{Ca}, \mathrm{Mg}, \mathrm{Na}, \mathrm{CIC}$ en meq/(100 g de suelo); $\mathrm{SB}=$ saturación en bases; $\mathrm{Ar}=\%$ arena, $\mathrm{Li}=\%$ limo, $\mathrm{Arc}=\%$ arcilla. 
Francisco, $7^{\text {a }}$ Sección de Treinta y Tres, Vuelta Grande e India Muerta (tratamientos 1 y 9 ) y Cebollatí (tratamiento 1 y 12) respectivamente. Algunas modificaciones surgidas en las ejecuciones sobre las bases previstas inicialmente (en factores 3 y 4 ), son comentadas en la presentación de resultados particular de cada sitio.

En las figuras 6 y 7 del Anexo II se presenta información climática registrada en la zafra 2016-2017 (temperatura y radiación solar).

Cuadro 8. Tecnologías testigo (tratamiento $N^{0} 1$ ) y alternativas (tratamientos 9 en Rincón de Ramírez, Costas de San Francisco, $7^{\text {a }}$ Sección de Treinta y Tres, Vuelta Grande e India Muerta y 12 en Cebollatí). Validaciones, zafra 2016-2017*.

\begin{tabular}{|c|c|c|c|c|c|c|c|c|}
\hline \multirow[t]{3}{*}{ Localidad } & \multirow{3}{*}{$\begin{array}{l}\text { Trt. } \\
\text { No }\end{array}$} & \multirow{3}{*}{$\frac{\text { Factor } 1}{\text { Cultiv ar }}$} & \multicolumn{2}{|c|}{ Factor 2} & \multicolumn{2}{|c|}{ Factor 3} & \multirow{2}{*}{\multicolumn{2}{|c|}{$\begin{array}{c}\text { Fact or } 4 \\
\text { Manejo de } \\
\text { enferme dades }\end{array}$}} \\
\hline & & & \multicolumn{2}{|c|}{ Instalación del cultivo } & \multirow{2}{*}{$\begin{array}{c}\text { Sub- actor } \\
\text { Fertilización } 1 \\
\text { kgiha }\end{array}$} & \multirow{2}{*}{$\begin{array}{l}\text { Sub- } \\
\text { factor } \\
\text { Fert- } \\
\text { Plus }\end{array}$} & & \\
\hline & & & $\begin{array}{l}\text { Densidad } \\
\mathrm{kg} / \mathrm{ha}\end{array}$ & Trat. Semillas & & & $1^{\mathrm{a}}$ aplic. & $\begin{array}{c}2^{3} \\
\text { aplic. }\end{array}$ \\
\hline \multirow{2}{*}{$\begin{array}{l}\text { Rincón } \\
\text { de } \\
\text { Ramírez }\end{array}$} & 1 & $\begin{array}{c}\text { EI Paso } \\
144\end{array}$ & 130 & $\begin{array}{l}\text { tebuxonazol } \\
\text { + thiametoxan }\end{array}$ & $\begin{array}{c}13 \mathrm{~N}_{55 \mathrm{P}_{2} \mathrm{O}_{5}} \\
25 \mathrm{~K}_{2} \mathrm{O} \\
\mathrm{C}(75+50)\end{array}$ & - & $\begin{array}{l}\text { tebuct } \\
\text { tryfilox. }\end{array}$ & $\begin{array}{l}\text { cyoro+ } \\
\text { azoxist. }\end{array}$ \\
\hline & 9 & $\begin{array}{c}\mathrm{CH} \\
\text { Quebracho }\end{array}$ & 130 & $\begin{array}{l}\text { tebuxonazol } \\
\text { + thiametoxan }\end{array}$ & $\begin{array}{c}10 \mathrm{~N}_{60 \mathrm{P}_{2} \mathrm{O}_{5}} \\
137 \mathrm{~K}_{2} \mathrm{O} \\
\text { VU1 } 85+\mathrm{UC} 50\end{array}$ & $\begin{array}{r}7,5 \mathrm{~S} \\
+\mathrm{Si}+ \\
\text { Micro } \\
\end{array}$ & \multicolumn{2}{|c|}{$\begin{array}{l}\text { Si + fosito de } \mathrm{K}+ \\
\text { azoxist+kresoxim } \\
\text { +c yoroconazol }\end{array}$} \\
\hline \multirow{2}{*}{$\begin{array}{c}\text { Costas } \\
\text { de San } \\
\text { Francisco }\end{array}$} & 1 & $\begin{array}{c}\text { El Paso } \\
144\end{array}$ & 130 & $\begin{array}{l}\text { tebuxonazoi } \\
\text { +thiametoxan }\end{array}$ & 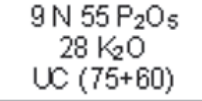 & - & $\begin{array}{l}\text { tebuct } \\
\text { tryfibx }\end{array}$ & $\begin{array}{l}\frac{\text { Opción }}{\text { çjoro+ }} \\
\text { azoxist. }\end{array}$ \\
\hline & 9 & INA Merín & 130 & $\begin{array}{l}\text { tebuxonazoi } \\
\text { +thiametoxan }\end{array}$ & $\begin{array}{c}17 \mathrm{Ng}_{95} \mathrm{P}_{2} \mathrm{O}_{5} \\
102 \mathrm{~K}_{2} \mathrm{O} \\
\text { VU1 } 65+\mathrm{UC} 50\end{array}$ & $\begin{array}{l}12 \mathrm{~S} \\
+\mathrm{Si}+ \\
\mathrm{Micro}\end{array}$ & \multicolumn{2}{|c|}{$\begin{array}{l}\text { fosfito de } \mathrm{K}+\mathrm{Si}+ \\
\text { azoxist+kresoxim } \\
\text { +c joroconazol }\end{array}$} \\
\hline \multirow{2}{*}{$\begin{array}{c}7^{a} \\
\text { Sección } \\
\text { de } \\
\text { Treinta y } \\
\text { Tres }\end{array}$} & 1 & $\begin{array}{c}\text { El Paso } \\
144\end{array}$ & 130 & $\begin{array}{l}\text { tebuxconazol } \\
\text { + thiametoxan }\end{array}$ & $\begin{array}{c}55 \mathrm{P}_{2} \mathrm{O}_{5} \\
25 \mathrm{~K}_{2} \mathrm{O} \\
\mathrm{UC}(75+50)\end{array}$ & - & $\begin{array}{l}\text { tebuct } \\
\text { tryfiox. }\end{array}$ & $\begin{array}{l}\text { Opción } \\
\text { cjoro+ } \\
\text { azoxist. }\end{array}$ \\
\hline & 9 & INA Merín & 130 & $\begin{array}{l}\text { tebuxonazoi } \\
\text { +thiametoxan }\end{array}$ & $\begin{array}{c}10 \mathrm{~N}_{60} \mathrm{P}_{2} \mathrm{O}_{5} \\
70 \mathrm{~K}_{2} \mathrm{O} \\
\text { VU1 } 65+\mathrm{UC} 50 \\
\end{array}$ & $\begin{array}{c}10 S \\
+\mathrm{Si+} \\
\mathrm{Micro} \\
\end{array}$ & \multicolumn{2}{|c|}{$\begin{array}{l}\text { fosfito de } \mathrm{K}+\mathrm{Si}+ \\
\text { azoxist+kresoxim } \\
\text { +c joroconazol }\end{array}$} \\
\hline \multirow[b]{2}{*}{ Cebollatí } & 1 & $\begin{array}{c}\text { ETPaso } \\
144\end{array}$ & 160 & $\begin{array}{l}\text { tebuxonazol } \\
\text { +thiametoxan }\end{array}$ & 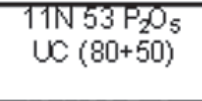 & & $\begin{array}{l}\text { tebuct } \\
\text { tryfiox. }\end{array}$ & $\begin{array}{l}\text { opcion } \\
\text { cjoro+ } \\
\text { azoxist. }\end{array}$ \\
\hline & 12 & Parao & $(x)$ & $\begin{array}{l}\text { tebuconazol } \\
\text { + thiametoxan } \\
\text { +Synergize } \\
\text { + Encorice }\end{array}$ & $\begin{array}{l}16 \mathrm{Ng} 2 \mathrm{P}_{2} \mathrm{O}_{5} \\
21 \mathrm{~K} 211,5 \mathrm{~S} \\
\text { Vu1 } 137+\mathrm{UC} 100\end{array}$ & $\begin{array}{l}11,55 \\
+ \text { Si+ } \\
\text { Micro }\end{array}$ & $\begin{array}{l}\text { tebuct } \\
\text { tryfiox. }\end{array}$ & $\begin{array}{l}\text { Opción } \\
\text { çoro + } \\
\text { azoxist. }\end{array}$ \\
\hline \multirow{2}{*}{$\begin{array}{l}\text { Vuelta } \\
\text { Grande }\end{array}$} & 1 & $\begin{array}{c}\text { INIA } \\
\text { Tac uań }\end{array}$ & 170 & $\begin{array}{l}\text { tebuxonazol } \\
\text { +thiametoxan }\end{array}$ & $\begin{array}{c}20 \mathrm{~N} 51 \mathrm{P}_{2} \mathrm{O}_{5} \\
\cup C(55+50)\end{array}$ & & $\begin{array}{l}\text { tebuct } \\
\text { tryfiox. }\end{array}$ & $\begin{array}{l}\frac{\text { Opción }}{\text { cjoro+ }} \\
\text { azoxist. }\end{array}$ \\
\hline & 9 & Parao & 170 & $\begin{array}{l}\text { tebuxonazol } \\
\text { + thiametoxan }\end{array}$ & $\begin{array}{c}13 \mathrm{~N}_{6} \mathrm{P}_{2} \mathrm{O}_{5} \\
21 \mathrm{~K}_{2} \mathrm{O} \\
\text { VU100+UC100 }\end{array}$ & $\begin{array}{l}9,5 \mathrm{~S} \\
+\mathrm{Si}+ \\
\mathrm{Micro} \\
\end{array}$ & $\begin{array}{l}\text { fosfito de } \\
\text { azoxist+ } \\
+ \text { cyora }\end{array}$ & $\begin{array}{l}\mathrm{K}+\mathrm{Si}+ \\
\text { resoxim } \\
\text { onazol }\end{array}$ \\
\hline \multirow{2}{*}{$\begin{array}{l}\text { India } \\
\text { Muerta }\end{array}$} & 1 & $\begin{array}{c}\text { INIA } \\
\text { Tacuań }\end{array}$ & 170 & $\begin{array}{l}\text { tebuxonazol } \\
\text { +thiametoxan }\end{array}$ & $\begin{array}{l}20 \mathrm{~N} 51 \mathrm{P}_{2} \mathrm{O}_{5} \\
\mathrm{UC}(61+50)\end{array}$ & & $\begin{array}{l}\text { tebuct } \\
\text { tryfiox. }\end{array}$ & $\begin{array}{l}\text { Opción } \\
\text { cyoro+ } \\
\text { azoxist. }\end{array}$ \\
\hline & 9 & Parao & 170 & $\begin{array}{l}\text { tebuxonazoi } \\
\text { +thiametoxan }\end{array}$ & $\begin{array}{c}0 \mathrm{NOP}_{2} \mathrm{O}_{5} \\
48 \mathrm{~K}_{2} \mathrm{O} \\
\mathrm{Vu} 45+\mathrm{UC} 100\end{array}$ & $\begin{array}{c}\text { Si+ } \\
\text { Micro }\end{array}$ & \multicolumn{2}{|c|}{$\begin{array}{l}\text { fosfito de } \mathrm{K}+\mathrm{Si}+ \\
\text { azoxist+kresoxm } \\
+ \text { c cjoroconazol }\end{array}$} \\
\hline
\end{tabular}

${ }^{*}$ Trt. = tratamiento; $\mathrm{N}=$ nitrógeno; $\mathrm{P}_{2} \mathrm{O}_{5}=$ fósforo; $\mathrm{K}_{2} \mathrm{O}=$ potasio; tebuc= tebuconazol; tryflox= trifloxystrobin; cipro= ciproconazol; Azoxist= azoxistrobin; $\mathrm{S}=$ azufre; $\mathrm{Si}=$ silicio; $\mathrm{UC}=$ Urea común; VU= Verde urea; Micro=, contiene B, Mn, Zn; Synergize, Endorice= productos comerciales; Manejo de enfermedades: $1^{\text {a }}$ aplicación a inicios de floración; $2^{a}$ se hace, si aparecen síntomas de Brusone a los 15-20 días después, salvo en Rincón de Ramírez donde se aplicará siempre; $(\mathrm{x})=$ a determinar por \% germinación; en Fert.-Plus de India Muerta no se agregó $\mathrm{S}$, dado el alto contenido de carbono del suelo. 


\section{3 - RESULTADOS}

3.1. Prácticas de manejo utilizadas por los productores del quintil superior de rendimientos Encuesta a productores de punta

\subsubsection{Edad y educación}

El $90 \%$ de los productores encuestados tenían entre 30 y 60 años. En el cuadro 9 se presenta una descripción de la composición del conjunto, según intervalos de 10 años desde los veinte hasta más de sesenta. Varias empresas entrevistadas, se encuentran codirigidas o gestionadas entre padre e hijo, o entre hermanos; en dichos casos, se anotó la información personal correspondiente al titular.
El $38,5 \%$ de los empresarios cursó enseñanza secundaria, el 38,5\% enseñanza terciaria (de los que un $35,9 \%$ corresponde a agronomía), el 5,1\% enseñanza terciaria incompleta, y el $10,3 \%$ es técnico agropecuario o similar (Cuadro 10).

En las figuras 2 y 3 se presenta la distribución de la información anterior, según quien la proporcionara perteneciera a uno de los 3 grupos predefinidos por localización geográfica y condiciones ambientales (Treinta y Tres, Cebollatí e India Muerta).

Se destaca como más frecuente la franja etaria de 41 a 50 años de edad en Cebollatí y Treinta y Tres (50 y 40\% respectivamente), mientras que ninguna clase supera el $30 \%$ en India Muerta (Figura 2).

Cuadro 9. Distribución de edades de los productores según fajas etarias de cada 10 años.

\begin{tabular}{cccccc}
\hline \multirow{2}{*}{ Edad } & \multicolumn{5}{c}{ Intervalo (en años) } \\
\cline { 2 - 6 } & $20-30$ & $31-40$ & $41-50$ & $51-60$ & 60 \\
\hline $\begin{array}{c}\% \text { de } \\
\text { productores }\end{array}$ & 2,6 & 20,5 & 41 & 28,2 & 7,7 \\
\hline
\end{tabular}

Cuadro 10. Niveles de educación.

\begin{tabular}{ccccc}
\hline \multicolumn{4}{c}{ Nivel de educación (\% deprodudores) } \\
\hline Primaria & Secundaria & Terciaria & Terciaria & Técnico Agropeduario \\
7,7 & & incompleta & & ò similar \\
& 38,5 & 5,1 & 38,5 & 10,3 \\
\hline
\end{tabular}

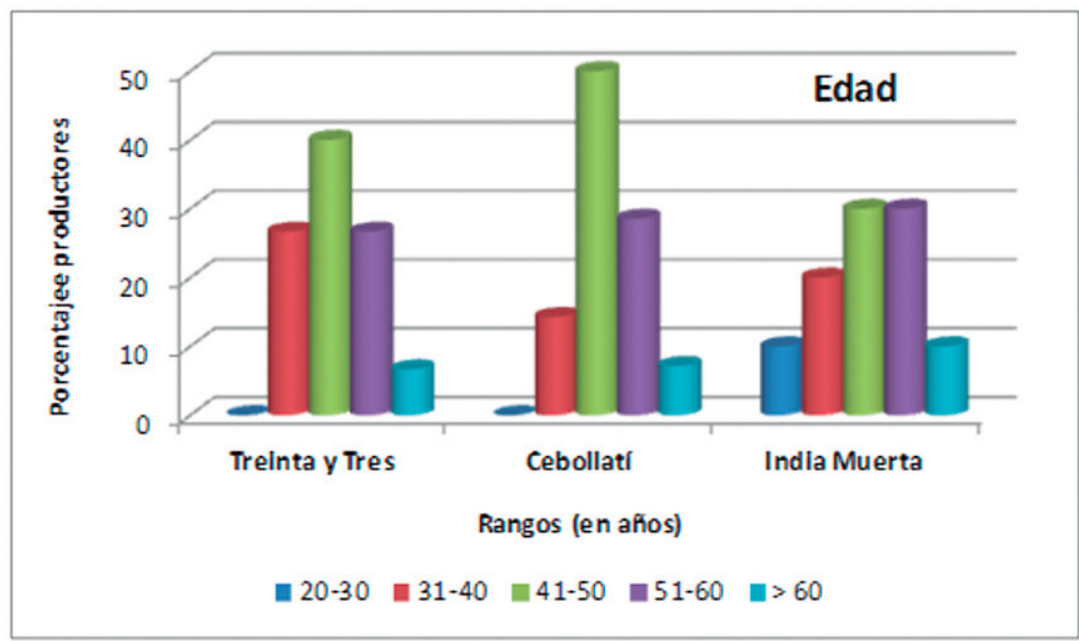

Figura 2. Edad de los entrevistados, según grupo de productores. 


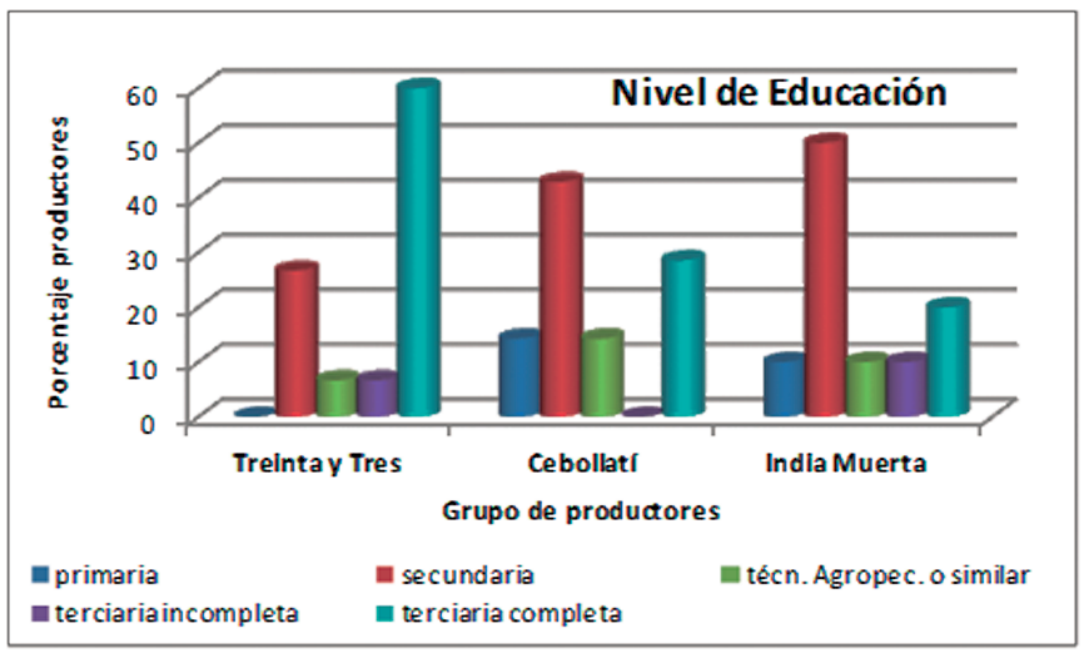

Figura 3. Nivel de educación, según grupo de productores

Más de la mitad de los productores del grupo Treinta y Tres tenía formación terciaria, mientras que en Cebollatí e India Muerta predominaba la educación secundaria (Figura 3).

\subsubsection{Tamaño de chacras}

En el cuadro 11 se presentan los tamaños promedio de chacras considerando en conjunto las 39 entrevistas; en general pre- dominaban las chacras de 100 a 500 ha, con un $67 \%$ de los productores.

Mientras que en Cebollatí predominaban las chacras de menor tamaño seguidas por las de 301-500 ha, en Treinta y Tres eran más frecuentes las mayores a 301 ha, con el mayor porcentaje ubicado en el segundo nivel (301 a 500 ha). A diferencia de los anteriores, India Muerta mostró las mayores presencias en los extremos, chacras menores de 300 ha y mayores a 700 ha (Figura 4).

Cuadro 11. Tamaño de chacras sembradas en los últimos 3-4 años.

\begin{tabular}{ccccc}
\hline Tamaño & \multicolumn{4}{c}{ Rango (en ha) } \\
\cline { 2 - 5 } & $100-300$ & $301-500$ & $501-700$ & más de 700 \\
\hline$\%$ Productores & 38,5 & 28,2 & 15,4 & 179 \\
\hline
\end{tabular}

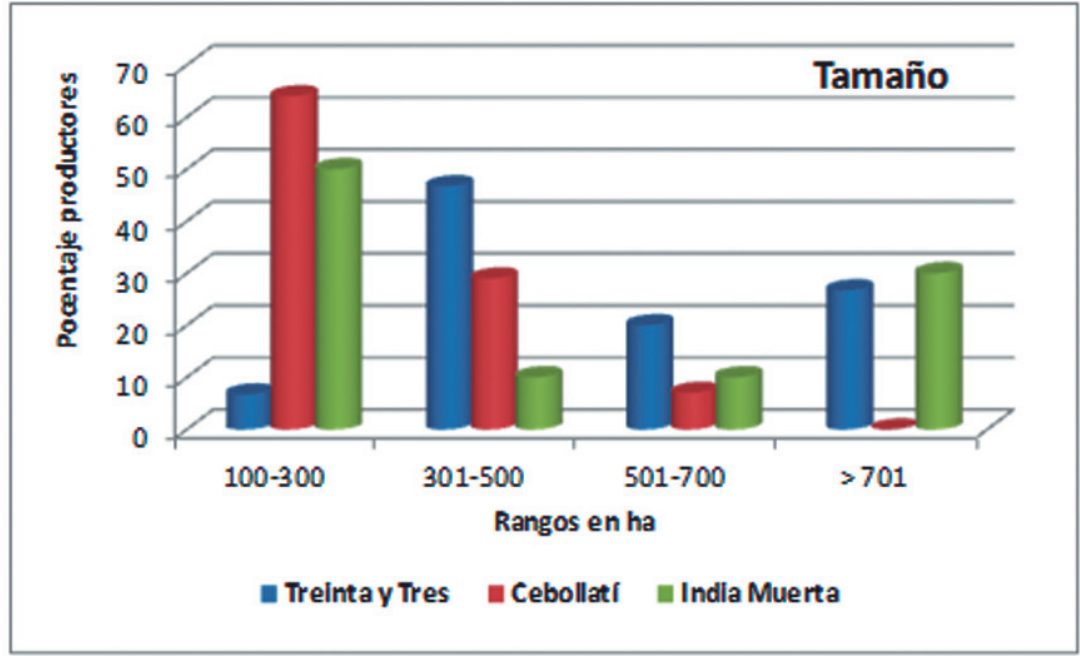

Figura 4. Tamaño de las chacras (ha), según grupo de productores 


\subsubsection{Localización}

Consultados en referencia a las razones por las que siembra en la zona, se obtuvieron las siguientes respuestas, aclarándose que las mismas no son excluyentes, pudiendo el entrevistado optar por más de una de ellas:

- $\quad 30,8 \%$ de los productores manifestó que hace años está instalado en ella;

- 12,8 \% considera que es la más apropiada desde el punto de vista productivo:

- $\quad 10,3 \%$ le ofrece ventajas desde el punto de vista logístico (insumos, talleres, industria);

- $\quad 64,1 \%$ de estas empresas tienen acceso a la propiedad de la tierra (parcial o total) o a sistemas de riego.

\subsubsection{Antecedentes de uso del suelo}

Se encontró un amplio rango de respuestas a la consulta realizada sobre los usos anteriores del suelo que precedieron a la producción de arroz en los últimos 3-4 años. Se destaca las distintas situaciones en que se encuentra el productor respecto a la tenencia de la tierra y la época de acceso a la misma, que condiciona el inicio de los trabajos de sistematización de las chacras y de preparación del suelo, así como la relación con los sistemas de riego. Estos 2 factores condicionan e inciden en forma importante, no sólo en los antecedentes de uso del suelo, sino que en varios aspectos generales del manejo del cultivo de arroz.

En un extremo del rango, se encontraba el $25,6 \%$ de los productores encuestados que sembraron exclusivamente sobre retornos, que incluían o no la siembra de praderas y/o sobre rastrojos de cultivos de secano o verdeos. En el otro extremo, se registró información de un productor que sembraba hasta el $80 \%$ de sus cultivos sobre rastrojos de arroz, u otros que sembraban en forma alternada un año todo sobre retorno y el siguiente $100 \%$ sobre rastrojos. El $15 \%$ de los encuestados manifestó que recibían los campos recién en agosto-setiembre para comenzar a prepararlos.
Dentro de esos límites, se encontraron una amplia gama de situaciones, siendo más frecuentes los casos donde el productor disponía en la misma zafra de retornos con o sin pradera y rastrojos de arroz para sembrar. Algunas empresas de tamaño medio a grande tenían condiciones diversas frente a los recursos tierra (propiedad y/o arrendamiento) y agua (comprada y/o de fuente propia), e incluso chacras en zonas distintas. De acuerdo a ello, un mismo productor manejaba diferentes usos del suelo y/o rotaciones, y como consecuencia también fueron diferentes sus respuestas a las preguntas formuladas.

Ante la consulta de si la empresa trata de elegir esas opciones de uso del suelo que utiliza actualmente, varios productores manifestaron su deseo de poder disponer en el futuro de un mayor porcentaje de retornos, y también de poder ingresar antes a los campos arrendados, para poder realizar los acondicionamientos necesarios para la siembra del arroz en tiempo y forma.

\subsubsection{Tipos de laboreo y siembra}

El 25,6 \% de los encuestados realizó laboreos de verano en toda el área de siembra, el 59,0 \% lo hizo en parte de la misma (en general en retornos), y el $15,4 \%$ no lo utilizó.

En los 3 grupos de productores predominó el uso del laboreo de verano en parte del área sembrada, pero se destaca el Grupo de India Muerta con un alto porcentaje de laboreos anticipados en toda la superficie (Figura 5)

Sobre el tipo de laboreo realizado en la primavera (cero, reducido, o convencional), y el tipo de siembra, un 10,3 \% manifestó haber utilizado cero laboreo y siembra directa en la mayoría del área y un 20,5\% lo hizo en parte del área. El 23,1 \% usó laboreo reducido en la mayoría del área sembrada, un 20,5\% laboreo reducido en parte, y un 56,4 \% laboreo convencional. Como ya fue mencionado en otros factores o prácticas consultadas, los porcentajes no suman 100 , ya que las respuestas están referidas en forma parcial a los «ambientes» o localizaciones manejados por los productores en 


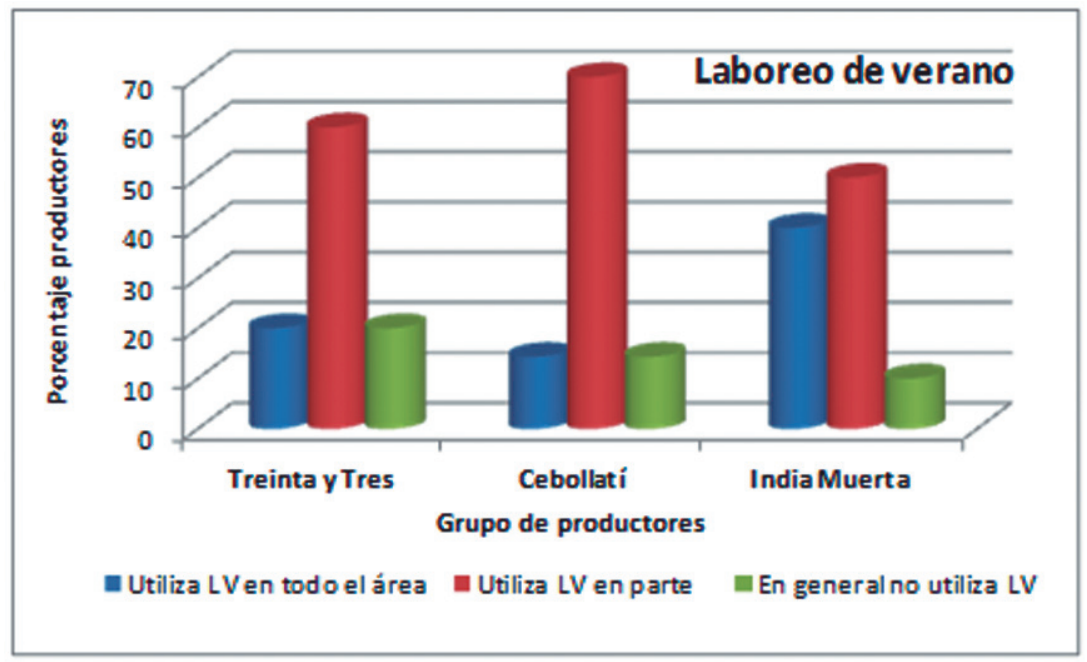

Figura 5. Utilización del laboreo de verano (LV) según grupo de productores.

años diferentes y no a la superficie total de la empresa.

En relación al uso aunque fuera ocasional de la siembra al voleo, el $92,3 \%$ de los productores manifestó no utilizarla, mientras que el $7,7 \%$ lo hizo en alguna oportunidad.

\subsubsection{Planificación de insumos a utilizar}

El $87,2 \%$ de los entrevistados, planificaba el uso de los insumos antes de comenzar la siembra; el 12,8\% lo hacía en la medida que se van presentando los problemas. No obstante, dentro del primer grupo, el $7,7 \%$ manifestó que la decisión respecto al uso de herbicidas es variable, según los años y disponibilidad de campos.

\subsubsection{Uso de glifosato}

La consulta formulada con relación al uso de glifosato fue dirigida a las épocas y can- tidad de veces que se aplica en una zafra, antes de realizar la siembra: 1) 1 vez en primavera; 2) 1 o 2 veces en primavera, dependiendo del enmalezamiento u otra razón; 3) 2 veces, una en el otoño previo y otra en primavera; 4) más de 2 veces.

En el cuadro 12 se presentan los resultados obtenidos, siendo necesario aclarar 2 aspectos en referencia a esta pregunta. En primer lugar, basta que un productor haya utilizado la doble aplicación otoño-primavera en una fracción de su chacra en un sólo año, para que el caso aparezca señalado. De acuerdo a ello, el porcentaje que aparece en el ítem correspondiente del cuadro, indica que $33,3 \%$ de las empresas utilizaron al menos una vez dicha técnica (o varias, dependiendo de cada una de ellas). Por otro lado, varios productores utilizaron después de sembrar, la aplicación de una mezcla de tanque de glifosato con el herbicida preemergente clomazone como primera

Cuadro 12. Épocas y cantidad de aplicaciones de glifosato realizadas antes de la siembra.

\begin{tabular}{|c|c|c|c|c|}
\hline \multirow[t]{2}{*}{ Opdones } & \multicolumn{2}{|c|}{ Aplicaciones } & \multirow[t]{2}{*}{ Menciones } & \multirow{2}{*}{$\begin{array}{c}\text { Empresas } \\
\%\end{array}$} \\
\hline & otoño & primavera & & \\
\hline 1 & - & 1 & 23 & 590 \\
\hline 2 & - & 10 & 12 & 308 \\
\hline $3^{*}$ & 1 & 1 & 13 & 333 \\
\hline 4 & - & más de 2 & 0 & 0 \\
\hline
\end{tabular}

*13 productores mencionaron haber usado aplicaciones otoño-primavera en alguna oportunidad, pero sólo 4 de ellos $(10,2 \%)$ lo hicieron como práctica general. 


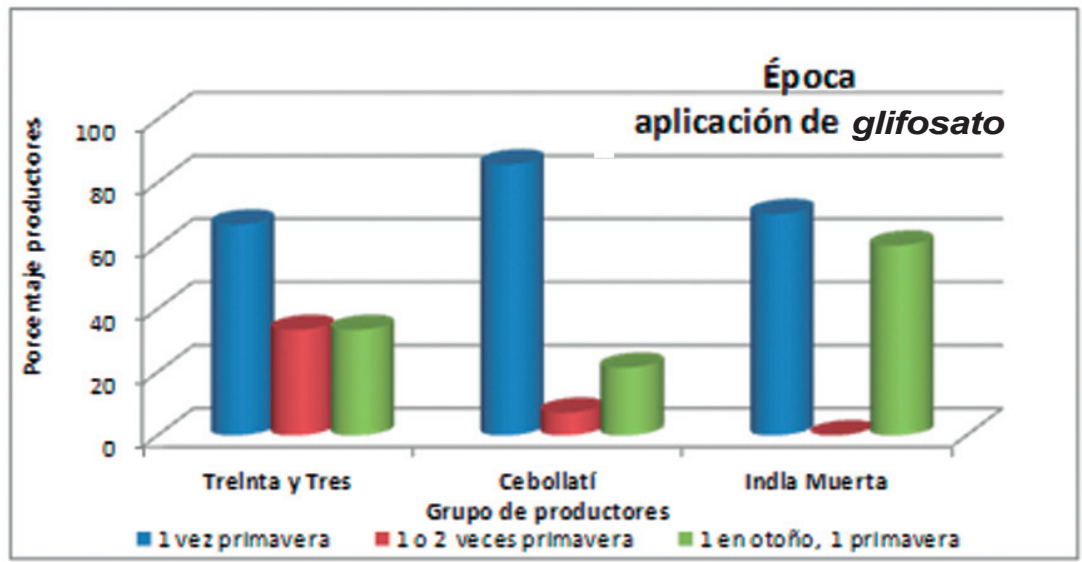

Figura 6. Aplicación de glifosato pre-siembra según grupo de productores.

medida de control en su estrategia del manejo de malezas. A los efectos de evitar la doble contabilización del uso del herbicida, estos casos no fueron incluidos en estas respuestas y sí aparecen en la sección manejo de malezas.

Del cuadro 12, donde se presenta la información en conjunto, como de la figura 6 donde se puede observar la misma según grupo de productores, la mayoría de las empresas aplicaba glifosato al menos una vez en la primavera, destacándose la zona de Rocha con un importante porcentaje de aplicaciones otoñales.

\subsubsection{Cultivares}

Fueron utilizados 12 cultivares: El Paso 144, INIA Tacuarí, CH-Arrayán, INIA Olimar, Inov CL, Gurí INTA CL, Parao, Coronilla, Camila, EEA 404, Hayate y Perla. En general, las empresas utilizaron más de una variedad, pero 10 productores $(25,6 \%)$ sembraron solamente un cultivar en el período considerado, correspondiendo 6 de los casos a INIA Tacuarí y 4 a EI Paso 144.

El $76,9 \%$ de los productores sembraron El Paso 144 y el 74,4\% INIA Tacuarí. El $20,5 \%$ mencionó Parao, el $15,4 \%$ Inov CL, y el $12,8 \% \mathrm{CH}$-Arrayán, dentro de los más destacados (Cuadro 13).

Dentro de las razones consideradas en la elección de los materiales a sembrar, se destacaron: 1) porque son los que mejor se adaptan a la zona $59,0 \%$; 2) porque son los
Cuadro 13. Cultivares sembrados. Número de menciones y porcentaje de encuestados*

\begin{tabular}{|c|c|c|}
\hline Cultivar & $N^{0}$ Menciones & $\%$ Encuestados \\
\hline El Paso 144 & 30 & 76,9 \\
\hline INIA Tacuarí & 29 & 74,4 \\
\hline Parao & 8 & 20.5 \\
\hline CH-Arrayán & 5 & 12,8 \\
\hline Inov $\mathrm{CL}^{\circ}$ & 6 & 15,4 \\
\hline $\begin{array}{l}\text { Gurí INTA CL } \\
\mathrm{CL}\end{array}$ & 2 & 5,1 \\
\hline INIA Olimar & 2 & 5,1 \\
\hline EEA 404 & 2 & 5,1 \\
\hline Perla & 2 & 5,1 \\
\hline Coronilla & 1 & 2,6 \\
\hline Hayate & 1 & 2,6 \\
\hline Camila & 1 & 2,6 \\
\hline
\end{tabular}

* $\mathrm{N}^{\circ}=$ número; \%= porcentaje

más productivos $53,8 \%$; 3 ) porque por ellos se recibe un sobreprecio $41,0 \%$; 4) por su calidad $20,5 \%$; 5) por su ciclo $17,9 \%$; 6 ) porque es el más flexible y se adapta bien en diferentes condiciones $15,4 \% ; 7$ ) para limpiar el campo de malezas $12,8 \%$; 8) por su sanidad $7,7 \%$.

En la figura 7 se observa que El Paso 144 fue el cultivar más mencionado en los grupos Treinta y Tres y Cebollatí (93 y $86 \%$ respectivamente), mientras que INIA Tacuarí fue el preferido en India Muerta (100\%). En Treinta y Tres, Parao les siguió en orden descendiente a los 2 anteriores (40\%), seguido por $\mathrm{CH}$-Arrayán y los híbridos $(27 \%)$. Los cultivares CL en conjunto (híbridos más variedades) ocuparon un área importante en Treinta y Tres (34\%) y algo menor en 


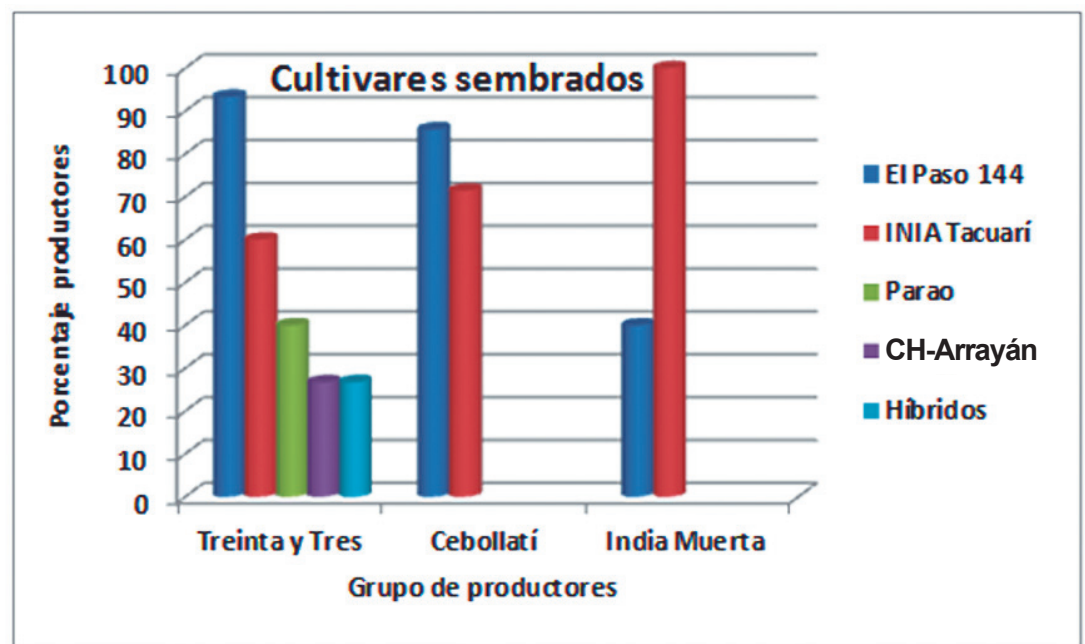

Figura 7. Cultivares sembrados según Grupo de productores (aparecen solamente cultivares con más de $25 \%$ de menciones)

Rocha (20\%); en esas menciones los híbridos constituían el $80 \%$ en el primer caso y el $50 \%$ en el segundo.

\subsubsection{Fechas de siembra}

El $90 \%$ de los encuestados manifestó la intención de sembrar antes del 20 de octubre, y más de la mitad de los mismos, hacerlo entre el 25 de setiembre y el 15 de octubre. Los porcentajes generales de respuestas obtenidas son presentados en el cuadro 14 existiendo algunas puntualizaciones por parte de los productores en casos en que ellos sembraran distintos cultivares en localidades diferentes (por ejemplo, del 25 de setiembre al 15 de octubre un cultivar en una zona, y del 1 de octubre al 20 de octubre otro cultivar en otra).

Cuadro 14. Períodos en que desearía ubicar la siembra de los cultivos.

\begin{tabular}{ccc}
\hline Período & Fechas & Productores $\%$ \\
\hline 1 & del 25 set al 15 oct & 51,3 \\
2 & del 1 oct al 20 oct & 38,5 \\
3 & del 5 oct al 25 oct & 5,1 \\
4 & del 10 oct al 30 oct & 5,1 \\
\hline
\end{tabular}

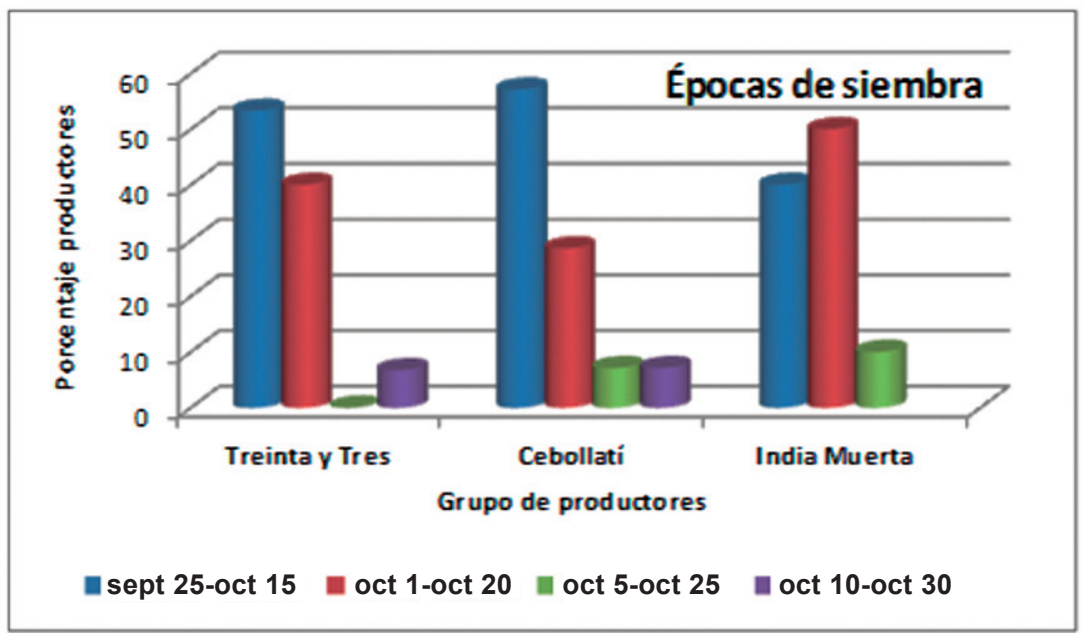

Figura 8. Épocas de siembra preferidas, según grupo de productores, 
Más de la mitad de los productores de los grupos Treinta y Tres y Cebollatí manifestaron que comenzarían a sembrar a partir del 25 de setiembre, mientras que los de India Muerta lo harían algo más tarde (Figura 8).

\subsubsection{Densidades de siembra}

Dejando de lado la siembra del híbrido $\mathrm{CL}$ que en general se maneja a $45 \mathrm{~kg} / \mathrm{ha}$, se encuentran diferencias importantes en referencia a la cantidad de semilla utilizada. Dentro de un rango que va de 100 a 200 $\mathrm{kg} / \mathrm{ha}$, lo más frecuentemente usado es en el entorno de $150 \mathrm{~kg} / \mathrm{ha}(53,8 \%)$.

El grupo Treinta y Tres utiliza una cantidad de semilla menor, siendo $125 \mathrm{~kg} / \mathrm{ha}$ la respuesta más frecuente $(67 \%)$, con menciones de uso de 100 kg/ha (Figura 9). En Cebollatí e India Muerta se utilizan densidades mayores, con menciones de uso de $175-200 \mathrm{~kg} / \mathrm{ha}$ en ambos grupos (43 y $21 \%$ en Cebollatí y $50-20 \%$ en India Muerta, respectivamente).

Las cantidades utilizadas varían de acuerdo con el cultivar, la época de siembra, la preparación y el uso anterior del suelo. De las 20 empresas que sembraron los
2 cultivares El Paso 144 e INIA Tacuarí en el período, 13 manifestaron no usar densidades de siembra diferentes, 5 usaron mayor cantidad de semilla con Tacuarí y 1 con EI Paso 144. Las 4 que usan $200 \mathrm{~kg} / \mathrm{ha}$ de semilla, lo hicieron en el departamento de Rocha (La Coronilla, Cebollatí, proximidades de Lascano). Una de ellas que ha sembrado las 2 variedades, en general utilizaba más semilla en los retornos y agregaba algo más, cuando lo hacía con INIA Tacuarí.

Las que usaron menores cantidades (100-125 kg/ha), sembraban en Rincón de Ramírez - La Charqueada, realizaban laboreo de verano en parte del área e instalaban el cultivo parte o la mayoría de la superficie con cero laboreo en la primavera.

\subsubsection{Tratamientos de semilla}

El $74,4 \%$ de los consultados, manifestaron tratar la semilla a utilizar con algún producto en todos los casos, y el $25,6 \%$ restante lo hacía en determinadas oportunidades. Las razones de estas últimas pueden ser:

- porque hace "semilla» del cultivar;

- por tratarse de las siembras más tempranas;

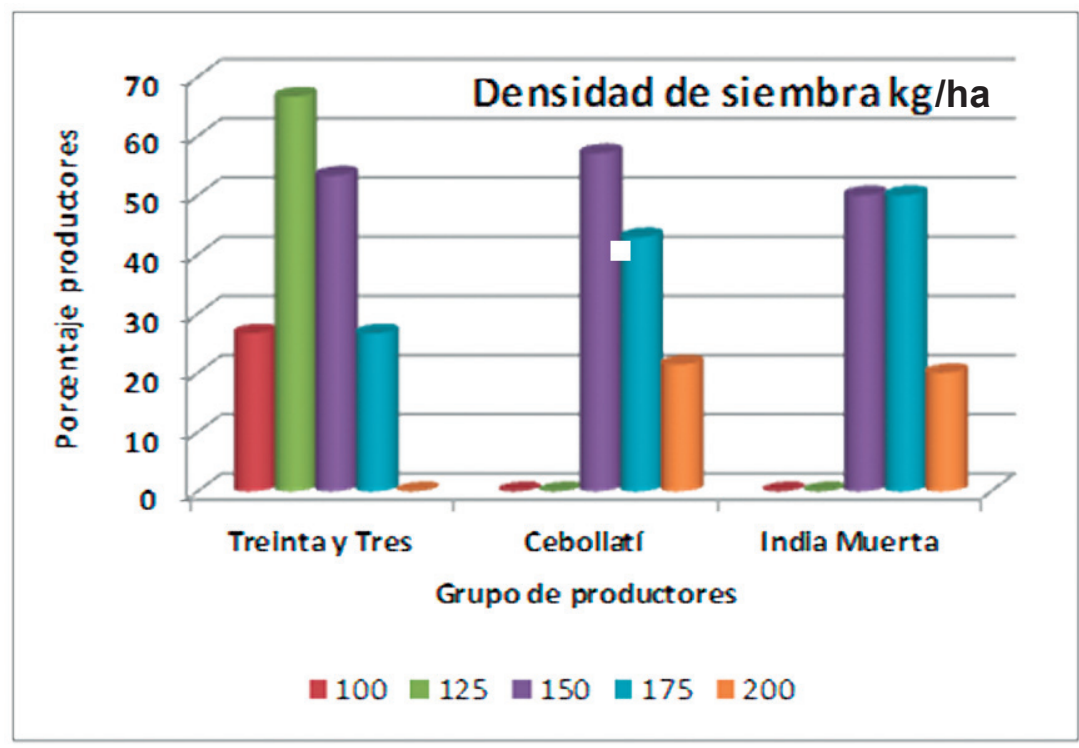

Figura 9. Densidad de siembra utilizada, según grupo de productores (el porcentaje de menciones no debe necesariamente sumar 100 , pues pueden corresponder a situaciones y/o años diferentes). 
- por los antecedentes de la chacra;

- para reducir la densidad de siembra.

Los tratamientos más utilizados fueron con fungicidas solamente $(41,1 \%)$, con insecticidas (10,3\%), o con mezclas de fungicidas con insecticidas $(66,7 \%)$. En otros casos, algunos productores trataban la semilla con zinc $(25,7 \%)$ en presencia de blanqueales, 5,1\% han usado protector para evitar la fitotoxicidad de clomazone y $2,6 \%$ inoculaban la semilla con endobacterias (Azospirillum + Herbaspirillum).

\subsubsection{Fertilización}

\section{Criterios para fertilizar}

Análisis de suelos. El $59 \%$ de los entrevistados utilizaba el análisis de suelos, como uno de los elementos a considerar en la fertilización del cultivo; un $20,5 \%$ no siempre lo utilizaba, y el restante $20,5 \%$ no lo consideraba. Los contenidos de fósforo y de potasio del suelo, eran tomados en cuenta en la definición de las cantidades de fertilizante basal utilizado (mencionado por el 17,9\% y $12,8 \%$ de los productores, respectivamente).

Otros elementos. Otros factores mencionados en la toma de decisiones fueron: el uso anterior de la chacra $(25,6 \%)$, el precio/fórmula de los fertilizantes disponibles $(17,9 \%)$, la variedad sembrada $(17,9 \%)$, y en menor proporción la época de siembra $(2,6 \%)$ y las condiciones climáticas previstas $(2,6 \%)$.

\section{Fertilizante basal}

Épocas de aplicación. El 35,9\% de los productores integrantes del quintil superior de rendimientos aplicaba en los últimos 3-4 años el fertilizante basal en forma anticipada a la siembra, mientras que el $64,1 \%$ lo hacía en la línea. Varios integrantes de este segundo subgrupo tenían la intención de comenzar en la zafra 2013-2014, o en un futuro no muy lejano, a fertilizar en forma anticipada. Como situación intermedia, se encontraban productores que fertilizaban en la línea con un binario (NP) y decidieron suministrar potasio al cultivo, aplicando $\mathrm{KCl}$ al voleo, poco tiempo antes de sembrar. Un productor que fertiliza con fosfato de amonio divide parte aplicado en la línea y el resto al voleo en forma previa e incorporado con rastra de espuelas.

Sobre razones o beneficios que les reporta la anticipación de la fertilización, la mayoría mencionó ventajas por mejor distribución del tiempo y recursos humanos en la siembra. Un productor opina que, dado que el arroz presenta una raíz fasciculada, una aplicación previa al voleo le ofrece a la planta una mejor distribución de los nutrientes.

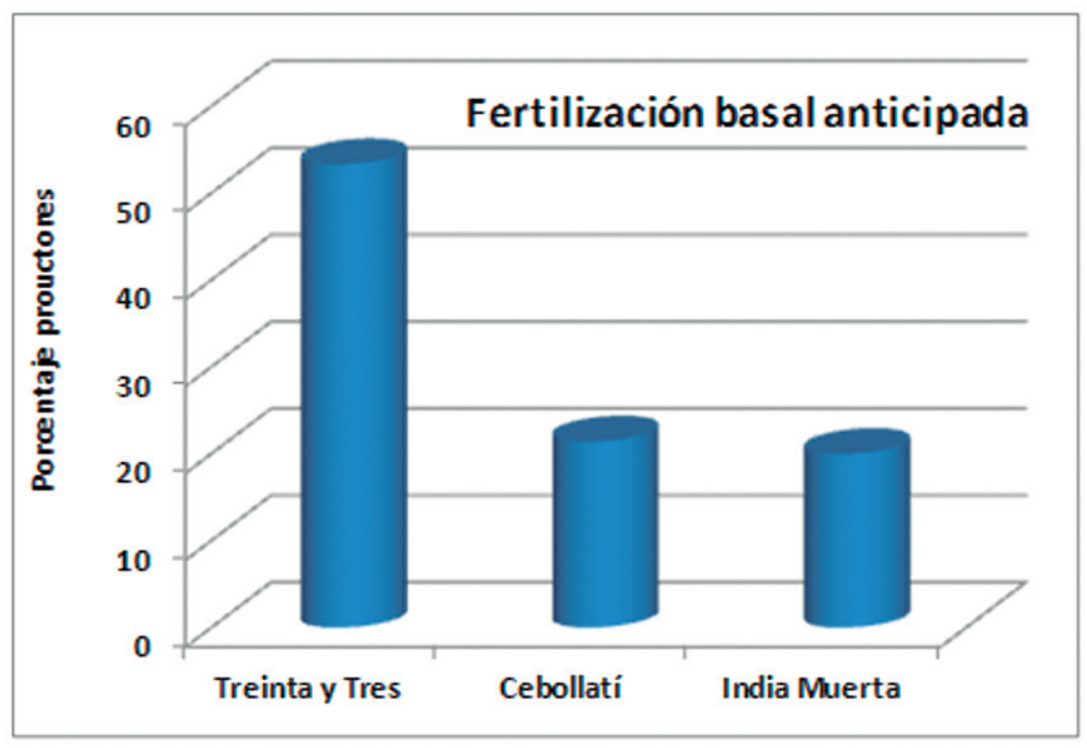

Figura 10. Aplicación de fertilizante anticipado a la siembra según Grupo de productores. 
En relación con los nutrientes aplicados en forma anticipada, un $5,1 \%$ de los productores reportó sólo $\mathrm{P}$, un $12,8 \%$ sólo $\mathrm{K}$, un $15,4 \% \mathrm{~N}$ y $\mathrm{P}$, un $10,3 \% \mathrm{P}$ y $\mathrm{K}$, y un $7,7 \% \mathrm{~N}$, $\mathrm{P}, \mathrm{y} \mathrm{K}$. Es de destacar que un mismo productor puede haber citado más de una de las opciones anteriores, de acuerdo con la situación y zafra considerada.

La práctica de adelantar la fertilización basal con relación a la siembra era más frecuente en el grupo Treinta y Tres que en Cebollatí e India Muerta (Figura 10)

\section{Fuentes de fertilizante}

Si bien el $58 \%$ de las respuestas obtenidas dan preferencia a la fórmula química en relación con las mezclas físicas, no todos los que lo afirmaron parecían muy convencidos de la misma, y además un $32 \%$ adicional opinó que no encontró diferencias entre las 2 opciones.
Se utilizaban fertilizantes que sólo contienen fósforo (fosforita y super triple), potasio (cloruro de potasio), binarios NP y ternarios NPK (varias fórmulas).

Considerando porcentajes de uso por parte de las empresas (no por superficie), los más citados fueron los binarios donde se destaca ampliamente el fosfato de amonio (64,1\%). El 35,9\% utilizaba, en parte o en toda su chacra fertilizantes NPK y un 33,3\% aplicaba también potasio en forma de cloruro. Muchas veces el productor utilizaba esta última alternativa de mayor contenido del nutriente, como complemento de aplicaciones de $\mathrm{N}$ y $\mathrm{P}$ como fosfato de amonio, pudiendo incrementar la proporción de $\mathrm{K}$ sin variar las cantidades de los otros 2. En el cuadro 15 se presentan los porcentajes de uso.

En la figura 11 se puede observar que a diferencia de Treinta y Tres, en los grupos Cebollatí e India Muerta predominaba la

Cuadro 15. Fertilizantes utilizados en aplicaciones basales.

\begin{tabular}{lcccc}
\hline & \multicolumn{4}{c}{ Nutrientes aportados } \\
\cline { 2 - 5 } Fertilizantes & $\mathrm{P}$ & $\mathrm{NP}$ & $\mathrm{K}$ & $\mathrm{NPK}$ \\
& Fosforita & $2-24 / 24$ & Cloruro de & $5-25-25$ \\
& Super triple & $10-50$ & potasio & $9-25-25$ \\
& & $12-52$ & & $5-30-15$ \\
& & $18-46$ & & $5-35-10$ \\
& & & & $9-39-15$ \\
\hline Productores $\%$ & 17,9 & 84,6 & 33,3 & $7-40-7$ \\
\hline
\end{tabular}

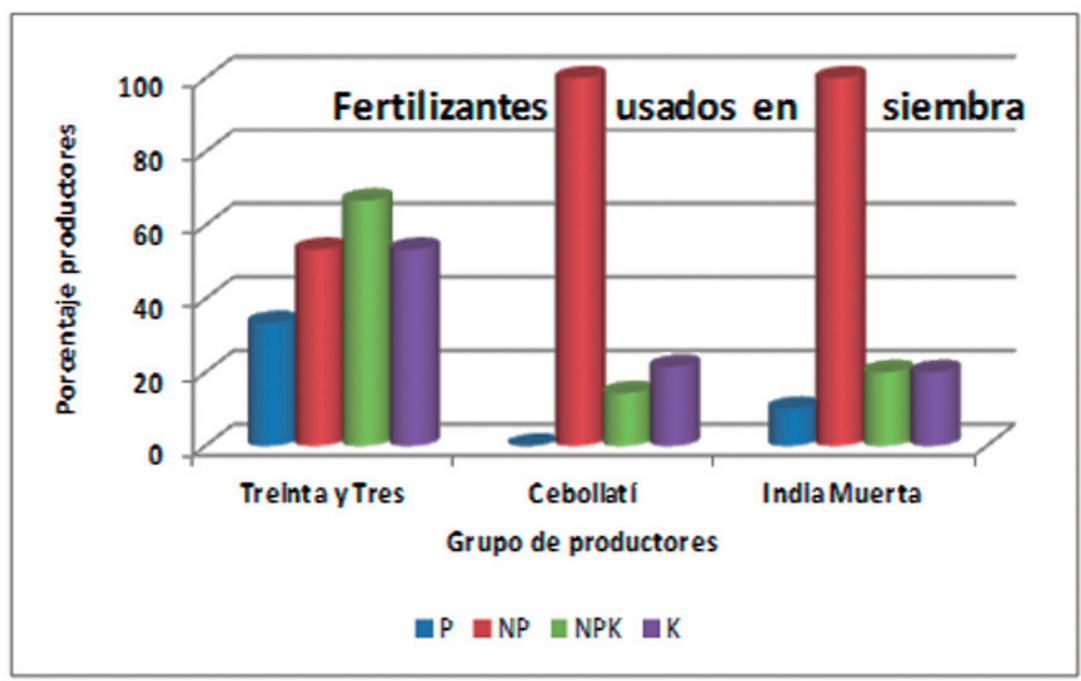

Figura 11. Tipo de fertilizante aplicado en la siembra según grupo de productores (el porcentaje de menciones no debe necesariamente sumar 100 , pues pueden corresponder a situaciones y/o años diferentes). 
aplicación de fertilizantes binarios (NP) con uso bastante menor o esporádico de ternarios (NPK) o de sólo fosfatados o potásicos. En el primero las fertilizaciones NPK o de fertilizantes NP, o de sólo $\mathrm{P}$, complementadas aparte con aplicaciones de cloruro de potasio, son más frecuentes y equilibradas.

\section{Fertilizaciones en cobertura}

\section{Nitrógeno}

El 94,9\% de los productores utilizó urea común y el $15,4 \%$ Verde urea (con inhibidor de la ureasa), en alguna de las épocas de aplicación. Productores que optaron por el uso de la Verde urea, en general (hay excepciones) lo hicieron únicamente al macollaje, o cuando hicieron doble cobertura utilizaron la verde en el macollaje y luego la común en la segunda oportunidad. Empresas que usaban hasta entonces urea común, manifestaron estar comenzando a utilizar la Verde urea, en la próxima zafra. Un productor aplicaba urea recubierta $(2,6 \%)$ y otros productores habían usado Entec $(7,6 \%)$ y/o Sulfammo $(2,6 \%)$ en alguna ocasión. En la figura 12 se presentan las fuentes de $\mathrm{N}$ utilizadas en las coberturas, según los 3 grupos de productores.

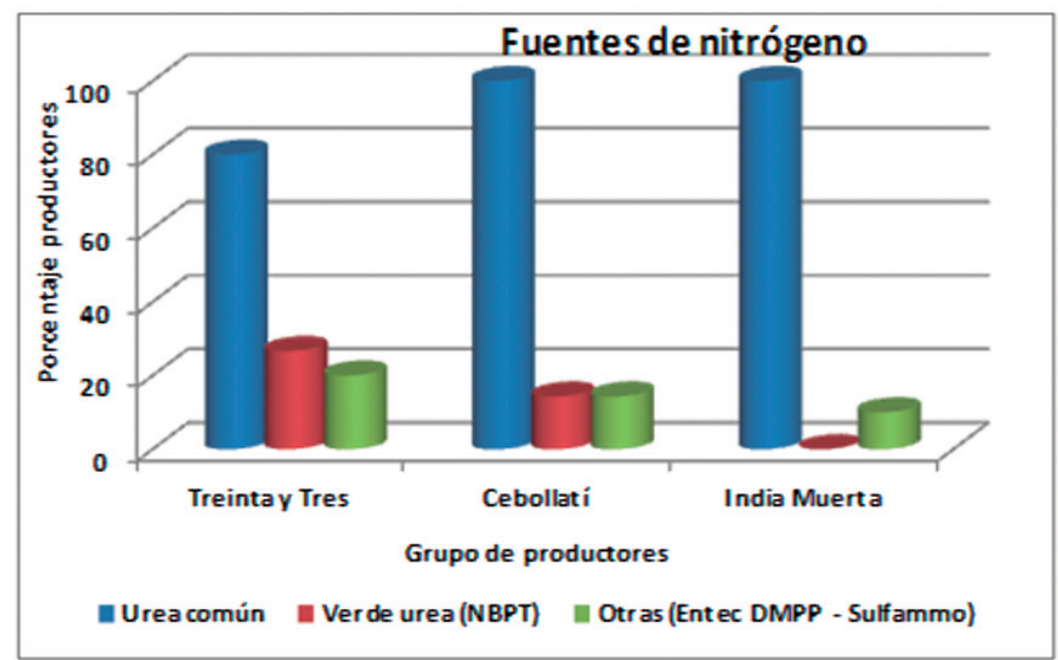

Figura 12. Fuentes de $\mathrm{N}$ utilizadas en coberturas según grupo de productores (el porcentaje de menciones no debe necesariamente sumar 100 , pues pueden corresponder a situaciones y/o años diferentes)

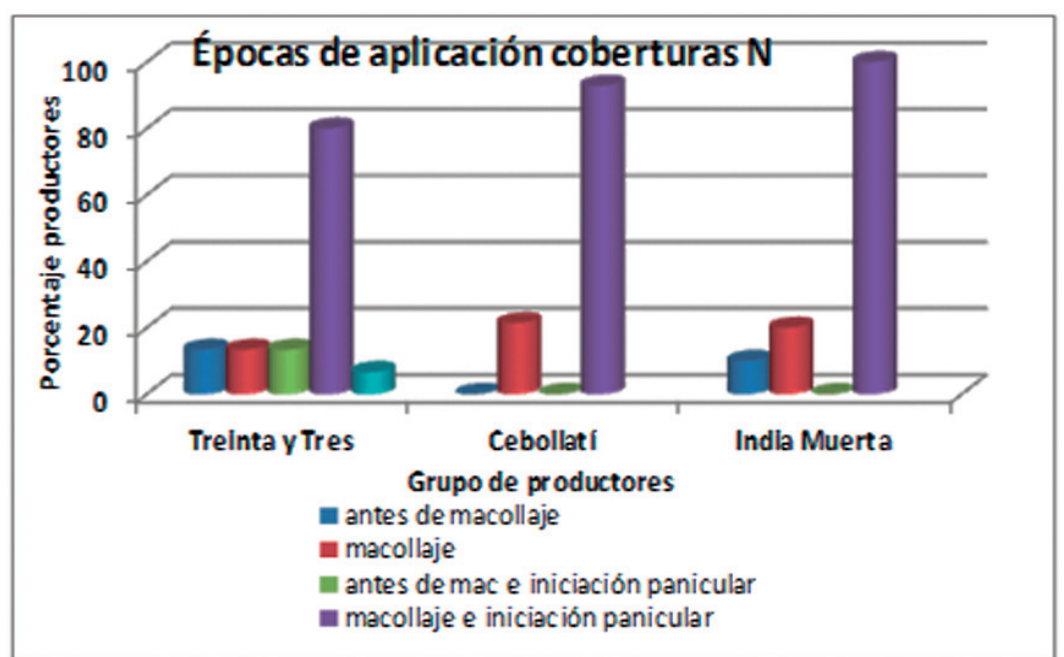

Figura 13. Épocas de aplicación de $\mathrm{N}$ en cobertura según grupo de productores (el porcentaje de menciones no debe necesariamente sumar 100 , pues pueden corresponder a situaciones y/o años diferentes) 
La mayoría de los productores encuestados realizaba en alguna de sus chacras una doble aplicación de nitrógeno en cobertura $(94,8 \%)$, realizando el $89,7 \%$ la primera en macollaje y la segunda en la elongación de entrenudos-primordio; el 5,1\% restante adelanta la primera aplicación para antes del inicio de macollaje. Dependiendo del cultivar sembrado, algunos productores manejaban en forma diferente la fertilización nitrogenada, y concentraban la fertilización en una aplicación única realizada al macollaje o previo al inicio del mismo $(17,9 \%$ y $5,1 \%$, respectivamente). En la figura 13 se presenta la distribución de las épocas de fertilización nitrogenada en cobertura según los grupos de productores.

Sobre la forma de aplicación de la primera cobertura, terrestre o aérea, y su re- lación con el ingreso del riego, se presentan en el cuadro 16 las respuestas obtenidas. El 87,2 \% de las empresas aplicaba el nitrógeno antes del ingreso del agua; el $30,8 \%$ lo hacía en forma terrestre, el $41 \%$ en forma aérea y un $17,9 \%$ algunas veces lo hacía en una u otra forma. Un $7,7 \%$ de los productores daba un baño y luego aplicaba el nitrógeno. En la figura 14 se puede observar la distribución de las respuestas según los grupos de productores; en Treinta y Tres e India Muerta, se realizaban las primeras coberturas nitrogenadas antes del ingreso del riego, siendo más frecuentes las aplicaciones terrestres en el primero y las aéreas en el segundo. En Cebollatí, algunos productores aplicaban el $\mathrm{N}$ después de un baño y un mínimo porcentaje lo hacía en forma aérea, a veces en seco y en otras después de ingresar el agua.

Cuadro 16. Formas de aplicación de la $1^{\text {a }}$ cobertura nitrogenada y su relación con el riego.

\begin{tabular}{ccc}
\hline & Tipo de aplicación & Productores \\
\hline Forma & Relación on el riego & 30,8 \\
\hline terrestre & antes de ingresar el agua & 41,0 \\
aérea & antes de ingresar el agua & 17,9 \\
aérea & antes de ingresar el agua & \\
aérea & aveces en seco, aveces & 2,6 \\
aérea & después de ingresar el agua & 7,7 \\
\hline
\end{tabular}

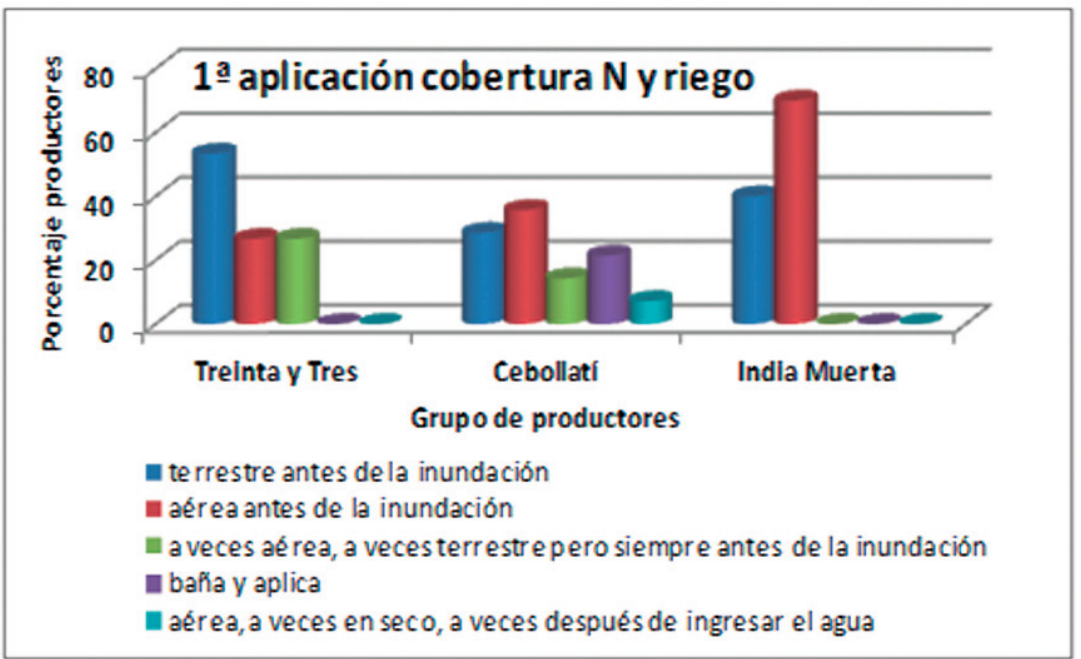

Figura 14. Forma de aplicación de la primera cobertura nitrogenada según grupo de productores (el porcentaje de menciones no debe necesariamente sumar 100 , pues pueden corresponder a situaciones y/o años diferentes) 
Cuadro 17. Razones para dividir o no el nitrógeno en diferentes proporciones y épocas.

\begin{tabular}{clc}
\hline No & Respuesta & Entrevistados $\%$ \\
\hline 1 & Por experiencia personal & 79,5 \\
2 & Por recomend ación de té cnico del molino & 12,8 \\
3 & Por recomendación de té cnico a sesor privado & 23,1 \\
4 & Por opinión de compañeros del grupo de productores & 7,7 \\
5 & Por practicidad o economía / terre trev una aérea & 35,9 \\
6 & Para compensar porque no usa N en la siembra & 7,7 \\
7 & Para que macolle mejor & 10,3 \\
8 & Por calidad de aplicación & 10,3 \\
9 & Por otras razones & 33,3 \\
\hline
\end{tabular}

*Dentro de otras razones, se incluye: información de la investigación, características de la variedad sembrada, recomendación técnicos de empresas receptoras de cultivares especiales, para darle más fuerza en el arranque, para evitar el Brusone.

La experiencia personal y la practicidad o economía que ofrece la aplicación terrestre frente a la aérea, fueron las respuestas más mencionadas en relación a las razones que motivan dichas diferencias. A su vez, las recomendaciones técnicas recibidas ya sea de parte de técnicos de la industria o de asesores privados suman en su conjunto un $35,9 \%$ (Cuadro 17 ).

\section{Potasio}

En su gran mayoría, los productores no aplicaban potasio en cobertura en posemergencia $(97,4 \%)$. Sólo un productor lo aplicaba en alguna oportunidad en forma conjunta con el nitrógeno, con la fórmula 300-20.

\section{Fertilizantes foliares}

La aplicación de fertilizantes foliares no es una práctica adoptada por los productores encuestados. Sin embargo, 8 empresas $(20,5 \%)$ habían hecho alguna prueba con este tipo de productos. Una de ellas quedó conforme con los resultados obtenidos, y aplicó el producto en el año siguiente en toda el área. En general consideraban difícil sacar conclusiones de este tipo de evaluaciones.

\section{Cantidades de nutrientes aportados por la fertilización}

Es difícil resumir en forma aritmética las cantidades totales de nutrientes aportados por la fertilización, teniendo en cuenta las diferentes zonas de producción, la capacidad de suministro de nutrientes de los suelos, los distintos antecedentes de usos de las chacras con la posibilidad que exista residualidad de aplicaciones anteriores, la diversidad de aplicaciones basales y coberturas, los cultivares sembrados. Como fue mencionado, algunos encuestados (no muchos) aplicaban fosforita en el otoño previo y si es necesario "corrigen» en la primavera. Algunos productores no usaban el análisis de suelos, otros lo utilizaban habitualmente como criterio de decisión, mientras que un tercer sector lo hacía sólo como guía de la evolución. Algunos fertilizaban en forma diferente los retornos de los rastrojos y otros no los diferenciaban. No obstante, se presenta a continuación una idea general de la fertilización, así como de los rangos o de los valores extremos utilizados, entre los cuales se ubican la mayoría de los casos encuestados.

Existen combinaciones cultivar-uso anterior del suelo, o cultivar-fecha de siembra, que se repiten, en aquellos productores que sembraron las 2 variedades: INIA Tacuarí y El Paso 144. En general, en dichos casos INIATacuarí era ubicado en los retornos y EI Paso 144 en los rastrojos. Ello no siempre se da así, por ejemplo, cuando el productor era «productor de semilla» de EI Paso 144. En relación a la época de siembra, en general EI Paso 144 fue sembrada antes, 
tratando de ubicar su floración en un período más adecuado a sus características.

Con relación a la fertilización, similar o diferente de rastrojos en comparación a los retornos, no existía una única posición de los productores. Hay quienes no las distinguían, hay quienes aplicaban más fertilizante a los retornos que a los rastrojos, y a la inversa. Algunas empresas ya establecían la diferencia en la fertilización basal (NP) y otras lo hacían en las coberturas nitrogenadas.

Las aplicaciones totales de nitrógeno realizadas a variedades variaron entre 39 y $106 \mathrm{~kg} / \mathrm{ha}$, siendo más frecuentes valores entre 60 y $70 \mathrm{~kg} / \mathrm{ha}$ de N. Se utilizaron dosis mayores de nitrógeno donde se sembró un híbrido CL (entre 83 a $114 \mathrm{~kg} / \mathrm{ha}$ de N; promedio 99). En la figura 15 se pueden observar los promedios registrados según los grupos de productores, de acuerdo con 3 rangos preestablecidos de 23 a 45, 47 a 69 y $70-83 \mathrm{~kg} / \mathrm{ha}$ respectivamente. Se aplicaron cantidades más altas en Treinta y Tres (gran mayoría en el rango medio), intermedias en Cebollatí y menores en India Muerta.

Las aplicaciones de fósforo realizadas en la primavera se ubicaron en un rango de 31 a $75 \mathrm{~kg} /$ ha de $\mathrm{P}_{2} \mathrm{O}_{5}$, con valores más frecuentes entre 46 y $60 \mathrm{~kg} / \mathrm{ha}$ de $\mathrm{P}_{2} \mathrm{O}_{5}$.

No todos los productores aplican potasio en todas las situaciones. Su uso está asociado a zonas con presencia de suelos más livianos, en otras a la siembra de rastrojos, y siempre a la presencia del híbrido. El rango de aplicaciones en este caso fue de 0 a $81 \mathrm{~kg} / \mathrm{ha}$ de $\mathrm{K}_{2} \mathrm{O}$, con valores más frecuentes de 25 a $35 \mathrm{~kg} / \mathrm{ha}$ de $\mathrm{K}_{2} \mathrm{O}$.

\subsubsection{Control de malezas}

\section{Aplicaciones de herbicidas}

\section{Productos}

Los productores utilizaron distintas estrategias en el control de sus malezas, que comprenden la aplicación de productos únicos, mezclas de tanque de 2, 3 y hasta 4 herbicidas en una época, así también como secuencias de 2 aplicaciones, en distintas épocas. En total se mencionaron 10 ingredientes activos, dentro de los cuales se incluye el glifosato y el Kifix, mezcla de imazapir e imazapic utilizado en las siembras del híbrido del sistema Clearfield $®$. A ellos se debe agregar 3 más, utilizados solos 0 generalmente en mezcla con los anteriores, para el control de ciperáceas y/o otras malezas de hoja ancha.

En el cuadro 18 se presenta un resumen de los ingredientes activos utilizados, de acuerdo a su forma de utilización (solos o en mezclas) y los porcentajes de encuestados que mencionaron haberlos utilizados, al menos en alguna ocasión en el período

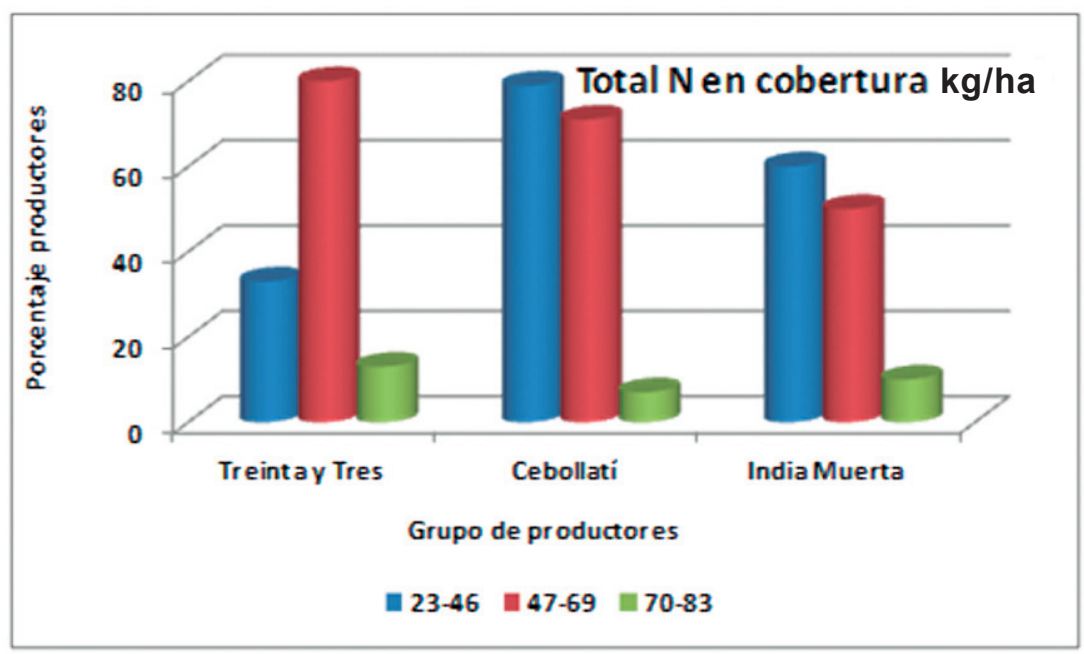

Figura 15. Total de $\mathrm{N}$ kg/ha aplicado en cobertura según grupo de productores (el porcentaje de menciones no debe necesariamente sumar 100, pues corresponde a situaciones y/o años diferentes). 
Cuadro 18. Herbicidas utilizados en el control de malezas.

\begin{tabular}{|c|c|c|c|}
\hline Productos & Forma & Ingrediente activo & $\begin{array}{c}\text { Productores }{ }^{*} \\
\%\end{array}$ \\
\hline \multirow{20}{*}{ Graminicidas } & \multirow{6}{*}{$\begin{array}{l}\text { sólo, aunque sea } \\
\text { esporádicamente }\end{array}$} & bispiribac & 23,1 \\
\hline & & clomazone & 7,7 \\
\hline & & cyhalofop butil & 15,4 \\
\hline & & imazapir+imazapic & 179 \\
\hline & & penoxsulam & 48,7 \\
\hline & & profoxidim (clefoxidim) & 5,1 \\
\hline & \multirow{10}{*}{ mezcla de 2} & bispiribac - cloma zone & 5,1 \\
\hline & & cyhalofop butil - clomazone & 7,7 \\
\hline & & penoxsulam - clomazone & 205 \\
\hline & & propanil-clomazone & 15,4 \\
\hline & & quinclorac-clomazone & 15,4 \\
\hline & & bispiribac - quinclorac & 2,6 \\
\hline & & cyhalofop butil - quinclorac & 10,3 \\
\hline & & penoxsulam - quinclorac & 2,6 \\
\hline & & cyhalofop - penoxsulam & 5,1 \\
\hline & & cyhalofop - profoxidim (clefoxidim) & 2,6 \\
\hline & \multirow{3}{*}{ mezcla de 3} & quinclorac - clomazone - propanil & 615 \\
\hline & & quinclorac - clomazone - cyhabofop butil & 5,1 \\
\hline & & quinclorac - penoxsulam - cyhalofop butil & 2,6 \\
\hline & secuencia & glifasato - clomazone & 56,4 \\
\hline \multirow{6}{*}{ Cipericidas } & \multirow{4}{*}{$\begin{array}{l}\text { en mezclas con } \\
\text { los anteriores }\end{array}$} & pyrazosulfuron & 692 \\
\hline & & metsulfuron & 5,1 \\
\hline & & triclopir & 15,4 \\
\hline & & $2-40$ & 2,6 \\
\hline & \multirow{2}{*}{ solos } & pyrazosulfuron & 2,6 \\
\hline & & metsulfuron & 2,6 \\
\hline
\end{tabular}

* \% de 39 productores encuestados, que mencionaron haberlos utilizado al menos en alguna ocasión en el período considerado.

considerado. Las aplicaciones de la mezcla glifosato-clomazone aquí presentadas son pos-siembra y en muchos casos adicionales a las ya vistas en el cuadro 12. En general, esta mezcla era aplicada en épocas tempranas, y de acuerdo con la evolución de la presencia de malezas, en aproximadamente el $70 \%$ de los casos debe ser acompañada por un segundo tratamiento de herbicidas. Por tal motivo, se la presenta en el cuadro como secuencia de productos.

En el cuadro 19 se presenta la misma información discriminada por grupo de productores y porcentajes relativos a los números de integrantes de cada uno.
En primera instancia, se destacan los valores de uso de las aplicaciones de glifosato + clomazone, en los 3 grupos (mayor en Treinta y Tres, intermedio en India Muerta y menor en Cebollatí) computadas aquí como un control de malezas, aparte de las menciones ya realizadas como preparatorias de la cama de siembra. El orden de uso parecería ligado al tipo de siembra utilizado en el grupo Treinta y Tres (mayor porcentaje de cero laboreo y siembra sobre taipas anticipadas) y una mayor problemática de malezas en los suelos de India Muerta.

En segundo lugar, es llamativa la presencia del herbicida clomazone, de tan buen 
Cuadro 19. Productos y/o mezclas de productos (ingredientes activos) utilizados en el manejo de malezas por grupo*.

\begin{tabular}{|c|c|c|c|}
\hline \multirow{2}{*}{$\begin{array}{l}\text { Producto(s) herbicidas } \\
\text { ingredientes activos }\end{array}$} & \multicolumn{3}{|c|}{ Grupo de productores } \\
\hline & Treinta y Tres & Cebollatí & India Muerta \\
\hline gífosato + clomazone & 66,7 & 35,7 & 50 \\
\hline propanil + quinclorac + clomazone & 53,3 & 57,1 & 80 \\
\hline penoxsulam & 60 & 64,3 & 10 \\
\hline penoxsulam + clamazone & 33,3 & 14,3 & 10 \\
\hline quinclorac + clomazone & 6,7 & 21,4 & 20 \\
\hline propanil + clomazone & 33,3 & 0 & 10 \\
\hline cyhalof $\alpha$ & 33,3 & 7,1 & 30 \\
\hline cyhalof $o p+$ penoxsulam & 0 & 0" & 20 \\
\hline chalof $\alpha$ + quindorac & 13,3 & 7,1 & 10 \\
\hline cyhalof op + clomazone & 6.7 & 7,1 & 10 \\
\hline cyhalof op + quindorac + penoxsulam & 6,7 & 0 & 0 \\
\hline cyhalofop + quindorac + clomazone & 6,7 & 0 & 10 \\
\hline
\end{tabular}

*\% de menciones de uso en relación al número de productores integrantes de los Grupos.

resultado en el control de malezas en etapas de preemergencia y postemergencia temprana, en distintos tipos de mezcla, ya sean de 2 o 3 herbicidas. Sería importante prestar atención a la posible acumulación del ingrediente activo como resultado de sucesivas aplicaciones del mismo.

Más de la mitad de los productores de los 3 grupos, seguía utilizando la siempre efectiva mezcla triple propanil + quincorac + clomazone, siendo el control de malezas más usado en India Muerta $(80 \%)$; en los grupos Treinta y Tres y Cebollatí, es superada levemente en el uso por el penoxsulam.

Finalmente, se puede observar la importancia que iba adquiriendo en los últimos años el uso del herbicida cyhalofop, ya sea sólo o en mezcla con otros productos (penoxsulam, quinclorac, clomazone).

\section{Fitotoxicidad}

Ante la pregunta realizada sobre observaciones de posibles efectos de fitotoxicidad de las aplicaciones de herbicidas en el cultivo de arroz, se obtuvieron las siguientes respuestas, relacionados a:

clomazone $79,5 \%$, bispiribac $12,8 \%$, penoxsulam $5,1 \%$, profoxidim $5,1 \%$,

Kifix (imazapir+imazapic) 7,7\%, propanil $5,1 \%$,

mezclas de dos productos $12,8 \%$, mezclas de tres productos $2,6 \%$.
En general los encuestados que mencionaron al clomazone coincidieron que fueron efectos leves de albinismo, totalmente recuperables, excepto en la variedad Perla donde en alguna oportunidad se llegó a percibir muerte de plantas.

Consultados si recordaban que existieran determinadas condiciones climáticas en días previos o posteriores a las aplicaciones, asociados a dichas observaciones, el $38,5 \%$ mencionó la ocurrencia de temperaturas bajas en días posteriores, el 12,8 \% lluvias en días post-aplicación, y otro $12,5 \%$ ambas condiciones frío y lluvia. Por el contrario, con relación a problemas asociados a propanil y/o mezclas triples donde se incluyó este herbicida, algunos productores destacaron las altas temperaturas existentes cuando se realizaron las aplicaciones. No obstante, opinaron que el arroz pudo recuperarse, sin afectar el rendimiento.

\section{Formas}

La mayoría de los productores utilizó surfactantes o adyuvantes o humectantes; sólo 3 de ellos manifestaron no usar. El $77 \%$ en general usaba el producto recomendado por el fabricante $y / 0$ un $33 \%$ en ocasiones usaba uno de su confianza.

En relación a la fuente de agua, los encuestados manifestaron preocuparse por utilizar «agua limpia» para realizar las aplicaciones, en especial las terrestres, surtiendo 
de canales con agua corriente o represas. En otros casos, mencionaron que las empresas aplicadoras se encargan de ese tema. El 12,8\% ha realizado análisis de $\mathrm{pH}$ y un $5,1 \%$ de dureza.

El $74,4 \%$ de las empresas preferían aplicar los herbicidas en forma aérea y un $66,7 \%$ terrestre, pero dentro de este último grupo el $38,5 \%$ sólo utilizaba esta forma para aplicar glifosato o Kifix. Dentro de los que aplican en forma terrestre el $38,5 \%$ reducía en forma importante la dosis de herbicida utilizado en relación a la aérea, en torno a un $10 \%(2,6 \%$ de los productores $), 15 \%$ $(15,4 \%)$, entre un 20 y un $30 \%(15,4 \%)$ y hasta un 30 a $40 \%(5,1 \%)$.

El $10,4 \%$ de los productores aplicaban en alguna oportunidad un insecticida en forma conjunta con el tratamiento de herbicidas. Ninguno de ellos había observado un efecto distinto (sinergia o antagonismo) en los tratamientos de control, atribuibles a la mezcla con el insecticida.

\subsubsection{Riego}

\section{Intervalos verticales}

Se presentan en el cuadro 20 los resultados obtenidos en relación al intervalo vertical utilizado en las chacras para la construcción de las taipas.

Sin considerar las situaciones sembradas en condiciones de laderas o de mayor pendiente, donde los intervalos utilizados fueron superiores a $8 \mathrm{~cm}$, la mayoría de los productores marcaba las taipas entre 3 y 6 $\mathrm{cm}$. Incluso algunos productores que utilizaban estos intervalos construían luego una taipa intermedia («loca»).

\section{Construcción de taipas}

En el cuadro 21 se presenta información sobre la época de construcción de las taipas en referencia a la siembra.

Consultados sobre la altura de las taipas construidas, el $17,9 \%$ de los productores contestó altas, un $17,9 \%$ medias, y el $64,1 \%$ bajas, quedando a criterio de los encuestados, qué se entiende por altas -medias bajas respectivamente.

\section{Manejo del agua}

Etapa inicial

El $87,2 \%$ había bañado la chacra en alguna oportunidad en el período inicial, para promover la emergencia y/o instalación del cultivo, ya sea porque el cultivo no nacía o para uniformizar su emergencia. El restante $12,8 \%$ no había dado baños.

Más de un productor mencionó que si podía, prefería evitar el baño, algunos porque promovían la emergencia de malezas, otros porque complicaban el manejo posterior; hay quien manejaba los pronósticos meteorológicos para tomar la decisión en este tema, y quien creía que en una zafra regar un cultivo de INIA Tacuarí en esa situación, le provocó mermas de rendimiento.

Cuadro 20. Intervalos verticales utilizados para la construcción de taipas*.

\begin{tabular}{lccccc}
\hline Intervalo vertical & $3-4 \mathrm{~cm}$ & $5-6 \mathrm{~cm}$ & 7 & $-8 \mathrm{~cm}$ & $>8 \mathrm{~cm}$ \\
\hline Productores \% & 59,0 & 56,4 & 12,8 & 15,4 \\
\hline
\end{tabular}

* Las respuestas obtenidas pueden integrar más de una de las opciones, ya sea porque excedían los límites propuestos, porque un mismo predio requirió de distintos intervalos de acuerdo con las pendientes existentes, o porque las empresas sembraron en más de una localización con diferente topografía.

Cuadro 21. Construcción de taipas.

\begin{tabular}{lcc}
\hline Época de construcción & Cono sin resiembra & Productores $^{*} \%$ \\
\hline Antes de sembrar & - & 23,1 \\
Después de sembrar & $\sin$ & 59,0 \\
Después de sembrar & con & 30,8 \\
\hline
\end{tabular}

*Algunas empresas hacen parte de la superficie de una forma y el resto de otra. 


\section{Postemergencia}

Se encontró diversidad en los manejos del riego posteriores a la emergencia del arroz, se haya dado o no un baño para favorecer la misma. El bañar para nacer, en general generaba una necesidad mayor de volver a dar un riego, antes de instalar la inundación definitiva.

Si bien había productores que preferían dejar ya el cultivo en etapas tempranas con cierto nivel de agua, hay un grupo de empresas que preferían «llevar» el cultivo a baños e inundaban más tarde. Quizás existan algunas condiciones del «ambiente regional» donde producen, que pueden incidir en esa forma de manejar el cultivo. También 2 productores mencionaron que cuando en una chacra se producen efectos fitotóxicos de los tratamientos de herbicidas, se los «lleva o recupera» a través de baños.

Una de las preguntas donde se encontró mayor dificultad en obtener la respuesta, fue la relativa a cuántos días después de la emergencia (dde), se establece normalmente la inundación de la chacra. Sin duda, la época está más relacionada al estado de desarrollo de las plantas, que a una fecha fija calendario relacionada a la emergencia. A su vez, los efectos de las temperaturas en los días postemergencia de una siembra de setiembre, son muy diferentes que los de una de mediados o fines de octubre. Por ello, es bastante relativa la información recogida, aunque marca ciertas tendencias (Cuadro 22). En los casos en que los productores contestaron un rango y no un valor (por ejemplo 25-30 dde), se tomó el mayor valor (30 dde) para ingresar el valor en el casillero y calcular el porcentaje correspondiente. Si bien no son mayoría, un $15 \%$ de los productores que integran el quintil superior de rendimientos inundaba las chacras, más allá de 35 días postemergencia.

Consultados sobre el nivel de agua con que se manejaban las chacras, en parte ya definido con la altura de construcción de las taipas, en el cuadro 23 se presentan las respuestas obtenidas. Varios productores manifestaron utilizar un nivel bajo al comienzo, el que iban elevando gradualmente hasta el primordio, donde sí lo hacen profundo, y alguno de ellos lo hacen pasar por encima de la taipa.

La mayoría usaba canales auxiliares para el riego, con áreas que oscilan entre 20-40 ha como máximo, unos más otros menos, de manera que les permitía manejar el agua en forma rápida. Fueron más los que llenaban la chacra de los cuadros inferiores hacia arriba, que aquellos que llenaban los cuadros superiores y van cortando al siguiente (aproximadamente $2 / 3-1 / 3$ ).

Un $61,5 \%$ de los encuestados manifestó que no le gustaba renovar el agua de los cuadros.

Para finalizar, se mencionan en forma textual algunas pautas recibidas en las entrevistas sobre los niveles de riego manejados:

- «hasta el primordio, riego mínimo, si pudiera sólo húmedo, después alto»;

- «hay que estar cinchando permanentemente, después de calzar, riego por arriba»;

- «riego corrido, por arriba de la taipa»;

- «cada 3-4 días hago pasar el agua, no la dejo secar... barrito»;

Cuadro 22. Épocas de inundación de los cultivos.

\begin{tabular}{lcccccc}
\hline & \multicolumn{5}{c}{ Días después de la emergencia (dde) } \\
\cline { 2 - 7 } Inundación & 15 & 20 & 25 & 30 & $35-40$ & 40 \\
\cline { 2 - 7 } Productores \% & 7,7 & 10,3 & 25,6 & 41,0 & 7,7 & 7,7 \\
\hline
\end{tabular}

Cuadro 23. Niveles de riego utilizados dentro de los cuadros.

\begin{tabular}{lccc}
\hline & \multicolumn{3}{c}{ Nivel de agua utilizado para regar } \\
\hline Categorías & Bajo & Hasta que dé la taipa & Otra manera \\
\hline Productores \% & 282 & 359 & 590 \\
\hline
\end{tabular}


- «riego bajito... barrito, el riego es medio corrido, la taipa me obliga»;

- «la dejo bajar y repongo, pero no secar»;

- «herbicida-urea-barrito... pero sin secarla más»;

- «busco dejar entreseco... Ileno, dejo resumir e inundo»;

- «dejo que se resuma, cuando va a blanquear, repongo»;

- «manejo con barro y agua baja...que no se seque nunca»

- «intermedio, ni barrito, ni colchón»;

- «nivel bajo... barro, luego levanto; a EI Paso 144 le gusta alta»;

- «en INIA Tacuarí ... bajo hasta floración»;

- «a INIA Tacuarí le gusta el agua bien baja, prefiero darle baños».

\subsubsection{Manejo de enfermedades}

\section{Previo al uso de fungicidas}

En la sección correspondiente a coberturas de nutrientes, se preguntó al azar si tenían conocimiento de resultados de la investigación nacional sobre posibles efectos del manejo del nitrógeno sobre la sanidad del cultivo. El 90,9\% de los consultados contestó afirmativamente y un 9,1\% manifestó no disponer claramente de dicho conocimiento.

En el cuadro 24, se presentan las respuestas obtenidas a la pregunta:

¿Sin considerar el uso del fungicida, a su criterio cuál sería un manejo adecuado del cultivo, para no tener problemas serios con las enfermedades?

El uso de los rastrojos (el alerta o consideración), ha sido el factor más nombrado, ya sea por la mención directa en el uso anterior del suelo, como por la reducción de la densidad de siembra en los mismos.

En un segundo nivel de mención se ubicó el manejo de la fertilización nitrogenada; algunos productores que mencionaron conocer los resultados de la investigación referentes al tema preferían aplicar el nutriente en niveles relativamente elevados para asegurar el potencial productivo y proteger el cultivo con el uso preventivo de fungicidas.

Algunos productores opinaron que, si bien el uso de una variedad resistente o tolerante sería una herramienta adecuada, con $\mathrm{CH}$-Arrayán la única variedad que cumple con tal requisito con el Brusone, no se llega a obtener los niveles productivos de las comúnmente sembradas.

Dos productores mencionaron la importancia de la inclusión de potasio, que si bien no fue mencionado por otros con relación a esta pregunta, se puede observar un uso más alto de $\mathrm{K}$ en los rastrojos en relación a los retornos. Finalmente, en otras prácticas, se mencionó el «monitoreo» del cultivo, y evitar llegar al estado de «barro» en los riegos.

\section{Estrategia en el uso de fungicidas}

En referencia a las aplicaciones de fungicidas, se consultó sobre la estrategia de uso de estos, tratando si fuera posible de diferenciar de qué enfermedad o grupo de enfermedades se trata de proteger. Dependiendo de la zona considerada, la respuesta a esta solicitud y/o distinción algunas veces resulta más fácil y en otras más difícil.

En el cuadro 25 se presentan las respuestas obtenidas para el manejo de las

Cuadro 24. Prácticas que contribuyen a prevenir problemas serios con enfermedades.

\begin{tabular}{lc}
\hline Prácticas & Productores \% \\
\hline Usar una variedad re sistente o tolerante & 7,7 \\
Considerar el uso anterior del suelo & 15,4 \\
Manejo de la fertilización nitrogenada & 18,0 \\
Reducir la densidad de siembra en rastrojos & 46,2 \\
Aplicar potasio & 5,1 \\
Otras* & 7,7 \\
\hline
\end{tabular}

${ }^{*}$ Otras = 1) monitorear el cultivo; 2) evitar llegar a barro, en los niveles de riego. 
Cuadro 25. Estrategias de uso de los fungicidas para el manejo de las enfermedades.

\begin{tabular}{lcc}
\hline Tipo de aplicadón & \multicolumn{2}{c}{ Productores \% } \\
\cline { 2 - 3 } & Enfermedades del tallo & Brusone \\
\hline 1 preventiva & 76,9 & 35,9 \\
1 preventiva +1 curativa & 15,4 & 56,4 \\
2 preventivas & 7,7 & 7,7 \\
Las necesarias, 3 o más & - & - \\
\hline
\end{tabular}

enfermedades del tallo y/o Brusone, respectivamente. Se destaca la diferente composición de la estrategia de uso de acuerdo con la mayor atención que requiere la presencia del Brusone. Algunos productores comentaron haber realizado más de 2 aplicaciones en alguna oportunidad, pero como casos excepcionales.

\section{Productos aplicados}

Se utilizaban 17 productos comerciales diferentes, correspondientes a 9 ingredientes activos únicos o en mezclas, estrobirulinas y triazoles. En el cuadro 26 se presenta un resumen de los ingredientes activos utilizados, ya sea en mezclas o por presencia del activo en distintos productos. El azoxistrobin y el tebuconazol, integrantes de distintas mezclas ya formuladas comercialmente, fueron en general los principios activos más utilizados.

En el cuadro 27 se pueden observar los ingredientes activos utilizados en el período, en los grupos de productores considerados. Contribuyen a ello, la existencia de enfermedades de distinto impacto según las zonas y que existían escasos cultivares con resistencia a Brusone. En los 3 grupos se

Cuadro 26. Fungicidas utilizados en el manejo de enfermedades*.

\begin{tabular}{|c|c|c|}
\hline \multicolumn{2}{|c|}{ Productos } & Productores \% \\
\hline Mezclas de ingredientes activos & Por principio activo & \\
\hline azoxystrobin + ciproconazol & & 28,2 \\
\hline azoxystrobin + difenoconazol & & 18,0 \\
\hline azoxystrobin + tebuconazol & & 30,8 \\
\hline kresoxim metil + epoxiconazol & & 17,9 \\
\hline trifoxystrobin + tebuconazoi & & 46,2 \\
\hline & azoxystrabin & 79,6 \\
\hline & ciproconazol & 28,2 \\
\hline & difenoconazol & 35,9 \\
\hline & kresoxim metil & 17,9 \\
\hline & tebuconazol & 92,4 \\
\hline & tricyclazol & 48,7 \\
\hline & trifioxystrobin & 46,2 \\
\hline
\end{tabular}

Cuadro 27. Productos y/o mezclas de productos (ingredientes activos) utilizados en el manejo de enfermedades por grupo*.

\begin{tabular}{lccc}
\hline Producto(s) fungicida(s) & \multicolumn{3}{c}{ Grupo de productores } \\
\cline { 2 - 4 } ingredientes activos & Treinta y Tres & Cebollatí & India Muerta \\
\hline azoxist robin + cjproconazole & 46,7 & 14,2 & 20 \\
azoxist robin + difenoconazole & 26,7 & 14,3 & 10 \\
tebuconazoi + trifibxystrobin & 53,3 & 42,9 & 40 \\
triciclazol & 60 & 28,6 & 30 \\
kresoxim met il + epoxiconazol & 13,3 & 21,4 & 20 \\
\hline
\end{tabular}

*\% de menciones de uso en relación con el número de productores integrantes de los grupos. 
Cuadro 28. Momentos y condiciones del día preferidos para realizar aplicaciones de fungicidas.

\begin{tabular}{|c|c|c|c|c|}
\hline \multirow{2}{*}{$\begin{array}{l}\text { Momento } \\
\text { del día }\end{array}$} & \multicolumn{2}{|c|}{ De mañana temprano } & \multirow{2}{*}{$\begin{array}{c}\text { De } \\
\text { tardecita }\end{array}$} & \multirow[t]{2}{*}{ Otra* } \\
\hline & $\begin{array}{c}\text { Sino hay mucho } \\
\text { rocío }\end{array}$ & $\begin{array}{c}\text { Haya o no mucho } \\
\text { rocío }\end{array}$ & & \\
\hline Productores \% & 12,8 & 76.9 & 7.7 & 2,6 \\
\hline
\end{tabular}

*La decisión es tomada por la empresa aeroaplicadora

destaca la aplicación de la mezcla tebuconazol + trifloxystrobin, probablemente vinculada a la primera aplicación preventiva, y en el Grupo Treinta y Tres el mayor uso de tricyclazol, ciproconazole y difenoconazol relacionados con la presencia de Brusone.

Los encuestados consideran importante las condiciones climáticas existentes al momento de realizar las aplicaciones de fungicidas, siendo el viento, la humedad y la temperatura del aire, los elementos más considerados (Cuadro 28).

En relación a los volúmenes de solución total utilizados en las aplicaciones de fungicidas, en el cuadro 29 se presentan las respuestas obtenidas, que se ubican en el rango de 5 a $10 \mathrm{l} / \mathrm{ha}$ (electrostáticas) a $40 \mathrm{l} / \mathrm{ha}$. Varios productores manifestaron que los números aportados probablemente sean más "un deseo o intención», y que la realidad corresponda a un volumen menor.

\subsubsection{Control de insectos}

Se consultó sobre el control de insectos en la etapa reproductiva del cultivo presentándose en el cuadro 30 las respuestas ob- tenidas. Un productor realizaba siempre un tratamiento junto con la primera aplicación preventiva de fungicida. De los 7 productores que habían realizado algún tratamiento de insecticidas en esta etapa, 2 ya habían manifestado hacerlo en una época más temprana, en una pregunta formulada en la sección 1.13 referente a herbicidas.

\subsubsection{Manejo del agua para realizar la cosecha}

El $30,8 \%$ de los productores había realizado la cosecha de su arroz con un nivel de agua en el suelo; uno de ellos, cosechaba en agua en una localización y drenaba la chacra en otra, mientras que otro entrevistado, si bien prefería hacerlo en seco, expresó que no siempre le era posible. El resto de los encuestados dejan de regar un tiempo antes de la cosecha y la mayoría de ellos corta el agua hacia afuera, transcurridos 5-10 días.

En el cuadro 31 se presenta en forma aproximada el manejo realizado, estimado en días antes de realizar la cosecha. Se debe tomar como un dato relativo, pues

Cuadro 29. Volúmenes de solución total utilizados en las aplicaciones aéreas de fungicidas*.

\begin{tabular}{lcccccc}
\hline & \multicolumn{7}{c}{ Volúmenes de solución total $\mathrm{l} / \mathrm{ha}$} \\
\cline { 2 - 7 } & $5-10$ & 15 & 20 & 25 & 30 & 40 \\
\hline Productores \% & 25,6 & 10,3 & 23,1 & 10,3 & 30,8 & 7,7 \\
\hline
\end{tabular}

* Los porcentajes superan el $100 \%$, pues 2 productores contestaron con un rango aproximado, y en esos casos se marcaron los casilleros correspondientes a los 2 extremos, y 1 productor utiliza electrostática en una localización y no en otra.

Cuadro 30. Tratamientos de control de insectos en la etapa reproductiva.

\begin{tabular}{lccc}
\hline \multirow{2}{*}{$\mathrm{Ha}$ aplicado insecticidas en la etapa reproductiva? } & No & \multicolumn{2}{c}{ Sí } \\
\cline { 3 - 4 } & & Algunavez & Siempre \\
\hline Productores \% & 82 & 15,4 & 26 \\
\hline
\end{tabular}


Cuadro 31. Manejo del riego para realizar la cosecha*.

\begin{tabular}{lllc}
\hline & Manejo del riego & Productores $\%$ \\
\cline { 1 - 2 } & & Epoca & 30,8 \\
\hline Mantiene el agua hasta la cosecha & & 2,6 \\
\multirow{3}{*}{ Deja de regar días } & hero no corta el agua & $20-25 \mathrm{dac}$ & 7,7 \\
antes de la cosecha & días después corta el & $25-30 \mathrm{dac}$ & 28,2 \\
& agua hacia afuera & $20-25 \mathrm{dac}$ & 12,8 \\
& $15-20 \mathrm{dac}$ & 23,1 \\
\hline
\end{tabular}

* dac= días antes de la cosecha. Realizar 2 manejos del agua distintos, dos productores (5,2 \%) están computados en 2 filas diferentes: (manteniendo el agua hasta la cosecha por un lado y dejando de regar días antes por otro)

varios productores se refirieron a la época de toma de dichas decisiones haciendo referencia al «estado» del cultivo (inicio, o mediados del doblado de la panoja), más que a días antes de la cosecha, por lo que es muy difícil hacer un resumen de este tipo, teniendo en consideración las épocas de siembra, los distintos cultivares sembrados, los manejos de las fertilizaciones y riego y como consecuencia de la combinación de dichos factores los respectivos largos de ciclos resultantes.

\subsubsection{Variabilidad en el nivel de rendimientos}

\section{Rango de rendimientos obtenidos dentro de una zafra de arroz}

Dentro del alto nivel de productividad que les distingue en los últimos años, se les formuló la pregunta sobre cuál es el rango de variación entre los máximos y mínimos cosechados dentro de una misma zafra (Cuadro 32). Varios de ellos opinaron que la variabilidad observada en el último año fue bastante mayor a las anteriores.

\section{Factores que pueden haber contribui- do a establecer diferencias}

Dentro de las posibles causas que pueden haber contribuido a generar esa variabilidad, los encuestados han hecho mención a distintos tipos:
- fecha de siembra (23\%);

- tipo de suelos (15,3\%);

- problemas en el manejo del riego (12,8\%);

- mayor variabilidad en el desempeño productivo de El Paso 144 en distintas condiciones $(10,3 \%)$;

- incidencia climática frío-luminosidad $(10,3 \%)$;

- presencia de Brusone (5,1\%);

- fecha de acceso a los campos (5,1\%);

- grado de preparación del suelo para la siembra $(5,1 \%)$;

- zonas difíciles de drenar (2,6\%);

- comportamiento productivo diferente de acuerdo con la pendiente: en plano, mejor que en ladera $(2,6 \%)$;

- control de malezas (2,6\%).

\section{Manejo anterior del suelo}

Como fue comentado en la sección 3.1.15, cuadro 24 , casi la mitad de los entrevistados reduce la densidad de siembra en los rastrojos.

De los 11 productores $(28,2 \%$ de los entrevistados) que mencionaron comparaciones entre cosechas de arroces sembrados sobre rastrojos y retornos, 3 dijeron que los rastrojos rinden menos que los retornos, 3 tienen esa sensación pero las diferencias no son grandes (en 2 de estos, la siembra

Cuadro 32. Rango de variabilidad de los rendimientos de un productor dentro de una zafra

\begin{tabular}{lcccc}
\hline Rango de variación & $<10$ & $10-15$ & $15-20$ & $>20$ \\
& $\mathrm{~b} / \mathrm{ha}$ & $\mathrm{b} / \mathrm{ha}$ & $\mathrm{b} / \mathrm{ha}$ & b/ha \\
\hline Productores \% & 20,5 & 20,5 & 23,1 & 369 \\
\hline
\end{tabular}


sobre el retorno corresponde a producción de semilla), 1 cosecha más en los rastrojos que en el retorno, 2 consideran que no hay diferencias entre retornos y rastrojos, un productor cosechó menos en un tercer año de arroz en relación a un segundo, y por último sembrando en una zafra un cuarto año un productor sacó 20 bolsas menos que el máximo obtenido. En general los retornos son sembrados más temprano y no siempre es utilizada la misma distribución de variedades con relación al uso anterior del suelo. En el caso citado, donde el productor cosechaba más en los rastrojos, sembraba en ellos EI Paso 144; otro colega que hacía lo mismo cosechaba más rendimiento con INIA Tacuarí sembrado en los retornos.

Para hacer posibles comparaciones entre comportamientos del arroz sembrado sobre rastrojos vs sembrados en retornos, o entre rastrojos de varios años, hay que tener en consideración las variedades utilizadas en uno y en otro, así como las fechas de siembra. Por pequeña que sea, siempre existe la posibilidad de que haya un aporte positivo o negativo, de alguno de estos 2 componentes en el resultado final en grano.

\subsubsection{Cómo incrementar los rendimientos según los productores}

A la pregunta ¿qué prácticas de manejo considera se podrían modificar para intentar elevar los rendimientos en su empresa? se obtuvo una lluvia de ideas, que están de acuerdo a las distintas problemáticas que enfrentan los productores en sus respectivas zonas de producción. tos

Se agruparon las mismas en 11 conjun-
a) posibilidad de ingresar antes a los cam- pos;
b) acceder a una rotación;
c) disponer de más laboreos de verano o anticipados;
d) mayor sistematización;
e) más drenajes;
f) fechas de siembra;

g) fertilización;

h) poder sembrar por encima de las taipas;

i) reducir la altura de las taipas;

j) manejo del riego y dentro de él un subconjunto referido específicamente a la velocidad del riego;

k) ajustes de cosecha y recibo del arroz producido;

I) variedades.

En la figura 16 se presentan como histogramas las menciones recibidas en cada uno de los temas, destacándose en forma muy importante la mejora del riego y en segundo lugar la posibilidad de incrementar el número de laboreos de verano, de hacer la siembra del cultivo por encima de las taipas y la fertilización. Dentro de las mejoras del manejo del riego, casi el $30 \%$ se refirió específicamente a la velocidad que se puede realizar el mismo. El $16 \%$ de los productores que integran el quintil superior de rendimientos de la zona este desearía poder ingresar antes a los campos que siembra, para poder realizar la preparación del suelo e instalación del cultivo en tiempo y forma.

Dentro de «rotaciones», se incluyó la posibilidad de acceder a una (un productor) y el destaque de 3 entrevistados de la inserción de la soja en la rotación arrocera, mejorando la sistematización, la implantación del cultivo, el control de malezas y disminuyendo los costos de producción.

En «fechas de siembra» 2 productores pensaban adelantar lo más posible la siembra, 2 marcaron como muy importante no sembrar tarde EI Paso 144, siendo preferible sembrarlo en los terrones, pero respetar las fechas y 1 productor mencionó que se debe mejorar la asociación «fecha de siembra - riego» en épocas tempranas.

En «fertilización» se sugirió las fertilizaciones $\mathrm{N}$ y $\mathrm{K}$, principalmente $\mathrm{N}$ (criterios, fuentes, afinamiento para alguna variedad), una mención a micronutrientes y aplicaciones en la fase forrajera.

Con relación a la siembra por encima de las taipas, se destacaron las posibilidades de lograr una mejor implantación en los préstamos, una disminución en la densidad 


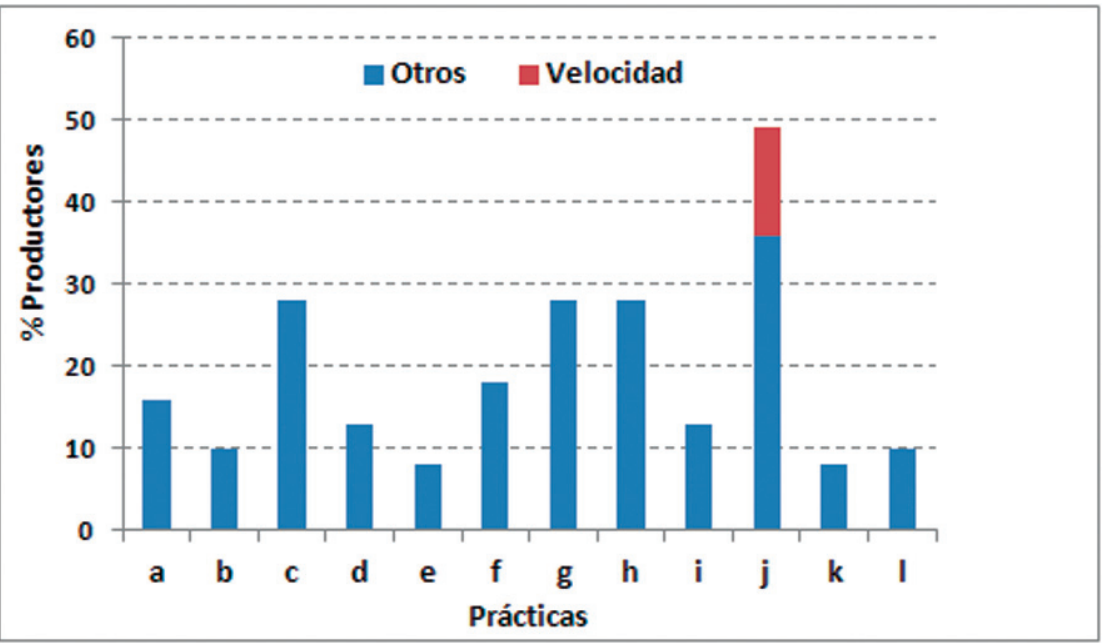

Figura 16. Prácticas que modificarían los productores para incrementar los rendimientos: a) ingresar antes a los campos; b) acceder a una rotación; c) más laboreos de verano o anticipados; d) mayor sistematización; e) más drenajes; f) fechas de siembra; g) fertilización; h) sembrar por encima de las taipas; i) reducir la altura de las taipas; j) manejo del riego, y dentro de él un subconjunto referido específicamente a la velocidad; k) ajustes entre cosecha y recibo del arroz producido; I) variedades.

de siembra, mayor uniformidad en el ciclo de las plantas y calidad de los granos.

Como se verá también en la sección siguiente, las pérdidas de cosecha y/o de la calidad de los granos producidos en EI Paso 144 es un tema que preocupa a varios productores.

De los productores que se refirieron al tema varietal, un encuestado opinó que no existen grandes saltos en la productividad, si no es a través de la siembra de nuevas variedades y que los productores deberían ser más abiertos a las pruebas. Otro, consideraba que se debe optimizar el manejo de las variedades nuevas, más aún con el problema que presenta El Paso 144 con el Brusone.

Se hizo referencia a la calidad de las sembradoras en el cruce de taipas y 2 productores mencionaron la distancia entre hileras como un tema a considerar.

Se mencionaron 2 interacciones en referencia a la eficiencia de cada componente, como nuevos problemas, a los que se debe buscar solución en relación a las épocas y formas de realizarlos: 1) interacciones entre las aplicaciones de herbicidas y el ingreso del agua, en particular en las siembras más tardías con mayor temperatura ambiente, y por lo tanto de mayor crecimiento de las malezas; 2) las aplicaciones de nitrógeno en cobertura, en especial las realizadas en forma terrestre, también con el riego.

\subsubsection{Factores más importantes que contribuyen al logro de una productividad alta}

Como cierre del intercambio de ideas realizadas con los productores, se les solicitó que nombraran cuáles son a su criterio los factores más importantes que contribuyen al logro de una alta productividad. En principio se les sugirió 6 ó 7 sin establecer un orden de importancia, quedando a decisión de los entrevistados el número a mencionar; mientras algunos de ellos no sugirieron más de 5 , otros llegaron a 10 . En el cuadro 33 se presenta un resumen de las respuestas obtenidas, agrupando las mismas en 24 divisiones, las que presentan un número muy diferente de menciones desde 1 a 37 (95\% de los productores). El riego, la fecha de siembra y el control de malezas fueron los 3 factores o prácticas más nombrados. 
Cuadro 33. Factores que contribuyen al logro de una productividad alta.

\begin{tabular}{lc}
\hline Grupos de factores o prácticas & Menciones \\
& $\%$ \\
Riego & 95 \\
Fecha de siembra & 77 \\
Control de malezas & 69 \\
Sistematización & 44 \\
Cosecha & 44 \\
Fertilización & 41 \\
Control de enfe medades & 41 \\
Uso del suelo & 36 \\
Gestión & 28 \\
Campos - suelos & 23 \\
Calidad de siembra & 21 \\
Rotación - sistema & 15 \\
Maquinaria & 13 \\
Relaciones con productores, con propietarios & \\
de tierra, con industria & 10 \\
Financiación del cultivo & 8 \\
Regionalizar manejo de la chacra & 5 \\
Densidad de siembra & 5 \\
Variedades & 5 \\
Tipo de siembra & 3 \\
Disponer de distintas opciones de siembra & 3 \\
Período siembra-25 d. posteriores & 3 \\
Control de in se ctos & 3 \\
Clima & 3 \\
\hline
\end{tabular}

\subsubsection{Taller realizado con productores}

En diciembre de 2013 se realizó un taller al que fueron invitados los productores encuestados y técnicos de las industrias involucradas, en el que de acuerdo con los resultados previamente presentados, se puso en consideración la propuesta de 20 prácticas de manejo como representativas de las tecnologías utilizadas por los mejores productores en las 3 zonas.

Luego de una presentación de la misma, los asistentes divididos en 3 grupos (2 de productores y 1 de técnicos), la discutieron y presentaron sus puntos de vista en una sesión plenaria. El comité técnico realizó una evaluación de la actividad menciona- da, analizó las sugerencias recibidas y consolidó la tecnología base a utilizar en los siguientes componentes del proyecto. En el cuadro 34 se presentan los testigos tecnológicos definidos en esa instancia de trabajo conjunto, que fueron luego utilizados para la definición del tratamiento 1 en los ensayos de campo de 2014-2015 y 2015-2016. Es importante destacar que no se consideraron algunas de las tecnologías identificadas como fundamentales para la obtención de altos rendimientos, pero cuyas características hacían imposible su inclusión en ensayos parcelarios. Entre ellas se mencionan las rotaciones, el manejo del riego, el laboreo previo, entre otras. 
Cuadro 34. Testigos tecnológicos de las 3 zonas.

\begin{tabular}{|c|c|c|c|c|}
\hline$N^{\circ}$ & Tecnología & $\begin{array}{c}\text { Grupo } 1 \\
\text { Treinta y Tres }\end{array}$ & $\begin{array}{l}\text { Grupo } 2 \\
\text { Cebollatí }\end{array}$ & $\begin{array}{c}\text { Grupo } 3 \\
\text { India Muerta }\end{array}$ \\
\hline & Superficie (ha) & $300-500$ & $100-300$ & $100-300$ \\
\hline 1 & $\begin{array}{l}\text { Aplicación de glifo sato } \\
\text { previo a sembra }\end{array}$ & 1 en primavera & 1 en primavera & $\begin{array}{c}1 \text { en otoño }+ \\
1 \text { en primavera }\end{array}$ \\
\hline 2 & Variedades & ETPaso 144 & ETPaso 144 & TNAT Tacuarí \\
\hline 3 & $\begin{array}{l}\text { Comienzo fe cha de } \\
\text { siembra }\end{array}$ & Antes de 10.10 & Antes 15.10 & Antes 20.10 \\
\hline 4 & $\begin{array}{l}\text { Laboreo de verano } \\
\text { antecesor }\end{array}$ & $\begin{array}{c}\text { Sí } \\
\text { retorno corto }\end{array}$ & $\begin{array}{c}\text { Sí } \\
\text { sin pradera }\end{array}$ & $\begin{array}{c}\text { Sí } \\
\text { conpradera }\end{array}$ \\
\hline 5 & Tipo de laboreo - siembra & $\begin{array}{l}\text { Reducido/ } \\
\text { cero laboreo }\end{array}$ & Corvencional & Corw encional \\
\hline 6 & Densidad siembra & $130 \mathrm{~kg} / \mathrm{ha}$ & $160 \mathrm{~kg} / \mathrm{ha}$ & $170 \mathrm{~kg} / \mathrm{ha}$ \\
\hline 7 & Tratamient o de semilla & $\begin{array}{l}\text { fungicida + } \\
\text { insecticida }\end{array}$ & $\begin{array}{l}\text { fungicida + } \\
\text { insectidida }\end{array}$ & $\begin{array}{l}\text { fungicida }+ \\
\text { insecticida }\end{array}$ \\
\hline 8 & $\begin{array}{l}\text { Aplicación } \\
\text { fertilizante basal }\end{array}$ & $\begin{array}{l}\text { Antes de } \\
\text { la siembra }\end{array}$ & $\begin{array}{c}\text { Simultánea a } \\
\text { la siembra }\end{array}$ & $\begin{array}{c}\text { Simult ánea a la } \\
\text { sembra }\end{array}$ \\
\hline 9 & $\begin{array}{l}\text { Fertilización basal } \\
\mathrm{kg} / \mathrm{ha}\end{array}$ & $\begin{array}{c}10-15 \mathrm{~N}+ \\
50-60 \mathrm{P}_{2} \mathrm{O}_{5}+ \\
20-30 \mathrm{~K}_{2} \mathrm{O}\end{array}$ & $\begin{array}{c}19,8 \mathrm{~N}+ \\
50,6 \mathrm{P}_{2} \mathrm{O}_{5}\end{array}$ & $\begin{array}{c}19,8 \mathrm{~N}+ \\
50,6 \mathrm{P}_{2} \mathrm{O}_{5}\end{array}$ \\
\hline 10 & $\begin{array}{l}1^{a} \text { Cobertura } N \text {-época } \\
\text { aplicación }\end{array}$ & $\begin{array}{l}\text { Urea común } \\
\text { en secoant es } \\
\text { de inundación }\end{array}$ & $\begin{array}{l}\text { Urea común en } \\
\text { seco ant es } \\
\text { de inundación }\end{array}$ & $\begin{array}{l}\text { Urea común en } \\
\text { seco ant es } \\
\text { de inundación }\end{array}$ \\
\hline 11 & $\begin{array}{l}\text { Coberturas } \mathrm{N}-\text { do sis urea- } \\
\text { fraccionamiento }\end{array}$ & $\begin{array}{l}75 \mathrm{~kg} / \mathrm{ha} \\
\text { macollaje. } \\
50 \mathrm{~kg} / \mathrm{ha} \\
\text { primordio }\end{array}$ & $\begin{array}{l}60 \mathrm{~kg} / \mathrm{ha} \\
\mathrm{macollaje} \\
50 \mathrm{~kg} / \mathrm{ha} \\
\text { primordio }\end{array}$ & $\begin{array}{l}60 \mathrm{~kg} / \mathrm{ha} \\
\mathrm{macollaje} \\
50 \mathrm{~kg} / \mathrm{ha} \\
\text { primordio }\end{array}$ \\
\hline 12 & $\begin{array}{l}\text { Aplicación } \\
\text { gúfosato + clomazone } \\
\text { inmediato a la siembra }\end{array}$ & Sí & No & Sí \\
\hline 13 & $\begin{array}{l}\text { Aplicación herbicidas } \\
\text { en postemergencia }\end{array}$ & penoxsulam & penoxsulam & $\begin{array}{c}\text { Triple mezcla } \\
\text { clom+quinctprop*. }\end{array}$ \\
\hline 14 & $\begin{array}{l}\text { Fungicidas aplicación } 1^{\mathbf{3}} \\
\text { preventiva /nicio floración }\end{array}$ & Sí & $\overline{\text { Sí }}$ & Sí \\
\hline 15 & $\begin{array}{l}\text { F ungicidas }-2^{a} \text { aplic. si } \\
\text { aparecen sintomas } \\
\text { Brusone }\end{array}$ & Sí & Sí & Sí \\
\hline 16 & $\begin{array}{l}\text { Fungicida - producto } \\
1^{\mathbf{a}} \text { aplicación }\end{array}$ & $\begin{array}{l}\text { tebuconazol + } \\
\text { trifioxystrobin }\end{array}$ & $\begin{array}{l}\text { tebuconazol + } \\
\text { trifioxystrobin }\end{array}$ & $\begin{array}{l}\text { tebuconazol + } \\
\text { trifloxystrobin }\end{array}$ \\
\hline 17 & $\begin{array}{l}\text { Intervalo vertical } \\
\text { altura de taipas }\end{array}$ & $\begin{array}{c}3-6 \mathrm{~cm} \\
\text { baja }\end{array}$ & $\begin{array}{c}3-6 \mathrm{~cm} \\
\text { media }\end{array}$ & $\begin{array}{c}3-6 \text { an } \\
\text { baja }\end{array}$ \\
\hline 18 & $\begin{array}{l}\text { Taipas - época de } \\
\text { construcción }\end{array}$ & $\begin{array}{l}\text { anticipada } \\
\text { a la siembra }\end{array}$ & $\begin{array}{l}\text { inmediato } \\
\text { a la siembra }\end{array}$ & $\begin{array}{l}\text { inmediato } \\
\text { ala siembra }\end{array}$ \\
\hline 19 & Epoca de inundación dde & 25 & $30-35$ & 30 \\
\hline 20 & $\begin{array}{l}\text { Manejo de agua } \\
\text { para cosecha }\end{array}$ & $\begin{array}{c}\text { suspende riego y } \\
\text { luego corta }\end{array}$ & $\begin{array}{l}\text { suspende riegoy } \\
\text { luego corta }\end{array}$ & $\begin{array}{c}\text { suspende riego y } \\
\text { luego corta }\end{array}$ \\
\hline
\end{tabular}

${ }^{*}$ clom+quinc+prop= clomazone + quinclorac + propanil; dde= días después de la emergencia. 
3.2. Propuestas tecnológicas alternativas para superar los rendimientos de los productores del quintil superior Investigación Parcelaria

\subsubsection{Zafra 2014-2015}

\subsubsection{Rincón de Ramírez 2014-2015}

De acuerdo a los contenidos de $\mathrm{P}, \mathrm{K}$ y PMN obtenidos en los análisis de suelos, en los tratamientos 4, 7, 8, 9, 11 y 12 se fertilizó con $63 \mathrm{~kg} / \mathrm{ha} \mathrm{P}_{2} \mathrm{O}_{5}$, y $78 \mathrm{~kg} / \mathrm{ha} \mathrm{K}_{2} \mathrm{O}$ en la siembra, y $155 \mathrm{~kg} / \mathrm{ha}$ de Verde urea al macollaje, como alternativa a la fertilización correspondiente al testigo tecnológico (tratamientos $1,2,3,5$, 6 y 10 respectivamente). En todos los tratamientos se aplicaron $50 \mathrm{~kg} / \mathrm{ha}$ de urea común previo a la iniciación panicular.

En el cuadro 35 se presentan los tratamientos aplicados y los rendimientos de arroz sano, seco y limpio (SSL) obtenidos. Con una media de rendimientos de 13,378 t/ha y un coeficiente de variación de $4,4 \%$, se obtuvieron diferencias estadísticamente muy significativas $(p<0,001)$ debidas a los tratamientos, alcanzándose la mayor productividad con el tratamiento 9.

Cuadro 35. Tratamientos aplicados y resultados en rendimiento de arroz sano, seco y limpio (SSL). Rincón de Ramírez, 2014-2015*.

\begin{tabular}{|c|c|c|c|c|c|c|c|c|}
\hline \multirow{2}{*}{\multicolumn{2}{|c|}{ Trt \# Cultivar }} & \multirow{3}{*}{\multicolumn{2}{|c|}{$\begin{array}{l}\text { Instalación cultivo } \\
\text { Densidad Trt semilla } \\
\mathrm{kg} / \mathrm{ha}\end{array}$}} & \multirow{3}{*}{$\begin{array}{c}\text { Fertiliz. } 1 \\
\text { kg/ha }\end{array}$} & \multirow[t]{3}{*}{ Fert. Plus } & \multirow{3}{*}{\multicolumn{2}{|c|}{$\begin{array}{l}\text { Prote cción de } \\
\text { enfeme dades }\end{array}$}} & \\
\hline & & & & & & & & \\
\hline & & & & & & & t/ha & 0,05 \\
\hline 1 & EIP $\approx 0144$ & 130 & Teb+thiom & TT & - & $\begin{array}{l}\text { (teb+triflox) + } \\
\text { (ciprot azoxis) }\end{array}$ & 12,803 & c \\
\hline 2 & CH Quebracho & 130 & Teb+thiom & TT & - & $\begin{array}{l}\text { (teb+triflox) + } \\
\text { (ciprot azoxis) }\end{array}$ & 13,269 & $\mathrm{bc}$ \\
\hline$\overline{3}$ & EIP $\mp 0144$ & 113 & $\begin{array}{l}\text { Teb+thiom } \\
+ \text { Syn+Endo }\end{array}$ & TT & - & $\begin{array}{l}\text { (teb+triflox) + } \\
\text { (ciprot azoxis) }\end{array}$ & 12,773 & $\mathrm{c}$ \\
\hline 4 & EIPæo 144 & 130 & Teb+thiom & al ternativa & - & $\begin{array}{l}\text { (teb+triflox) + } \\
\text { (ciprot azoxis) }\end{array}$ & 13,151 & $\mathrm{bc}$ \\
\hline$\overline{5}$ & EIP $\mp 0144$ & 130 & Tebrthiom & TT & S+SitMicro & $\begin{array}{l}\text { (teb+triflox) + } \\
\text { (ciprot azoxis) }\end{array}$ & 13,037 & $\mathrm{bc}$ \\
\hline 6 & EIPæo 144 & 130 & Teb+thiom & TT & - & $\begin{array}{c}\text { Sit Fo fito Kt } \\
\text { (az oxist kre sotcip) }\end{array}$ & 12,699 & $c$ \\
\hline 7 & CH Quebracho & 140 & $\begin{array}{l}\text { Teb+thiam } \\
+ \text { Syn+Endo }\end{array}$ & alte mativa & S+ Si+ Micro & $\begin{array}{c}\text { Sit Fo fito } \mathrm{K}+ \\
\text { (azoxis+kresotcip) }\end{array}$ & 13,901 & $\mathrm{~b}$ \\
\hline 8 & EIP $\approx 0144$ & 113 & $\begin{array}{l}\text { Teb+thiom } \\
+ \text { Syn+Endo }\end{array}$ & altemativa & S+Si+Micro & $\begin{array}{c}\text { Sit Fo fito } \mathrm{K}+ \\
\text { (azoxis+kresotcip) }\end{array}$ & 12,931 & $\mathrm{bc}$ \\
\hline 9 & CH Quebracho & 130 & Teb+thiom & alte mativa & S+Si+ Micro & $\begin{array}{c}\text { Sit Fo fito K+ } \\
\text { (azoxis+kresotcip) }\end{array}$ & 14,899 & $\mathrm{a}$ \\
\hline 10 & CHQuebracho & 140 & $\begin{array}{l}\text { Teb+thiom } \\
+ \text { Syn+Endo }\end{array}$ & TT & S+ Si+ Micro & $\begin{array}{c}\text { Sit Fo fito K+ } \\
\text { (azoxis+kresotcip) }\end{array}$ & 13,030 & $b$ \\
\hline$\overline{11}$ & CH Quebracho & 140 & $\begin{array}{l}\text { Teb+thiom } \\
+ \text { Syn+Endo }\end{array}$ & altemativa & - & $\begin{array}{c}\text { Sit Fo sito Kt } \\
\text { (az oxist kre so+cip) }\end{array}$ & 13,598 & $\mathrm{bc}$ \\
\hline 12 & CH Quebracho & 140 & $\begin{array}{l}\text { Teb+thiom } \\
+ \text { Syn+Endo }\end{array}$ & alte mativa & S+SitMicro & $\begin{array}{l}\text { (teb+triflox) }+ \\
\text { (cipro+azoxis) }\end{array}$ & 14,448 & $b c$ \\
\hline
\end{tabular}

* Trt= tratamiento; Teb+thiam = tebuconazol + thiametoxan; Teb+thiam +Syn+Endo= tebuconazol+ thiametoxan+ Synergize+ Endorice; Fertiliz. 1 *: TT= $55 \mathrm{~kg} / \mathrm{ha} \mathrm{P}_{2} \mathrm{O}_{5}, 25 \mathrm{~kg} / \mathrm{ha} \mathrm{K}_{2} \mathrm{O}$ en la siembra, y $75 \mathrm{~kg} / \mathrm{ha} \mathrm{de} \mathrm{urea} \mathrm{común} \mathrm{al}$ macollaje; alternativa $=63 \mathrm{~kg} / \mathrm{ha} \mathrm{P}_{2} \mathrm{O}_{5}, 78 \mathrm{~kg} / \mathrm{ha} \mathrm{K}_{2} \mathrm{O}$ en la siembra, y $155 \mathrm{~kg} / \mathrm{ha}$ de Verde urea al macollaje; $\mathrm{S}+\mathrm{Si}+$ Micro $=$ azufre + silicio + micronutrientes; $($ teb+triflox $)+($ cipro + azoxis $)=$ tebuconazol + trifloxystrobin + ciproconazol + azoxistrobin; $\mathrm{Si}+$ Fosfito $\mathrm{K}+($ azoxis + kreso+cip $)=$ silicio + fosfito de potasio + azoxistrobin+kresoxim metil+ ciproconazol; MDS= mínima diferencia significativa al $5 \%$ de probabilidad -números seguidos por la(s) misma(s) letras no difieren significativamente. 


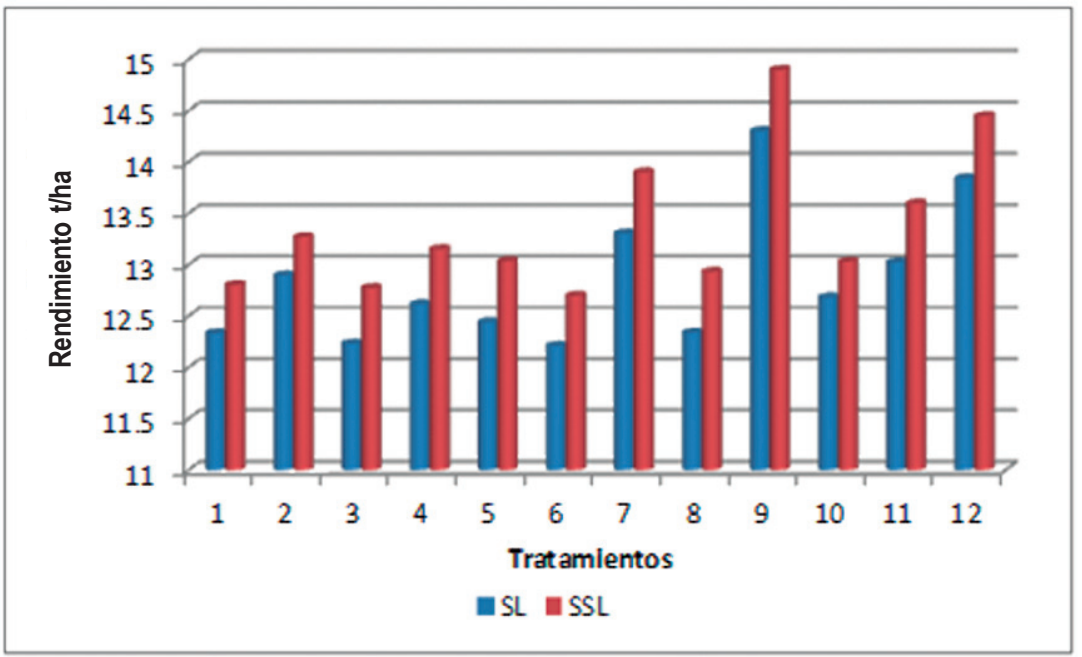

Figura 17. Rendimientos secos y limpios (SL) y sanos, secos y limpios (SSL) obtenidos en Rincón de Ramírez, zafra 2014-2015.

De acuerdo a la calidad de granos lograda en general, se obtuvieron premios con todos los tratamientos. Se destacan el 9, 12 y 7 , con incrementos de 16,13 y $9 \%$ respectivamente sobre la productividad obtenida con el tratamiento 1 correspondiente al testigo tecnológico (Figura 17).

Las alturas de las plantas fueron mayores en el tratamiento 4 de EI Paso 144 que incluyó el sub-factor Fertilización1 alternativo, donde se aplicaron $80 \mathrm{~kg} / \mathrm{ha}$ más de urea al macollaje. El cambio de fertilización
$\mathrm{N}$ al macollaje de TT (testigo tecnológico) a la alternativa, hizo que las plantas de El Paso 144 pasaran de $92,8 \mathrm{~cm}$ a $97,1 \mathrm{~cm}$ (4,6\% de incremento) y las de $\mathrm{CH}$ Quebracho pasaran de $87 \mathrm{~cm}$ a $93,9 \mathrm{~cm}(7,9 \%$ de incremento).

En el análisis de varianza general, se evalúan los efectos combinados de los tratamientos (con la posible existencia de sinergias, o antagonismos, o con ausencia de ellos, entre los factores/sub-factores componentes). En el cuadro 36 se presentan

Cuadro 36. Contrastes ortogonales de factores y/o sub-factores. Rincón, 2014-2015*

\begin{tabular}{|c|c|c|c|c|c|}
\hline \multirow{2}{*}{$\begin{array}{c}\text { Factor/ } \\
\text { sub-factor } \\
\text { Cultivar }\end{array}$} & \multirow{4}{*}{$\begin{array}{c}\text { Contraste } \\
\text { tratamientos } \\
1 \text { vs } 2 \\
7 \text { vs } 8 \\
\text { (1 } 8 \text { ) vs }(27)\end{array}$} & \multicolumn{2}{|c|}{$\begin{array}{c}\text { Rendimientos SSL } \\
\text { t/ha }\end{array}$} & \multirow{4}{*}{$\begin{array}{c}\text { Diferencia } \\
\text { t/ha } \\
-0,466 \\
-0,970 \\
-0,718\end{array}$} & \multirow{4}{*}{$\begin{array}{c}\text { Probabilidad } \\
\text { esadística } \\
\text { ns } \\
0,06 \\
0,05\end{array}$} \\
\hline & & 12,803 & 13,269 & & \\
\hline & & 13,901 & 12,931 & & \\
\hline & & 12,867 & 13,585 & & \\
\hline \multirow[t]{3}{*}{ Instalación } & 1 vs 3 & 12,803 & 12,773 & 0,030 & $\mathrm{~ns}$ \\
\hline & 7 vs 9 & 13,901 & 14,899 & $-0,899$ & 0,05 \\
\hline & (19) vs $(3,7)$ & 13,851 & 13,337 & 0,514 & 0,14 \\
\hline \multirow[t]{3}{*}{ Fertilización 1} & 1 vs 4 & 12,803 & 13,151 & $-0,348$ & $\mathrm{~ns}$ \\
\hline & 7 vs 10 & 13,901 & 13,030 & 0,871 & 0,08 \\
\hline & $(1,10)$ v s $(4,7)$ & 12,917 & 13,526 & $-0,610$ & 0,09 \\
\hline Fertilización & 1 vs 5 & 12,803 & 13,037 & $-0,234$ & ns \\
\hline \multirow[t]{2}{*}{ Plus } & 7 vs 11 & 13,901 & 13,598 & 0,303 & ns \\
\hline & $(1,11)$ v s $(5,7)$ & 13,201 & 13,469 & $-0,269$ & $\mathrm{~ns}$ \\
\hline Protección & $1 \vee s 6$ & 12,803 & 12,699 & 0,104 & ns \\
\hline \multirow[t]{2}{*}{ Enfermedades } & 7 vs 12 & 13,901 & 13,448 & 0,453 & ns \\
\hline & $(1,12)$ vs 6,7$)$ & 13,126 & 13,300 & $-0,174$ & ns \\
\hline
\end{tabular}

*Rincón= Rincón de Ramírez; SSL= arroz sano, seco y limpio; ns= no significativa. 
los resultados del análisis de contrastes ortogonales, una forma diferente de evaluar la importancia de los efectos de los factores y/o sub-factores integrantes de las denominadas tecnologías TT y alternativa, con un número reducido de tratamientos.

A modo de ejemplo, el rendimiento de $\mathrm{CH}$ Quebracho fue algo mayor al de El Paso 144 (466 kg/ha), cuando el resto de los factores considerados corresponde a la tecnología TT, pero esa diferencia no fue estadísticamente significativa. Por el contrario, utilizando todas las otras prácticas de la tecnología alternativa, la diferencia de rendimiento entre las variedades fue de $970 \mathrm{~kg} / \mathrm{ha}$ a favor de CH Quebracho, siendo la probabilidad de error del $6 \%$. En la comparación de la productividad obtenida con un cultivar versus el otro en su conjunto, sin diferenciar el resto de las prácticas manejadas, contraste (1,8 vs 2,7$)$, CH Quebracho supera a El Paso 144 en 718 kg/ha, siendo la diferencia estadísticamente significativa $(5 \%)$.

De igual manera, el cambio obtenido en el tratamiento de instalación del cultivo en El Paso 144, no produjo diferencias en los rendimientos con la tecnología TT, pero cuando se utilizaron todas las otras prácticas de la «tecnología alternativa» (incluyendo el cambio de cultivar), se lograron mejores resultados con el tratamiento de semillas y la densidad de siembra utilizadas habitualmente por el productor. Esas diferencias no resultan tan claras, en la prueba conjunta (contraste 1,9 vs 3,7 ), donde la probabilidad de error se eleva al $14 \%$.

El cambio en la «Fertilización 1» tuvo poco impacto en la productividad de EI Paso 144 con la tecnología TT (348 kg/ha), resultando mayor en $\mathrm{CH}$ Quebracho con la tecnología alternativa $(871 \mathrm{~kg} / \mathrm{ha})$, siendo esta última diferencia significativa al $8 \%$. Al ser ambos efectos incrementales en el mismo sentido (610 kg/ha), la prueba conjunta $(1,10$ vs 4,7 ) resulta significativa al $9 \%$.

Los efectos de la «Fertilización Plus», agregado o supresión de azufre en la siembra, más aplicaciones foliares de silicio y micronutrientes, no produjeron cambios importantes en los rendimientos en ninguna de las situaciones planteadas (agregado en el caso del tratamiento 5 versus el 1 con la tecnología TT, o quita en el caso del tratamiento 11 versus el 7 , con la tecnología alternativa).

En relación con la protección de enfermedades, tampoco se encuentran diferencias estadísticamente significativas entre los 2 manejos planteados: doble aplicación de fungicidas versus 1 sola con la aplicación de ingredientes activos diferentes y el agregado de silicio y fosfito de potasio en mezcla de tanque. En el caso de El Paso 144 con las prácticas habituales del productor, la diferencia fue de sólo $104 \mathrm{~kg} / \mathrm{ha}$, mientras que en el caso de CH Quebracho, cultivar resistente a Brusone acompañado de todas las otras prácticas alternativas, la diferencia fue de $453 \mathrm{~kg} / \mathrm{ha}$ a favor de la alternativa propuesta, que no resulta estadísticamente significativa. En la prueba conjunta, sin distinguir las otras prácticas de tecnología acompañantes, la diferencia resulta de $174 \mathrm{~kg} / \mathrm{ha}$, que tampoco es significativa.

\subsubsection{2 $7^{a}$ Sección de Treinta y Tres 2014-2015}

De acuerdo a la estrategia de fertilización usada y los contenidos de $\mathrm{P}$ 6,2 ppm, $\mathrm{K} 0,26 \mathrm{meq} / 100 \mathrm{~g}$ y PMN $27 \mathrm{mg} / \mathrm{kg}$ del análisis de suelos, en los tratamientos 4, 7, 8, 9, 11 y 12 se fertilizó con $68 \mathrm{~kg} / \mathrm{ha} \mathrm{P}_{2} \mathrm{O}_{5}$, y $27 \mathrm{~kg} / \mathrm{ha} \mathrm{K}_{2} \mathrm{O}$ en la siembra, y $116 \mathrm{~kg} / \mathrm{ha}$ de Verde urea al macollaje, como alternativa a la fertilización correspondiente al testigo tecnológico (tratamientos 1, 2, 3, 5, 6 y 10 respectivamente). En todos los tratamientos se aplicaron $50 \mathrm{~kg} / \mathrm{ha}$ de urea común previo a la iniciación panicular.

Debido a hechos imprevistos, se debió anular las evaluaciones correspondientes al factor "Protección de enfermedades», correspondientes a los tratamientos 6 y 12, ya que quedaron idénticos a los tratamientos 1 y 7 respectivamente. A su vez, en comparación con los otros experimentos conducidos en el proyecto, aunque se desconoce su posible aporte o efecto independiente de la contribución a una mayor sanidad de las plantas, se destaca que los tratamientos 7 , 
$8,9,10$ y 11 no recibieron la aplicación de fosfito de potasio y la segunda de silicio que hubieran sido aplicados en mezcla de tanque con el fungicida.

Al momento de iniciación panicular, se apreció un problema fisiológico en varias de las parcelas del experimento, con mayor intensidad y afección en las correspondientes a INIA Merín. Se podía observar un «entorchamiento» de las hojas que aún permanecían dentro de sus vainas, aparentemente un síntoma de similares características al «DPS, síndrome de fitotoxicidad retardada» reportado por Groth et al., en 1996 en Louisiana, Estados Unidos. El cultivar EI Paso 144 se repuso en pocos días del problema (más leve), mientras que INIA Merín finalizó perdiendo en muchos casos esa hoja aún en formación, cuando quedó expuesta. Como consecuencia, el inicio de floración y el largo del ciclo de dichas plantas se vio incrementado.
En el cuadro 37 se presentan los rendimientos de arroz sano, seco y limpio (SSL) obtenidos de acuerdo los tratamientos aplicados. Con una media de rendimientos de $11,455 \mathrm{t} / \mathrm{ha}$ y un coeficiente de variación de $3,3 \%$, se obtuvieron diferencias estadísticamente muy significativas $(p<0,002)$ debidas a los tratamientos.

A pesar de los inconvenientes señalados, al igual que en Rincón de Ramírez los tratamientos, 9,7 y 11 se destacan en la productividad. En la figura 18 se presentan los rendimientos SL y SSL obtenidos; si bien todos los tratamientos recibieron premio por calidad, en esta localidad los beneficios logrados por la misma fueron menores y también los incrementos de rendimiento sobre el tratamiento testigo $(6 \%)$.

En el cuadro 38 se presentan los resultados de los análisis estadísticos por contrastes ortogonales entre factores y sub-factores. Los 2 cultivares rindieron en forma

Cuadro 37. Tratamientos aplicados y resultados en rendimiento de arroz sano, seco y limpio (SSL). $7^{\text {a }}$ Sección de Treinta y Tres, 2014-2015*.

\begin{tabular}{|c|c|c|c|c|c|c|c|c|}
\hline \multirow{2}{*}{$\begin{array}{l}\text { Trt } \\
N^{\circ}\end{array}$} & \multirow[t]{2}{*}{ Oultivar } & \multicolumn{2}{|c|}{ Instalación ncultivo } & \multirow{2}{*}{$\begin{array}{c}\text { Fertiliz. } 1 \\
\mathrm{~kg} / \mathrm{ha}\end{array}$} & \multirow[t]{2}{*}{ Fert. Plus } & \multirow{2}{*}{$\begin{array}{l}\text { Proteción de } \\
\text { enfemedades }\end{array}$} & \multicolumn{2}{|c|}{ Rendimiento } \\
\hline & & $\begin{array}{c}\text { Densidad } \\
\mathrm{kg} / \mathrm{ha}\end{array}$ & $\begin{array}{c}\text { Trt } \\
\text { semilla }\end{array}$ & & & & $\begin{array}{c}\text { SSL } \\
\mathrm{kg} / \mathrm{ha}\end{array}$ & $\begin{array}{l}\text { MDS } \\
0,05 \\
\end{array}$ \\
\hline 1 & El Paso 144 & 130 & Teb+thiom & TT & - & - & 11,491 & bed \\
\hline 2 & INIA Merín & 130 & Teb+thiom & TT & - & - & 11,160 & d \\
\hline 3 & El Paso 144 & 113 & $\begin{array}{l}\text { Teb+thiam } \\
+ \text { Syn+Endo }\end{array}$ & TT & - & - & 10,981 & d \\
\hline 4 & El Paso 144 & 130 & Teb+thiom & alte mativa & - & - & 11,468 & bcd \\
\hline 5 & El Paso 144 & 130 & Teb+thiom & TT & $\begin{array}{l}\text { St Sit } \\
\text { Micro }\end{array}$ & - & 10,980 & g \\
\hline 6 & - & - & - & - & - & - & - & - \\
\hline 7 & INIA Merín & 120 & $\begin{array}{l}\text { Teb+thiom } \\
+ \text { +Syn+Endo }\end{array}$ & altemativa & $\begin{array}{l}\text { S+Sit } \\
\text { Micro }\end{array}$ & - & 12,075 & $\mathrm{abc}$ \\
\hline 8 & El Paso 144 & 113 & $\begin{array}{l}\text { Teb+thiom } \\
\text { +Syn+Endo }\end{array}$ & altemativa & $\begin{array}{l}\text { StSit } \\
\text { Micro }\end{array}$ & - & 10,966 & d \\
\hline 9 & INIA Merín & 130 & Tebothiom & altemativa & $\begin{array}{l}\text { St Sit } \\
\text { Micro }\end{array}$ & - & 12,205 & a \\
\hline 10 & INA Merín & 120 & $\begin{array}{l}\text { Teb+thiom } \\
+ \text { +Syn+Endo }\end{array}$ & TT & $\begin{array}{l}\text { S+Sit } \\
\text { Micro }\end{array}$ & - & 11,330 & cd \\
\hline 11 & INAA Merín & 120 & $\begin{array}{l}\text { Teb+thiom } \\
\text { +Syn+Endo }\end{array}$ & alte mativa & - & - & 11,969 & $\mathrm{abc}$ \\
\hline 12 & - & - & - & - & - & - & - & - \\
\hline
\end{tabular}

* Trt= tratamiento; Teb+thiam = tebuconazol + thiametoxan; Teb+thiam +Syn+Endo=tebuconazol+thiametoxan+ Synergize+ Endorice; Fertiliz. 1 *: TT= $55 \mathrm{~kg} / \mathrm{ha} \mathrm{P}_{2} \mathrm{O}_{5}, 25 \mathrm{~kg} / \mathrm{ha} \mathrm{K}_{2} \mathrm{O}$ en la siembra, y kg/ha de urea común al macollaje; alternativa $=68 \mathrm{~kg} / \mathrm{ha} \mathrm{P}_{2} \mathrm{O}_{5}, 27 \mathrm{~kg} / \mathrm{ha} \mathrm{K}{ }_{2} \mathrm{O}$ en la siembra, y $116 \mathrm{~kg} / \mathrm{ha}$ de Verde urea al macollaje; $\mathrm{S}+\mathrm{Si}+\mathrm{Micro}=$ azufre + silicio + micronutrientes; MDS = mínima diferencia significativa al $5 \%$ de probabilidad números seguidos por la(s) misma(s) letras no difieren significativamente. 


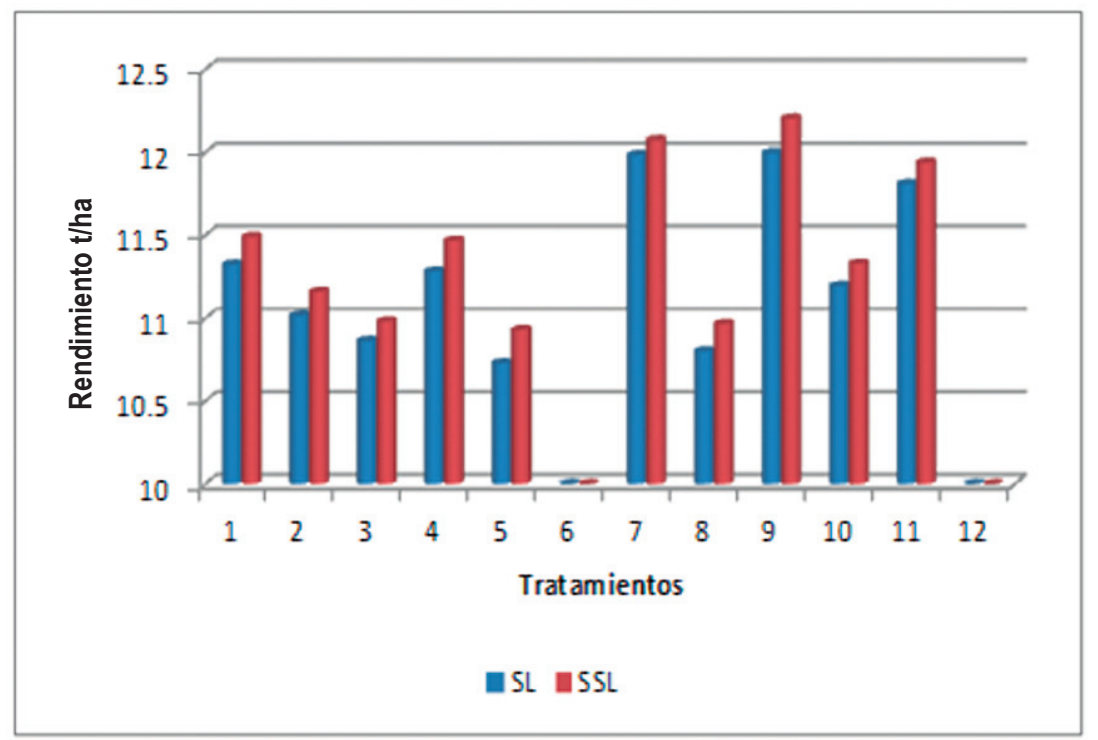

Figura 18. Rendimientos secos y limpios (SL) y sanos, secos y limpios (SSL) obtenidos en $7^{\text {a }}$ Sección de Treinta y Tres, zafra 2014-2015

similar cuando el manejo del cultivo fue el habitual en los productores del quintil superior /TT), pero INIA Merín rindió $1.109 \mathrm{~kg} / \mathrm{ha}$ más cuando el resto de las prácticas de manejo correspondieron a las alternativas propuestas. Cuando la comparación entre los rendimientos de las 2 variedades se realiza sin tener en consideración las otras prácticas de manejo del cultivo, INIA Merín rindió $389 \mathrm{~kg} / \mathrm{ha}$ más, diferencia que resulta significativa sólo al $9 \%$ de probabilidad.

En referencia al factor «instalación del cultivo», la alternativa propuesta rindió 510 $\mathrm{kg} / \mathrm{ha}$ menos usando a la vez las otras prácticas de la tecnología del productor (TT), lo que resultó significativo al $11 \%$ (contraste 1 vs 3 ). Cuando se usaron simultáneamente las otras alternativas acompañantes no hubo diferencias (7 vs 9 ), y tampoco existieron cuando la comparación se hizo en general sin distinguir el resto de las prácticas $(1,9)$ vs $(3,7)$.

El Paso 144 no incrementó su producción al aumentar la aplicación basal de $P$ $\left(13 \mathrm{~kg} / \mathrm{ha} \mathrm{P}_{2} \mathrm{O}_{5}\right.$ ) y la cobertura nitrogenada al macollaje (19 kg/ha de $\mathrm{N}$ ), manteniendo

Cuadro 38. Contrastes ortogonales de factores y/o sub-factores. $7^{\text {a }}$ Sección de Treinta y Tres. 2014-2015*.

\begin{tabular}{|c|c|c|c|c|c|}
\hline \multirow{3}{*}{$\begin{array}{c}\text { Factor/ } \\
\text { sub-factor } \\
\text { Cultivar }\end{array}$} & \multirow{4}{*}{$\begin{array}{c}\text { Contraste } \\
\text { tratamientos } \\
1 \text { vs } 2 \\
7 \text { vs } 8 \\
\text { (1 } 8 \text { ) vs (27) }\end{array}$} & \multicolumn{2}{|c|}{$\begin{array}{c}\text { Rendimientos SSL } \\
\text { t/ha }\end{array}$} & \multirow{4}{*}{$\begin{array}{c}\text { Diferencia } \\
\text { kg/ha } \\
0,331 \\
1,109 \\
-0,389 \\
\end{array}$} & \multirow{4}{*}{$\begin{array}{c}\text { Probabilidad } \\
\text { esadística } \\
\text { ns } \\
0,001 \\
0,09\end{array}$} \\
\hline & & 11,491 & 11,160 & & \\
\hline & & 12,075 & 10,966 & & \\
\hline & & 11,229 & 11,618 & & \\
\hline \multirow[t]{3}{*}{ Instalación } & 1 vs 3 & 11,491 & 10,981 & 0,510 & 0,11 \\
\hline & 7 vs 9 & 12,075 & 12,205 & $-0,130$ & ns \\
\hline & (19) vs (37) & 11,848 & 11,528 & 0,320 & ns \\
\hline \multirow[t]{3}{*}{ Fertilización 1} & 1 vs 4 & 11,491 & 11,460 & 0,031 & ns \\
\hline & 7 vs 10 & 12,075 & 11,330 & 0.745 & 0,03 \\
\hline & $(1,10)$ v s $(4,7)$ & 11,411 & 11,768 & $-0,357$ & 0,11 \\
\hline Fertilización & 1 vs 5 & 11,491 & 10,930 & 0,561 & 0,08 \\
\hline \multirow[t]{2}{*}{ Plus } & 7 vs 11 & 12,075 & 11,939 & 0,136 & ns \\
\hline & $(1,11)$ v s $(5,7)$ & 11,715 & 11,503 & 0,212 & ns \\
\hline
\end{tabular}

${ }^{*} 7^{\mathrm{a}}=$ Séptima; SSL= arroz sano, seco y limpio; ns= no significativa 
sin modificaciones las otras prácticas (1 vs 4). En el caso de INIA Merín, esta disminuyó $745 \mathrm{~kg} / \mathrm{ha}$ su producción cuando se utilizó la fertilización TT con todas las otras prácticas alternativas propuestas (7 vs 10 ). Cuando se comparan los 4 tratamientos (2 a 2) sin distinguir las otras prácticas $(1,10$ vs 4,7 ), la diferencia se reduce a la mitad, resultando apenas significativo al $11 \%$.

En este suelo, el agregado de la «Fertilización Plus» al manejo TT de los productores, redujo $561 \mathrm{~kg} / \mathrm{ha}$ el rendimiento de El Paso 144, lo que resulta significativo al $8 \%$. Sin embargo, en un nivel productivo superior logrado con el tratamiento 7 , la quita de su aplicación no provocó diferencias (7 vs 11). De acuerdo a esas comparaciones, cuando no se consideran los otros factores en juego, los promedios $(1,11)$ y $(5,7)$ no se distinguen significativamente.

\subsubsection{Cebollatí 2014-2015}

De acuerdo a los contenidos de $\mathrm{P}, \mathrm{K}$ y PMN del análisis de suelos, en los tratamientos $4,7,8,9,11$ y 12 se fertilizó con 63 $\mathrm{kg} / \mathrm{ha} \mathrm{P}_{2} \mathrm{O}_{5}, 11 \mathrm{~kg} / \mathrm{ha} \mathrm{K}_{2} \mathrm{O}$ en la siembra, y $103 \mathrm{~kg} / \mathrm{ha}$ de Verde urea al macollaje, como alternativa a la fertilización correspondiente al testigo tecnológico (tratamientos 1, 2, $3,5,6$ y 10 respectivamente). Además, en esta localidad, así como también en India Muerta donde el cultivar alternativo utilizado fue Parao, en los tratamientos mencionados en primera instancia se aplicaron 100 $\mathrm{kg} / \mathrm{ha}$ de urea común previo a la iniciación panicular, en vez de los $50 \mathrm{~kg} / \mathrm{ha}$ usados en los correspondientes al testigo tecnológico (TT). En esta localidad, en el factor «Protección de enfermedades» correspondiente a la tecnología TT, sólo se realizó una aplicación de fungicida.

El ensayo fue sembrado el 28 de octubre y se realizaron 2 aplicaciones de herbicidas en postemergencia para el control de malezas. Primero se hizo una aplicación terrestre de una mezcla de propanil y clomazone durante la tarde con altas temperaturas $\left(30^{\circ} \mathrm{C}\right)$ y viento, con una importante reducción térmica en horas de la noche. En días posteriores se pudo notar un impacto variable de los herbicidas en las plantas de arroz de distintas parcelas. La inundación definitiva del cultivo quedó establecida el 20 de diciembre.

En el cuadro 39 se presentan los tratamientos aplicados y los rendimientos de arroz sano, seco y limpio (SSL) obtenidos. Con una media de rendimientos de 9,947 t/ha y un coeficiente de variación de $5,3 \%$, se obtuvieron diferencias estadísticamente significativas al $3,5 \%$ de probabilidad. La productividad media obtenida es la más baja de los 4 experimentos instalados en la zafra 2014-2015.

Varios tratamientos superaron la productividad del testigo, 8 de ellos con incrementos mayores o iguales al $5 \%$. Se obtuvo el máximo rendimiento ( $15 \%$ superior al 1$)$ con el tratamiento 8, correspondiente a la variedad El Paso manejada con todas las prácticas alternativas propuestas (instalación del cultivo, fertilización 1 y Plus y con una aplicación de fungicida acompañada en tanque con silicio y fosfito de potasio).

Además de los tratamientos 9 y 12 (con incrementos de 11 y $10 \%$ ), se destacó el $N^{\circ}$ 3 , de El Paso 144, que tenía como única variante el factor «instalación del cultivo», esto es reducción de la densidad de siembra, con el agregado de zinc en el tratado de la semilla que fue posteriormente inoculada con Endorice. (Herbaspirillum)», con un incremento de $803 \mathrm{~kg} / \mathrm{ha}$ ( $9 \%$ de aumento).

En la figura 19 se presentan los rendimientos secos y limpios (SL) y sanos secos y limpios (SSL), habiéndose logrado en general incrementos de un $4 \%$ por calidad de grano.

En el cuadro 40 se presentan los resultados de los análisis estadísticos por contrastes ortogonales entre factores y subfactores. Los 2 cultivares rindieron en forma similar cuando el manejo del cultivo fue el habitual en los productores del quintil superior /TT), pero El Paso 144 rindió 774 $\mathrm{kg} / \mathrm{ha}$ más cuando el resto de las prácticas de manejo correspondieron a las alternativas propuestas $(p=0,09)$. Cuando la comparación entre los rendimientos de las 2 variedades se realiza en conjunto, sin tener en consideración las otras prácticas de manejo del cultivo, El Paso 144 rindió 534 
Cuadro 39. Tratamientos aplicados y resultados en rendimiento de arroz sano, seco y limpio (SSL). Cebollatí. 2014-2015*.

\begin{tabular}{|c|c|c|c|c|c|c|c|c|}
\hline \multirow{2}{*}{$\begin{array}{l}\text { Trt } \\
\text { NNo }\end{array}$} & \multirow{2}{*}{ Cultivar } & \multicolumn{2}{|c|}{ Instalación cultivo } & \multirow{2}{*}{$\begin{array}{c}\text { Fertiliz. } 1 \\
\mathrm{~kg} / \mathrm{ha}\end{array}$} & \multirow[t]{2}{*}{ Fert. Plus } & \multirow{2}{*}{$\begin{array}{l}\text { Prote cción de } \\
\text { enfermedades }\end{array}$} & \multicolumn{2}{|c|}{ Rendimiento } \\
\hline & & $\begin{array}{c}\text { Densidad } \\
\mathrm{kg} / \mathrm{ha}\end{array}$ & Trt semilla & & & & $\begin{array}{l}S S L \\
t / h a\end{array}$ & $\begin{array}{l}\text { MDS } \\
0,05\end{array}$ \\
\hline 1 & El Paso 144 & 160 & Teb+thiom & TT & - & $\begin{array}{c}\text { tebuco nazol } \\
+ \text { trifloxy trobin }\end{array}$ & 9,397 & of \\
\hline 2 & Parao & 160 & Teb+thiom & TT & - & $\begin{array}{c}\text { te buco nazol } \\
+ \text { trifloxy trobin }\end{array}$ & 9,102 & d \\
\hline 3 & El Paso 144 & 141 & $\begin{array}{l}\text { Teb+thiom } \\
+\$ / n+E \text { ndo }\end{array}$ & TT & - & $\begin{array}{c}\text { tebuco nazol } \\
+ \text { trifloxy } \$ \text { trobin }\end{array}$ & 10,200 & abc \\
\hline 4 & EI Paso 144 & 160 & Teb+thiom & atemativa & - & $\begin{array}{c}\text { tebuco nazol } \\
+ \text { trifloxy strobin }\end{array}$ & 10,057 & abc \\
\hline 5 & El Paso 144 & 160 & Teb+thiom & TT & S+ Si+ Micro & $\begin{array}{c}\text { tebuco nazol } \\
+ \text { trifloxy strobin }\end{array}$ & 9,825 & bod \\
\hline 6 & El Paso 144 & 160 & Teb+thiom & TT & - & $\begin{array}{c}\text { SitFosfito Kt } \\
\text { (azoxistkresot cip) }\end{array}$ & 9,601 & bod \\
\hline 7 & Parao & 143 & $\begin{array}{l}\text { Teb+thiom } \\
+\$ / n+E \text { indo }\end{array}$ & alterndiva & S+Si+Micro & $\begin{array}{c}\text { Sit Fosito K+ } \\
\text { (azoxistkresot cip) }\end{array}$ & 10,043 & abc \\
\hline 8 & EI Paso 144 & 141 & $\begin{array}{l}\text { Teb+thiom } \\
+\$ / n+\text { Endo }\end{array}$ & alte rndiva & \$+\$i+Micro & $\begin{array}{c}\text { Sit Fosfito K+ } \\
\text { (azoxistkresot cip) }\end{array}$ & 10,817 & $a$ \\
\hline 9 & Parao & 160 & Teb+thiom & alterndiva & $\$+\$ i+$ Micro & $\begin{array}{c}\text { Sit Fosito K+ } \\
\text { (azoxistkresot cip) }\end{array}$ & 10,409 & ab \\
\hline 10 & Parao & 143 & $\begin{array}{l}\text { Teb+thiom } \\
+S / n+E \text { indo }\end{array}$ & TT & S+Si+Micro & $\begin{array}{c}\text { Sit Fosfito K+ } \\
\text { (azoxistkresot cip) }\end{array}$ & 9,559 & bod \\
\hline$\overline{11}$ & Parao & 143 & $\begin{array}{l}\text { Teb+thiom } \\
+\$ / n+E \text { indo }\end{array}$ & alterndiva & - & $\begin{array}{c}\text { Sit Fosito K+ } \\
\text { (azoxistkresot cip) }\end{array}$ & 10,037 & $\mathrm{abc}$ \\
\hline 12 & Parao & 140 & $\begin{array}{l}\text { Teb+thiom } \\
+\$ / n+E \text { indo }\end{array}$ & alte rndiva & S+SitMicro & $\begin{array}{c}\text { tebuco nazol } \\
+ \text { trifloxy strobin }\end{array}$ & 10,311 & ab \\
\hline
\end{tabular}

* Trt= tratamiento; Teb+thiam = tebuconazol + thiametoxan; Teb+thiam +Syn+Endo= tebuconazol+ thiametoxan+ Synergize+ Endorice; Fertiliz. 1; TT= 19,8 kg/ha N, 50,6 kg/ha $\mathrm{P}_{2} \mathrm{O}_{5}$ en la siembra, $60 \mathrm{~kg} / \mathrm{ha}$ de urea común al macollaje y $50 \mathrm{~kg} / \mathrm{ha}$ de urea común a la inic|iación panicular; alternativa= $63 \mathrm{~kg} / \mathrm{ha} \mathrm{P}_{2} \mathrm{O}_{5}, 11 \mathrm{~kg} / \mathrm{ha} \mathrm{K}_{2} \mathrm{O}$ en la siembra, $103 \mathrm{~kg} / \mathrm{ha}$ de Verde urea al macollaje y $100 \mathrm{~kg} / \mathrm{ha}$ de urea común a la iniciación panicular; S+Si+Micro= azufre +silicio + micronutrientes; Si+ Fosfito $\mathrm{K}+($ azoxis+kreso+cip) $=$ silicio + fosfito de potasio + azoxistrobin+kresoxim metil+ ciproconazol; MDS= mínima diferencia significativa al $5 \%$ de probabilidad -números seguidos por la(s) misma(s) letras no difieren significativamente.

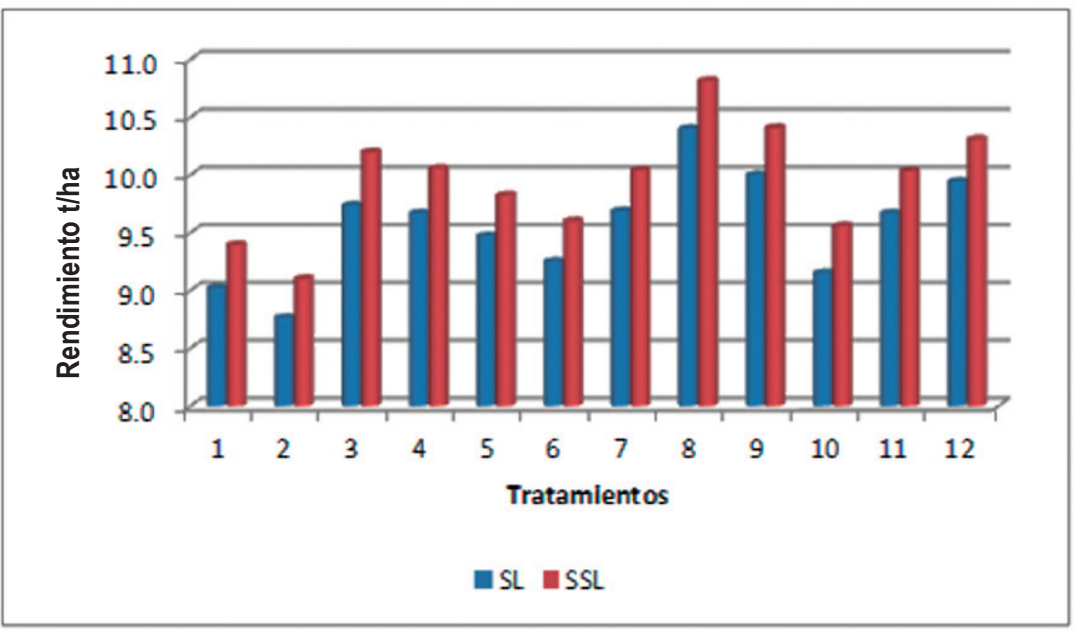

Figura 19. Rendimientos secos y limpios (SL) y sanos, secos y limpios (SSL) obtenidos en Cebollatí, zafra 2014-2015. 
Cuadro 40. Contrastes ortogonales de factores y/o sub-factores. Cebollatí. 2014-2015*.

\begin{tabular}{|c|c|c|c|c|c|}
\hline \multirow{3}{*}{$\begin{array}{c}\text { Factor } / \\
\text { sub-factor } \\
\text { Cultivar }\end{array}$} & \multirow{4}{*}{$\begin{array}{c}\text { Contraste } \\
\text { tratamientos } \\
1 \text { vs } 2 \\
7 \text { vs } 8 \\
\text { (1 } 18 \text { ) vs }(2,7)\end{array}$} & \multicolumn{2}{|c|}{$\begin{array}{c}\text { Rendimientos SSL } \\
\text { t/ha }\end{array}$} & \multirow{4}{*}{$\begin{array}{c}\text { Diferencia } \\
\text { t/ha } \\
0,295 \\
-0,774 \\
0,534\end{array}$} & \multirow{4}{*}{$\begin{array}{c}\text { Probabilidad } \\
\text { estadística } \\
\text { Ns } \\
0,09 \\
0,09\end{array}$} \\
\hline & & 9,397 & 9,102 & & \\
\hline & & 10,043 & 10,817 & & \\
\hline & & 10,107 & 9573 & & \\
\hline \multirow[t]{3}{*}{ Instalación } & 1 vs 3 & 9,397 & 10,200 & $-0,803$ & 0,08 \\
\hline & 7 vs 9 & 10,043 & 10,409 & $-0,366$ & ns \\
\hline & $(19)$ v $(3,7)$ & 9,903 & 10,122 & $-0,219$ & ns \\
\hline \multirow[t]{3}{*}{ Fertilización 1} & 1 vs 4 & 9,397 & 10,057 & $-0,660$ & ns \\
\hline & 7 vs 10 & 10,043 & 9559 & 0,484 & ns \\
\hline & $(1,10)$ y s $(4,7)$ & 9,478 & 10,050 & $-0,5 / 2$ & 0,07 \\
\hline \multirow{3}{*}{ Plus } & 1 vs 5 & 9,397 & 9825 & $-0,428$ & ns \\
\hline & 7 vs 11 & 10,043 & 10,037 & 0,006 & ns \\
\hline & $(1,11)$ v s $(5,7)$ & 9,717 & 9934 & $-0,217$ & ns \\
\hline Protección & $1 v s 6$ & 9,397 & 9601 & $-0,204$ & ns \\
\hline \multirow[t]{2}{*}{ Enfemedades } & 7 vs 12 & 10,043 & 10,311 & $-0,268$ & ns \\
\hline & $(1,12)$ vs 6,7$)$ & 9,854 & 9822 & 0,032 & $\mathrm{~ns}$ \\
\hline
\end{tabular}

* SSL= arroz sano, seco y limpio; ns= no significativa.

$\mathrm{kg} / \mathrm{ha}$ más lo que también resulta significativo al $9 \%$ de probabilidad.

En referencia al factor instalación del cultivo, la utilización de la alternativa propuesta rindió $803 \mathrm{~kg} / \mathrm{ha}$ más, usando a la vez todas las otras prácticas de la tecnología TT del productor (significativo al 8 de probabilidad; contraste 1 vs 3 ). Cuando se usaron simultáneamente las otras alternativas acompañantes no hubo diferencias (7 vs 9), y tampoco existieron cuando la comparación se hizo en general sin distinguir el resto de las prácticas $(1,9)$ vs $(3,7)$.

El Paso 144 incrementó su producción $660 \mathrm{~kg} / \mathrm{ha}$ al utilizarse la estrategia alternativa de fertilización (F1; tratamientos 1 vs 4 ), pero esa diferencia no fue estadísticamente significativa. En el caso de Parao ( 7 vs 10 ), esa diferencia fue menor $484 \mathrm{~kg} / \mathrm{ha}$, disminuyendo la productividad al reducir la fertilización. Cuando se comparan los 4 tratamientos sin distinguir las otras prácticas, al resultar los efectos anteriores en un mismo sentido, la diferencia de $572 \mathrm{~kg} / \mathrm{ha}$ fue significativa al $7 \%$ de probabilidad $(1,10$ vs $4,7)$.

La «Fertilización Plus» no provocó cambios significativos en ninguno de los 2 escenarios, participando como adición a la tecnología TT testigo, ni cuando fue quitada del conjunto de alternativas propuestas (tratamientos 5 y 11 respectivamente).
En la comparación de manejos de protección al cultivo de enfermedades (1 vs 6 ; 7 vs 12) tampoco se encontraron diferencias significativas. Al respecto, se recuerda que en esta oportunidad no fue necesario realizar una segunda aplicación de fungicidas en la tecnología TT, al no observarse síntomas de Brusone en plantas dentro del experimento y/o en la chacra. De acuerdo a ello, el contraste se reduce a productos, más que a estrategias.

\subsubsection{India Muerta 2014-2015}

Este experimento fue instalado el 10 de noviembre sobre un suelo fértil, con el antecedente inmediato de una pradera mixta de gramíneas y leguminosas para uso pecuario durante varios años. A diferencia de las anteriores, en esta localidad se utilizó la variedad INIA Tacuarí en el testigo tecnológico, sembrada con $170 \mathrm{~kg} / \mathrm{ha}$ de semilla.

En contraposición a los casos ya presentados, de acuerdo a la estrategia planificada de antemano y a los contenidos de $\mathrm{P}, \mathrm{K}$ y $\mathrm{Mg}$ en el suelo, detectados en el análisis de realizado ( $P$ : 17,7 ppm; K: 0,38 meq/100 g, Mg 4,9 meq/100 g , se decidió no aplicar fósforo ni potasio en la siembra en los tratamientos alternativos 4, 7, 8, 9, 11 y 12 . Dado que no se disponía aún de los resultados de PMN (análisis de potencial de 
mineralización de nitrógeno) al inicio de macollaje, se decidió por seguridad realizar una cobertura de $40 \mathrm{~kg} / \mathrm{ha}$ de Verde Urea, como alternativa a la aplicación de $60 \mathrm{~kg} / \mathrm{ha}$ de urea común establecidos en el testigo tecnológico (TT). El resultado del análisis de PMN recibido con posterioridad, indicó que tampoco hubiera sido necesario realizar la primera aplicación nitrogenada.

Al igual que fue mencionado para Cebollatí, en India Muerta se utilizó el cultivar Parao como alternativa de INIA Tacuarí. En la segunda cobertura nitrogenada se aplicaron $100 \mathrm{~kg} / \mathrm{ha}$ de urea común previo a la iniciación panicular, en vez de los 50 $\mathrm{kg} / \mathrm{ha}$ usados en los tratamientos correspon- dientes a la tecnología TT. En esta localidad, en el factor "Protección de enfermedades» correspondiente a la tecnología TT, se realizaron 2 aplicaciones de fungicidas, por observación de síntomas de Brusone en algunas parcelas.

La inundación definitiva del cultivo quedó establecida el 17-18 de diciembre.

En el cuadro 41 se presentan los tratamientos aplicados y los rendimientos de arroz sano, seco y limpio (SSL) obtenidos. Con un promedio de rendimiento de 12,019 t/ha y un coeficiente de variación de $2,1 \%$, se obtuvieron diferencias estadísticamente muy significativas $(p=0,001)$. A pesar de haber sido el experimento sembrado más

Cuadro 41. Tratamientos aplicados y resultados en rendimiento de arroz sano, seco y limpio (SSL). India Muerta. 2014-2015*

\begin{tabular}{|c|c|c|c|c|c|c|c|c|}
\hline \multirow{2}{*}{$\begin{array}{l}\text { Trt } \\
\#\end{array}$} & \multirow[t]{2}{*}{ Cultiv ar } & \multicolumn{2}{|c|}{ Instalación cultivo } & \multirow{2}{*}{$\begin{array}{l}\text { Fertiliz. } 1 \\
\text { kgiha }\end{array}$} & \multirow{2}{*}{$\begin{array}{l}\text { Fert. } \\
\text { Plus }\end{array}$} & \multirow{2}{*}{$\begin{array}{l}\text { Protección de } \\
\text { enfermedades }\end{array}$} & \multicolumn{2}{|c|}{ Rendimient 0} \\
\hline & & $\begin{array}{l}\text { Densidad } \\
\text { kg/ha }\end{array}$ & $\begin{array}{c}\text { Trt } \\
\text { semilla }\end{array}$ & & & & $\begin{array}{l}\text { SSL } \\
\text { t/ha }\end{array}$ & $\begin{array}{l}\text { MDS } \\
0,05\end{array}$ \\
\hline 1 & $\begin{array}{l}\text { INIA } \\
\text { Tacuarí }\end{array}$ & 170 & Teb+thiom & TT & - & $\begin{array}{l}(\text { teb+trifox) }+ \\
\text { (ciprotozoxs) }\end{array}$ & 11,561 & e \\
\hline 2 & Parao & 170 & Teb+thiom & TT & - & $\begin{array}{l}\text { (teb+trifox) }+ \\
\text { (ciprotozoxs) }\end{array}$ & 12,502 & a \\
\hline 3 & $\begin{array}{l}\text { INIA } \\
\text { Tacuarí }\end{array}$ & 113 & $\begin{array}{l}\text { Teb+thiom } \\
\text { +Syn+Endo }\end{array}$ & TT & - & $\begin{array}{l}\text { (teb+trifox)+ } \\
\text { (ciprotozoxs) }\end{array}$ & 11,859 & ode \\
\hline 4 & $\begin{array}{l}\text { INIA } \\
\text { Tacuarí }\end{array}$ & 170 & Teb+thiom & alternativa & - & $\begin{array}{l}\text { (teb+trifox) }+ \\
\text { (ciprotozoxs) }\end{array}$ & 11,789 & de \\
\hline 5 & $\begin{array}{l}\text { INIA } \\
\text { Tacuarí }\end{array}$ & 170 & Teb+thiom & TT & $\begin{array}{l}\text { St Sit } \\
\text { Mi cro }\end{array}$ & $\begin{array}{l}(\text { teb+trifox })+ \\
(\text { ciprot ozoxs })\end{array}$ & 11,593 & de \\
\hline 6 & $\begin{array}{l}\text { INIA } \\
\text { Tacuarí }\end{array}$ & 170 & Teb+thiom & TT & - & $\begin{array}{c}\text { Si+Fosfito K+ } \\
\text { (acoxis+kreso+ap) }\end{array}$ & 11,777 & de \\
\hline 7 & Parao & 143 & $\begin{array}{l}\text { Teb+thiom } \\
\text { +Syn+Endo }\end{array}$ & altem diva & $\begin{array}{l}\text { S+Sit } \\
\text { Micro }\end{array}$ & $\begin{array}{c}\text { Si+ Fosfito K+ } \\
(\text { azoxis+kreso+cip) }\end{array}$ & 12016 & $\mathrm{abc}$ \\
\hline 8 & $\begin{array}{l}\text { INIA } \\
\text { Tacuarí }\end{array}$ & 113 & $\begin{array}{l}\text { Teb+thiom } \\
\text { +Syn+Endo }\end{array}$ & altemaiva & $\begin{array}{l}\text { S+Sit } \\
\text { Micro }\end{array}$ & $\begin{array}{c}\text { Si+ Fosfito K+ } \\
(a z o \times i s+k r e s o+d p)\end{array}$ & 11,544 & e \\
\hline 9 & Parao & 170 & Teb+thiom & altem diva & $\begin{array}{l}\text { S+Sit } \\
\text { Micro }\end{array}$ & $\begin{array}{c}\text { Si+ Fosfito K+ } \\
(\text { azoxis+kreso+cip) }\end{array}$ & 12,636 & a \\
\hline 10 & Parao & 143 & $\begin{array}{l}\text { Teb+thiom } \\
\text { +Syn+Endo }\end{array}$ & TT & $\begin{array}{l}\text { S+Sit } \\
\text { Micro }\end{array}$ & $\begin{array}{c}\text { Si+ Fosfito K+ } \\
(\text { azoxis+kreso+cip) }\end{array}$ & 12,392 & ab \\
\hline 11 & Parao & 143 & $\begin{array}{l}\text { Teb+thiom } \\
+ \text { Syn+Endo }\end{array}$ & altem diva & - & $\begin{array}{c}\text { Si+ Fosfito K+ } \\
\text { (acoxs+kreso+op) }\end{array}$ & 12,230 & $\mathrm{abc}$ \\
\hline 12 & Parao & 143 & $\begin{array}{l}\text { Teb+thiom } \\
\text { +Syn+Endo }\end{array}$ & atem diva & $\begin{array}{l}\text { St Sit } \\
\text { Mi cro }\end{array}$ & $\begin{array}{l}\text { (teb+trifox) }+ \\
\text { (ciprot ozoxs) }\end{array}$ & 12,329 & ab \\
\hline
\end{tabular}

* Teb+thiam = tebuconazol + thiametoxan; Teb+thiam +Syn+Endo= tebuconazol+ thiametoxan+ Synergize+ Endorice; Fertiliz. 1 *: TT= 19,8 kg/ha N, $50,6 \mathrm{~kg} / \mathrm{ha} \mathrm{P}_{2} \mathrm{O}_{5}$ en la siembra, $60 \mathrm{~kg} / \mathrm{ha}$ de urea común al macollaje y $50 \mathrm{~kg} / \mathrm{ha}$ de urea común a la iniciación panicular; alternativa $=0 \mathrm{~kg} / \mathrm{ha} \mathrm{P}_{2} \mathrm{O}_{5}, 0 \mathrm{~kg} / \mathrm{ha} \mathrm{K}_{2} \mathrm{O}$ en la siembra, 40 $\mathrm{kg} / \mathrm{ha}$ de Verde urea al macollaje y $100 \mathrm{~kg} / \mathrm{ha}$ de urea común a la iniciación panicular; $\mathrm{S}+\mathrm{Si}+\mathrm{Micro}=$ azufre +silicio + micronutrientes; $($ teb+triflox $)+($ cipro + azoxis $)=$ tebuconazol + trifloxystrobin + ciproconazol + azoxistrobin; Si+ Fosfito K + (azoxis +kreso+cip $)=$ silicio + fosfito de potasio + azoxistrobin+kresoxim metil+ ciproconazol; MDS= mínima diferencia significativa al $5 \%$ de probabilidad -números seguidos por la(s) misma(s) letras no difieren significativamente. 


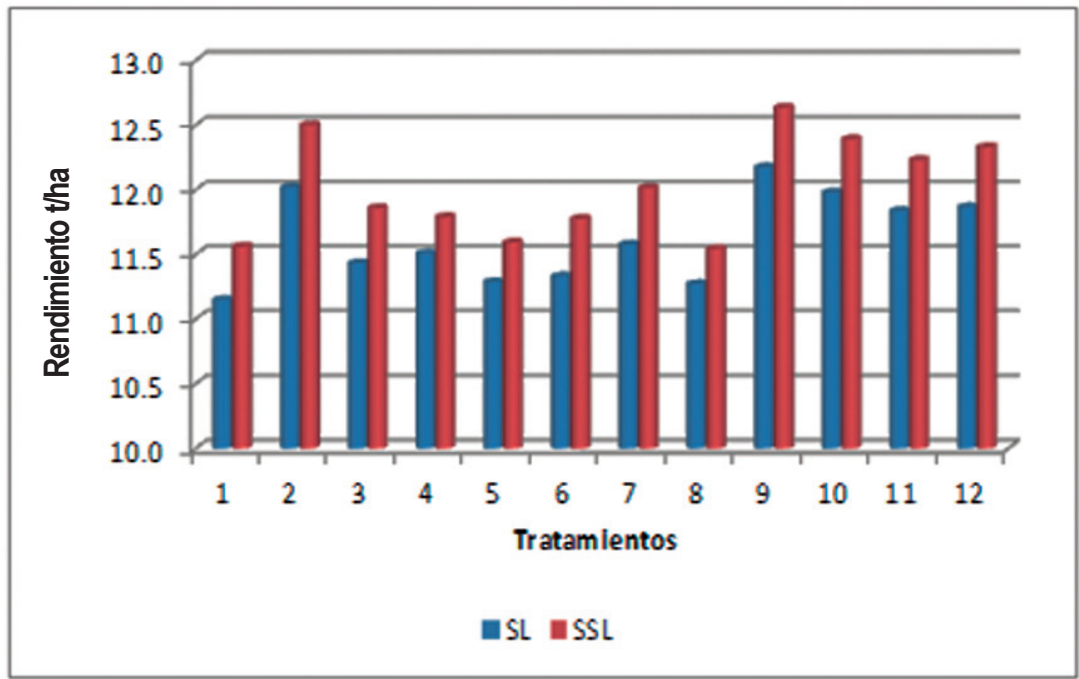

Figura 20. Rendimientos secos y limpios (SL) y sanos, secos y limpios (SSL) obtenidos en India Muerta. 2014-2015

tarde de los 4 conducidos en la zafra 20142015 , la productividad media obtenida se ubica en el segundo lugar.

El tratamiento testigo ( $\left.N^{\circ} 1\right)$ rindió 11,561 t/ha. Los 6 tratamientos que fueron sembrados con el cultivar Parao, independientemente de las prácticas utilizadas, superaron las $12 \mathrm{t} / \mathrm{ha}$ y 5 de ellos rindieron entre 6 y $9 \%$ más que el 1 ; se obtuvo la máxima productividad con el tratamiento $\mathrm{N}^{\circ} 9$ $(12,636 \mathrm{t} / \mathrm{ha})$.

En la figura 20 se presentan los rendimientos secos y limpios (SL) y sanos secos y limpios (SSL), habiéndose logrado en general incrementos de un $3,4 \%$ por calidad de grano.

En el cuadro 42 se presentan los resultados de los análisis estadísticos por contrastes ortogonales entre factores y subfactores. En relación a cultivares, en este caso resulta clara la superioridad de Parao con respecto a INIA Tacuarí, en las 3 situaciones planteadas: a) con la tecnología TT de los productores del quintil superior de rendimientos (1 vs $2 ; 941 \mathrm{~kg} / \mathrm{ha}$ de incremento; p: 0,000); b) con las tecnologías alternativas (7 vs $8 ; 472 \mathrm{~kg} / \mathrm{ha}$ de diferencia; p: 0,03$) ; y$ c) en la prueba conjunta sin considerar la tecnología (1-8 vs 2-7), $706 \mathrm{~kg} / \mathrm{ha}$ de incremento; $p: 0,000)$.
En el factor «instalación del cultivo» no se detectan diferencias cuando se utilizan las otras prácticas del manejo del productor (TT), pero se produce una diferencia de $620 \mathrm{~kg} / \mathrm{ha}$ (significativa a $\mathrm{p}=0,008$ ) a favor del tratamiento habitualmente usado por el productor en la semilla, cuando se usan simultáneamente todas las otras prácticas alternativas propuestas (7 vs 9 ). En la prueba conjunta sin distinción de las tecnologías, nuevamente no se encuentran diferencias.

En la comparación de estrategias de fertilización (recordando que en la propuesta alternativa «F1» no se aplicó fósforo en la base) no hay diferencias en rendimiento usando el resto de las prácticas TT, que incluye la siembra de INIA Tacuarí (1 vs 4). Cuando se usó el resto de las prácticas alternativas con la siembra de la variedad Parao, el agregado de fósforo y poco más de nitrógeno en el tratamiento $10\left(\mathrm{P}_{50,6} \mathrm{~N}_{6}\right)$ incrementó algo la productividad (376 kg/ha; p:0,09). En la prueba conjunta, las diferencias se diluyen por efectos contrarios en las pruebas individuales, encontrándose tan solo $74 \mathrm{~kg} / \mathrm{ha}$ de diferencia en el rendimiento.

Tanto la «Fertilización Plus», como la «Protección de enfermedades» alternativas no incidieron en forma importante en ninguna de las 3 situaciones analizadas ( 1 vs 5 ; 7 vs $11 ; 1-11$ vs $5-7$ ) por un lado y (1 vs $6 ; 7$ vs $12 ; 1-12$ vs $6-7$ ) por otro. 
Cuadro 42. Contrastes ortogonales de factores y/o sub-factores. India Muerta. 2014-2015*.

\begin{tabular}{|c|c|c|c|c|c|}
\hline $\begin{array}{c}\text { Factor/ } \\
\text { sub-factor }\end{array}$ & $\begin{array}{c}\text { Contraste } \\
\text { tratamientos }\end{array}$ & Rend & $\overline{S S S L}$ & $\begin{array}{c}\text { Diferencia } \\
\text { tha }\end{array}$ & $\begin{array}{l}\text { Probabilidad } \\
\text { estadística }\end{array}$ \\
\hline Cultivar & 1 vs 2 & 11,561 & 12,502 & $-0,941$ & 0,000 \\
\hline & 7 vs 8 & 12,016 & 11,544 & 0,472 & 0,03 \\
\hline & $(1,8)$ vs $(2,7)$ & 11,553 & 12,259 & $-0,706$ & 0,000 \\
\hline Instalación & 1 vs 3 & 11,561 & 11,859 & $-0,298$ & $\mathrm{~ns}$ \\
\hline & 7 vs 9 & 12,016 & 12,636 & $-0,620$ & 0,008 \\
\hline & (19) vs $(3,7)$ & 12,099 & 11,938 & 0,161 & ns \\
\hline Fertilización 1 & 1 vs 4 & 11,561 & 11,789 & $-0,228$ & ns \\
\hline & 7 vs 10 & 12,016 & 12,392 & $-0,376$ & 0,09 \\
\hline & $(1,10)$ v s $(4,7)$ & 11,977 & 11,903 & 0,074 & ns \\
\hline Fertilización & 1 vs 5 & 11,561 & 11,593 & $-0,032$ & $\mathrm{~ns}$ \\
\hline Plus & 7 vs 11 & 12,016 & 12,230 & $-0,214$ & $\mathrm{~ns}$ \\
\hline & $(1,11)$ v s $(5,7)$ & 11,896 & 11,805 & 0,091 & $\mathrm{~ns}$ \\
\hline Protección & 1 vs 6 & 11,561 & 11,777 & $-0,216$ & ns \\
\hline Enfemedades & 7 vs 12 & 12,016 & 12,329 & $-0,313$ & ns \\
\hline & $(1,12)$ vs 6,7$)$ & 11,945 & 11,897 & 0,048 & $\mathrm{~ns}$ \\
\hline
\end{tabular}

* SSL= arroz sano, seco y limpio; ns= no significativa.

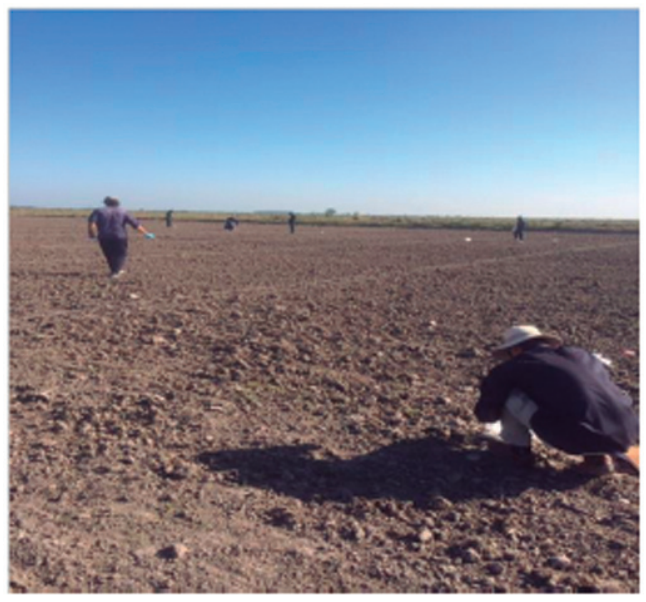

Foto 1. Fertilización basal al voleo, a mano.

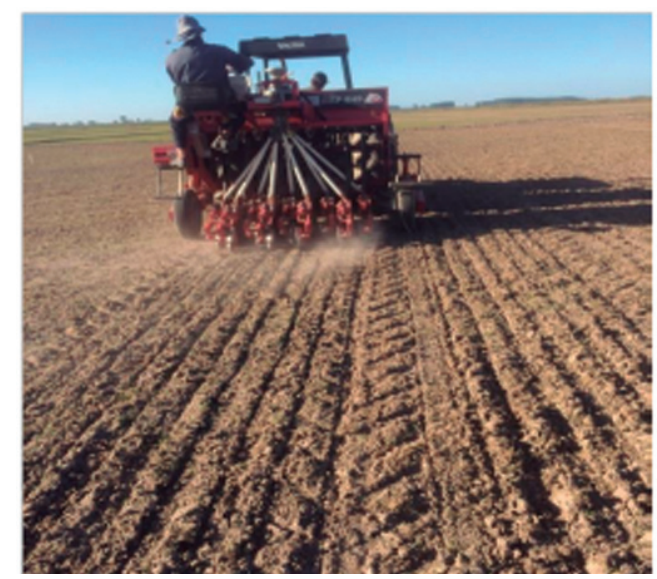

Foto 2. Siembra con sembradora experimental.

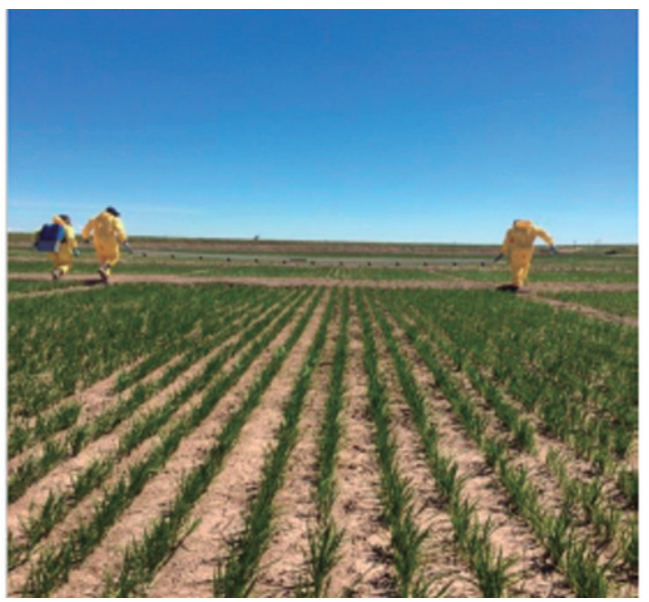

Foto 3. Aplicación fertilizante foliar.

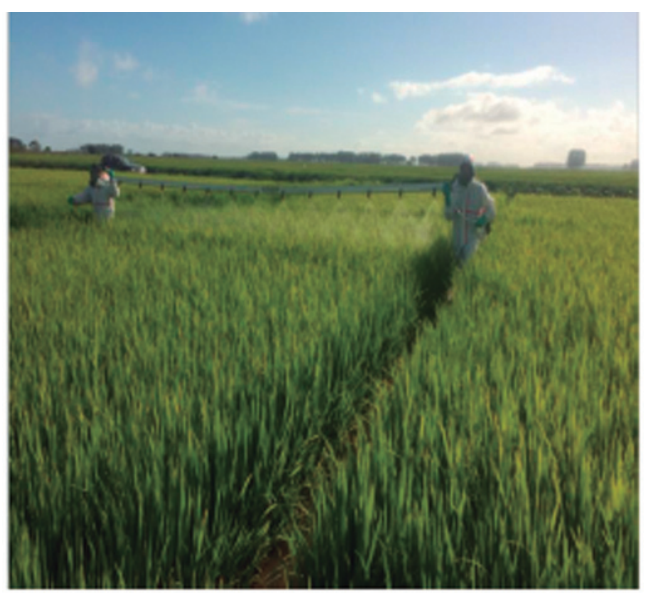

Foto 4. Aplicación fungicidas. 


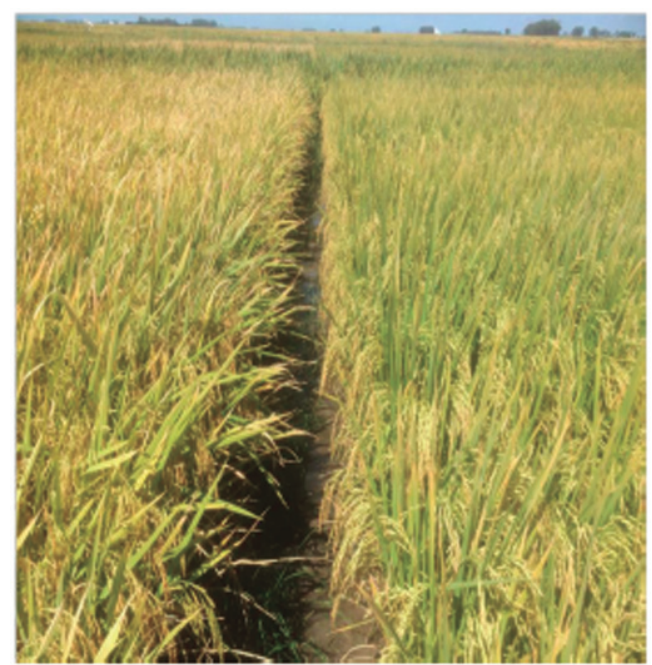

Foto 5. Vista de parcelas previo a la cosecha.

\subsubsection{Zafra 2015-2016}

\subsubsection{Rincón de Ramírez 2015-2016}

El sitio de Rincón de Ramírez en la zafra 2015-16 se sembró sobre un suelo de textura muy similar al de la zafra 2014-15, pero a diferencia de este, su antecedente inmediato fue una pradera artificial de gramíneas y leguminosas roturada con laboreo convencional.

De acuerdo a los contenidos de $\mathrm{P} 4,3$ ppm, K 0,18 meq/100 g y PMN $46 \mathrm{mg} / \mathrm{kg}$ del análisis de suelos, se fertilizó con $87 \mathrm{~kg} / \mathrm{ha}$ $\mathrm{P}_{2} \mathrm{O}_{5}$, y $55 \mathrm{~kg} / \mathrm{ha} \mathrm{K}_{2} \mathrm{O}$ en la siembra y $33 \mathrm{~kg} /$ ha de Verde urea al macollaje, en los tratamientos $4,7,8,9,11$ y 12 como alternativa a la fertilización correspondiente al testigo tecnológico (tratamientos 1, 2, 3, 5, 6 y 10 respectivamente). En todos los tratamientos se aplicaron $50 \mathrm{~kg} / \mathrm{ha}$ de urea común previo a la iniciación panicular.

En el cuadro 43 se presentan los tratamientos aplicados y los rendimientos de arroz sano, seco y limpio (SSL) obtenidos. Con una media de rendimientos de 13,549 t/ha $(1,3 \%$ superior a la lograda el año anterior) y un coeficiente de variación de $3,1 \%$, no se obtuvieron diferencias estadísticamente significativas; los rendimientos se ubicaron en un rango de $751 \mathrm{~kg} / \mathrm{ha}$, y los tratamientos 1 (testigo tecnológico) y 5 , fueron los de mayor productividad $(13,886$ y $13,876 \mathrm{t} / \mathrm{ha}$ respectivamente). En la figura

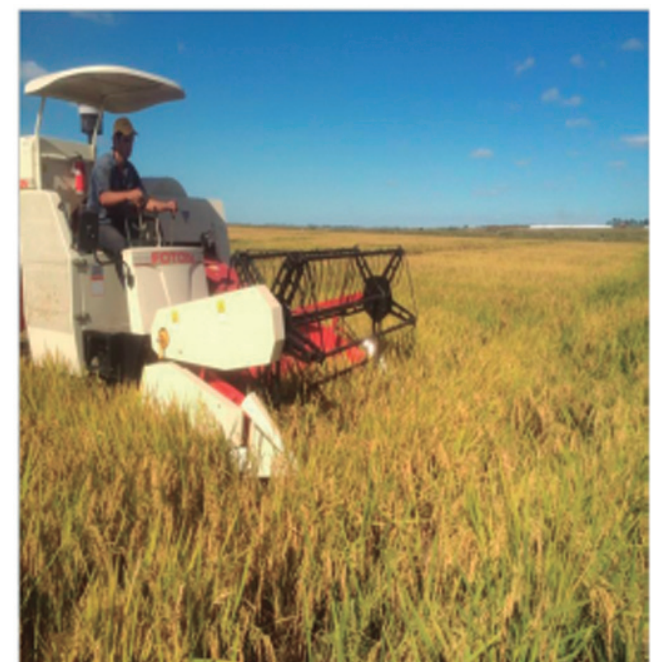

Foto 6. Cosecha mecánica con máquina automotriz.

21 se muestran los rendimientos secos y limpios (SL) y sanos, secos y limpios (SSL).

Confirmando los resultados obtenidos en el análisis de varianza general, no se encontraron diferencias estadísticamente significativas en ninguno de los 15 análisis de contrastes realizados entre factores $\mathrm{y} / \mathrm{o}$ subfactores (Cuadro 44).

\subsubsection{Costas de San Francisco 2015- 2016}

En la zafra 2015-2016 el ensayo se instaló en las Costas de San Francisco, en las proximidades de la Ruta 91 entre La Charqueada y Vergara en sustitución del sitio de la 7 ma sección de Treinta y Tres de la zafra anterior. De acuerdo al análisis de suelos, en los tratamientos $4,7,8,9,11$ y 12 se fertilizó con $77 \mathrm{~kg} / \mathrm{ha} \mathrm{P}_{2} \mathrm{O}_{5}, 10,5 \mathrm{~kg} / \mathrm{ha} \mathrm{K}_{2} \mathrm{O}$ en la siembra, y $133 \mathrm{~kg} / \mathrm{ha}$ de Verde urea al macollaje, como alternativa a la fertilización correspondiente al testigo tecnológico (tratamientos 1, 2, 3, 5, 6 y 10 respectivamente). Se utilizó INIA Merín como cultivar alternativo a El Paso 144 y en todos los tratamientos se aplicaron $50 \mathrm{~kg} / \mathrm{ha}$ de urea común en la iniciación panicular. En el factor «Protección de enfermedades» correspondiente a la tecnología TT, sólo se realizó una aplicación de fungicida.

En el cuadro 45 se presentan los tratamientos aplicados y los rendimientos de 
Cuadro 43. Tratamientos aplicados y resultados en rendimiento de arroz sano, seco y limpio (SSL). Rincón de Ramírez. 2015-2016*.

\begin{tabular}{|c|c|c|c|c|c|c|c|}
\hline \multirow{2}{*}{$\begin{array}{c}\text { Trt } \\
\#\end{array}$} & \multirow[t]{2}{*}{ Oultivar } & \multicolumn{2}{|c|}{ Instal ación cultivo } & \multirow{2}{*}{$\begin{array}{l}\text { Fertiliz. } 1 \\
\text { kg/ha }\end{array}$} & \multirow{2}{*}{$\begin{array}{l}\text { Fert. } \\
\text { Plus }\end{array}$} & \multirow{2}{*}{$\begin{array}{l}\text { Proteción de } \\
\text { enfemedades }\end{array}$} & \multirow{2}{*}{$\begin{array}{l}\text { Rendimiento } \\
\text { SSL t } \mathrm{ha}^{-1}\end{array}$} \\
\hline & & $\begin{array}{l}\text { Dersidad } \\
\mathrm{kg} / \mathrm{ha}\end{array}$ & $\begin{array}{c}\text { Trt } \\
\text { semilla }\end{array}$ & & & & \\
\hline 1 & $\begin{array}{l}\text { El Paso } \\
144\end{array}$ & 130 & Teb+thiom & TT & - & $\begin{array}{l}\text { (teb+triflox) }+ \\
\text { (ciprot azoxis) }\end{array}$ & 13,886 \\
\hline 2 & $\begin{array}{l}\text { OH } \\
\text { Quebracho }\end{array}$ & 130 & Teb+thiom & TT & - & $\begin{array}{l}\text { (teb+triflox) + } \\
\text { (ciprot azoxis) }\end{array}$ & 13,541 \\
\hline 3 & $\begin{array}{l}\text { El Paso } \\
144\end{array}$ & 105 & $\begin{array}{l}\text { Teb+thiom } \\
+ \text { +SyntE ndo }\end{array}$ & TT & - & $\begin{array}{l}\text { (teb+triflox) + } \\
\text { (ciprot azoxis) }\end{array}$ & 13,652 \\
\hline 4 & $\begin{array}{l}\text { El Paso } \\
144\end{array}$ & 130 & Teb+thiom & alternativa & - & $\begin{array}{l}\text { (teb+triflox) }+ \\
\text { (ciprot azoxis) }\end{array}$ & 13,444 \\
\hline 5 & $\begin{array}{l}\text { El Paso } \\
144\end{array}$ & 130 & Teb+thiom & TT & $\begin{array}{l}\text { S+Sit } \\
\text { Micro }\end{array}$ & $\begin{array}{l}\text { (teb+triflox) + } \\
\text { (ciprot azoxis) }\end{array}$ & 13,876 \\
\hline 6 & $\begin{array}{l}\text { El Paso } \\
144\end{array}$ & 130 & Teb+thiom & TT & - & $\begin{array}{c}\text { Sit Fo sito Kt } \\
\text { (az oxi st kre sotcip) }\end{array}$ & 13,610 \\
\hline 7 & $\begin{array}{l}\mathrm{OH} \\
\text { Quebracho }\end{array}$ & 120 & $\begin{array}{l}\text { Teb+thiom } \\
\text { +Synte ndo }\end{array}$ & alternativa & $\begin{array}{l}\text { St Sit } \\
\text { Micro }\end{array}$ & $\begin{array}{c}\text { Sit Fo sito K+ } \\
\text { (azoxis+kresotcip) }\end{array}$ & 13,502 \\
\hline 8 & $\begin{array}{l}\text { El Paso } \\
144\end{array}$ & 105 & $\begin{array}{l}\text { Teb+thiom } \\
+ \text { +SyntE ndo }\end{array}$ & alternativa & $\begin{array}{l}\text { St Sit } \\
\text { Micro }\end{array}$ & $\begin{array}{c}\text { Sit Fo sito Kt } \\
\text { (azoxis+kresotcip) }\end{array}$ & 13,405 \\
\hline 9 & $\begin{array}{l}\text { OH } \\
\text { Quebracho }\end{array}$ & 120 & Teb+thiom & alternativa & $\begin{array}{l}\text { St Sit } \\
\text { Micro }\end{array}$ & $\begin{array}{c}\text { Sit Fo sito K+ } \\
\text { (azoxis+kresotcip) }\end{array}$ & 13,135 \\
\hline 10 & $\begin{array}{l}\text { OH } \\
\text { Quebracho }\end{array}$ & 120 & $\begin{array}{l}\text { Teb+thiom } \\
\text { +Synte ndo }\end{array}$ & TT & $\begin{array}{l}\text { St Sit } \\
\text { Micro }\end{array}$ & $\begin{array}{c}\text { Sit Fo sito K+ } \\
\text { (azoxis+kresotcip) }\end{array}$ & 13,818 \\
\hline 11 & $\begin{array}{l}\mathrm{OH} \\
\text { Quebracho }\end{array}$ & 120 & $\begin{array}{l}\text { Teb+thiom } \\
\text { +SyntE ndo }\end{array}$ & alternativa & - & $\begin{array}{c}\text { Sit Fo sfito Kt } \\
\text { (az oxi st kre so+cip) }\end{array}$ & 13,517 \\
\hline 12 & $\begin{array}{l}\text { OH } \\
\text { Quebracho }\end{array}$ & 120 & $\begin{array}{l}\text { Teb+thiom } \\
\text { +SyntE ndo }\end{array}$ & alternativa & $\begin{array}{l}\text { StSit } \\
\text { Micro }\end{array}$ & $\begin{array}{l}\text { (teb+triflox) + } \\
\text { (ciprot azoxis) }\end{array}$ & 13,196 \\
\hline
\end{tabular}

* Trt= tratamiento; Teb+thiam = tebuconazol + thiametoxan; Teb+thiam +Syn+Endo= tebuconazol+ thiametoxan+ Synergize+ Endorice; Fertiliz. 1 *: TT= $55 \mathrm{~kg} / \mathrm{ha} \mathrm{P}_{2} \mathrm{O}_{5}, 25 \mathrm{~kg} / \mathrm{ha} \mathrm{K}_{2} \mathrm{O}$ en la siembra, y $75 \mathrm{~kg} / \mathrm{ha}$ de urea común al macollaje; alternativa $=87 \mathrm{~kg} / \mathrm{ha} \mathrm{P}_{2} \mathrm{O}_{5}, 55 \mathrm{~kg} / \mathrm{ha} \mathrm{K}_{2} \mathrm{O}$ en la siembra y $33 \mathrm{~kg} / \mathrm{ha}$ de Verde urea al macollaje; $\mathrm{S}+\mathrm{Si}+$ Micro $=$ azufre +silicio + micronutrientes; $($ teb+triflox $)+($ cipro + azoxis $)=$ tebuconazol + trifloxystrobin + ciproconazol + azoxistrobin; $\mathrm{Si}+$ Fosfito $\mathrm{K}+($ azoxis $+k r e s o+c i p)=$ silicio + fosfito de potasio + azoxistrobin $+k r e s o x i m$ metil+ ciproconazol.

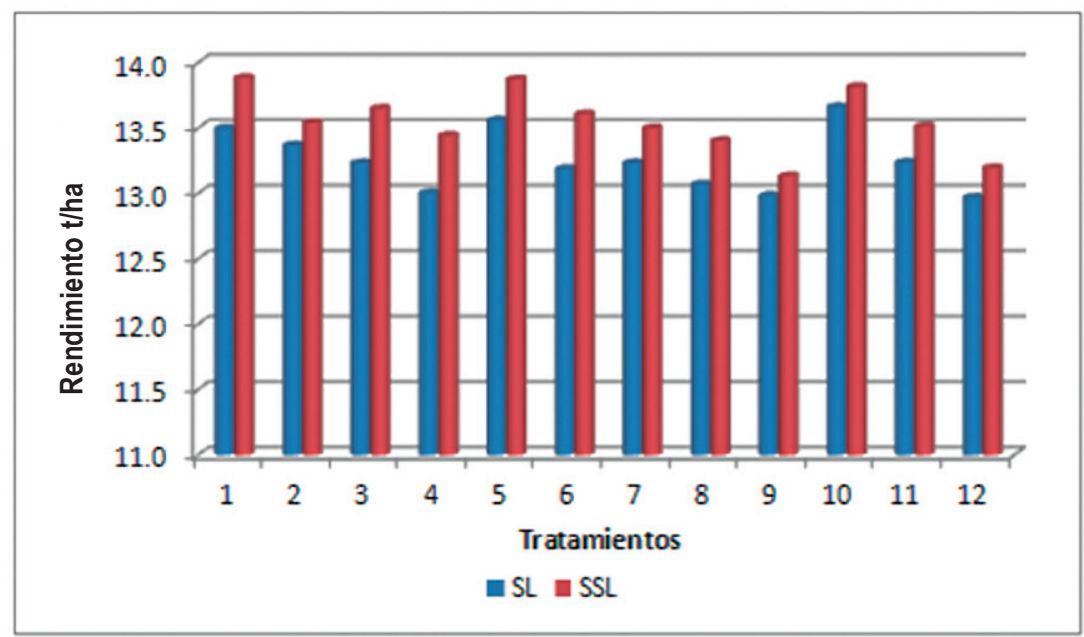

Figura 21. Rendimientos secos y limpios (SL) y sanos, secos y limpios (SSL) obtenidos en Rincón de Ramírez, zafra 2015-2016. 
Cuadro 44. Contrastes ortogonales de factores y/o sub-factores. Rincón. 2015-2016*.

\begin{tabular}{|c|c|c|c|c|c|}
\hline $\begin{array}{c}\text { Factor / } \\
\text { sub-factor }\end{array}$ & $\begin{array}{l}\text { Contraste } \\
\text { tratamientos }\end{array}$ & \multicolumn{2}{|c|}{$\begin{array}{l}\text { Rendimientos SSL } \\
\text { t/ha }\end{array}$} & $\begin{array}{c}\text { Diferencia } \\
\text { tha }\end{array}$ & $\begin{array}{c}\text { Probabilidad } \\
\text { estadística }\end{array}$ \\
\hline \multirow[t]{3}{*}{ Cultivar } & $1 \vee s 2$ & 13,886 & 13,541 & 0,345 & ns \\
\hline & $7 \vee 58$ & 13,502 & 13,405 & 0,097 & ns \\
\hline & $(1,8) \cup s(2,7)$ & 13,646 & 13,522 & 0,124 & ns \\
\hline \multirow[t]{3}{*}{ Instalación } & $1 \vee 53$ & 13,886 & 13,652 & 0,234 & ns \\
\hline & $7 \vee s 9$ & 13,502 & 13,135 & 0,367 & ns \\
\hline & $(1,9)$ $s(3,7)$ & 13.511 & 13,577 & $-0,066$ & ns \\
\hline \multirow[t]{3}{*}{ Fertilización 1} & $1 \vee 4$ & 13,886 & 13,444 & 0,442 & ns \\
\hline & $7 \vee s 10$ & 13,502 & 13,818 & $-0,316$ & ns \\
\hline & $(1,10)$ vs $(4,7)$ & 13,852 & 13.473 & 0,379 & ns \\
\hline Fertilización & $1 \vee 55$ & 13,886 & 13,876 & 0,010 & ns \\
\hline \multirow[t]{2}{*}{ Plus } & $7 \vee s 11$ & 13,502 & 13,517 & $-0,015$ & ns \\
\hline & $(1,11)$ vs $(5,7)$ & 13,702 & 13,689 & 0,013 & ns \\
\hline Protección & $1 \vee 56$ & 13,886 & 13,610 & 0,276 & ns \\
\hline \multirow[t]{2}{*}{ Enfemedades } & $7 \vee s 12$ & 13,502 & 13,196 & 0,306 & ns \\
\hline & $(1,12) \vee s 6,7)$ & 13,541 & 13,556 & $-0,015$ & ns \\
\hline
\end{tabular}

*Rincón= Rincón de Ramírez; SSL= arroz sano, seco y limpio; ns= no significativa.

Cuadro 45. Tratamientos aplicados y resultados en rendimiento de arroz sano, seco y limpio (SSL). Costas de San Francisco. 2015-2016*.

\begin{tabular}{|c|c|c|c|c|c|c|c|}
\hline \multirow{2}{*}{$\begin{array}{c}\text { Trt } \\
\#\end{array}$} & \multirow[t]{2}{*}{ Qultivar } & \multicolumn{2}{|c|}{ Instal ación cultivo } & \multirow{2}{*}{$\begin{array}{c}\text { Fertiliz. } 1 \\
\text { kg/ha }\end{array}$} & \multirow{2}{*}{$\begin{array}{l}\text { Fert. } \\
\text { Plus }\end{array}$} & \multirow{2}{*}{$\begin{array}{l}\text { Proteción de } \\
\text { enfe me dades }\end{array}$} & \multirow{2}{*}{$\begin{array}{c}\text { Rendimiento } \\
\text { SSL } t / h a\end{array}$} \\
\hline & & $\begin{array}{l}\text { Dersidad } \\
\text { kg/ha }\end{array}$ & $\begin{array}{c}\text { Trt } \\
\text { semilla }\end{array}$ & & & & \\
\hline 1 & $\begin{array}{l}\text { El Paso } \\
144\end{array}$ & 130 & Teb+thiom & TT & - & $\begin{array}{l}\text { (tebuconazal } \\
\text { trifloxystrabin) }\end{array}$ & 12,336 \\
\hline 2 & INIA Merín & 130 & Teb+thiom & TT & - & $\begin{array}{l}\text { (tebuconazat } \\
\text { trifloxystrabin) }\end{array}$ & 12,856 \\
\hline 3 & $\begin{array}{l}\text { El Paso } \\
144\end{array}$ & 105 & $\begin{array}{l}\text { Teb+thiom } \\
\text { +SyntE ndo }\end{array}$ & TT & - & $\begin{array}{l}\text { (tebuconazal } \\
\text { trifloxystrabin) }\end{array}$ & 12,175 \\
\hline 4 & $\begin{array}{l}\text { El Paso } \\
144\end{array}$ & 130 & Teb+thiom & alternativa & - & $\begin{array}{l}\text { (tebucanazal } \\
\text { trifloxystrabin) }\end{array}$ & 13,285 \\
\hline 5 & $\begin{array}{l}\text { El Paso } \\
144\end{array}$ & 130 & Teb+thiom & TT & $\begin{array}{l}\text { S+Sit } \\
\text { Micro }\end{array}$ & $\begin{array}{l}\text { (tebuconazal } \\
\text { trifloxystrabin) }\end{array}$ & 12,385 \\
\hline 6 & $\begin{array}{l}\text { El Paso } \\
144\end{array}$ & 130 & Teb+thiom & TT & - & $\begin{array}{c}\text { Sit Fo fito Kt } \\
\text { (az oxist kre so+cip) }\end{array}$ & 12,565 \\
\hline 7 & INIA Merín & 109 & $\begin{array}{l}\text { Teb+thiom } \\
+ \text { +Synte ndo }\end{array}$ & alternativa & $\begin{array}{l}\text { St Sit } \\
\text { Micro }\end{array}$ & $\begin{array}{c}\text { Sit Fo fito } \mathrm{K}+ \\
\text { (azoxistkresotcip) }\end{array}$ & 12,930 \\
\hline 8 & $\begin{array}{l}\text { El Paso } \\
144\end{array}$ & 105 & $\begin{array}{l}\text { Teb+thiom } \\
\text { +Synte ndo }\end{array}$ & alternativa & $\begin{array}{l}\text { St Sit } \\
\text { Micro }\end{array}$ & $\begin{array}{c}\text { Sit Fo fito } \mathrm{K}+ \\
(\text { azoxis+kresotcip })\end{array}$ & 12,398 \\
\hline 9 & INIA Merín & 130 & Teb+thiom & alternativa & $\begin{array}{l}\text { St Sit } \\
\text { Micro }\end{array}$ & $\begin{array}{c}\text { Sit Fo fito } \mathrm{K}+ \\
\text { (azoxis+kresotcip) }\end{array}$ & 12,957 \\
\hline 10 & INIA Mlerín & 109 & $\begin{array}{l}\text { Teb+thiom } \\
\text { +SyntE ndo }\end{array}$ & TT & $\begin{array}{l}\text { St Sit } \\
\text { Micro }\end{array}$ & $\begin{array}{c}\text { Sit Fo sito } \mathrm{K}+ \\
\text { (azoxis+kresotcip) }\end{array}$ & 12,346 \\
\hline 11 & INIA Merín & 109 & $\begin{array}{l}\text { Teb+thiom } \\
+ \text { +SyntE ndo }\end{array}$ & alternativa & - & $\begin{array}{c}\text { Sit Fo fito } K+ \\
\text { (az oxist kre so+cip) }\end{array}$ & 12,993 \\
\hline 12 & INIA Mlerín & 109 & $\begin{array}{l}\text { Teb+thiom } \\
+S y n+\text { E ndo }\end{array}$ & alternativa & $\begin{array}{l}\text { S+Sit } \\
\text { Micro }\end{array}$ & $\begin{array}{l}\text { (tebuconazat } \\
\text { trifloxystrobin) }\end{array}$ & 13,205 \\
\hline
\end{tabular}

* Trt= tratamiento; Teb+thiam = tebuconazol + thiametoxan; Teb+thiam +Syn+Endo= tebuconazol+ thiametoxan+ Synergize+ Endorice; Fertiliz. 1 *: TT= $55 \mathrm{~kg} / \mathrm{ha} \mathrm{P}_{2} \mathrm{O}_{5}, 25 \mathrm{~kg} / \mathrm{ha} \mathrm{K}_{2} \mathrm{O}$ en la siembra, y $75 \mathrm{~kg} / \mathrm{ha}$ de urea común al macollaje; alternativa $=77 \mathrm{~kg} / \mathrm{ha} \mathrm{P}_{2} \mathrm{O}_{5}, 10,5 \mathrm{~kg} / \mathrm{ha} \mathrm{K} \mathrm{K}_{2}$ en la siembra y $133 \mathrm{~kg} / \mathrm{ha}$ de Verde urea al macollaje; $\mathrm{S}+\mathrm{Si}+$ Micro= azufre +silicio + micronutrientes; $\mathrm{Si}+$ Fosfito $\mathrm{K}+($ azoxis $+k r e s o+c i p)=$ silicio + fosfito de potasio + azoxistrobin+kresoxim metil+ ciproconazol. 
arroz sano, seco y limpio (SSL) obtenidos. Con una media de rendimientos de 12,703 t/ha y un coeficiente de variación de $4,4 \%$, no se obtuvieron diferencias estadísticamente significativas por efectos de los tratamientos. Con un rango de $949 \mathrm{~kg} / \mathrm{ha}$ en la productividad, los tratamientos 4 y 12 fueron los de mayor rendimiento, en torno a las $13,2 \mathrm{t} / \mathrm{ha}$ que significa un incremento de $7 \%$ por encima de la producción del testigo tecnológico ( $\left.\mathrm{N}^{\circ} 1\right)$.

En la figura 22 se presentan los rendimientos secos y limpios (SL) y sanos, secos y limpios (SSL) obtenidos en Costas de San Francisco. A diferencia de todos los casos presentados, en esta oportunidad no se obtuvieron premios por calidad.

Es posible que las condiciones ambientales menos favorables de fin del ciclo en 2016, por disminución importante en la radiación solar (Cuadro 46), hayan afectado la calidad de los granos, principalmente a INIA Merín que maduró más tarde.
En los análisis de contrastes ortogonales entre factores y/o subfactores se encontraron algunas diferencias significativas (Cuadro 47).

En relación con cultivares, las diferencias de 0,5 t/ha encontradas en las comparaciones «dentro de cada tecnología (TT 1 vs 2 , o alternativa 7 vs 8 )» no resultan estadísticamente significativas, pero en la prueba conjunta sin distinción de las prácticas de manejo, al considerar un número mayor de parcelas, se observó una tendencia por la que INIA Merín resulta superior $(p=0,12)$.

El Paso 144 incrementó su producción $949 \mathrm{~kg} / \mathrm{ha}$ al utilizarse la estrategia alternativa de fertilización ( $\mathrm{F} 1$; tratamientos 1 vs 4), manteniendo el resto de las prácticas de manejo habituales del productor, lo que resulta estadísticamente significativo ( $p$ : 0,05).

En el caso de INIA Merín, la reducción de $584 \mathrm{~kg} / \mathrm{ha}$, al pasar de la «fertilización 1» a la estrategia del productor (7 vs 10$)$ no fue significativa. Al igual que en la comparación de

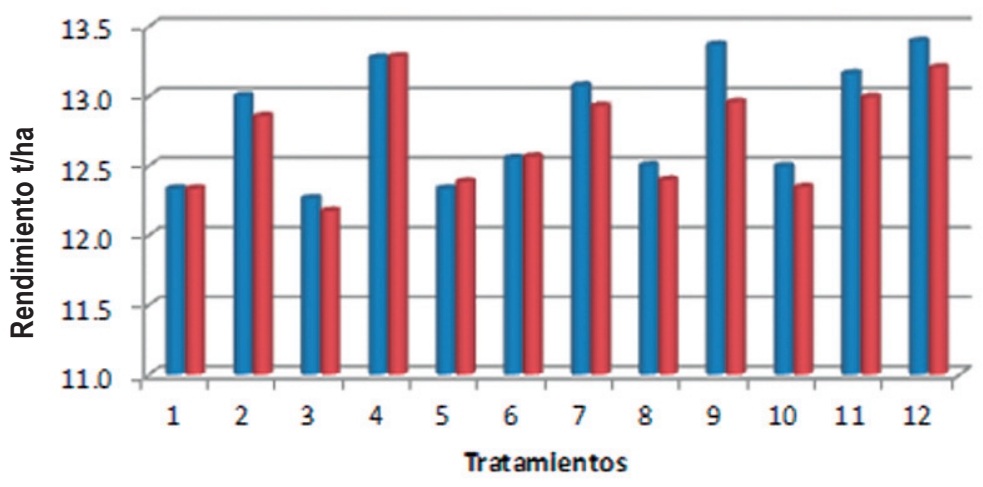

nSL $\backsim S S L$

Figura 22. Rendimientos secos y limpios (SL) y sanos, secos y limpios (SSL) obtenidos en Costas de San Francisco, zafra 2015-2016.

Cuadro 46. Radiación solar diaria promedio $\left(\mathrm{MJ} / \mathrm{m}^{2} /\right.$ día) por décadas. Años 2015, 2016.

\begin{tabular}{ccccc}
\hline Año & \multicolumn{3}{c}{ Marzo } & Abril \\
\cline { 2 - 5 } & $1^{\mathrm{a}} \mathrm{d}$ & $2^{\mathrm{a}} \mathrm{d}$ & $3^{\mathrm{a}} \mathrm{d}$ & $1^{\mathrm{a}} \mathrm{d}$ \\
\hline 2015 & 20,0 & 20,7 & 13,9 & 17,4 \\
2016 & 16,2 & 15,8 & 13,8 & 7,8 \\
Diferencia en \% 2015 & -19 & $-23,7$ & $-0,7$ & $-56,2$ \\
\hline
\end{tabular}


Cuadro 47. Contrastes ortogonales de factores y/o sub-factores. Costas de San Francisco. 2015-2016*.

\begin{tabular}{|c|c|c|c|c|c|}
\hline $\begin{array}{c}\text { Factor/ } \\
\text { sub-factor }\end{array}$ & $\begin{array}{l}\text { Contraste } \\
\text { tratamientos }\end{array}$ & Rendi & $\overline{S S S L}$ & $\begin{array}{c}\text { Diferencia } \\
\text { tha }\end{array}$ & $\begin{array}{l}\text { Probabilidad } \\
\text { esadística }\end{array}$ \\
\hline Cultivar & 1 vs 2 & 12,336 & 12,856 & $-0,520$ & ns \\
\hline & 7 vs 8 & 12,930 & 12,398 & 0,532 & ns \\
\hline & $(1,8)$ vs $(2,7)$ & 12,367 & 12,893 & $-0,526$ & 0,12 \\
\hline Instalación & 1 vs 3 & 12,336 & 12,175 & 0,161 & ns \\
\hline & 7 vs 9 & 12,930 & 12,957 & $-0,027$ & ns \\
\hline & (19) v $(3,7)$ & 12,647 & 12,553 & 0,094 & ns \\
\hline Fertilización 1 & 1 vs 4 & 12,336 & 13,285 & $-0,949$ & 0,05 \\
\hline & 7 vs 10 & 12,930 & 12,346 & 0,584 & ns \\
\hline & $(1,10)$ v s $(4,7)$ & 12,341 & 13,108 & $-0,767$ & 0,03 \\
\hline Fertilización & 1 vs 5 & 12,336 & 12,385 & $-0,049$ & ns \\
\hline Plus & 7 vs 11 & 12,930 & 12,993 & $-0,063$ & ns \\
\hline & $(1,11)$ v s $(5,7)$ & 12,665 & 12,658 & 0,007 & ns \\
\hline Protección & 1 vs 6 & 12,336 & 12,565 & $-0,229$ & ns \\
\hline Enfemedades & 7 vs 12 & 12,930 & 13,205 & $-0,275$ & ns \\
\hline & $(1,12) \cup(6,7)$ & 12,771 & 12,748 & 0,023 & ns \\
\hline
\end{tabular}

* SSL= arroz sano, seco y limpio; ns= no significativa.

cultivares, en la prueba conjunta de estrategias de fertilización sin hacer distinción de las otras prácticas acompañantes, al disponer de un número mayor de repeticiones en la comparación hace que la diferencia de $767 \mathrm{~kg} / \mathrm{ha}$ resulte estadísticamente significativa con $p=0,03$ de probabilidad, a favor de la alternativa propuesta.

No se encontraron diferencias debidas a los factores «instalación del cultivo», «fertilización plus», ni "protección de enfermedades»; en relación a este último, cabe recordar que en el manejo TT se realizó sólo una aplicación de fungicidas.

\subsubsection{Cebollatí 2015-2016}

En el cuadro 5 (Materiales y Métodos), se aprecian varias características similares entre los suelos donde se instalaron los ensayos de las 2 zafras en Cebollatí. En primer lugar, se obtuvieron valores muy próximos en $\mathrm{pH}(6,5-6,2)$, PMN (30 - 33), CO $(2,0-2,0), K(0,33-0,32), Z n(0,91-0,91)$ y CIC $(14,5$ - 13,2) respectivamente. En referencia a la textura del suelo, muestran prácticamente el mismo contenido de arcilla (26 - $25 \%$ ), pero una diferencia importante en la presencia de arena y limo: mientras que en $2014-15$ el suelo tenía una relación $30 \%$ arena y $44 \%$ de limo, en 2015-16 el limo fue ampliamente dominante $(14 \%$ de arena, $61 \%$ de limo).

De acuerdo a los contenidos de $\mathrm{P} 4,3$

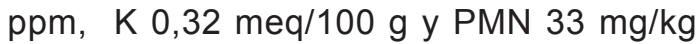
del análisis de suelos, como alternativa a la fertilización correspondiente al testigo tecnológico, se fertilizó con $87 \mathrm{~kg} / \mathrm{ha} \mathrm{P}_{2} \mathrm{O}_{5}, 11$ $\mathrm{kg} / \mathrm{ha} \mathrm{K}_{2} \mathrm{O}$ en la siembra y $90 \mathrm{~kg} / \mathrm{ha}$ de Verde urea al macollaje, en los tratamientos 4, $7,8,9,11$ y 12 . Igual al año anterior, por utilizarse Parao como cultivar alternativo, en estos tratamientos se aplicaron $100 \mathrm{~kg} / \mathrm{ha}$ de urea común previo a la iniciación panicular, en vez de los $50 \mathrm{~kg} / \mathrm{ha}$ usados en los correspondientes al testigo tecnológico (TT). En esta oportunidad, en el factor «Protección de enfermedades» correspondiente a la tecnología testigo se realizaron 2 aplicaciones de fungicida debido a la aparición de síntomas de Brusone en las proximidades del ensayo.

Este experimento instalado el 6 de noviembre, tuvo una inundación algo tardía y fue cosechado tarde (2-3 de mayo), después de un período prolongado de lluvias. Previo a la cosecha, hubo días de viento fuerte y algunas parcelas con plantas de arroz altas y con buena producción de grano volcaron.

En el cuadro 48 se presentan los tratamientos aplicados y los rendimientos de arroz sano, seco y limpio (SSL) obtenidos. 
Cuadro 48. Tratamientos aplicados y resultados en rendimiento de arroz sano, seco y limpio (SSL). Cebollatí 2015-2016*

\begin{tabular}{|c|c|c|c|c|c|c|c|c|}
\hline \multirow{2}{*}{$\begin{array}{c}\text { Trt } \\
\#\end{array}$} & \multirow[t]{2}{*}{ Oultivar } & \multicolumn{2}{|c|}{ Instaladón cultivo } & \multirow{2}{*}{$\begin{array}{c}\text { Fertiliz. } 1 \\
\text { kg/ha }\end{array}$} & \multirow{2}{*}{$\begin{array}{l}\text { Fert. } \\
\text { Plus }\end{array}$} & \multirow{2}{*}{$\begin{array}{l}\text { Protección de } \\
\text { enfermedades }\end{array}$} & \multicolumn{2}{|c|}{ Rendimiento } \\
\hline & & $\begin{array}{c}\text { Dersidad } \\
\mathrm{kg} / \mathrm{ha}\end{array}$ & $\begin{array}{c}\text { Trt } \\
\text { semilla }\end{array}$ & & & & $\begin{array}{l}\text { SSL } \\
\text { t/ha }\end{array}$ & $\begin{array}{l}\text { MDS } \\
005\end{array}$ \\
\hline 1 & $\begin{array}{l}\text { El Paso } \\
144\end{array}$ & 160 & Teb+thiom & TT & - & $\begin{array}{l}\text { (teb+triflox) + } \\
\text { (ciprot azoxis) }\end{array}$ & 12,092 & $a b c$ \\
\hline 2 & Parao & 160 & Teb+thiom & TT & - & $\begin{array}{l}\text { (teb+triflox) + } \\
\text { (ciprot azoxis) }\end{array}$ & 12,020 & $a b c$ \\
\hline 3 & $\begin{array}{l}\text { El Paso } \\
144\end{array}$ & 132 & $\begin{array}{l}\text { Teb+thiom } \\
\text { +Syn+Endo }\end{array}$ & TT & - & $\begin{array}{l}\text { (teb+triflox) + } \\
\text { (ciprot azoxis) }\end{array}$ & 11,826 & bed \\
\hline 4 & $\begin{array}{l}\text { El Paso } \\
144\end{array}$ & 160 & Teb+thiom & alternativa & - & $\begin{array}{l}\text { (teb+triflox) + } \\
\text { (ciprot azoxis) }\end{array}$ & 11,555 & cd \\
\hline 5 & $\begin{array}{l}\text { El Paso } \\
144\end{array}$ & 160 & Teb+thiom & TT & $\begin{array}{l}\text { S+ Sit } \\
\text { Mioro }\end{array}$ & $\begin{array}{l}\text { (teb+triflox) + } \\
\text { (ciprot azoxis) }\end{array}$ & 11,889 & bc \\
\hline 6 & $\begin{array}{l}\text { El Paso } \\
144\end{array}$ & 160 & Teb+thiom & TT & - & $\begin{array}{c}\text { SitFosfito Kt } \\
\text { (as oxist kresotcip) }\end{array}$ & 11,190 & cd \\
\hline 7 & Parao & 139 & $\begin{array}{l}\text { Teb+thiom } \\
+ \text { +Sy+Endo }\end{array}$ & alternativa & $\begin{array}{l}\text { St Sit } \\
\text { Micro }\end{array}$ & $\begin{array}{c}\text { Sit Fosfito K+ } \\
\text { (czoxis+kresot cip) }\end{array}$ & 11,939 & bc \\
\hline 8 & $\begin{array}{l}\text { El Paso } \\
144\end{array}$ & 132 & $\begin{array}{l}\text { Teb+thiom } \\
+ \text { Syn+Endo }\end{array}$ & alternativa & $\begin{array}{l}\text { S+ Sit } \\
\text { Micro }\end{array}$ & $\begin{array}{c}\text { Sit Fosfito K+ } \\
\text { (azoxistkresotcip) }\end{array}$ & 10,879 & d \\
\hline 9 & Parao & 160 & Teb+thiom & alternativa & $\begin{array}{l}\text { S+ Sit } \\
\text { Micro }\end{array}$ & $\begin{array}{c}\text { Sit Fosfito K+ } \\
(\text { czoxist kresot cip) }\end{array}$ & 11,997 & bc \\
\hline 10 & Parao & 139 & $\begin{array}{l}\text { Teb+thiom } \\
+ \text { SyntEndo }\end{array}$ & TT & $\begin{array}{l}\text { St Sit } \\
\text { Micro }\end{array}$ & $\begin{array}{c}\text { Sit Fosfito K+ } \\
\text { (azoxist kresot cip) }\end{array}$ & 11,959 & bc \\
\hline 11 & Parao & 139 & $\begin{array}{l}\text { Teb+thiom } \\
+ \text { Syr+Endo }\end{array}$ & alternativa & - & $\begin{array}{c}\text { Sit Fosfito K+ } \\
\text { (a oxist kresotcip) }\end{array}$ & 12,606 & $a b$ \\
\hline 12 & Parao & 139 & $\begin{array}{l}\text { Teb+thiom } \\
+ \text { SyntEndo }\end{array}$ & alternativa & $\begin{array}{l}\text { S+Sit } \\
\text { Mioro }\end{array}$ & $\begin{array}{l}\text { (teb+triflox) }+ \\
\text { (ciprot azoxis) }\end{array}$ & 12,949 & a \\
\hline
\end{tabular}

* Trt= tratamiento; Teb+thiam = tebuconazol + thiametoxan; Teb+thiam +Syn+Endo= tebuconazol+ thiametoxan+ Synergize+ Endorice; Fertiliz. 1 *: TT= 19,8 kg/ha N, 50,6 kg/ha $\mathrm{P}_{2} \mathrm{O}_{5}$ en la siembra, $60 \mathrm{~kg} / \mathrm{ha}$ de urea común al macollaje y $50 \mathrm{~kg} / \mathrm{ha}$ de urea común a la iniciación panicular; alternativa $=87 \mathrm{~kg} / \mathrm{ha} \mathrm{P}_{2} \mathrm{O}_{5}, 11 \mathrm{~kg} / \mathrm{ha} \mathrm{K}_{2} \mathrm{O}$ en la siembra, $90 \mathrm{~kg} / \mathrm{ha}$ de Verde urea al macollaje y $100 \mathrm{~kg} / \mathrm{ha}$ de urea común a la iniciación panicular; $\mathrm{S}+\mathrm{Si}+\mathrm{Micro}=$ azufre +silicio + micronutrientes; $($ teb+triflox $)+($ cipro + azoxis $)=$ tebuconazol + trifloxystrobin + ciproconazol + azoxistrobin; $\mathrm{Si}+$ Fosfito $\mathrm{K}+($ azoxis + kreso+cip $)=$ silicio + fosfito de potasio + azoxistrobin+kresoxim metil+ ciproconazol; MDS 0,05= mínima diferencia significativa al $5 \%$ de probabilidad - números seguidos por la(s) misma(s) letras no difieren significativamente.

Con una media de rendimientos de 11,908 t/ha y un coeficiente de variación de $4,7 \%$, se obtuvieron diferencias estadísticamente significativas ( $p: 0,02)$. El promedio de rendimientos de los 12 tratamientos fue 19,7\% superior al logrado en 2014-2015, mientras que el tratamiento 1 , correspondiente a la tecnología de los productores del quintil superior, rindió $28,7 \%$ más que el año anterior.

En la figura 23 se presentan los rendimientos secos y limpios (SL) y sanos, secos y limpios (SSL) obtenidos en Cebollatí 2015-2016. Se observa una muy buena per- formance del testigo tecnológico (tratamiento 1), tanto en SL como en SSL, así como de los tratamientos 12 y 11 con incrementos de 7 y $4 \%$ respectivamente sobre el anterior. El tratamiento 8 con una productividad igual a la obtenida en la zafra anterior, donde había superado al testigo en un $15 \%$, sólo alcanzó el $90 \%$ del rendimiento de éste en 2015-2016. Se destaca la calidad de los tratamientos donde se sembró la variedad Parao, con premios superiores a los $560 \mathrm{~kg} / \mathrm{ha}$ en todos ellos.

En el cuadro 49 se presentan los resultados de los análisis estadísticos por 


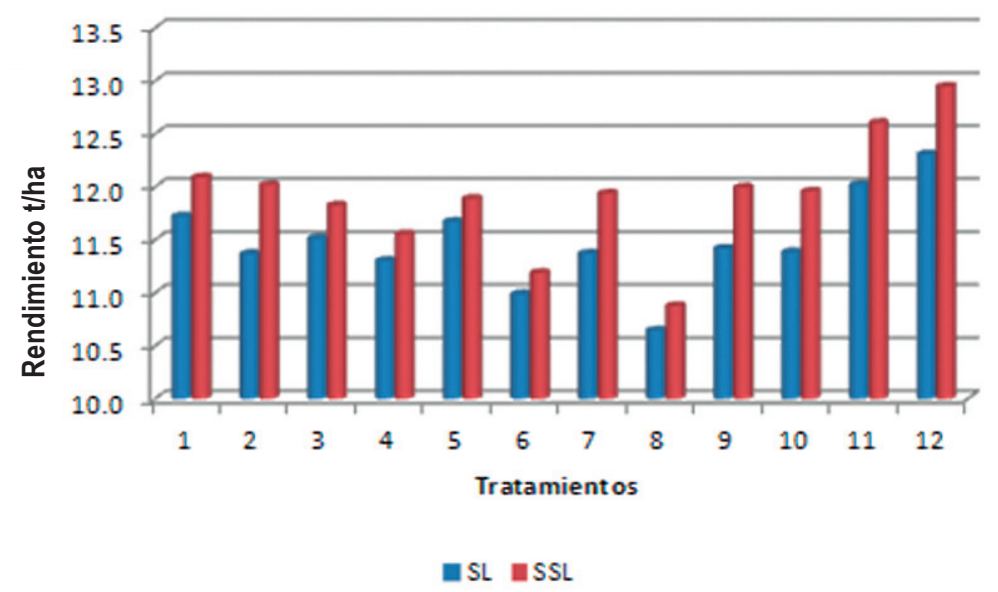

Figura 23. Rendimientos secos y limpios (SL) y sanos, secos y limpios (SSL) obtenidos en Cebollatí, zafra 2015-2016,

Cuadro 49. Contrastes ortogonales de factores y/o sub-factores. Cebollatí. 2015-2016*.

\begin{tabular}{|c|c|c|c|c|c|}
\hline $\begin{array}{c}\text { Factor/ } \\
\text { sub-factor }\end{array}$ & $\begin{array}{c}\text { Contraste } \\
\text { tratamientos }\end{array}$ & Rendi & $\overline{S S S L}$ & $\begin{array}{c}\text { Diferencia } \\
\text { tha }\end{array}$ & $\begin{array}{l}\text { Probabilidad } \\
\text { esadística }\end{array}$ \\
\hline Cultivar & 1 vs 2 & 12,092 & 12,020 & 0,072 & ns \\
\hline & 7 vs 8 & 11,939 & 10,879 & 1,060 & 0,03 \\
\hline & $(1,8)$ vs $(2,7)$ & 11,486 & 11,980 & $-0,494$ & 0,14 \\
\hline Instalación & 1 vs 3 & 12,092 & 11,826 & 0,266 & ns \\
\hline & 7 vs 9 & 11,939 & 11,997 & $-0,058$ & ns \\
\hline & $(1,9)$ vs $(3,7)$ & 12,045 & 11,883 & 0,162 & ns \\
\hline Fertilización 1 & 1 vs 4 & 12,092 & 11,555 & 0,537 & ns \\
\hline & 7 vs 10 & 11,939 & 11,959 & $-0,020$ & ns \\
\hline & $(1,10)$ v s $(4,7)$ & 12,026 & 11,747 & 0,279 & ns \\
\hline Fertilización & 1 vs 5 & 12,092 & 11,889 & 0,203 & $\mathrm{~ns}$ \\
\hline Plus & 7 vs 11 & 11,939 & 12,606 & $-0,667$ & 0,16 \\
\hline & $(1,11)$ v s $(5,7)$ & 12,349 & 11,914 & 0,435 & ns \\
\hline Protección & 1456 & 12,092 & 11,190 & 0,902 & 0,06 \\
\hline Enfemedades & 7 vs 12 & 11,939 & 12,949 & $-1,010$ & 0,04 \\
\hline & $(1,12)$ vs 67$)$ & 12,521 & 11,565 & 0,956 & 0,007 \\
\hline
\end{tabular}

* SSL= arroz sano, seco y limpio; ns= no significativa.

contrastes ortogonales entre factores y subfactores.

Los 2 cultivares rindieron en forma similar cuando el manejo del cultivo fue el habitual de los productores del quintil superior (tratamientos 1 vs 2), pero Parao rindió $1.060 \mathrm{~kg} / \mathrm{ha}$ más cuando el resto de las prácticas de manejo correspondieron a las alternativas propuestas (tratamientos 7 vs 8 ; $p=0,03$ de probabilidad). En la comparación en conjunto entre las 2 variedades, sin tener en consideración las otras prácticas de manejo del cultivo, Parao rindió 534 kg/ha más que El Paso 144, pero esa diferencia no resulta significativa (tratamientos $1-8$ vs $2-7 ; p=0,14)$.

En referencia al factor instalación del cultivo, no se encontraron diferencias en ninguno de los 3 contrastes realizados (1 vs $3 ; 7$ vs $9 ; 1-9$ vs $3-7$ ).

La «Fertilización 1 » alternativa (87 kg/ha $\mathrm{P}_{2} \mathrm{O}_{5}, 11 \mathrm{~kg} / \mathrm{ha} \mathrm{K} \mathrm{O}$ en la siembra, $90 \mathrm{~kg} / \mathrm{ha}$ de Verde urea al macollaje y $100 \mathrm{~kg} / \mathrm{ha}$ de urea común a la iniciación panicular) no 
produjo diferencias significativas en los rendimientos en relación a la utilizada por los productores (TT= 19,8 kg/ha N, 50,6 kg/ha $\mathrm{P}_{2} \mathrm{O}_{5}$ en la siembra, $60 \mathrm{~kg} / \mathrm{ha}$ de urea común al macollaje y $50 \mathrm{~kg} / \mathrm{ha}$ de urea común a la iniciación panicular) en ninguno de los 3 contrastes realizados (tratamientos 1 vs $4 ; 7$ vs $10 ; 1-10$ vs 4,7 ). La diferencia de $537 \mathrm{~kg} / \mathrm{ha}$ existente entre los tratamientos 1 y 4 de El Paso 144 no es estadísticamente diferente según el análisis correspondiente.

La «Fertilización Plus» no tuvo efectos estadísticamente significativos en ninguno de los 2 escenarios, participando como adición a la tecnología TT testigo (tratamiento 1 vs 5), ni cuando fue quitada del conjunto de propuestas alternativas (tratamientos 7 vs 11) respectivamente. Tampoco hubo diferencias en la prueba conjunta (1-11 vs 57).

En el factor «protección de enfermedades», debido a la presencia de Brusone y una cosecha tardía provocada por lluvias abundantes, se encontraron diferencias importantes y significativas a favor de la doble aplicación de fungicidas, utilizada por la tecnología TT de los productores (1 vs $6 ; 7$ vs 12 y $1-12$ vs $6-7$, con probabilidades de $p=$ $0,06, p=0,04$ y $p=0,007$ respectivamente).

\subsubsection{India Muerta 2015-2016}

$\mathrm{Al}$ igual que en la zafra anterior, en esta localidad el experimento fue instalado en noviembre (7 nov., 3 días calendario antes), sobre un suelo menos fértil y un uso previo diferente, que incluyó la siembra y pastoreo de sorgo forrajero en 2010. Posteriormente se sembró una pradera convencional.

Las texturas del suelo no difirieron mayormente (15-47-38 en 2014-2015, 16-5727 en 2015-206, como porcentajes de arena-limo-arcilla respectivamente). Pero, al momento de siembra se disponía del $84 \%$ de $\mathrm{CO}, 30 \%$ de PMN, $50 \%$ de $\mathrm{K}, 45 \%$ de $\mathrm{Mg}, 324 \%$ de $\mathrm{Na}$, igual cantidad de $\mathrm{Zn}$ y $45 \%$ de capacidad de intercambio catiónico, en relación con el año anterior.

De acuerdo a los análisis de suelo, $\mathrm{P}=$ $10,7 \mathrm{ppm}, \mathrm{K}=0,19 \mathrm{meq} / 100 \mathrm{~g}$ y $\mathrm{PMN}=22$ $\mathrm{mg} / \mathrm{kg}$, como alternativa a la fertilización del testigo tecnológico, se fertilizó con $40 \mathrm{~kg} / \mathrm{ha}$ $\mathrm{P}_{2} \mathrm{O}_{5}, 43 \mathrm{~kg} / \mathrm{ha} \mathrm{K} \mathrm{O}$ en la siembra y $137 \mathrm{~kg} / \mathrm{ha}$ de Verde urea al macollaje, en los tratamientos $4,7,8,9,11$ y 12 . Como ya se mencionó para el año anterior, por utilizarse Parao como cultivar alternativo, en estos tratamientos se aplicaron además $100 \mathrm{~kg} / \mathrm{ha}$ de urea común previo a la iniciación panicular, en vez de los $50 \mathrm{~kg} / \mathrm{ha}$ usados en los correspondientes al testigo tecnológico (TT).

En esta oportunidad, en el factor «Protección de enfermedades» correspondiente a la tecnología testigo (TT) sólo se realizó una aplicación de fungicida.

En el cuadro 50 se presentan los tratamientos aplicados y los rendimientos de arroz sano, seco y limpio (SSL) obtenidos. Con un rendimiento promedio de $12,438 \mathrm{t} / \mathrm{ha}$ (3,5 \% superior al logrado en $2014-2015)$ y un coeficiente de variación de $3,7 \%$, se obtuvieron diferencias estadísticamente muy significativas (probabilidad $p=0,000$ ). Los máximos rendimientos SSL correspondieron a los tratamientos 11,9 y 7 con incrementos de $11,5,8,7$ y $7,2 \%$ respectivamente, sobre la productividad obtenida con el testigo tecnológico (tratamiento 1).

En la figura 24 se presentan los rendimientos secos y limpios (SL) y sanos secos y limpios (SSL). En general se obtuvieron incrementos importantes por calidad de granos, habiéndose logrado premios de 5,1 y $3 \%$ para INIA Tacuarí y Parao respectivamente.

En el cuadro 51 se presentan los resultados de los análisis estadísticos por contrastes ortogonales entre factores y sub-factores.

En relación con variedades, en este suelo de menor fertilidad, no se distinguen cuando fueron manejadas con la tecnología del productor (tratamientos 1 vs 2), pero resulta clara la diferencia $(863 \mathrm{~kg} / \mathrm{ha}$; $p=0,03$ ) a favor de Parao cuando son manejadas con todas las otras prácticas alternativas ( 7 vs 8 ). En la prueba conjunta, de contraste de las variedades sin tener en consideración el resto de las prácticas utilizadas (tratamientos $1-8$ vs 2-7), la diferencia de $493 \mathrm{~kg} / \mathrm{ha}$ de incremento promedio a 
Cuadro 50. Tratamientos aplicados y resultados en rendimiento de arroz sano, seco y limpio (SSL). India Muerta. 2015-2016*.

\begin{tabular}{|c|c|c|c|c|c|c|c|c|}
\hline \multirow{2}{*}{$\begin{array}{l}\text { Trt } \\
N^{\circ}\end{array}$} & \multirow[t]{2}{*}{ Cultiv ar } & \multicolumn{2}{|c|}{ Insalación cultivo } & \multirow{2}{*}{$\begin{array}{l}\text { Fertiliz. } 1 \\
\mathrm{~kg} \mathrm{ha}^{-1}\end{array}$} & \multirow{2}{*}{$\begin{array}{l}\text { Fert. } \\
\text { Plus }\end{array}$} & \multirow{2}{*}{$\begin{array}{l}\text { Prot ección de } \\
\text { enfermedades }\end{array}$} & \multicolumn{2}{|c|}{ Rendimiento } \\
\hline & & $\begin{array}{c}\text { Densidad } \\
\mathrm{kg} / \mathrm{ha}\end{array}$ & $\begin{array}{c}\text { Trt } \\
\text { semilla }\end{array}$ & & & & $\begin{array}{l}\mathrm{SSL} \\
\mathrm{t} / \mathrm{ha}\end{array}$ & $\begin{array}{l}\text { MDS } \\
0,05\end{array}$ \\
\hline 1 & $\begin{array}{l}\text { INIA } \\
\text { Tacuarí }\end{array}$ & 170 & Teb+thiom & TT & - & $\begin{array}{l}\text { tebuconazolt } \\
\text { trifloxistrabin }\end{array}$ & 12,208 & def \\
\hline 2 & Parao & 170 & Teb+thiom & TT & - & $\begin{array}{l}\text { tebuconozolt } \\
\text { trifloxistrobin }\end{array}$ & 12,331 & cde \\
\hline 3 & $\begin{array}{l}\text { INIA } \\
\text { Tacuarí }\end{array}$ & 109 & $\begin{array}{l}\text { Teb+thiom } \\
\text { +Syn+Endo }\end{array}$ & TT & - & $\begin{array}{l}\text { tebuonnazolt+ } \\
\text { trifloxistrabin }\end{array}$ & 11,549 & $f$ \\
\hline 4 & $\begin{array}{l}\text { INIA } \\
\text { Tacuarí }\end{array}$ & 170 & Teb+thiom & alternativa & - & $\begin{array}{l}\text { tebuconazolt } \\
\text { trifloxiotrabin }\end{array}$ & 11,668 & f \\
\hline 5 & $\begin{array}{l}\text { INIA } \\
\text { Tacuarí }\end{array}$ & 170 & Teb+thiom & TT & $\begin{array}{l}\text { S+Sit } \\
\text { Micro }\end{array}$ & $\begin{array}{l}\text { tebuonozol+ } \\
\text { trifloxistrobin }\end{array}$ & 11,831 & f \\
\hline 6 & $\begin{array}{l}\text { INIA } \\
\text { Tacuarí }\end{array}$ & 170 & Teb+thiom & TT & - & $\begin{array}{c}\text { S+Fosito K+ } \\
(a r o x i s+\text { keso +cip) }\end{array}$ & 11,627 & gf \\
\hline 7 & Parao & 139 & $\begin{array}{l}\text { Teb+thiom } \\
\text { +Syn+Endo }\end{array}$ & altem diva & $\begin{array}{l}\text { S+Sit } \\
\text { Micro }\end{array}$ & $\begin{array}{c}\text { Si+ Fosito K + } \\
(\text { ozoxis }+k r e o+c i p)\end{array}$ & 13,092 & $a b c$ \\
\hline 8 & $\begin{array}{l}\text { INIA } \\
\text { Tacuarí }\end{array}$ & 100 & $\begin{array}{l}\text { Teb+thiom } \\
+ \text { Syn+Endo }\end{array}$ & altem diva & $\begin{array}{l}\text { S+Sit } \\
\text { Micro }\end{array}$ & $\begin{array}{c}\text { Si+ FosfitoK+ } \\
\text { (ozoxis+kreso+cip) }\end{array}$ & 12,229 & $d \theta$ \\
\hline 9 & Parao & 170 & Teb+thiom & attem diva & $\begin{array}{l}\text { S+Sit } \\
\text { Micro }\end{array}$ & $\begin{array}{l}\text { Si+ FositoK+ } \\
(\text { ozoxis+kreso+cip) }\end{array}$ & 13,272 & $a b$ \\
\hline 10 & Parao & 139 & $\begin{array}{l}\text { Teb+thiom } \\
\text { +Syn+Endo }\end{array}$ & TT & $\begin{array}{l}\text { StSit } \\
\text { Micro }\end{array}$ & $\begin{array}{c}\text { Si+ Fosito }+ \\
(\text { ozoxis }+k r e o+c i p)\end{array}$ & 12,800 & bed \\
\hline 11 & Parao & 139 & $\begin{array}{l}\text { Teb+thiom } \\
+ \text { +Syn+Endo }\end{array}$ & altem diva & - & $\begin{array}{c}\text { Si+ FositoK+ } \\
\text { (aroxis+ breso+cip) }\end{array}$ & 13,616 & a \\
\hline 12 & Parao & 139 & $\begin{array}{l}\text { Teb+thiom } \\
\text { +Syn+Endo }\end{array}$ & attem diva & $\begin{array}{l}\text { StSit } \\
\text { Micro }\end{array}$ & $\begin{array}{l}\text { tebuconazolt+ } \\
\text { trifloxiotrobin }\end{array}$ & 13,030 & $a b c$ \\
\hline
\end{tabular}

- Ieb+thıam = tebuconazol + thıametoxan; 1 eb+thıam + syn+tndo= tebuconazol+ thımetoxan+ synergize+ Endorice; Fertiliz. 1 *: TT= 19,8 kg/ha N, 50,6 kg/ha $\mathrm{P}_{2} \mathrm{O}_{5}$ en la siembra, $60 \mathrm{~kg} / \mathrm{ha}$ de urea común al macollaje y $50 \mathrm{~kg} / \mathrm{ha}$ de urea común a la iniciación panicular; alternativa $=40 \mathrm{~kg} / \mathrm{ha} \mathrm{P}_{2} \mathrm{O}_{5}, 43 \mathrm{~kg} / \mathrm{ha} \mathrm{K}_{2} \mathrm{O}$ en la siembra, $137 \mathrm{~kg} / \mathrm{ha}$ de Verde urea al macollaje y $100 \mathrm{~kg} / \mathrm{ha}$ de urea común a la iniciación panicular; $\mathrm{S}+\mathrm{Si}+$ Micro= azufre +silicio + micronutrientes; Si+ Fosfito K + (azoxis+kreso+cip $)=$ silicio + fosfito de potasio + azoxistrobin+kresoxim metil+ ciproconazol; MDS= mínima diferencia significativa al $5 \%$ de probabilidad -números seguidos por la(s) misma(s) letras no difieren significativamente.

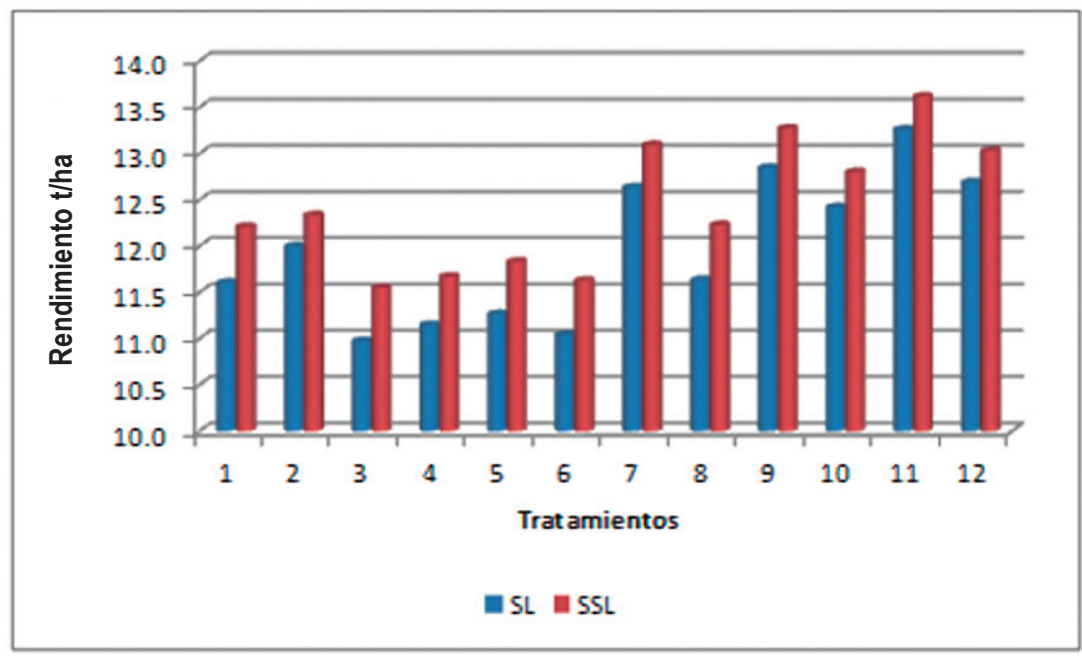

Figura 24. Rendimientos secos y limpios (SL) y sanos, secos y limpios (SSL) obtenidos en India Muerta, zafra 2015-2016. 
Cuadro 51. Contrastes ortogonales de factores y/o sub-factores. India Muerta. 2015$2016^{*}$

\begin{tabular}{|c|c|c|c|c|c|}
\hline $\begin{array}{c}\text { Factor / } \\
\text { sub-factor }\end{array}$ & $\begin{array}{l}\text { Contraste } \\
\text { tratamientos }\end{array}$ & \multicolumn{2}{|c|}{$\begin{array}{l}\text { Rendimientos SSL } \\
\text { t/ha }\end{array}$} & $\begin{array}{c}\text { Diferencia } \\
\text { tha }\end{array}$ & $\begin{array}{c}\text { Probabilidad } \\
\text { estadística }\end{array}$ \\
\hline \multirow[t]{3}{*}{ Cultivar } & $1 \vee s 2$ & 12,208 & 12,331 & $-0,123$ & ns \\
\hline & $7 v 88$ & 13,092 & 12,229 & 0,863 & 0,03 \\
\hline & $(1,8) \cup s(2,7)$ & 12,219 & 12,712 & $-0,493$ & 0,07 \\
\hline \multirow[t]{3}{*}{ Instalación } & $1 \vee s 3$ & 12,208 & 11,549 & 0,659 & 0,09 \\
\hline & $7 \vee 59$ & 13,092 & 13,272 & $-0,180$ & ns \\
\hline & $(1,9)$ \s $(3,7)$ & 12,740 & 12,321 & 0,419 & 0,12 \\
\hline \multirow[t]{3}{*}{ Fertilización 1} & $1 \mathrm{vs} 4$ & 12,208 & 11,668 & 0,540 & 0,16 \\
\hline & $7 \vee s 10$ & 13,092 & 12,800 & 0,292 & ns \\
\hline & $(1,10)$ vs $(4,7)$ & 12,504 & 12,380 & 0,124 & ns \\
\hline Fertilización & 1 vs 5 & 12,208 & 11,831 & 0,377 & ns \\
\hline \multirow[t]{2}{*}{ Plus } & $7 \vee s 11$ & 13,092 & 13,616 & $-0,524$ & 0,17 \\
\hline & $(1,11)$ vs $(5,7)$ & 12,912 & 12,462 & 0,450 & 0,10 \\
\hline Protección & $1 \sqrt{16} 6$ & 12,208 & 11,627 & 0,581 & 0,13 \\
\hline \multirow[t]{2}{*}{ Enfemedades } & 7 s 12 & 13,092 & 13,030 & 0,062 & ns \\
\hline & $(1,12) \vee s 6,7)$ & 12,619 & 12,360 & 0,259 & ns \\
\hline
\end{tabular}

* SSL= arroz sano, seco y limpio; ns= no significativa

favor de Parao, presenta una probabilidad de error de $p=0,07$.

En el factor «instalación del cultivo» se detecta una tendencia de superioridad de la tecnología TT $(p=0,09)$ con una diferencia de $659 \mathrm{~kg} / \mathrm{ha}$ cuando se usan a la vez todas las otras prácticas del manejo del productor (1 vs 3.). Cuando se utilizan las otras medidas de manejo propuestas, las diferencias desaparecieron (7 vs 9 ) y no surge un valor importante en la prueba conjunta, con una probabilidad de error mayor $(419 \mathrm{~kg} / \mathrm{ha}$; $p=0,12$ ).

En la comparación de estrategias de fertilización (TT= 19,8 kg/ha N, 50,6 kg/ha $\mathrm{P}_{2} \mathrm{O}_{5}$ en la siembra, $60 \mathrm{~kg} / \mathrm{ha}$ de urea común al macollaje y $50 \mathrm{~kg} / \mathrm{ha}$ de urea común a la iniciación panicular; alternativa $=40 \mathrm{~kg} / \mathrm{ha}$ $\mathrm{P}_{2} \mathrm{O}_{5}, 43 \mathrm{~kg} / \mathrm{ha} \mathrm{K} \mathrm{O}_{2}$ en la siembra, $137 \mathrm{~kg} / \mathrm{ha}$ de Verde urea al macollaje y $100 \mathrm{~kg} / \mathrm{ha}$ de urea común a la iniciación panicular), no se encontraron diferencias en ninguno de los 3 contrastes realizados. La merma de 540 $\mathrm{kg} / \mathrm{ha}$ del rendimiento de INIA Tacuarí al ser fertilizado con mayores cantidades, acompañado con todas las otras prácticas del productor, no fue estadísticamente significativa ( 1 vs $4 ; p=0,16)$. En la prueba conjunta las diferencias se diluyeron (124 kg/ha) por efectos contrarios en las pruebas individuales (1-10 vs 4-7).

Tanto la merma que produjo la «Fertilización Plus» a la tecnología TT del productor (1 vs $5 ; 377 \mathrm{~kg} / \mathrm{ha}$ ), así como el incremento producido por su retiro de las prácticas alternativas propuestas ( 7 vs $11 ; 524$ $\mathrm{kg} / \mathrm{ha}$ ), no resultaron estadísticamente significativos. Sin embargo, en la prueba conjunta de evaluación de los efectos del subfactor, sin tener en consideración las otras prácticas de manejo acompañantes, sugiere la no inclusión del mismo en la tecnología a adoptar $(p=0,10)$.

En «Protección de enfermedades», recordando que aquí se realizó una sola aplicación de fungicida en la tecnología TT, no se encuentran diferencias relevantes. 
- Propuestas tecnológicas alternativas para superar los rendimientos de los productores del quintil superior - Selección de alternativas para validación

\subsubsection{Análisis conjuntos por localidad}

\subsubsection{Rincón de Ramírez}

Se realizó un análisis de varianza conjunto de los resultados obtenidos en rendimientos (SSL) en las zafras 2014-2015 y
2015-2016, cuyos resultados son presentados en el cuadro 52.

Con un promedio de $13,463 \mathrm{t} / \mathrm{ha}$ se encontró una probabilidad de $p=0,11$ de encontrar diferencias debidas a los tratamientos y no se detectaron diferencias significativas debidas al factor año. Sin embargo, se

Cuadro 52. Rincón de Ramírez. Resultados del análisis conjunto de rendimientos SSL, zafras 2014-2015 y 2015-2016*

\begin{tabular}{|c|c|c|c|c|c|c|}
\hline Trt & Tratamiento / Fador & & Zafra: & & Análisis & $\%$ \\
\hline No. & & $\begin{array}{c}2014-15 \\
\text { tiha }\end{array}$ & $\begin{array}{l}\text { MDS } \\
0.05\end{array}$ & $\begin{array}{c}2015-16 \\
\text { tiha }\end{array}$ & $\begin{array}{c}2 \text { zafras } \\
\text { tiha }\end{array}$ & trt 1 \\
\hline 1 & Testigo Tecnológico (TT) & 12,803 & c & 138866 & 13,344 & 100,0 \\
\hline 2 & Cultiv ar alternativo & 13,269 & $b c$ & 13541 & 13,405 & 100,5 \\
\hline 3 & Instal ación alte rnativa & 12,773 & c & 13652 & 13,212 & 99,0 \\
\hline 4 & Fertilización alternativa & 13,151 & bc & 13,444 & 13,297 & 99,6 \\
\hline 5 & +Fertilizadón Fus & 13,037 & bc & 13876 & 13,457 & 100,8 \\
\hline 6 & Prot. Enfemedades. 1 aplic & 12,699 & c & 13610 & 13,155 & 98,6 \\
\hline 7 & Propue sas alternativas & 13,901 & b & 13,502 & 13,701 & 102,7 \\
\hline 8 & Cultiv ar testigo & 12,931 & $\mathrm{bc}$ & 13,405 & 13,168 & 98,7 \\
\hline 9 & Instal ación stand ard TT & 14,899 & a & 13,135 & 14,014 & 105,0 \\
\hline 10 & Fertilización standard TT & 13,030 & b & 138,818 & 13,424 & 100,6 \\
\hline 11 & Sin fertilización Plus & 13,598 & $\mathrm{bc}$ & 13517 & 13,668 & 101,6 \\
\hline 12 & Prot. Enfemedades 2 aplic. & 14,448 & $\mathrm{bc}$ & 13,196 & 13,822 & 103,6 \\
\hline prom & & 13,378 & & 13,549 & 13,463 & \\
\hline C. $\vee \%$ & & 4,4 & & 3,1 & 38 & \\
\hline$p(t r t)$ & & 0,001 & & ns & 0,11 & \\
\hline$p$ (año) & & & & & ns & \\
\hline$p$ (axtrt) & & & & & 0,000 & \\
\hline
\end{tabular}

*Trt= tratamientos; MDS 0,05=mínima diferencia significativa al $5 \%$ de probabilidad - números seguidos por la(s) misma(s) letras no difieren significativamente; prom= promedio; C.V.= coeficiente de variación; $\operatorname{pr}($ trt $)=$ probabilidad estadística de efecto de tratamientos; $p(a n ̃ o)=$ probabilidad de efecto año; $p(\operatorname{axtrt})=$ probabilidad defecto de la interacción año $x$ tratamientos.
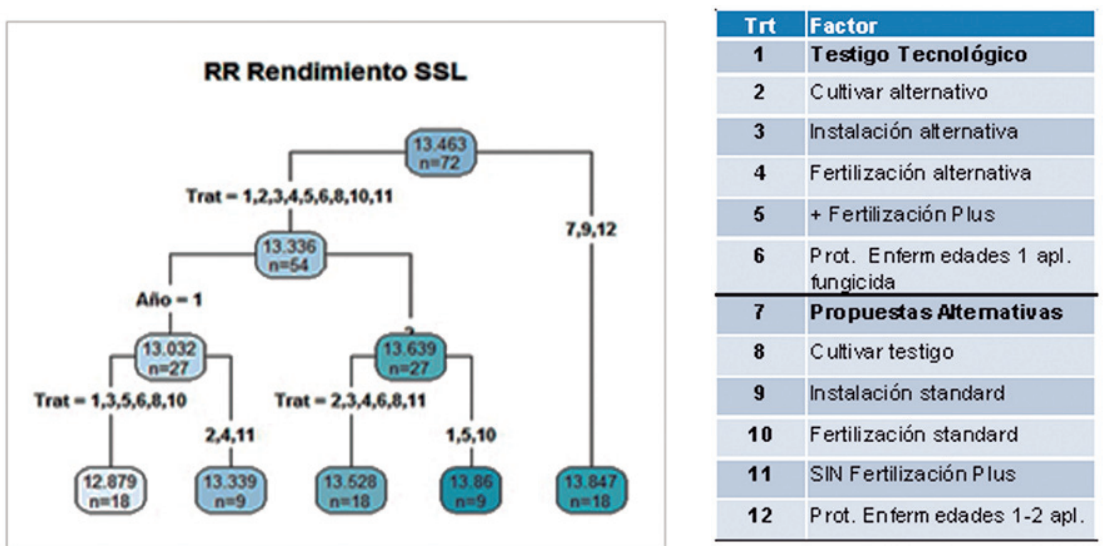

Figura 25. Análisis estadístico de rendimientos SSL Rincón de Ramírez, zafras 2014-2015 2015- 2016, según el método del «árbol». 
observó una interacción estadísticamente muy significativa de tratamientos con los años $(p=0,000)$.

En el cuadro 52 se observan los resultados en cada zafra con su separación de medias (si corresponde), los promedios del análisis conjunto y los porcentajes de cada tratamiento en relación con el logrado en el tratamiento 1, correspondiente al testigo tecnológico. Se destacaron los tratamientos 9,12 y 7 , con incrementos de $5,3,6$ y $2,7 \%$ respectivamente sobre el testigo; esos mismos 3 tratamientos fueron los que ofrecieron la mayor productividad en 2014-2015.

Utilizando otro tipo de análisis, que confirma lo anterior, la figura 25 muestra los resultados del método del árbol de decisiones, donde el primer factor de separación fueron los tratamientos y en segundo lugar de importancia el año. La primera división destaca precisamente a los tratamientos 79-12 del resto, con un promedio de 13,847 t/ha.

\subsubsection{2 $7^{a}$ Sección de Treinta y Tres - Costas de San Francisco}

En el cuadro 53 se presentan los resultados en la $7^{\text {a }}$ Sección de Treinta y Tres en la zafra 2014-2015 y en la Costa de San Francisco en 2015-2016. Como se recordará en el primer experimento debido a problemas surgidos en la ejecución, se eliminaron 2 tratamientos e incluso alguno de los restantes fueron ejecutado en forma parcial. Por ese motivo, no se corrió un análisis de varianza conjunto, pero se presentan los análisis individuales de cada uno de ellos y los promedios correspondientes a las 2 zafras. También se presenta el análisis por el método del árbol de regresión.

Los tratamientos $9,7,11$ y 4 fueron los de rendimiento promedio más altos en el conjunto de los 2 años, con incrementos de $5,6-4,9-4,6$ y $3,9 \%$ respectivamente sobre el rendimiento del $\mathrm{N}^{\circ} 1$, sin considerar los $N^{\circ} 6$ y 12 que fueron eliminados en la primera zafra.

Cuadro 53. $7^{\text {a }}$ S. de Treinta y Tres - C. de San Francisco. Resultados del análisis de rendimientos SSL, zafras $2014-2015$ y $2015-2016^{*}$.

\begin{tabular}{|c|c|c|c|c|c|c|}
\hline \multirow{2}{*}{$\begin{array}{l}\text { Trt } \\
\text { No. }\end{array}$} & \multirow[t]{2}{*}{ Tratamiento / Fador } & \multicolumn{3}{|c|}{ Zafras } & Análisis 2 & $\%$ \\
\hline & & $\begin{array}{c}2014-15 \\
\text { tiha }\end{array}$ & $\begin{array}{l}\text { MDS } \\
0,05\end{array}$ & $\begin{array}{c}2015-16 \\
\text { tiha }\end{array}$ & $\begin{array}{c}\text { zafras } \\
\text { thiha }\end{array}$ & trt 1 \\
\hline 1 & Teșigo Te cnológico (TT) & 11,491 & bcd & 12,336 & 11,914 & 100,0 \\
\hline 2 & Cultiv ar alternativo & 11,160 & d & 12,856 & 12,008 & 111.8 \\
\hline 3 & Instal ación alte rnativa & 10981 & d & 12,175 & 11,578 & 97,9 \\
\hline 4 & Fertilización alternativa & 11,468 & bcd & 13,285 & 12,377 & 103,9 \\
\hline 5 & +Fertilizadión Flus & 10930 & d & 12,385 & 11,658 & 97,9 \\
\hline 6 & Prot. Enfemedades 1 apl & - & - & 12,565 & - & - \\
\hline 7 & Propuesas alternativas & 12,075 & $a b c$ & 12,930 & 12,503 & 104,9 \\
\hline 8 & Cultiv ar testigo & 10966 & d & 12,398 & 11,682 & 98,1 \\
\hline 9 & Instal ación standard TT & 12205 & a & 12,957 & 12,581 & 105,6 \\
\hline 10 & Fertilización standard TT & 11,330 & cd & 12,346 & 11,838 & 99,4 \\
\hline 11 & Sin fertilización Plus & 11939 & $a b c$ & 12,993 & 12,466 & 104,6 \\
\hline 12 & Prot. Enfemedades 2 apl & - & - & 13,205 & - & - \\
\hline $\begin{array}{l}\text { prom } \\
C . \vee \% \\
\text { pitrti) }\end{array}$ & & $\begin{array}{c}11,454 \\
3,3 \\
0 \times 2\end{array}$ & & $\begin{array}{c}12,703 \\
4,4\end{array}$ & 12,070 & \\
\hline P(II) & & 0,002 & & ns & & \\
\hline
\end{tabular}

*Trt= tratamientos; MDS 0,05=mínima diferencia significativa al $5 \%$ de probabilidad - números seguidos por la(s) misma(s) letras no difieren significativamente; Prot. Enfermedades 1 apl. = protección enfermedades 1 aplicación; prom= promedio; C.V.= coeficiente de variación; pr(trt)= probabilidad estadística de efecto de tratamientos. 


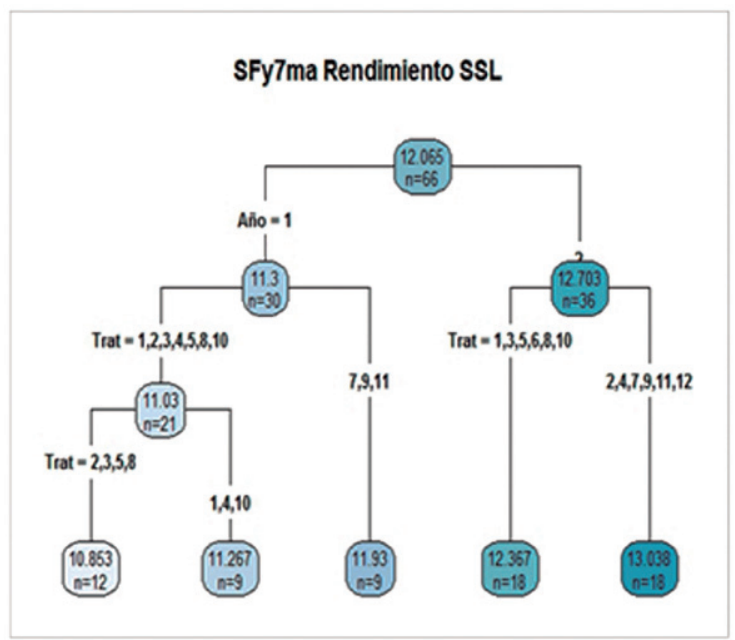

\begin{tabular}{|c|l|}
\hline Trt & Factor \\
\hline $\mathbf{1}$ & Testigo Tecnológico \\
\hline $\mathbf{2}$ & Cultivar alternativo \\
\hline $\mathbf{4}$ & Instalación altemativa \\
\hline $\mathbf{5}$ & Fertilización alternativa \\
\hline $\mathbf{6}$ & Prot. Entilización Plus \\
\hline $\mathbf{7}$ & Propuestas edades 1 apl. \\
\hline $\mathbf{8}$ & Cultivar testigo \\
\hline $\mathbf{9}$ & Instalación standard \\
\hline 10 & Fertilización standard \\
\hline 11 & SiN Fertilización Plus \\
\hline 12 & Prot. En ferm edades 1-2 apl. \\
\hline
\end{tabular}

Figura 26. Análisis estadístico de rendimientos SSL $7^{\text {a }} \mathrm{S}$. de Treinta y Tres $-\mathrm{C}$. de San Francisco, zafras 2014-2015 2015- 2016, según el método del «árbol».

Según el método del árbol, en estas localidades la primera ramificación se produjo debido al año, destacándose los rendimientos del 2015-2016. A su vez, en esta zafra los más productivos resultan los $\mathrm{N}^{\circ} 2$, $4,7,9,11$ y 12 ; excepto el $N^{\circ} 4$ donde se sembró el cultivar testigo (El Paso 144), 5 de los 6 tratamientos más productivos co- rresponden a la variedad INIA Merín (Figura 26).

\subsubsection{Cebollatí}

Se presentan los resultados obtenidos en las 2 zafras y también el resultante del análisis conjunto de los 2 años (Cuadro 54). Se detectaron diferencias significativas debidas

Cuadro 54. Cebollatí. Resultados del análisis conjunto de rendimientos SSL, zafras 20142015 y $2015-2016^{*}$

\begin{tabular}{|c|c|c|c|c|c|c|c|}
\hline Trt & Tratamiento / Factor & & Zafras & & & Análisis & $\%$ \\
\hline No. & & $\begin{array}{c}2014-15 \\
\text { tha }\end{array}$ & $\begin{array}{l}M D S \\
0,05\end{array}$ & $\begin{array}{c}2015-16 \\
\text { tiha }\end{array}$ & $\begin{array}{l}\text { MDS } \\
0,05 \\
\end{array}$ & $\begin{array}{c}2 \text { zafras } \\
\text { tha }\end{array}$ & trt 1 \\
\hline 1 & Testigo Tecnológico (TT) & 9,397 & cd & 12,092 & $a b c$ & 10,744 & 100,0 \\
\hline 2 & Cultivar alt ernativo & 9,102 & d & 12,020 & $a b c$ & 10,561 & 98,3 \\
\hline$\overline{3}$ & Instalación alternativa & 10,200 & $a b c$ & 11,826 & bed & 11,013 & 102,5 \\
\hline 4 & Fertilización alt ernativa & 10,057 & $a b c$ & 11,556 & cd & 10,806 & 100,5 \\
\hline 5 & +Fertilización Plus & 9,825 & $\mathrm{bcd}$ & 11,889 & $\mathrm{bc}$ & 10,857 & 101,1 \\
\hline 6 & Pr. Enfermed.1 aplic. & 9,601 & bcd & 11,190 & $\mathrm{~cd}$ & 10,396 & 968 \\
\hline 7 & Propuestas alternativas & 10,043 & $a b c$ & 11939 & $\mathrm{bc}$ & 10,991 & 102,3 \\
\hline 8 & Cultiv ar te stigo & 10,817 & a & 10,879 & d & 10,848 & 101,0 \\
\hline 9 & Instalación standard TT & 10,409 & $a b$ & 11997 & bc & 11,203 & 104,3 \\
\hline 10 & Fertilización standard $\Pi$ & 9,569 & bcd & 11959 & bc & 10,759 & 100,1 \\
\hline 11 & Sin fertilizadón Plus & 10,037 & $a b c$ & 12,606 & $a b$ & 11,322 & 105,4 \\
\hline 12 & Prot. Enfermed. 1-2 aplic. & 10,311 & $a b$ & 12949 & a & 11,630 & 108,2 \\
\hline prom & & 9947 & & 11908 & & 10,927 & \\
\hline C. $\vee \%$ & & 5,3 & & 4,7 & & 50 & \\
\hline$p($ trt $)$ & & 0,04 & & 0,02 & & 0,03 & \\
\hline$p($ añ́o) & & & & & & 0,000 & \\
\hline$p$ (axtrt) & & & & & & 0,003 & \\
\hline
\end{tabular}

*Trt= tratamientos; MDS 0,05=mínima diferencia significativa al $5 \%$ de probabilidad - números seguidos por la(s) misma(s) letras no difieren significativamente; Pr. Enfermed.1 aplic. = protección enfermedades 1 aplicación; prom $=$ promedio; $C . V .=$ coeficiente de variación; $\operatorname{pr}($ trt $)=$ probabilidad estadística de efecto de tratamientos; $p(a n ̃ o)=$ probabilidad de efecto año; $p($ axtrt $)=$ probabilidad efecto de la interacción año $x$ tratamientos. 


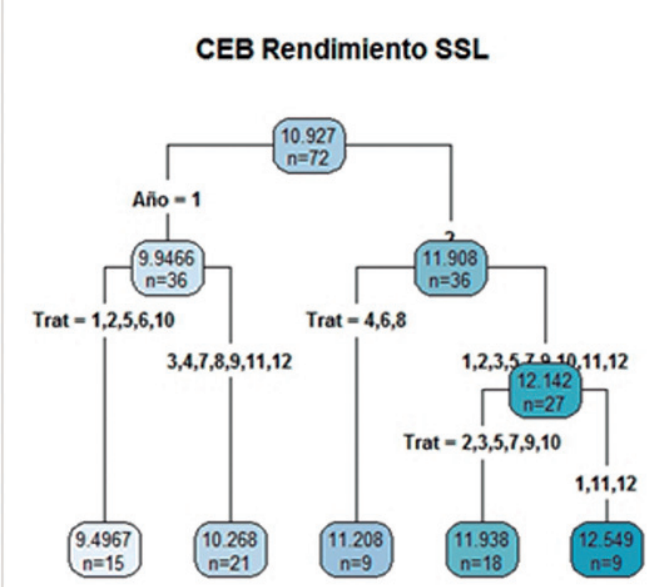

\begin{tabular}{|c|l|}
\hline Trt & Factor \\
\hline 1 & Testigo Tecnológico \\
\hline 2 & Cultivar alternativo \\
\hline 3 & Instalación alternativa \\
\hline 4 & Fertilización alternativa \\
\hline $\mathbf{5}$ & + Fertilización Plus \\
\hline $\mathbf{6}$ & $\begin{array}{l}\text { Prot. Enfermedades } 1 \text { apl. } \\
\text { fungicida }\end{array}$ \\
\hline $\mathbf{7}$ & Propuestas Alternativas \\
\hline $\mathbf{8}$ & Cultivar testigo \\
\hline $\mathbf{9}$ & Instalación standard \\
\hline 10 & Fertilización standard \\
\hline 11 & SIN Fertilización Plus \\
\hline 12 & Prot. Enfermedades 1 -2 apl. \\
\hline
\end{tabular}

Figura 27. Análisis estadístico de rendimientos. Cebollatí, zafras 2014-2015 20152016, según el método del «árbol»

a tratamientos $(p=0,03)$, a años $(p=0,000)$ y al igual que en Rincón de Ramírez, a la interacción de los tratamientos con los años $(p=0,003)$. Los tratamientos 12,11 y 9 se destacaron como los de mayor rendimiento promedio, con incrementos de 8,2 5,4 y $4,3 \%$ respectivamente.
En la figura 27 se presenta el resultado del análisis del árbol de regresión. Al igual que en el caso anterior ( $7^{\mathrm{a}} \mathrm{S}$. de Treinta y Tres - C. de San Francisco), la primera división se produjo por efecto de los años y en segunda instancia por los tratamientos. Dentro de este grupo final, los números 1,11 y 12 son los que conforman el promedio de $12,549 \mathrm{t} /$ ha superior de rendimiento.

Cuadro 55. India Muerta. Resultados del análisis conjunto de rendimientos SSL, zafras 2014-2015 y 2015-2016*

\begin{tabular}{|c|c|c|c|c|c|c|c|}
\hline Trt & Tratamiento / Factor & & Zafra & & & Análisis & $\%$ \\
\hline No. & & $\begin{array}{c}2014-15 \\
\text { tha }\end{array}$ & $\begin{array}{l}\text { MDS } \\
0,05\end{array}$ & $\begin{array}{c}2015-16 \\
\text { tiha }\end{array}$ & $\begin{array}{l}\text { MDS } \\
0,05\end{array}$ & $\begin{array}{c}2 \text { zafras } \\
\text { tha }\end{array}$ & trt 1 \\
\hline 1 & Testigo Tecnológico (TT) & 11561 & e & 12208 & def & 11,885 & 100,0 \\
\hline 2 & Cultivar alt ernativo & 12502 & a & 12,331 & cde & 12,417 & 104,5 \\
\hline 3 & Instalación alternativa & 11.859 & cde & 11549 & f & 11,704 & 985 \\
\hline 4 & Fertilización alt ernativa & 11,789 & de & 11668 & ef & 11,729 & 98,7 \\
\hline 5 & +Fertilización Plus & 11593 & de & 11831 & ef & 11,712 & 985 \\
\hline 6 & Pr. Enfermed. 1 aplic. & 11,777 & de & 11627 & ef & 11,702 & 985 \\
\hline 7 & Propuestas alternativas & 12016 & $\mathrm{bcd}$ & 13,092 & $a b c$ & 12,554 & 105,6 \\
\hline 8 & Cultiv ar te stigo & 11544 & e & 12229 & def & 11.887 & 1000 \\
\hline 9 & Insalación standard TT & 12636 & & 13272 & $a b$ & 12,954 & 109,0 \\
\hline 10 & Fertilización standard TT & 12,392 & $a b$ & 12,800 & bed & 12,596 & 106,0 \\
\hline 11 & Sin fertilizadón Plus & 12230 & $a b c$ & 13616 & a & 12,923 & 108,7 \\
\hline 12 & Prot. Enfermed. 1-2 aplic. & 12,329 & $a b$ & 13030 & $a b c$ & 12,680 & 106,7 \\
\hline prom & & $12 \square 19$ & & 12,438 & & 12,228 & \\
\hline C. $\vee \%$ & & 2,1 & & 37 & & 30 & \\
\hline$p(t r t)$ & & 0,000 & & 0,000 & & 0,000 & \\
\hline$p$ (año) & & & & & & 0,06 & \\
\hline$p$ (axtrt) & & & & & & 0,003 & \\
\hline
\end{tabular}

*Trt= tratamientos; MDS 0,05=mínima diferencia significativa al $5 \%$ de probabilidad - números seguidos por la(s) misma(s) letras no difieren significativamente; Prot. Enfermedades 1 apl. = protección enfermedades 1 aplicación; prom= promedio; $\mathrm{C} . \mathrm{V} .=$ coeficiente de variación; $\operatorname{pr}(\mathrm{trt})=$ probabilidad estadística de efecto de tratamientos; $\mathrm{p}(\mathrm{año})=$ probabilidad de efecto año; $p($ axtrt $)=$ probabilidad efecto de la interacción año $x$ tratamientos. 


\subsubsection{India Muerta}

En el cuadro 55 se presentan los resultados del análisis conjunto de los rendimientos obtenidos en los 2 años de ensayos instalados en la zona de India Muerta. Para su comparación también se incluyen los resultados obtenidos en cada una de las zafras en particular.

Esta es la única localidad, en donde los promedios de 2 años obtenidos con los tratamientos 2-7-9-10-11-12 sembrados con el cultivar alternativo (Parao en esta situación) superan el logrado con el testigo tecnológico. En particular los $\mathrm{N}^{\circ} 9,11,12,10$, presentan la productividad mayor con $9,8,7$, 6,7 y $6 \%$ de incremento sobre el $\mathrm{N}^{0} 1$.

En la figura 28 se observan los resultados del análisis del árbol de regresión, que también presenta diferencias con los anteriores. En la primera división fueron agrupados hacia la izquierda todos los tratamientos sembrados con INIA Tacuarí y a la derecha los sembrados con Parao, sin conside- rar las alternativas de manejo utilizadas. En segunda instancia, los segundos aparecen agrupados por los promedios obtenidos por los mismos, según la zafra considerada.

\subsubsection{Selección de tratamientos para validación}

Luego de analizar los resultados presentados en la Sección 2.3.1, el comité técnico seleccionó una propuesta por localidad, para validar su performance en áreas comerciales en chacras de productores, manejadas por ellos mismos.

En el cuadro 56 se presentan los tratamientos seleccionados junto al testigo tecnológico para su validación en parcelas apareadas de 4-5 hectáreas cada una en 6 localidades, 3 en el Departamento de Treinta y Tres (Rincón de Ramírez, Costas de San Francisco y $7^{\text {a }}$ Sección) y en 3 el Departamentos de Rocha (Cebollatí, India Muerta y Vuelta Grande).
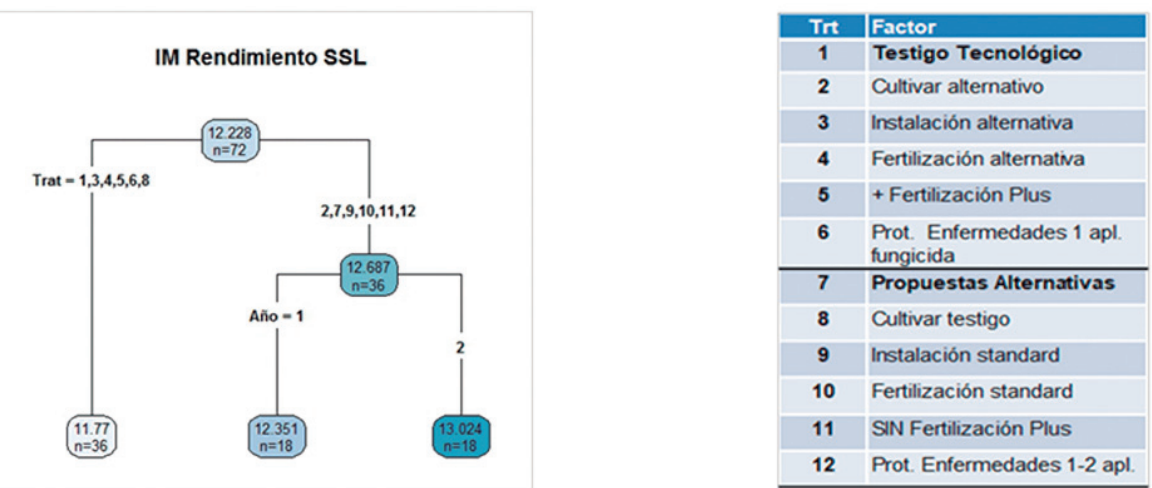

Figura 28. Análisis estadístico de rendimientos. India Muerta, zafras 2014-2015 y 2015- 2016, según el método del «árbol».

Cuadro 56. Tratamientos seleccionados para la etapa de validación.

\begin{tabular}{|c|c|c|}
\hline Localidad & $\begin{array}{l}\text { Tratamiento } \\
\text { seleccionado }\end{array}$ & Características \\
\hline Rincón de Ramírez & No9 & $\begin{array}{c}\text { En general propuestas alte rnativas, excepto el } \\
\text { factor "Instalación del cultiv o" }\end{array}$ \\
\hline C. de San Francisco & Nog & $\begin{array}{c}\text { En general propuestas alternativas, excepto el } \\
\text { factor "In s alación del cultiv o" }\end{array}$ \\
\hline $7^{a} \mathrm{~S}$ de Treinta y Tres & $N \circ 9$ & $\begin{array}{c}\text { En general propuestas alternativas, excepto el } \\
\text { factor" In staladión del cultiv o" }\end{array}$ \\
\hline Cebollatí & No 12 & $\begin{array}{l}\text { En general propuestas alte rnativas, excep to el } \\
\text { factor "Protección de enfermedades" }\end{array}$ \\
\hline India Muerta & $N \circ 9$ & $\begin{array}{c}\text { En general propuestas alternativas, excepto el } \\
\text { factor "Instalación del cultiv o" }\end{array}$ \\
\hline Vuelta Grande & Nog & $\begin{array}{c}\text { En general propuestas alternativas, excepto el } \\
\text { factor "Instalación del cultw o" }\end{array}$ \\
\hline
\end{tabular}




\subsection{Propuestas tecnológicas alternativas para superar los rendimientos de los productores del quintil superior - Validaciones}

Para los trabajos de validación, en setiembre de 2016 se seleccionaron 6 sitios con superficies de 8-10 ha divididas al medio según 2 manejos contrastantes. En general las operativas fueron realizadas por los productores con su maquinaria, con la supervisión de los técnicos del proyecto.

De acuerdo con los análisis de suelos de los sitios (Cuadro 7, Materiales y Métodos), se decidieron las dosis de fertilizante a aplicar en el factor 3 de los tratamientos $\mathrm{N}^{\circ} 9$ en Rincón de Ramírez, Costas de San Fran- cisco, $7^{\text {a }}$ Sección de Treinta y Tres, India Muerta, Vuelta Grande y No 12 en Cebollatí.

En el cuadro 8 de Materiales y Métodos se presentan los detalles de cada uno de los manejos conducidos en las distintas localidades. Algunas modificaciones surgidas en las ejecuciones sobre las bases previstas inicialmente (factores 3 y 4 ), son comentadas en la presentación de resultados particular de cada sitio.

\subsubsection{Rincón de Ramírez}

El cultivo fue sembrado el 27 de setiembre en forma directa sobre taipas, en un suelo que había sido cultivado arroz en la zafra 2014-2015 y en el que se había aplicado glifosato sobre el tapiz existente. Dadas las condiciones ambientales del período

Cuadro 57. Resumen de prácticas de manejo según tratamientos y resultados obtenidos en la validación. Rincón de Ramírez, zafra 2016-2017*.

\begin{tabular}{|c|c|c|c|}
\hline $\begin{array}{l}\text { Descripción } \\
\text { Fecha de siembra }\end{array}$ & $\begin{array}{l}\text { Fecha } \\
27 \text { set }\end{array}$ & Trat amiento 1 & Tratamient o 9 \\
\hline Variedad & \multirow{11}{*}{$\begin{array}{c}1 \text { oct } \\
14 \text { now } \\
20 \text { now } \\
24 \text { dic } \\
27 \text { ene } \\
28 \text { ene } \\
17 \text { mar }\end{array}$} & \multirow{2}{*}{\multicolumn{2}{|c|}{$\begin{array}{c}\text { El Paso } 144 \quad \text { CH Quebracho } \\
\text { tebuconazol + thiametoxan }\end{array}$}} \\
\hline Tratamiento de semillas & & & \\
\hline Densidad de siembra $\mathrm{kg} / \mathrm{ha}$ & & \multirow{2}{*}{$\begin{array}{l}130 \\
\text { N13 P55 K25 }\end{array}$} & \multirow{4}{*}{$\begin{array}{c}130 \\
\text { N10 P60 K137 S7 } 5 \\
\text { N104 } \\
\text { si }\end{array}$} \\
\hline Fertilización basal $\mathrm{kg} / \mathrm{ha}$ & & & \\
\hline Aplicación $1^{\mathrm{a}}$ oo bertura $\mathrm{N}$ kgha & & N32 & \\
\hline Aplicación F oliares (micros silice) & & - & \\
\hline Aplicación $2^{\mathrm{a}}$ oobertura $\mathrm{N}$ kgha & & N24 K10 & \multirow{3}{*}{$\begin{array}{c}\text { N } 24 \mathrm{~K} 10 \\
\text { azox+difen thic } \\
\text { si }\end{array}$} \\
\hline Ap licación fun gicida & & azoxt difen tric & \\
\hline Aplicación Fosfito de potasio + Si & & - & \\
\hline $\begin{array}{l}\text { Cosecha } \\
\text { Acumulación térmica }\end{array}$ & & sí & sí \\
\hline Siembra-Cosecha $\left(G_{10}\right)$ & & 1.913 & 1.913 \\
\hline \multicolumn{4}{|l|}{ Registros } \\
\hline No plantas instaladas & \multirow{8}{*}{$10 \mathrm{now}$} & 226 & 182 \\
\hline $\begin{array}{l}\text { Producción MS en grano tha } \\
\text { DE }\end{array}$ & & $\begin{array}{c}11,916 \\
2,0\end{array}$ & $\begin{array}{l}12,886 \\
2,0\end{array}$ \\
\hline $\begin{array}{l}\text { Producción MS en paja tha } \\
\mathrm{DE}\end{array}$ & & $\begin{array}{c}8,856 \\
1,7\end{array}$ & $\begin{array}{l}8,749 \\
1,8\end{array}$ \\
\hline $\begin{array}{l}\text { Producoión MS total t/ha } \\
\mathrm{DE}\end{array}$ & & $\begin{array}{c}20,771 \\
3,7\end{array}$ & $\begin{array}{c}21,635 \\
3,6\end{array}$ \\
\hline $\begin{array}{l}\text { Indice de cosecha (IC) } \\
D E\end{array}$ & & $\begin{array}{l}0,57 \\
0,02\end{array}$ & $\begin{array}{l}0,60 \\
0,03\end{array}$ \\
\hline $\begin{array}{l}\text { PMG }(g) \\
D E\end{array}$ & & $\begin{array}{c}28,90 \\
0,44\end{array}$ & $\begin{array}{l}31,81 \\
0,70\end{array}$ \\
\hline Rendimiento SL tha & & 9,700 & 10,565 \\
\hline $\begin{array}{l}\text { Rendimiento SSL tha } \\
\text { Diferencia (trt. } 9 \text {-trt. 1) SSL t/ha }\end{array}$ & & 9908 & 10,576 \\
\hline
\end{tabular}

* $\mathrm{K}=\mathrm{K}_{2} \mathrm{O} ; \mathrm{P}=\mathrm{P}_{2} \mathrm{O}_{5} ; \mathrm{S}$ azufre; micros= micronutrientes; azox+ difen +tric= azoxistrobin+ difenoconazol+tricyclazol; Acumulación térmica $\left(\mathrm{GD}_{10}\right)$ grados día base 10, con registros de Paso de la Laguna; $\mathrm{MS}=$ materia seca; $\mathrm{DE}=$ desvío estándar; PMG= peso de granos, $\mathrm{SL}=$ seco y limpio; $\mathrm{SSL}=$ sano, seco y limpio. 
pos-siembra (humedad, temperatura), las plantas de arroz recién emergieron a fines de octubre, lográndose una implantación de 205 y 189 plantas de arroz $/ \mathrm{m}^{2}$ (tratamientos 1 y 9 respectivamente), según conteos realizados el 6 de diciembre.

Las primeras aplicaciones de nitrógeno en cobertura fueron realizadas el 14 de noviembre en forma terrestre. El 20 de enero se comenzó la floración de algunas plantas en la parcela de $\mathrm{CH}$ Quebracho (en forma aislada) y el 27 de enero se aplicaron los fungicidas en forma aérea.

Se cometieron errores en las 2 operativas mencionadas: 1) en el caso de $\mathrm{N}$ se aplicó una cantidad excesiva de urea, $21 \%$ superior a la deseada en el tratamiento $\mathrm{N}^{\circ}$ 9 (103,5 kg/ha de N); 2) en la protección de enfermedades, se aplicaron los mismos productos azoxistrobin + difenoconazol + tricyclazol; en las 2 parcelas. Un día después de aplicar los fungicidas, se hizo una cobertura aérea adicional agregando el fosfito de potasio y la segunda dosis de sílice en el tratamiento 9.

Se cosechó el 17 de marzo la totalidad del área, y la producción fue entregada a la industria, quien realizó las evaluaciones de cantidad y calidad pertinentes.

En el cuadro 57 se resumen las prácticas de manejo del cultivo realizadas en cada tratamiento y los rendimientos de granos seco y limpio (SL) y sano seco y limpio (SSL) obtenidos. El tratamiento $\mathrm{N}^{\circ} 9$ tuvo un rendimiento SSL $668 \mathrm{~kg} / \mathrm{ha}$ mayor al logrado con el $\mathrm{N}^{\circ} 1$, lo que representa un incremento del $6,7 \%$. Los muestreos de partes aéreas de plantas (paja y grano), realizado en 5 sitios diferentes de cada parcela el mismo día de la cosecha, muestran que se obtuvo casi la misma producción de grano, pero con mejor índice de cosecha (relación grano sobre materia seca total) en el tratamiento 9; $\mathrm{CH}$ Quebracho presentó un peso de grano 10,1\% mayor que EI Paso 144.
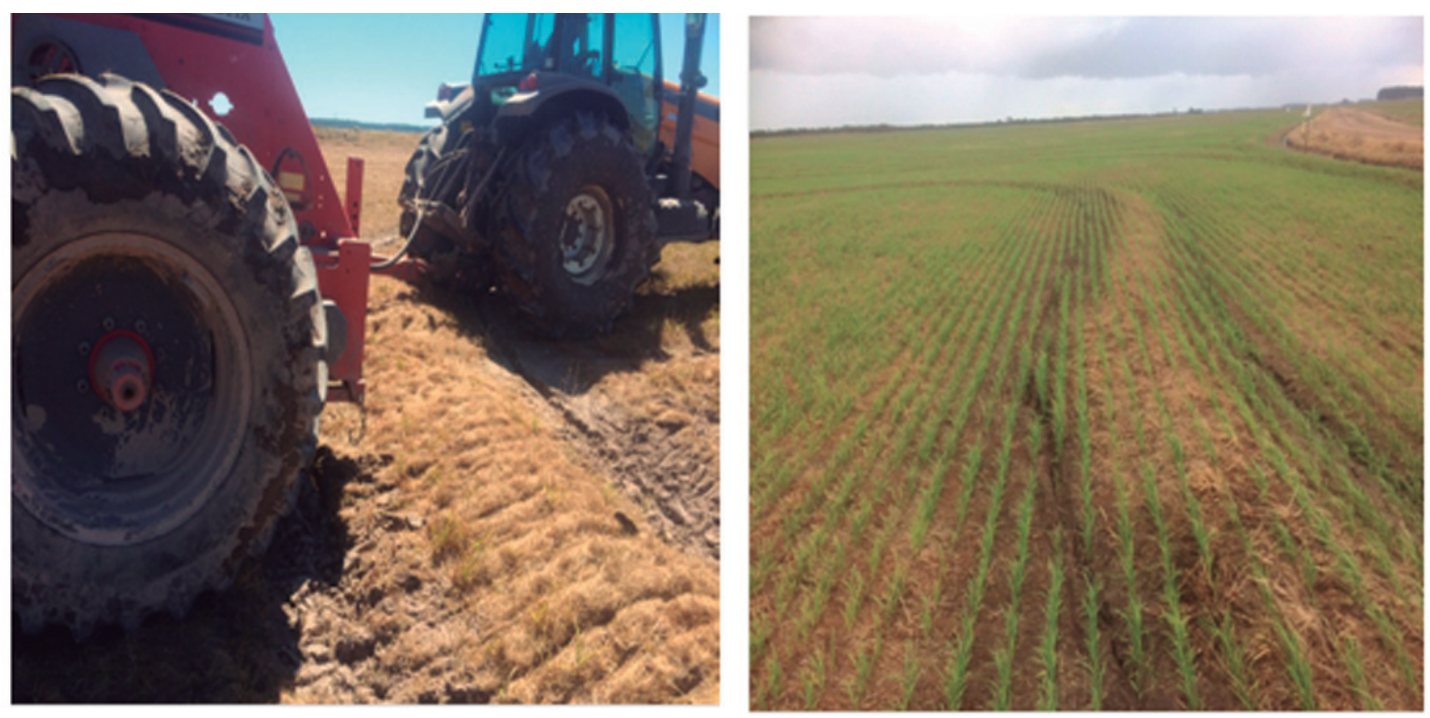

Validación en Rincón de Ramírez, zafra 2016-2017.

Foto 7. Siembra directa con cero laboreo sobre taipa.
Foto 8. Instalación del cultivo en taipa, préstamo y cuadro. 


\subsubsection{Costas de San Francisco}

Estas parcelas fueron sembradas el 14-15 de octubre sobre taipas construidas previamente, en un suelo que fue preparado en forma convencional sobre un retorno de 3 años sin siembra de pasturas. Entre el día de la siembra y posterior, se registraron $20 \mathrm{~mm}$ de precipitaciones. La fertilización basal se realizó el 14 de octubre, un día antes de la siembra.

La fertilidad del suelo del sitio donde se realizó la validación fue más pobre respecto al sitio experimental del año anterior relativamente cercano (Cuadros 5 y 7 , Materiales y Métodos). Destaca el pH algo mayor (5,8 vs 5,3 ), menor PMN (15 vs 23 ), $44 \%$ de contenido de $\mathrm{K}(0,14$ vs 0,32$), 18 \%$ de $\mathrm{Zn}(0,21$ vs
$1,17), 77 \%$ de $M g(1,53$ vs 2,0$)$ y $69 \%$ más de $\mathrm{Na}(0,49$ vs 0,29$)$. Los valores de capacidad de intercambio catiónico $(\mathrm{CIC})$ y de saturación en bases (SB), si bien menores no resultan tan diferentes ( $83 \%$ de CIC y $91 \% \mathrm{SB}$ ).

El 10 de noviembre se realizó una evaluación de la instalación del cultivo en 5 sitios al azar, registrándose promedios de 173 y 179 plantas de arroz $/ \mathrm{m}^{2}$ en los tratamientos 1 y 9 respectivamente.

Las primeras aplicaciones en cobertura de nitrógeno se realizaron el 21 de noviembre en forma terrestre, seguidas un día después por los tratamientos foliares (micronutrientes y sílice) y al día siguiente ingresó el riego. El 6 de febrero se hicieron los primeros

Cuadro 58. Resumen de prácticas de manejo según tratamientos y resultados obtenidos en la validación. Costas de San Francisco, zafra 2016-2017*.

\begin{tabular}{|c|c|c|c|}
\hline Descripción & Fecha & Tratamiento 1 & Tratamiento 9 \\
\hline $\begin{array}{l}\text { Fecha de siembra } \\
\text { Variedad }\end{array}$ & \multirow{11}{*}{$\begin{array}{c}14 \text { oct } \\
21 \text { now } \\
22 \text { now } \\
21 \text { dic } \\
4 \text { feb } \\
4 \text { feb } \\
22 \mathrm{feb} \\
7 \mathrm{abr}\end{array}$} & \multirow{10}{*}{$\begin{array}{c}\text { El Paso } 144 \\
\text { tebucon } \\
130 \\
\text { N9 P55 K28 } \\
N 35 \\
- \\
\text { N28 } \\
\text { teb+ trifioxist. } \\
- \\
\text { azox+difeno } \\
\text { si }\end{array}$} & \multirow{2}{*}{$\begin{array}{l}\text { INIA Merín } \\
\text { I + thiamet oxan }\end{array}$} \\
\hline Tratamiento de semillas & & & \\
\hline Densidad de sie mbra $\mathrm{kg} / \mathrm{ha}$ & & & 130 \\
\hline Fertilización basal kg/ha & & & N17 P95 K102 S119 \\
\hline Aplicación $1^{\mathrm{a}}$ o bertura $\mathrm{N}$ kgha & & & N76 \\
\hline Aplicación F oliares (micros sílice) & & & sí \\
\hline Aplicación $2^{a}$ obertura $\mathrm{N}$ kgha & & & N 28 \\
\hline $\begin{array}{l}1^{3} \text { Aplicación fungicida } \\
\text { Ap licación F osfito de potasio }+S i\end{array}$ & & & $\begin{array}{c}\text { azox+krestcipro } \\
\text { si }\end{array}$ \\
\hline $2^{3}$ Aplicación fungicida & & & azox + difeno \\
\hline $\begin{array}{l}\text { Cosecha } \\
\text { Acumulación térmica }\end{array}$ & & & si \\
\hline Siembra-Cosecha $\left(\mathrm{GD}_{10}\right)$ & & 2034 & 2034 \\
\hline \multicolumn{4}{|l|}{ Registros } \\
\hline$N^{\circ}$ plantas instaladas & \multirow[t]{11}{*}{10 now } & 173 & 179 \\
\hline $\begin{array}{l}\text { Producción MS en grano tha } \\
\text { DE }\end{array}$ & & $\begin{array}{c}11,155 \\
2,0\end{array}$ & $\begin{array}{c}12,820 \\
1,4\end{array}$ \\
\hline $\begin{array}{l}\text { Producción MS en paja tha } \\
\text { DE }\end{array}$ & & $\begin{array}{c}10,586 \\
2,2\end{array}$ & $\begin{array}{c}11,981 \\
1,4\end{array}$ \\
\hline $\begin{array}{l}\text { Producción MS total t/ha } \\
\text { DE }\end{array}$ & & $\begin{array}{c}21,741 \\
4,3\end{array}$ & $\begin{array}{l}24,804 \\
2,7\end{array}$ \\
\hline $\begin{array}{l}\text { Indice de Cosecha (IC) } \\
D E\end{array}$ & & $\begin{array}{l}0,51 \\
0,02\end{array}$ & $\begin{array}{l}0,52 \\
0,01\end{array}$ \\
\hline$N^{\circ}$ de granos llenos $/ \mathrm{m}^{2}$ & & 47.729 & 52.473 \\
\hline $\mathrm{DE}$ & & 10.217 & 7.110 \\
\hline $\begin{array}{l}\text { PMG (g) } \\
D E\end{array}$ & & $\begin{array}{l}28,45 \\
0,75\end{array}$ & $\begin{array}{l}28,35 \\
0,58\end{array}$ \\
\hline Rendimiento SL tha & & 9,461 & 11,979 \\
\hline Rendimiento SSL tha & & 9,507 & 12,234 \\
\hline Diferencia (trt. 9-trt.1) SSL tha & & & 2,727 \\
\hline
\end{tabular}

Acumulación térmica $\left(\mathrm{GD}_{10}\right)$ grados día base 10, con registros de Paso de la Laguna; $\mathrm{MS}=$ materia seca; $\mathrm{DE}=$ desvío estándar; $\mathrm{PMG}=$ peso de granos, $\mathrm{SL}=$ seco y limpio; $\mathrm{SSL}=$ sano, seco y limpio. 
tratamientos de protección de enfermedades en forma aérea de acuerdo con lo previsto: 1) tebuconazol + trifloxystrobin en el tratamiento $1 ; 2$ ) fosfito de $\mathrm{K}+\mathrm{Si}+$ azoxistrobin + kresoxim metil + ciproconazol, en el 9. Posteriormente, se realizó por error una segunda aplicación de fungicidas en las 2 parcelas, cuando hubiera correspondido sólo en la № 1 .

El 7 de abril se realizó la cosechó de ambas parcelas, entregándose la producción a la industria correspondiente. A esa fecha, utilizándose los registros de la Estación Agroclimática de Paso de la Laguna, entre la siembra y cosecha se habían acumulado 2.034 UT unidades térmicas, mientras que en Rincón de Ramírez tal como pudo observarse en el cuadro 55 la cosecha se realizó con una suma de 1.913 UT.

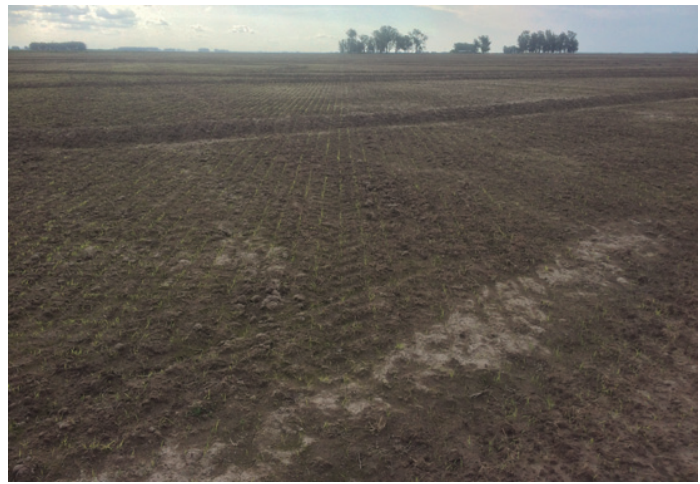

Validación en Costas de San Francisco, zafra 2016-2017.

Foto 9. Siembra convencional sobre taipa construida en forma previa.

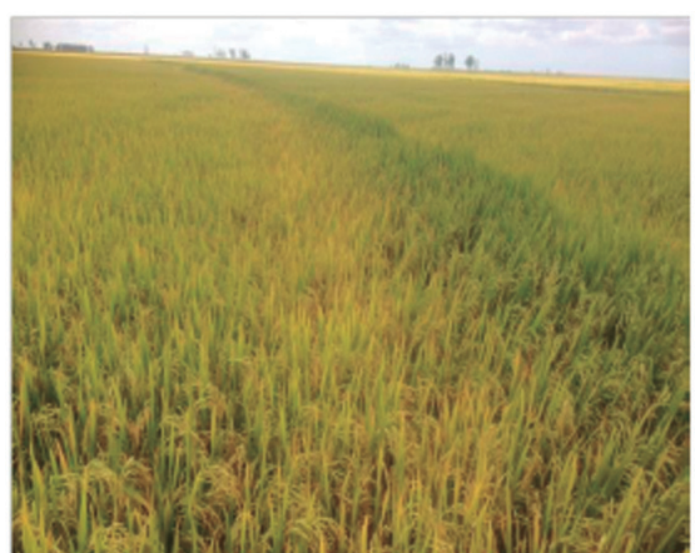

Foto 11. Estado del cultivo en llenado de granos, mostrando la buena implantación del cultivo en préstamos y lomo de las taipas (tratamiento $N^{\circ} 9$, variedad INIA Merín).

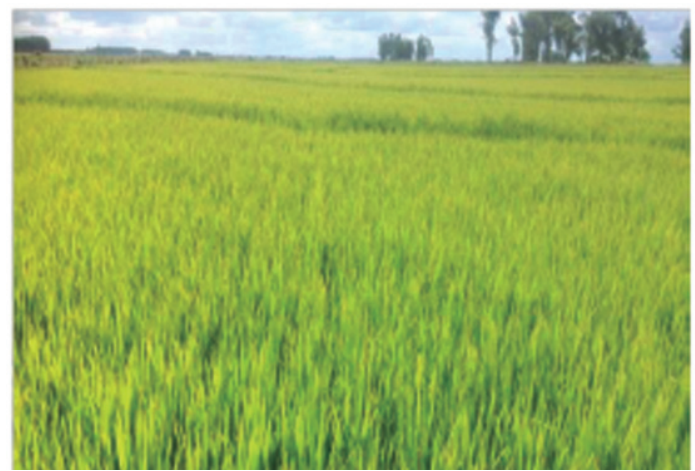

En el cuadro 58 se resumen las prácticas de manejo del cultivo según los tratamientos y los rendimientos de granos seco y limpio (SL) y sano seco y limpio (SSL) obtenidos. En este caso no hubo una gran diferencia en el índice de cosecha $(0,52$ vs 0,51$)$, pero se observó una superioridad general del tratamiento 9, en producción de materia seca en grano, en paja y total, así como en el número de granos llenos por unidad de superficie; además, las desviaciones estándar son menores. Fueron superiores las producciones generales de grano SL y SSL del tratamiento alternativo; en el área cosechada el tratamiento $\mathrm{N}^{\circ} 9$ tuvo un rendimiento SSL $2.727 \mathrm{~kg} / \mathrm{ha}$ superior al logrado con el $\mathrm{N}^{\circ} 1$, lo que representa un incremento del $28,7 \%$.

Foto 10. Estado del cultivo en tratamiento $\mathrm{N}^{\circ} 9$ (var. INIA Merín) previo a la floración.

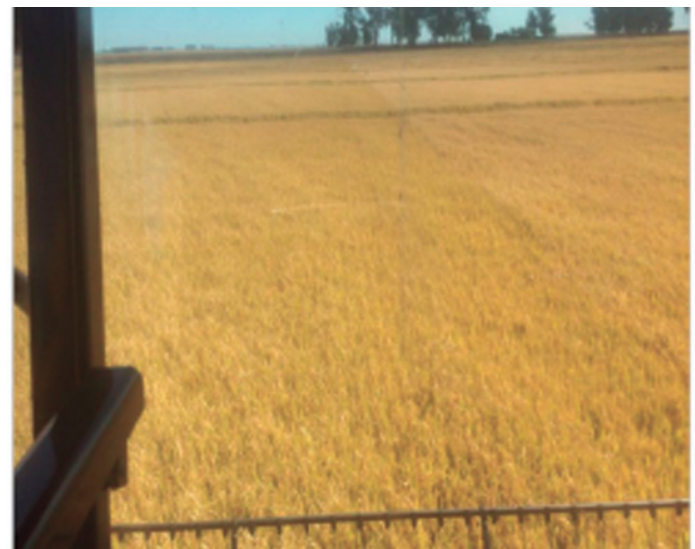

Foto 12. Inicio de cosecha, mostrando el estado de las 2 parcelas, tratamiento $N^{\circ} 9$ variedad INIA Merín a la izquierda y tratamiento $\mathrm{N}^{\circ} 1$ variedad $\mathrm{El}$ Paso 144 a la derecha. 


\subsection{3 $7^{a}$ Sección de Treinta y Tres}

Al igual que en Costas de San Francisco, en esta localización se planteó la misma comparación entre los tratamientos 1 y 9 , utilizando en este último la variedad INIA Merín. La siembra se realizó el 8 de noviembre (24 días más tarde que en el anterior) sobre un suelo de buena fertilidad donde se había sembrado una pradera de gramíneas y leguminosas para uso pecuario. Las taipas fueron construidas posteriormente.

Con respecto a la fertilización basal, además de considerar los criterios generales de la estrategia utilizada detallados en materiales y métodos, en este caso se conside- ró importante reforzar la aplicación de potasio. Si bien los análisis de suelos mostraban un contenido de $0,23 \mathrm{meq} / 100 \mathrm{~g} \mathrm{~K}$, existía una presencia mayor de $\mathrm{Mg}$ y $\mathrm{Ca}$, que hacían que las relaciones $\mathrm{Mg} / \mathrm{K}$ y $(\mathrm{Mg}+\mathrm{Ca})$ / $\mathrm{K}$ fueran de 15,2 y 65,2 respectivamente.

La implantación fue de 189 y 205 plantas de arroz $/ \mathrm{m}^{2}$ en los tratamientos 1 y 9 respectivamente, según conteos realizados el 6 de diciembre. Ese mismo día se aplicó la primera cobertura nitrogenada y los fertilizantes foliares (micronutrientes y sílice) en forma aérea. El 9 de enero se realizó la segunda cobertura y 18 días después se aplicaron los tratamientos de fungicidas preventivos para enfermedades; en este caso no

Cuadro 59. Resumen de prácticas de manejo según tratamientos y resultados obtenidos en la validación. $7^{\text {a }}$ Sección de Treinta y Tres, zafra 2016-2017*.

\begin{tabular}{|c|c|c|c|}
\hline Descripción & Fecha & Trat amiento 1 & Tratamiento 9 \\
\hline $\begin{array}{l}\text { Fecha de sembra } \\
\text { Varie dad }\end{array}$ & \multirow{8}{*}{$\begin{array}{c}9 \text { nov } \\
6 \text { dic } \\
6 \text { dic } \\
9 \text { ene } \\
27 \text { ene } \\
27 \text { ene } \\
12-13 \text { abr }\end{array}$} & \multirow{7}{*}{$\begin{array}{c}\text { El Paso } 144 \\
\text { tebucon } \\
130 \\
\text { P55 K25 } \\
\text { N36 } \\
- \\
\text { N23 } \\
\text { teb }+ \text { trif bxist. } \\
- \\
\text { sí }\end{array}$} & \multirow{7}{*}{$\begin{array}{c}\text { INIA Merín } \\
\text { + thiametoxan } \\
130 \\
\text { N10 P60 KV0 } 510 \\
\text { N76 } \\
\text { sí } \\
\text { N } 23 \\
\text { azox+krestapro } \\
\text { sí } \\
\text { sí }\end{array}$} \\
\hline Tratamiento de semillas & & & \\
\hline Densidad de sie mbra kg/ha & & & \\
\hline $\begin{array}{l}\text { Fertilización basal kg/ha } \\
\text { Aplicación } 1^{\mathrm{a}} \text { oobertura } \mathrm{N} \mathrm{kgha} \\
\text { Aplicación } \mathrm{F} \text { oliares (́micro s sílice) }\end{array}$ & & & \\
\hline Aplicación $2^{a}$ obertura $\mathrm{N}$ kgha & & & \\
\hline $\begin{array}{l}\text { Aplicación fungicida } \\
\text { Aplicación F osfito de potasio }+\mathrm{Si}\end{array}$ & & & \\
\hline $\begin{array}{l}\text { Cosecha } \\
\text { Acumulación térmica }\end{array}$ & & & \\
\hline Siembra-Cosecha $\left(\mathrm{GD}_{10}\right)$ & & 1859 & 1859 \\
\hline \multicolumn{4}{|l|}{ Registros } \\
\hline$N^{\circ}$ plantas instaladas & \multirow[t]{11}{*}{$\overline{6 d i c}$} & 205 & 189 \\
\hline $\begin{array}{l}\text { Producción MS en grano tha } \\
\mathrm{DE}\end{array}$ & & $\begin{array}{c}11,684 \\
2,2\end{array}$ & $\begin{array}{c}13,704 \\
1,1\end{array}$ \\
\hline $\begin{array}{l}\text { Producción MS en paja tha } \\
\text { DE }\end{array}$ & & $\begin{array}{c}9,229 \\
1,5\end{array}$ & $\begin{array}{c}11,253 \\
1,1\end{array}$ \\
\hline $\begin{array}{l}\text { Produccón MS total t/ha } \\
\mathrm{DE}\end{array}$ & & $\begin{array}{c}20,914 \\
3,6\end{array}$ & $\begin{array}{c}24,957 \\
2,3\end{array}$ \\
\hline $\begin{array}{l}\text { Indice de cosecha (IC) } \\
\mathrm{DE}\end{array}$ & & $\begin{array}{l}0,56 \\
0,02\end{array}$ & $\begin{array}{l}0.55 \\
0,01\end{array}$ \\
\hline $\begin{array}{l}N^{\circ} \text { de granos llenos } / \mathrm{m}^{2} \\
\mathrm{DE}\end{array}$ & & $\begin{array}{l}44.234 \\
10.380\end{array}$ & $\begin{array}{l}54.744 \\
10.849\end{array}$ \\
\hline PVG $(g)$ & & 27,09 & 26,39 \\
\hline $\mathrm{DE}$ & & 0,68 & 0.53 \\
\hline Rendimiento SL tha & & 8,683 & 10901 \\
\hline Rendimiento SSL tha & & 8,631 & 10945 \\
\hline Diferencia (trt. 9 -trt. 1) SSL & & & 314 \\
\hline
\end{tabular}

${ }^{*} \mathrm{~K}=\mathrm{K}_{2} \mathrm{O} ; \mathrm{P}=\mathrm{P}_{2} \mathrm{O}_{5} ; \mathrm{S}$ azufre; micros= micronutrientes teb. + trifloxist. = tebuconazol + trifloxystrobin; azox+kres+cipro: azoxistrobin+kresoxim metil +ciproconazol; Acumulación térmica $\left(\mathrm{GD}_{10}\right)$ grados día base 10, con registros de Paso de la Laguna; $M S=$ materia seca; $D E=$ desvío estándar; $P M G=$ peso de granos, $S L=$ seco y limpio; SSL= sano, seco y limpio. 
se consideró necesario realizar una segunda aplicación.

La cosecha del área se realizó el 12-13 de abril, con una acumulación térmica entre siembra y cosecha de 1.859 UT. El producto generado en las 2 parcelas fue remitido a la industria correspondiente, para su evaluación de cantidad y calidad.

En el cuadro 59 se resumen las prácticas de manejo del cultivo realizadas en cada tratamiento y los rendimientos de granos seco y limpio (SL) y sano seco y limpio (SSL) obtenidos. El tratamiento 9 tuvo un rendimiento SSL $2.314 \mathrm{~kg} / \mathrm{ha}$ superior al logrado con el 1 , lo que representa un incremento del $26,8 \%$.

Los muestreos de partes aéreas de plantas (paja y grano), muestran en los 2 tratamientos índices de cosecha (IC) mayores que los encontrados en San Francisco, pero al igual que en esa localización no muy diferentes entre sí. No obstante, el volumen de producción tanto de grano, de paja, como biomasa total, del $\mathrm{N}^{\circ} 9$ resulta muy superior al testigo. También es un $24 \%$ mayor la cantidad granos Ilenos $/ \mathrm{m}^{2}$ y $25,5 \%$ la producción de grano seco y limpio (SL).

\subsubsection{Cebollatí}

Esta fue la única localización, donde el comité técnico seleccionó una alternativa diferente para comparar con el tratamiento testigo, dados los resultados obtenidos en las 2 zafras anteriores. En particular, en la zafra 2015-2016 donde hubo presencia de Pyricularia sp. en la chacra circundante y además existieron condiciones de viento y lluvia próximas al tiempo de madurez durante un largo período, que impidió realizar la cosecha en el tiempo más adecuado, el tratamiento 12 con el factor instalación del cultivo alternativo (tratamiento de semilla con tebuconazol + thiametoxan +Synergize + Endorice) y una doble aplicación de fungicida, fue el que mayor rendimiento ofreció con un incremento del $7 \%$ sobre el obtenido con el tratamiento 1.

El área de validación fue sembrada el 1415 de noviembre sobre un suelo de características más similares al utilizado en la zafra 2014-2015 (Cuadros 5 y 7, Materiales y Métodos) que al del año anterior, en textura, $\mathrm{pH}$ y $\mathrm{CIC}$, con valores menores de $\mathrm{PMN}$ (22 vs 30$), \mathrm{K}(0,27$ vs 0,33$), \mathrm{Mg}(3,8$ vs 4,3$)$ más del doble de contenido de sodio $(1,26$ vs 0,57$)$ y similares de $\mathrm{Ca}(7,2$ vs 7,4$)$. Se realizó una preparación inverno-primaveral del suelo sobre un retorno que no recibió siembra de forrajeras. Las taipas fueron construidas con posterioridad.

Debido a la baja germinación de la semilla de Parao, se sembró la misma densidad de semilla de las 2 variedades, cuando de haberse dispuesto de una calidad normal, de acuerdo con el tratamiento 12 hubiera correspondido usar una cantidad más baja con esta variedad.

EI Paso 144 sembrado en una zona relativamente más alta y con mayor presencia de arena en su textura, se instaló rápidamente y con buena densidad. Por el contrario, en la parcela correspondiente al tratamiento 12, la emergencia de plantas fue mucho más lenta y despareja. Según conteos realizados el 6 de diciembre había 322 y 158 plantas de arroz $\mathrm{m}^{2}$ en los tratamientos 1 y 12 respectivamente. En zonas de este último, se notaban espacios importantes sin planta alguna.

Los fertilizantes foliares (micronutrientes y primera de sílice) y las primeras coberturas nitrogenadas fueron realizadas el 8 de diciembre en forma terrestre. La segunda cobertura de $\mathrm{N}$ (50 y $100 \mathrm{~kg} / \mathrm{ha}$ de urea en tratamientos 1 y 12 respectivamente) fue aplicada El 7 de enero.

El 16 de febrero se aplicó el fungicida preventivo en forma aérea en ambas parcelas (el mismo tratamiento). No se consideró necesario realizar más tarde una segunda aplicación.

Se cosechó el tratamiento 1 (El Paso 144) el 17 de abril y recién el 30 de abril el tratamiento 9 (Parao). En ambos casos la producción fue entregada a la industria, quien realizó las evaluaciones de cantidad y calidad pertinentes.

En el cuadro 60 se resumen las prácticas de manejo del cultivo realizadas en cada tratamiento y los rendimientos de granos seco y limpio (SL) y sano seco y limpio (SSL) 
Cuadro 60. Resumen de prácticas de manejo según tratamientos y resultados obtenidos en la validación. Cebollatí, zafra 2016-2017*.

\begin{tabular}{|c|c|c|c|}
\hline Descripción & Fecha & Trat amiento1 & Tratamiento 12 \\
\hline Fecha de sembra & 14-15 now & \multirow{4}{*}{$\begin{array}{c}\text { El Paso } 144 \\
\text { tebsconozol } \\
\text { +thiometoxon } \\
160\end{array}$} & \multirow{4}{*}{$\begin{array}{c}\text { Parao } \\
\text { tebuconazol+thiometoxon } \\
\text { +Synergize+ Endorioe } \\
160\end{array}$} \\
\hline Variedad & \multirow{6}{*}{$\begin{array}{l}18 \text { nov } \\
8 \mathrm{dic} \\
8 \mathrm{dic} \\
7 \mathrm{ene} \\
16 \mathrm{feb}\end{array}$} & & \\
\hline Tratamiento de semillas & & & \\
\hline Densidad de siembra $\mathrm{kg} / \mathrm{ha}$ & & & \\
\hline $\begin{array}{l}\text { Fertilización basal } \mathrm{kg} / \mathrm{ha} \\
\text { Aplicación } 1^{\mathrm{a}} \text { obertura } \mathrm{N} \mathrm{kgha} \\
\text { Aplicación F oliares (micros silice) }\end{array}$ & & $\begin{array}{l}\text { N11 P53 } \\
\text { N38 } \\
-\end{array}$ & 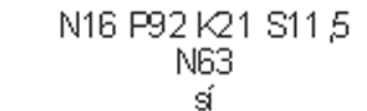 \\
\hline Aplicación $2^{a}$ pobertura $N$ kgha & & $N 23$ & N46 \\
\hline Aplicación fungicida & & $\begin{array}{l}\text { tebuconazol. + } \\
\text { trifloxystrobin. }\end{array}$ & $\begin{array}{l}\text { tebuconazol. + } \\
\text { trifloxystrobin. }\end{array}$ \\
\hline Cosecha & \multirow[t]{2}{*}{$\begin{array}{l}17 \mathrm{abr} \\
30 \mathrm{abr}\end{array}$} & sí & si \\
\hline $\begin{array}{l}\text { Acumulación térmica } \\
\text { Siembra-Cosecha }\left(\mathrm{GD}_{10}\right)\end{array}$ & & 1844 & 1946 \\
\hline Registros & & & \\
\hline $\begin{array}{l}\text { Noplantas instaladas } \\
\text { Producción MS en grano tha } \\
\text { DE }\end{array}$ & \multirow[t]{9}{*}{$10 / 11$} & $\begin{array}{c}322 \\
11,637 \\
3,0\end{array}$ & $\begin{array}{c}158 \\
11,725 \\
29\end{array}$ \\
\hline $\begin{array}{l}\text { Producción MS en paja tha } \\
\text { DE }\end{array}$ & & $\begin{array}{c}11,490 \\
3,2\end{array}$ & $\begin{array}{l}9,804 \\
2,4\end{array}$ \\
\hline $\begin{array}{l}\text { Producción MS total t/ha } \\
\text { DE }\end{array}$ & & $\begin{array}{c}23,127 \\
6,3\end{array}$ & $\begin{array}{l}21,529 \\
52\end{array}$ \\
\hline $\begin{array}{l}\text { Indice de cosecha }(\mathrm{IC}) \\
\mathrm{DE}\end{array}$ & & $\begin{array}{l}0,50 \\
0,03\end{array}$ & $\begin{array}{l}0,54 \\
0,03\end{array}$ \\
\hline $\begin{array}{l}\text { No de granos llenos } / \mathrm{m}^{2} \\
\mathrm{DE}\end{array}$ & & $\begin{array}{l}40.753 \\
9.690\end{array}$ & $\begin{array}{l}54.073 \\
10.205\end{array}$ \\
\hline $\begin{array}{l}\text { PMG (g) } \\
D E\end{array}$ & & $\begin{array}{c}27,69 \\
1,44\end{array}$ & $\begin{array}{c}25,98 \\
1,09\end{array}$ \\
\hline Rendimiento SL tha & & 8,780 & 8,759 \\
\hline Rendimiento SSL tha & & 9,077 & 9,254 \\
\hline Diferencia (trt. 9 -trt. 1) SSL t/ha & & \multicolumn{2}{|r|}{0,177} \\
\hline
\end{tabular}

${ }^{*} \mathrm{~K}=\mathrm{K}_{2} \mathrm{O} ; \mathrm{P}=\mathrm{P}_{2} \mathrm{O}_{5} ; \mathrm{S}$ azufre; micros= micronutrientes; azox+difen +tric= azoxistrobin + difenoconazol + tricyclazol; Acumulación térmica $\left(\mathrm{GD}_{10}\right)$ grados día base 10 , con registros de Paso de la Laguna; $\mathrm{MS}=$ materia seca; $\mathrm{DE}=$ desvío estándar; $\mathrm{PMG}=$ peso de granos, $\mathrm{SL}=$ seco y limpio; $\mathrm{SSL}=$ sano, seco y limpio.

obtenidos. No existieron diferencias en la productividad a pesar de que el tratamiento 1 dispuso al momento de realizar los conteos del doble de número de plantas y de que, durante la mayor parte del crecimiento y desarrollo del cultivo, las mismas lucían mejor. Luego de la aplicación de las coberturas nitrogenadas Parao comenzó a cubrir los espacios vacíos sin plantas con macollaje y área foliar, atrasó su ciclo (floreció después que El Paso 144, cuando lo común es hacerlo antes) y finalizó con un rendimiento similar. El tratamiento 1 rindió $9,077 \mathrm{t} / \mathrm{ha} S S L(8,780 \mathrm{t} / \mathrm{ha} \mathrm{SL})$ y el 129,254 t/ha SSL $(8,759$ t/ha SL).
La producción biomasa de paja fue mayor en el tratamiento 1 y no se observaron diferencias de materia seca en grano de acuerdo a muestreos realizados en 5 sitios diferentes de las parcelas. Lo mismo se vio reflejado en diferencias importantes en el índice de cosecha $(0,50$ vs 0,54 a favor del tratamiento 12).

El índice de cosecha es una de las características destacadas del cultivar Parao y no llama la atención esta diferencia en una situación particular, donde partiendo de una población más baja tuvo una gran recuperación en base a la fertilización nitrogenada 
que le permitió producir lo mismo que El Paso 144.

La capacidad potencial estimada en base a los componentes de rendimiento indicaría un mayor rendimiento en el tratamiento 12. Es probable que exista una subestimación del número de granos llenos en el tratamiento 1, dado que se puede apreciar un desvío mayor con respecto a sus promedios.

En la parcela del tratamiento 12 se observó una zona con plantas con aparentes síntomas de salinidad. En algunos cuadros las plantas volcaron, mientras que en la taipa quedaron en pie, inclinadas, pero con un porcentaje de granos vacíos elevado.
Muestreado el suelo en esas zonas se compararon los resultados del análisis con el promedio del área de validación previo a la siembra.

En el cuadro 61 se observa un gradiente entre los contenidos de sodio en el suelo de la parcela $(\mathrm{meq} / 100 \mathrm{~g})$ y también en el porcentaje de Na sobre la capacidad de intercambio catiónico, alcanzando un $17,3 \%$ en la parte de mayor afección. Cabe destacar que en los estados de Rio Grande del Sur y Santa Catarina de Brasil, se considera que valores de $15-20 \%$ de $\mathrm{Na} / \mathrm{CIC}$ ya representan riesgos para la producción de arroz (SOSBAI, 2016).

Cuadro 61. Análisis de muestras de suelos en área con afección de plantas de arroz. Validación Cebollatí, zafra 2016-2017

\begin{tabular}{lccccccc}
\hline $\begin{array}{l}\text { Lugar de } \\
\text { extracción }\end{array}$ & $\mathrm{pH}$ & $\mathrm{Ca}$ & $\mathrm{Mg}$ & $\mathrm{K}$ & $\mathrm{Na}$ & $\mathrm{ClC}$ & $\mathrm{Na} / \mathrm{ClC}$ \\
\cline { 3 - 7 } & & \multicolumn{7}{c}{$\mathrm{Meq} / 100 \mathrm{~g}$} & & & $\%$ \\
\hline Cuadro & 6,7 & 4,4 & 3,1 & 0,18 & 2,06 & 11,9 & 17,3 \\
Taipa & 6,2 & 4,3 & 2,8 & 0,20 & 1,34 & 10,5 & 12,9 \\
media validación & 6,5 & 7,2 & 38 & 0,27 & 1,26 & 15,0 & 8,4 \\
\hline
\end{tabular}

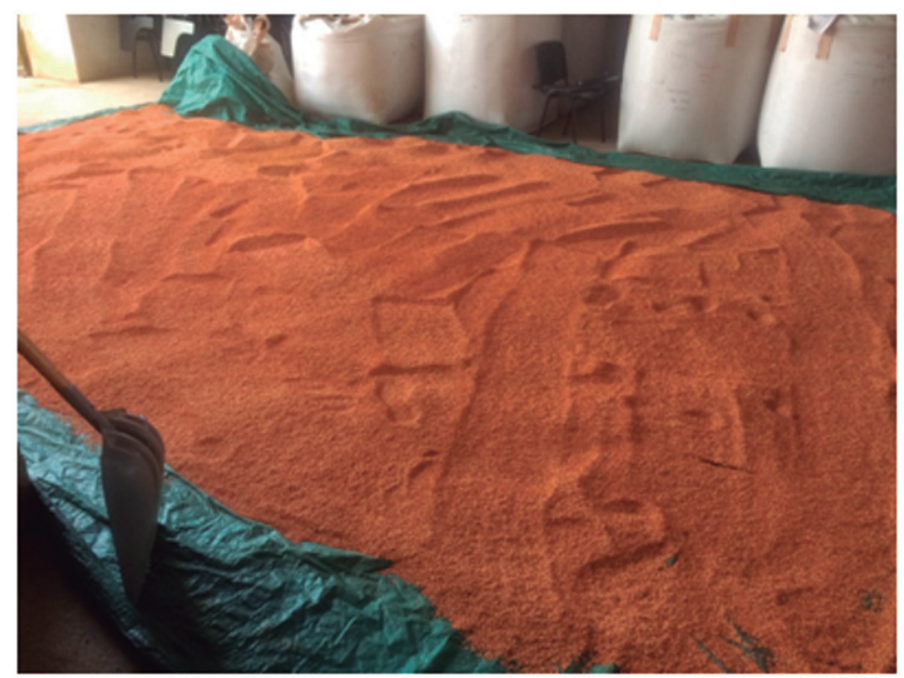

Foto 13. Validación en Cebollatí, zafra 2016-2017. Semilla de Parao, tratada con tebuconazol + thiametoxan + Synergize y posteriormente inoculada con Endorice (Herbaspirillum), pronta para ser trasladada a la chacra para la siembra. 


\subsubsection{Vuelta Grande}

Este es el único trabajo de los 14 conducidos (8 de investigación y 6 de validación) que fue instalado en un suelo que tuvo un cultivo de soja como antecesor inmediato. Varios de los productores que han utilizado esta opción, han señalado las ventajas que ofrece incluir la soja dentro de la rotación cultivo-pecuaria que manejan.

Independientemente de la rentabilidad que puede o no brindar el cultivo de soja, deja un rastrojo muy favorable para la instalación del cultivo de arroz posterior, con un suelo nivelado y en general con malezas fácilmente controlables. Además, también es una buena herramienta para la disminución de infecciones de arroz rojo, en suelos donde se constata su presencia.

Se decidió usar la Vuelta Grande como la tercera localización en el Departamento de Rocha, adicional a las de Cebollatí e India Muerta, donde se habían conducido los trabajos de investigación en las 2 zafras anteriores. Se debió optar por una de las alternativas a instalar en forma conjunta con el tratamiento 1, ya que las seleccionadas en Cebollatí (tratamiento12) e India Muerta (tratamiento 9) no coincidían. Se consideró que el ambiente a utilizar presenta más similitud con las condiciones de India Muerta, por lo que se contrastó la alternativa testigo con las prácticas del tratamiento 9 , utilizando INIA Tacuarí como variedad utilizada por los productores y Parao como alternativa.

Para apreciar la ubicación de Vuelta Grande dentro de las otras 2 en relación a algunas de sus características del suelo previo a la siembra, en el cuadro 62 se presen- tan algunos valores extraídos del cuadro 7 (Materiales y métodos).

En Vuelta Grande varios valores de análisis fueron intermedios entre los encontrados en Cebollatí e India Muerta $(\mathrm{pH}, \mathrm{PMN}$, $\mathrm{CO}, \mathrm{K}, \mathrm{Ca}, \mathrm{Zn}, \mathrm{ClC}$ y SB) y menores en $\mathrm{Mg}$ y $\mathrm{Na}$. Sin duda, algunos de ellos fueron influenciados por el uso previo de los suelos, retorno sin pradera en Cebollatí, soja en Vuelta Grande y pradera en India Muerta. La textura tuvo menor porcentaje de arena que Cebollatí, diferencia distribuida en limo y arcilla, pero bastante inferior en el contenido de esta última fracción en relación a India Muerta.

El arroz fue sembrado el 5-6 de noviembre sobre un suelo finamente preparado en forma convencional. La fertilización basal fue realizada el mismo día de la siembra en el tratamiento 1 y un día después en el tratamiento 9. En esta oportunidad, el potasio no fue suministrado en la siembra, sino, junto a la primera cobertura nitrogenada. Las fertilizaciones foliares fueron realizadas en forma terrestre el 24 de noviembre. La implantación de las 2 variedades, medida 17 días pos-siembra fue muy buena, con promedios de 394 y 238 plantas $/ \mathrm{m}^{2}$ en INIA Tacuarí y Parao respectivamente.

En la segunda quincena de diciembre se constataron problemas de manejo de malezas/riego en zonas de las 2 parcelas, por lo que se decidió realizar una aplicación complementaria de herbicida para mitigarlos. El 8 de enero se realizó la segunda aplicación nitrogenada con el doble de $\mathrm{N}$ en el tratamiento $9(100 \mathrm{~kg} / \mathrm{ha}$ vs $50 \mathrm{~kg} / \mathrm{ha}$ en el tratamiento 1$)$ y el 27 de enero los tratamientos de prevención de enfermedades correspondientes a

Cuadro 62. Algunas características de suelos comparativas de las localizaciones Cebollatí, Vuelta Grande, India Muerta. Validaciones, zafra 2015-2016*.

\begin{tabular}{cccccccccccc}
\hline Loc & $\mathrm{pH}$ & $\begin{array}{c}\mathrm{PMN} \\
\mathrm{mg} \mathrm{kg}\end{array}$ & $\begin{array}{r}\mathrm{CO} \\
\%\end{array}$ & $\begin{array}{c}\mathrm{K} \\
\mathrm{meq}\end{array}$ & $\begin{array}{c}\mathrm{Ca} \\
\mathrm{meq}\end{array}$ & $\begin{array}{c}\mathrm{Mg} \\
\mathrm{meq}\end{array}$ & $\begin{array}{c}\mathrm{Na} \\
\mathrm{meq}\end{array}$ & $\begin{array}{c}\mathrm{Zn} \\
\mathrm{mg} \mathrm{kg}^{-1}\end{array}$ & $\begin{array}{c}\mathrm{ClC} \\
\mathrm{meq}\end{array}$ & $\begin{array}{c}\mathrm{SB} \\
\%\end{array}$ & $\begin{array}{c}\text { Textura } \\
\text { Ar-L-ArC }\end{array}$ \\
\hline CE & 6,5 & 22 & 1,8 & 0,27 & 72 & 3,8 & 1,26 & 0,29 & 15 & 82,3 & $33-36-31$ \\
VG & 5,7 & 29 & 19 & 0,29 & 11,7 & 3,1 & 0,46 & 0,66 & 19,7 & 77,8 & $23-40-37$ \\
IM & 5,6 & 44 & 4,7 & 0,45 & 18,2 & 7,3 & 0,54 & 3,12 & 35 & 75,7 & $9-40-51$ \\
\hline
\end{tabular}

*Loc= Iocalización; CE= Cebollatí; VG= Vuelta Grande; IM= India Muerta; PMN= potencial de mineralización; $\mathrm{CO}=$ carbono orgánico; $\mathrm{CIC}=$ capacidad de intercambio catiónico; $\mathrm{SB}=$ saturación en bases; $\mathrm{K}-\mathrm{Ca}-\mathrm{Mg}-\mathrm{Na}-\mathrm{CIC}$ valores en meq/100 de suelo. 
cada tecnología. Posteriormente, no se consideró necesario realizar una segunda aplicación.

La cosecha se realizó el 17-18 de marzo en la totalidad del área de validación y la producción fue entregada a la industria, quien realizó las evaluaciones de cantidad y calidad pertinentes.

En el cuadro 63 se resumen las prácticas de manejo del cultivo realizadas en cada tratamiento y los rendimientos de granos seco y limpio (SL) y sano seco y limpio (SSL) obtenidos. El tratamiento $\mathrm{N}^{\circ} 9$ tuvo un rendimiento SSL $1.411 \mathrm{~kg} /$ ha mayor al logrado con el $\mathrm{N}^{\circ} 1$, lo que representa un incremento del $17,8 \%$.
El índice de cosecha, estimado mediante muestreos de paja y grano en 5 sitios de cada parcela, fue mayor en el tratamiento 9 comparado con el tratamiento 1 (IC: 0,60 vs 0,58$)$. En los otros muestreos extraídos para análisis de componentes del rendimiento, el tratamiento 1 (INIA Tacuarí) presentó un $34 \%$ más de granos $I l e n o s / \mathrm{m}^{2}$ con un peso de grano 21,53 (los mil granos) contra 25,86 g de Parao. Si se estimara el rendimiento potencial en base a estas muestras, el tratamiento 1 debía haber rendido más que el tratamiento 9. Se destaca que, en este sitio, se utilizaron las parcelas más largas de las 6 localizaciones, distando en el caso más extremo $750 \mathrm{~m}$ unos nuestros

Cuadro 63. Resumen de prácticas de manejo según tratamientos y resultados obtenidos en la validación. Vuelta Grande, zafra 2016-2017*.

\begin{tabular}{|c|c|c|c|}
\hline Descripción & Fecha & Tratamiento.1 & Tratamiento 9 \\
\hline $\begin{array}{l}\text { Fecha de sembra } \\
\text { Varie dad } \\
\text { Densidad de siembra } \mathrm{kg} / \mathrm{ha} \\
\text { Tratamiento de semillas }\end{array}$ & \multicolumn{3}{|c|}{$\begin{array}{cc}\text { INIA Tacuarí } & \text { Parao } \\
170 & 170 \\
\text { tebuconazol +thiametoxan }\end{array}$} \\
\hline $\begin{array}{l}\text { Fertilización basal } \mathrm{kg} / \mathrm{ha} \\
\text { Aplicación } 1^{\mathrm{a}} \text { ob bertura } \mathrm{N} \mathrm{kg} / \mathrm{ha} \\
\text { Aplicación } \mathrm{F} \text { oliares (micros silice) } \\
\text { Aplicación } 2^{\mathrm{a}} \text { o bertura } \mathrm{N} \mathrm{kgha}\end{array}$ & \multirow{3}{*}{$\begin{array}{c}56 \text { nov } \\
28 \text { nov } \\
24 \text { nov } \\
8 \text { ene } \\
27 \text { ene } \\
27 \text { ene } \\
15-18 \text { abr }\end{array}$} & \multirow{3}{*}{$\begin{array}{c}\text { N20 F51 } \\
\text { N24 } \\
- \\
\text { N23 } \\
\text { teb }+ \text { trifioxist. } \\
- \\
\text { si }\end{array}$} & \multirow{3}{*}{$\begin{array}{c}\text { + thlametoxan } \\
\text { N13P76 S95 } 5 \\
\text { N51 K21 } \\
\text { sí } \\
\text { N } 46 \\
\text { azox+krestapro } \\
\text { sí } \\
\text { sí }\end{array}$} \\
\hline $\begin{array}{l}\text { Aplicación fungicida } \\
\text { Aplicación F osfito de potasio }+\mathrm{Si}\end{array}$ & & & \\
\hline $\begin{array}{l}\text { Cosecha } \\
\text { Acumulación térmica } \\
\text { Siembra-Cosecha }\left(\mathrm{GD}_{10}\right)\end{array}$ & & & \\
\hline Registros & & & \\
\hline $\begin{array}{l}\text { Noplantas instaladas } \\
\text { Producción MS en grano tha } \\
D E\end{array}$ & \multirow[t]{9}{*}{23 nov } & $\begin{array}{c}394 \\
9,908 \\
1,3\end{array}$ & $\begin{array}{c}238 \\
9,965 \\
1,0\end{array}$ \\
\hline $\begin{array}{l}\text { Producción MS en paja tha } \\
D E\end{array}$ & & 7,210 & $\begin{array}{l}6,706 \\
1,4\end{array}$ \\
\hline $\begin{array}{l}\text { Producción MS total t/ha } \\
\mathrm{DE}\end{array}$ & & $\begin{array}{c}17,118 \\
2,2\end{array}$ & $\begin{array}{c}16,671 \\
2,3\end{array}$ \\
\hline $\begin{array}{l}\text { Indice de cosecha (IC) } \\
\text { DE }\end{array}$ & & $\begin{array}{l}0,58 \\
0,02\end{array}$ & $\begin{array}{l}0,60 \\
0,02\end{array}$ \\
\hline $\begin{array}{l}N^{\circ} \text { de granos lle nos } / \mathrm{m}^{2} \\
\mathrm{DE}\end{array}$ & & $\begin{array}{l}53.208 \\
12.134\end{array}$ & $\begin{array}{l}39.834 \\
10.732\end{array}$ \\
\hline PMG (g) & & 21,53 & 25,86 \\
\hline $\mathrm{DE}$ & & 1,29 & 1,10 \\
\hline $\begin{array}{l}\text { Rendimiento SL tha } \\
\text { Rendimiento SSL tha }\end{array}$ & & $\begin{array}{l}7,924 \\
7,919\end{array}$ & $\begin{array}{l}9,235 \\
9,330\end{array}$ \\
\hline Diferencia (trt. 9 -trt. 1) SSL t/ha & & \multicolumn{2}{|c|}{1,411} \\
\hline
\end{tabular}

$*: \mathrm{K}=\mathrm{K}_{2} \mathrm{O} ; \mathrm{P}=\mathrm{P}_{2} \mathrm{O}_{5} ; \mathrm{S}$ azufre; micros= micronutrientes teb. + trifloxist. = tebuconazol + trifloxystrobin; azox+kres+cipro: azoxistrobin + kresoxim metil +ciproconazol; Acumulación térmica $\left(\mathrm{GD}_{10}\right)$ grados día base 10 , con registros de Paso de la Laguna; $M S=$ materia seca; $\mathrm{DE}=$ desvío estándar; $\mathrm{PMG}=$ peso de granos, $\mathrm{SL}=$ seco y limpio; SSL= sano, seco y limpio. 
de otros; por otra parte, existieron algunos problemas puntuales de manejo en algunas zonas, pudiéndose haberse extraído muestras en alguno de ellos. Ello estaría reflejado en los altos valores de desvío estándar (DE) encontrados en Vuelta Grande, tanto en el número de granos llenos como en el peso de estos.

\subsubsection{India Muerta}

La validación fue instalada en una zona cercana y sobre un suelo con historia de uso y características parecidas (no iguales) a donde se condujo el primer año de la investigación parcelaria (2014-2015).
La siembra del cultivo se realizó el 9-11 de noviembre sobre un suelo de alta fertilidad, donde se había instalado una pradera con siembra de gramíneas y leguminosas. Comparados los resultados de análisis de suelos de la validación con los encontrados en 2014-2015 (Cuadros 4 y 7, Materiales y Métodos), destacan igual $\mathrm{pH}(5,6)$, alto PMN pero menor (44 vs 74$)$, mayor $\%$ CO (4,7 vs 1,9), similares contenidos de $\mathrm{P}$ y K (P 18,7/ $17,7 ; \mathrm{K} 0,45 / 0,38)$, mayores contenidos de $\mathrm{Ca}, \mathrm{Mg}$ y $\mathrm{Na}$ (Ca 18,2/8,8; Mg 7,3/4,9; $\mathrm{Na}$ $0,54 / 0,17)$ y mayores CIC (35 vs 21,1$)$ y saturación en bases ( 75,7 vs $68,2 \%)$.

El suelo no presentaba un buen grado de afinamiento y se produjeron algunas

Cuadro 64. Resumen de prácticas de manejo según tratamientos y resultados obtenidos en la validación. India Muerta, zafra 2016-2017*

\begin{tabular}{|c|c|c|c|}
\hline Descripción & Fecha & Trt at amiento1 & Tratamiento 9 \\
\hline $\begin{array}{l}\text { Fecha de sembra } \\
\text { Variedad }\end{array}$ & $9-11$ now & INUA Tacuarí & Parao \\
\hline Tratamiento de semillas & & \multicolumn{2}{|c|}{ tebuconazol + thiametoxan } \\
\hline Densidad de sie mbra kg/ha & & 175 & 175 \\
\hline $\begin{array}{l}\text { Fertilización basal kg/ha } \\
\text { Aplicación } 1^{\mathrm{a}} \text { obertura } \mathrm{N} \text { kqha }\end{array}$ & $\begin{array}{l}5 \text { now } \\
6 \mathrm{dic}\end{array}$ & $\underset{N 28}{\operatorname{N20} P 51}$ & $\begin{array}{l}\text { NO PO K48 } \\
\text { N21 }\end{array}$ \\
\hline Ap licación F oliares (micros sílice) & 6 dic & - & sí \\
\hline Aplicación $2^{a}$ oobertura $\mathrm{N} \mathrm{kgha}$ & 12 ene & N23 & N46 \\
\hline Aplicación fungicida & $4 \mathrm{feb}$ & teb- trifloxist. & azox $+k$ res + apro \\
\hline Aplicación Fosfito de potasio $+\mathrm{Si}$ & $4 \mathrm{feb}$ & - & sí \\
\hline $\begin{array}{l}\text { Cosecha } \\
\text { Acumulación térmica }\end{array}$ & 12-13 abr & sí & sí \\
\hline Siembra-Cosecha $\left(G_{10}\right)$ & & 1873 & 1873 \\
\hline \multicolumn{4}{|l|}{ Registros } \\
\hline $\begin{array}{l}\text { No plantas instaladas } \\
\text { Producción MS en grano tha } \\
\text { DE }\end{array}$ & $5 / 12$ & $\begin{array}{c}196 \\
13,080 \\
2,1\end{array}$ & $\begin{array}{l}129 \\
15,071 \\
35\end{array}$ \\
\hline $\begin{array}{l}\text { Producción MS en paja tha } \\
\text { DE }\end{array}$ & & $\begin{array}{l}11,210 \\
2,9\end{array}$ & $\begin{array}{l}11,790 \\
2,8\end{array}$ \\
\hline $\begin{array}{l}\text { Producción MS total t/ha } \\
\text { DE }\end{array}$ & & $\begin{array}{c}24,290 \\
4,3\end{array}$ & $\begin{array}{l}26,861 \\
6,6\end{array}$ \\
\hline $\begin{array}{l}\text { Indice de cosecha }(\mathrm{IC}) \\
\mathrm{DE}\end{array}$ & & $\begin{array}{l}0,54 \\
0,04\end{array}$ & $\begin{array}{l}0,56 \\
0,01\end{array}$ \\
\hline $\begin{array}{l}N^{\circ} \text { de granos llenos } / \mathrm{m}^{2} \\
\mathrm{DE}\end{array}$ & & $\begin{array}{c}63.398 \\
8.428\end{array}$ & $\begin{array}{l}59.269 \\
7.846\end{array}$ \\
\hline $\begin{array}{l}\text { PMG (g) } \\
\text { DE } \\
\text { Rendimiento SL tha } \\
\text { Rendimiento SSL tha } \\
\text { Diferencia (trt. } 9 \text { - trt. 1) SSL t/ha }\end{array}$ & & $\begin{array}{l}20,12 \\
0,67 \\
9,629 \\
10,095\end{array}$ & $\begin{array}{l}25,46 \\
0,50 \\
10,686 \\
10,816\end{array}$ \\
\hline
\end{tabular}

${ }^{*} \mathrm{~K}=\mathrm{K}_{2} \mathrm{O} ; \mathrm{P}=\mathrm{P}_{2} \mathrm{O}_{5} ; \mathrm{S}$ azufre; micros= micronutrientes; azox+difen +tric= azoxistrobin + difenoconazol + tricyclazol; Acumulación térmica $\left(\mathrm{GD}_{10}\right)$ grados día base 10 , con registros de Paso de la Laguna; $\mathrm{MS}=$ materia seca; $\mathrm{DE}=$ desvío estándar; $\mathrm{PMG}=$ peso de granos, $\mathrm{SL}=$ seco y limpio; $\mathrm{SSL}=$ sano, seco y limpio. 
precipitaciones previo a la siembra, por lo que las condiciones no fueron favorables para la instalación. La implantación, evaluada el 5 de diciembre, fue de 196 y 129 plantas de arroz $/ \mathrm{m}^{2}$ en los tratamientos $1 \mathrm{y}$ 9 respectivamente. Las taipas fueron construidas posteriormente a la siembra.

De acuerdo con el análisis de suelos, en el tratamiento 9 sólo se aplicó potasio en la siembra y en la primera cobertura nitrogenada el $75 \%$ de la dosis usada en el testigo.

Las primeras coberturas de nitrógeno, así como las fertilizaciones foliares (micronutrientes y sílice) se realizaron en forma terrestre el 6 de diciembre. El 12 de enero se aplicaron las segundas coberturas de nitrógeno (100 y $50 \mathrm{~kg} / \mathrm{ha}$ de urea en los tratamientos 9 y 1 , respectivamente) y el 4 de febrero las aplicaciones correspondientes a la prevención de enfermedades. No se consideró necesario realizar una segunda aplicación de fungicidas.

La cosecha se realizó El 12-13 de abril sobre el total del área de validación y la producción fue entregada a la industria, quien realizó las evaluaciones de cantidad y calidad pertinentes.

En el cuadro 64 se resumen las prácticas de manejo del cultivo realizadas en cada tratamiento y los rendimientos de granos seco y limpio (SL) y sano seco y limpio (SSL) obtenidos. En el área cosechada el trata-

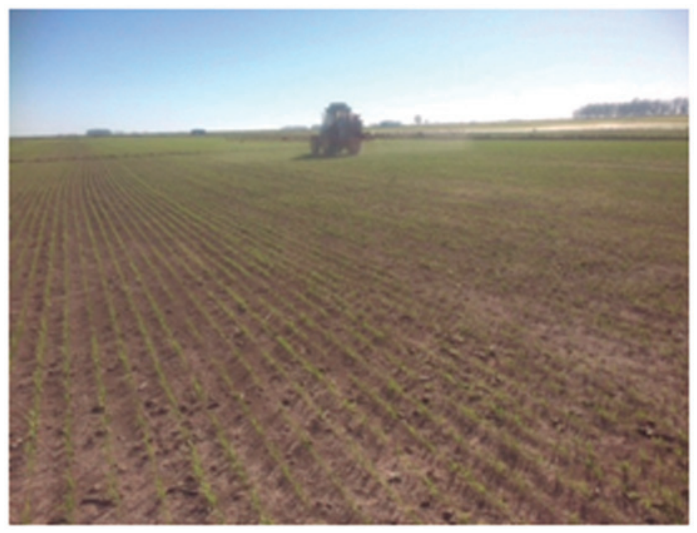

miento 9 tuvo un rendimiento SSL $721 \mathrm{~kg} / \mathrm{ha}$ superior al logrado con el 1 , lo que representa un incremento del $7,1 \%$.

Se debe mencionar que la variedad Parao tiene un largo de ciclo mayor que INIA Tacuarí, y se decidió cosechar todo el trabajo el mismo día, dado que el productor finalizaba las tareas con retiro de la maquinaria de ese campo. A esa fecha se habían acumulado desde la siembra 1873 GD $_{10}$ (grados día base 10), según los registros de temperatura de Paso de la Laguna, lo que equivale a 10 días calendario antes que el tiempo a cosecha usado en Cebollatí y Vuelta Grande (1946 y 1952 GD $_{10}$ respectivamente) utilizando valores reales de acumulaciones térmicas promedio en el período 10-19 de abril 2016.

En los muestreos de partes aéreas de plantas, realizado en 5 sitios diferentes de cada parcela, se nota una mayor producción de materia seca en grano $(15 \%)$, en paja $(5 \%)$ y total $(11 \%)$ en el tratamiento 9 , reflejado de acuerdo a esas proporciones en un mayor índice de cosecha $(0,56$ vs $0,54)$. Respecto a los componentes del rendimiento se observó que aunque el tratamiento 1 presenta más granos $l$ lenos $/ \mathrm{m}^{2}$ (63.398 vs 59.269), el mayor peso de granos de Parao (25,46 vs 20,12 gramos), más que contrarresta esa diferencia resultando un rendimiento potencial $18 \%$ superior a favor del tratamiento 9 .

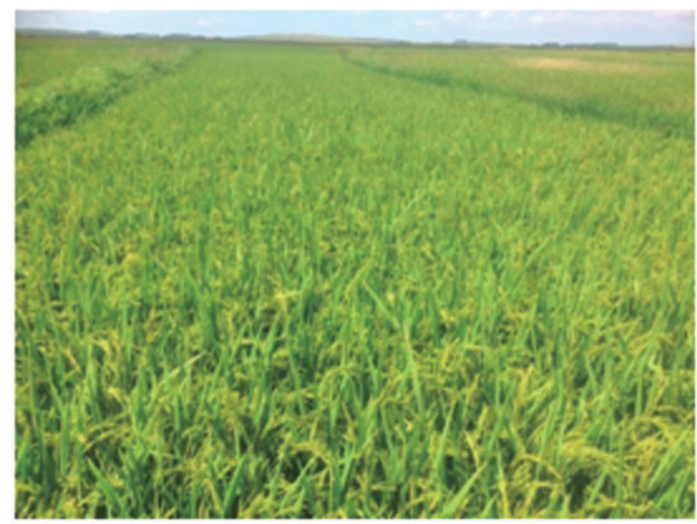

Validación en India Muerta, zafra 2016-2017.

Foto 14. Aplicación terrestre de fertilizante foliar (tratamiento $\mathrm{N}^{\circ} 9$ ).
Foto 15. Vista del cultivo en tratamiento $N^{\circ} 9$ (variedad Parao) en el doblado de panojas. 


\subsubsection{Resumen}

Se instalaron 6 trabajos de validación en la zafra 2016-2017, en diferentes localizaciones, fechas de siembra, antecedentes de uso y condiciones del suelo, que fueron manejados en general por los productores colaboradores.

Se trató de acompañar las prácticas generales del productor, realizándose las siembras, aplicaciones de fertilizante y fungicida, cuando el productor lo indicó, de manera de interferir lo mínimo posible con su operativa. En 4 localidades se colaboró realizando las fertilizaciones foliares, vía terrestre (Costas de San Francisco, Cebollatí,
Vuelta Grande e India Muerta); en las otras 2 (Rincón de Ramírez y $7^{a}$ Sección de Treinta y Tres), las mismas fueron realizadas en forma aérea.

En el cuadro 65 se presenta el conjunto de trabajos y los resultados obtenidos. En 3 de las localidades la alternativa propuesta produjo incrementos superiores al $10 \%$, en 2 de ellas fue superior al $5 \%$ y en Cebollatí rindió lo mismo. En el promedio de las 6 experiencias, las alternativas produjeron un $14,6 \%$ por encima del promedio del rendimiento obtenido con la tecnología utilizada por los productores del quintil superior de rendimientos.

Cuadro 65. Trabajos de validación 2016-2017. Resultados Rendimientos SL y SSL*.

\begin{tabular}{|c|c|c|c|c|c|c|c|c|}
\hline \multirow[t]{2}{*}{ Loc } & \multirow[t]{2}{*}{ Trt } & \multirow[t]{2}{*}{ Cultivar } & \multirow{2}{*}{$\begin{array}{c}\text { Rendimiento } \\
\text { SL } \\
\text { t/ha }\end{array}$} & \multicolumn{2}{|c|}{$\begin{array}{c}\text { Incremento } \\
\text { SL }\end{array}$} & \multirow{2}{*}{$\begin{array}{c}\text { Rendimiento } \\
\text { SSL } \\
\text { tha }\end{array}$} & \multicolumn{2}{|c|}{$\begin{array}{c}\text { Incremento } \\
\text { SSL }\end{array}$} \\
\hline & & & & tha & $\%$ & & tha & $\%$ \\
\hline RR & $\begin{array}{l}\text { TT } \\
\text { AP }\end{array}$ & $\begin{array}{l}\text { B Paso } 144 \\
\text { CH Quebracho }\end{array}$ & $\begin{array}{r}9,700 \\
10,555\end{array}$ & 0,86 & 88 & $\begin{array}{r}9908 \\
10576\end{array}$ & 0,67 & 6,7 \\
\hline $\mathrm{CSF}$ & $\begin{array}{l}\text { TT } \\
\text { AP }\end{array}$ & $\begin{array}{l}\text { 日 Paso } 144 \\
\text { INIAMerín }\end{array}$ & $\begin{array}{r}9,461 \\
11,979\end{array}$ & 2,52 & 26,6 & $\begin{array}{r}9,507 \\
12,234\end{array}$ & 2,73 & 28,7 \\
\hline $\begin{array}{l}7^{a} S \\
\pi\end{array}$ & $\begin{array}{l}\text { TT } \\
\text { AP }\end{array}$ & $\begin{array}{l}\text { 日 Paso } 144 \\
\text { INIAMerín }\end{array}$ & $\begin{array}{r}8,683 \\
10,901\end{array}$ & 2,22 & 25,5 & $\begin{array}{r}8,631 \\
10,945\end{array}$ & 2,31 & 268 \\
\hline $\mathrm{CE}$ & $\begin{array}{l}\text { TT } \\
\text { AP }\end{array}$ & $\begin{array}{l}\text { 日Paso } 144 \\
\text { Parao }\end{array}$ & $\begin{array}{l}8,780 \\
8,759\end{array}$ & $-0,02$ & $-0,24$ & $\begin{array}{l}9,077 \\
9254\end{array}$ & 0,18 & 1,9 \\
\hline VG & $\begin{array}{l}\text { TT } \\
\text { AP }\end{array}$ & $\begin{array}{l}\text { INIATacuarí } \\
\text { Parao }\end{array}$ & $\begin{array}{l}7,924 \\
9,235\end{array}$ & 1,31 & 17 & $\begin{array}{l}79919 \\
9330\end{array}$ & 1,41 & 17,8 \\
\hline $\mathrm{IM}$ & $\begin{array}{l}\text { TT } \\
\text { AP }\end{array}$ & $\begin{array}{l}\text { INIA Tacuarí } \\
\text { Parao }\end{array}$ & $\begin{array}{r}9,629 \\
10,685 \\
\end{array}$ & 1,06 & 11 & $\begin{array}{l}10,095 \\
10,816 \\
\end{array}$ & 0,72 & 7,1 \\
\hline $\begin{array}{l}\text { prom } \\
\text { 6loc }\end{array}$ & $\begin{array}{l}\text { TT } \\
\text { AP }\end{array}$ & $\begin{array}{l}\mathrm{EP} 144-\mathrm{Tac} \\
\mathrm{CHQ}-\mathrm{IMe}-\mathrm{P}\end{array}$ & $\begin{array}{r}9,029 \\
10,352\end{array}$ & 1,32 & 14,6 & $\begin{array}{r}9,189 \\
10,526\end{array}$ & 1,34 & 146 \\
\hline
\end{tabular}

*SL= seco y limpio; SSL= sano, seco y limpio; Loc= localización; Trt= tratamiento; RR= Rincón de Ramírez; $\mathrm{CSF}=$ Costa de San Francisco; $7^{\mathrm{a} S T T}=7^{\text {a }}$ Sección de Treinta y Tres; CE= Cebollatí; VG= Vuelta Grande; IM= India Muerta; $\mathrm{TT}=$ testigo tecnológico; $\mathrm{AP}=$ alternativa propuesta; prom= promedio; $\mathrm{EP} 144=\mathrm{EI}$ Paso 144; Tac= INIA Tacuarí; $\mathrm{CHQ}=\mathrm{CH}$ Quebracho; IMe= INIA Merín; P= Parao. 


\section{4 - DISCUSIÓN}

\subsection{Etapas realizadas}

El proyecto se construyó a través de la planificación de distintas etapas, realización de la encuesta a productores integrantes del quintil superior de rendimientos, investigación parcelaria durante 2 años y validación en el último año, importantes cada una de ellas e interdependientes, de tal manera que la ejecución de la siguiente precisó disponer de los resultados de la anterior para definir su ejecución.

Previo a la realización de la segunda etapa correspondiente a la investigación parcelaria, el comité técnico discutió y seleccionó factores y/o subfactores cuyos efectos pudieran ser estudiados en pequeñas o medianas parcelas, dispuestas al azar y con repeticiones, instaladas en predios de productores y manejadas por los mismos. Existe vasta experiencia de investigación regional, sobre las incomodidades que acarrea a los productores el realizar manejos diferentes en tiempo y forma a los generales puestos en práctica en sus predios, lo que conduce a posibilidades de incrementar pérdidas o alteraciones de los tratamientos inicialmente planificados. Por tal motivo, no se tuvieron en consideración como variables de estudio en los trabajos de evaluación factores importantes a tener en cuenta para lograr altos rendimientos, como lo son sin duda la época de siembra, la nivelación de suelos y construcción de drenajes y el uso del riego en tiempo y forma.

Sin cumplir con esos requisitos o prácticas fundamentales, de nada sirven los resultados generados en este trabajo. De acuerdo a su objetivo general, el proyecto buscó detectar alternativas para lograr incrementos del rendimiento por encima de los obtenidos por los productores integrantes del quintil superior. Las bases fundamentales del manejo necesarias para obtener alta productividad, quedan explícitas en la información recogida y presentada en los resultados de la encuesta.
Cuanto más próximos al rendimiento potencial nos encontremos, más pequeña será la posibilidad de lograr aumentos. Para ello fue indispensable que la estrategia de fertilización aplicada permitiera superar los déficits nutricionales del suelo y que los productores hayan aplicado el manejo adecuado al sitio de producción y logrado una fecha de siembra que asegure la radiación solar y las temperaturas necesarias para la expresión del potencial productivo. Cualquier alteración a estos aspectos de manejo, condicionan la posible expresión de resultados favorables a esperar en las condiciones climáticas disponibles.

Otra decisión adoptada por el comité técnico en forma previa a la segunda etapa fue considerar solamente variedades convencionales de alta productividad y resistencia a Brusone como cultivares alternativos a incluir en los tratamientos, excluyendo como opción la posibilidad de seleccionar materiales híbridos. Estos estaban disponibles, pero al momento de definición de este tema, existían dudas respecto a su aceptación en los mercados del arroz uruguayo.

\subsection{Formación del rendimiento}

La intensificación del sistema de producción de arroz debe ser lograda a través del uso de prácticas de calidad ambiental aceptables, lo que se suele definir como «intensificación sostenible».

En su análisis sobre la «Intensificación ecológica de los sistemas de producción de cereales» Cassman (1999) concluye que la seguridad alimentaria mundial dentro de 30 años dependerá de los rápidos avances científicos en la comprensión de la base fisiológica del potencial de rendimiento, los procesos que rigen la relación entre la calidad del suelo, la productividad de los cultivos y la ecología de las plantas, relacionadas con los factores ambientales que 
interactúan y determinan los rendimientos de los cultivos

Matsushima (1966) fue uno de los pioneros en el análisis del rendimiento utilizando varios de sus componentes en arroz irrigado. Estos componentes, número de plantas por metro cuadrado, número de panojas por planta, número de espiguillas por panoja, peso de granos, se forman secuencialmente en diferentes etapas del ciclo de crecimiento de la planta (Yoshida, 1981). Los valores máximos o potenciales de estos componentes de rendimiento dependen del cultivar (Siband et al., 1999). La estructura de rendimiento de cultivares modernos convencionales ampliamente adoptados son muy diferentes, tienen menos panojas por planta pero significativamente más espiguillas por panoja (Khush y Peng, 1996). Estas características contribuyen a determinar el rendimiento potencial de una variedad, incluida su plasticidad en la formación de los componentes del rendimiento en función de las relaciones de competencia por los recursos (Siband et al., 2004).

Cada componente de rendimiento tiene un valor máximo específico relativo a la variedad, que solo puede lograrse en condiciones climáticas óptimas, de la radiación solar y la temperatura (Yoshida, 1981). La formación de algunos componentes de rendimiento es muy variable y puede depender de los componentes de rendimiento formados previamente; si las panojas por unidad de superficie son más numerosas, generalmente también son más pequeñas. Esto surge de la presión de la competencia dentro de la población de plantas, es decir, la competencia entre las plantas con respecto a la formación de macollos, espiguillas o granos. El estado de competencia o la plasticidad fenotípica en la formación de componentes de rendimiento es específico de variedad y se puede definir como la capacidad de la planta para reaccionar a las condiciones del entorno de cultivo a través de la variación del componente de rendimiento (Siband et al., 2004).

Los componentes de rendimiento también se ven afectados por las condiciones de estrés locales, es decir, los relacionados con la disponibilidad de nutrientes, las prácticas de cultivo, la salinidad, la acidez o las plagas y enfermedades (Wey et al., 1999). En algunos casos, el efecto de un componente de rendimiento puede ser compensado parcial o totalmente por un mayor valor del componente de rendimiento siguiente (Deambrosi et al., 2007).

El nitrógeno, el fósforo y el potasio son elementos esenciales para el crecimiento de las plantas de arroz. Las mismas pueden obtener gran parte del $\mathrm{N}$ que requieren del suelo. En Uruguay aproximadamente 50$70 \%$ del $\mathrm{N}$ absorbido al tiempo de la elongación de entrenudos (Méndez y Deambrosi, 2009) proviene del suelo, pero no es suficiente para obtener muy altos rendimientos, por lo que se debe suministrar el complemento necesario. La demanda de $\mathrm{N}$ está asociada a las etapas de crecimiento: al comienzo con el macollaje, contribuyendo a la formación del número de panojas $/ \mathrm{m}^{2}$, con la cantidad de granos por panoja al tiempo de formación de estas últimas, y en presencia de buenas condiciones de radiación solar con el llenado de granos en la maduración. El fósforo es importante en las primeras etapas de crecimiento promoviendo el desarrollo de las raíces y el macollaje; también tiene incidencia en el acortamiento del ciclo, promoviendo floraciones y madurez más tempranas. El potasio no es un componente de compuestos orgánicos en las plantas, pero es un cofactor para 60 o más enzimas, es importante para la respiración, y translocación de asimilatos. Dentro de sus efectos generales favorece el macollaje, incrementa el tamaño y peso de granos, participa en la apertura y cierre de estomas, otorga mayor tolerancia a condiciones climáticas desfavorables, contribuye a una mayor tolerancia a las enfermedades, incrementa la fortaleza de los tallos reduciendo el vuelco y aumenta la respuesta a la aplicación de otros nutrientes ( $\mathrm{N}$ y $\mathrm{P}$ principalmente). 


\subsection{Variables climáticas}

\subsubsection{Temperatura, precipitaciones, viento}

De mayor incidencia localidad-específica han sido las variaciones de temperatura que ocurren durante el período de siembracosecha en las distintas zonas de producción del país, con énfasis en la zona ubicada más al Sur de la Cuenca de la Laguna Merín. Según nuestra experiencia, cuando ocurren temperaturas mínimas bajas, especialmente durante 3 o 4 días consecutivos en las etapas más sensibles del cultivo (estado de microsporas jóvenes después de la división meiótica) se ve afectada la producción de arroz (Deambrosi et al., 1997, 2007). Cuando esos problemas no suceden, las chacras ubicadas en el Departamento de Rocha que muchos años tienen un rendimiento inferior pasan a ser de las más potencialmente productivas.

Se tomaron registros en estaciones agroclimáticas instaladas próximas a los experimentos, durante parte del período de conducción de los mismos, en la zafra 20142015 en Rincón de Ramírez, Cebollatí e India Muerta.

En general se observaron tendencias generales similares en las variaciones de temperatura, no detectándose períodos críticos de ocurrencia de bajas temperaturas por debajo de $15^{\circ} \mathrm{C}$, considerada problemática en nuestras condiciones (Figura 1 , Anexo II). Las temperaturas más bajas ocurrieron en la zona de India Muerta; en Cebollatí las temperaturas máximas fueron menores, y las mínimas mayores, dando como resultado una amplitud térmica menor que en las otras 2 localidades.

Para dar una idea indirecta de la escasa nubosidad presente en las chacras durante los períodos reproductivo y de llenado de granos de la primera zafra, se pueden observar las precipitaciones ocurridas entre el 13 de enero y 13 de marzo; se registraron 147 mm en Rincón, 115 mm en Cebollatí y $101 \mathrm{~mm}$ en India Muerta (Figura 2, Anexo II).
Se destaca la ocurrencia de viento, en proximidades de la Laguna Merín, presentando Cebollatí los máximos valores de velocidad de viento durante la mayor parte del período de registro (Figura 3, Anexo II). Este es un problema que afecta seriamente el manejo del cultivo de los productores de la zona, por su alta incidencia en la calidad de la aplicación de los agroquímicos, en especial de herbicidas y fungicidas y en menor grado en las coberturas nitrogenadas y en consecuencia en la eficiencia de utilización de los mismos.

De forma similar, en la zafra siguiente 2015-2016 se tomaron algunos registros en Costas de San Francisco y Cebollatí. En el mes de febrero se pudieron observar registros más altos de temperaturas máximas en San Francisco. Confirmando las observaciones del año anterior, con respecto a las características particulares de Cebollatí, nuevamente se registraron allí temperaturas mínimas más altas y amplitudes térmicas menores, así como vientos más fuertes (Figuras 4 y 5 , Anexo II).

Si bien no es la idea principal su presentación y discusión en esta sección, en el caso de San Francisco donde se tomaron registros desde la primavera, se puede observar la ocurrencia de temperaturas mínimas por debajo de $10^{\circ} \mathrm{C}$ en noviembre y principios de diciembre. Es importante considerar estos eventos, al momento de aplicar algunos herbicidas sobre plantas de arroz recién emergidas, en particular del tipo indica, pues pueden encontrarse en estado de estrés térmico y pasibles de manifestar efectos fitotóxicos al recibir los productos.

Utilizando registros de la zafra 20162017, se comparó si en sitios no muy distantes, como pueden ser Paso de la Laguna e India Muerta (no más de $60-70 \mathrm{~km}$ en línea recta), pueden existir diferencias importantes en temperatura, influenciadas quizás por las condiciones topográficas.

Se calcularon las acumulaciones térmicas (Grados Días, GD con base 10), registradas en ambas localidades entre el 1 de enero y el 10 de abril de 2017 (metodología utilizada para la predicción de ocurrencia de eventos fisiológicos en el Boletín 
Agroclimático de INIA). Las mismas son presentadas con la suma térmica total del período mencionado y en forma parcial a través de los promedios diarios mensuales de enero-febrero-marzo y los últimos 10 días del mes de abril. En su totalidad, en India Muerta se acumularon 1156,7 GD, 125,9 menos que en Paso de la Laguna (1282,5 GD), lo que representa un $9,2 \%$. A su vez, todos los valores parciales en los distintos meses resultan también menores. Esto significa que en esas condiciones, un material genético precisa de más días calendario para completar su ciclo siembra-madurez (Cuadro 1, Anexo II). Dependiendo de cuándo se siembre una chacra y qué cultivar se utilice, se puede estimar cuándo ocurrirán los procesos. Por ello, es muy importante la elección de la variedad a utilizar, dependiendo de las posibilidades de las que dispone el productor, de manera de no sólo ubicar la floración en una época de menor riesgo con respecto a las bajas temperaturas, sino también la fecha de madurez para cosechar el grano en las mejores condiciones ambientales.

\subsubsection{Radiación solar}

Yoshida y Parao (1976) encontraron que el factor limitante más importante del rendimiento fue el número de espiguillas por unidad de superficie, que estuvo altamente correlacionado con la radiación solar y temperatura durante el estado reproductivo, 25 días antes de la floración. También indicaron que los efectos de sombreado sobre el rendimiento durante este período fueron mayores que durante el llenado de granos. Por su parte, Evans y De Data (1979) concluyeron de sus estudios que es evidente la importancia de la radiación solar en ambos períodos antes y después de la floración. En nuestra zona de producción, se encontró una alta asociación de la respuesta de cultivares indica, EI Paso 144 e INIA Olimar, a la aplicación de nitrógeno con la mayor disponibilidad de radiación solar durante el período de 40 días en torno al $50 \%$ de floración, 20 días antes a 20 días después de la misma (Deambrosi y Méndez, 2007).
Según Abal et al. (2011) la variación territorial de la irradiación en Uruguay es mucho menor que la estacional, debido a la relativa uniformidad geográfica de nuestro territorio. La irradiación global diaria, promedio del territorio nacional es de $4,4 \mathrm{kWh} / \mathrm{m}^{2}$. La variación estacional es grande con valores mínimos de $2 \mathrm{kWh} / \mathrm{m}^{2}$ en junio y máximos de $7 \mathrm{kWh} / \mathrm{m}^{2}$ en los diciembre-enero. Las medias anuales muestran un mínimo de $3,9 \mathrm{kWh} / \mathrm{m}^{2}$ en Rocha y un máximo de 4,7 $\mathrm{kWh} / \mathrm{m}^{2}$ en la zona norte (Artigas, Rivera, Paysandú). En términos relativos al promedio, la variabilidad territorial es algo mayor en invierno (llegando a 14\%) que en verano $(8 \%)$. Los autores reportan que existe una rotación estacional de las isolíneas de irradiación constante; en los meses de invierno aparecen casi alineadas con los paralelos, y a medida que se avanza hacia el verano, se observa una rotación de las isolíneas en sentido antihorario, de modo que durante el período del cultivo de arroz presentan una alineación aproximada SurOeste - Nor-Este, aproximadamente paralelas a la costa oceánica.

Para disponer de un mayor respaldo de información climática en los trabajos de validación, en 2016 se adquirieron piranómetros para medir la radiación solar disponible en diferentes sitios. En la figura 7 (Anexo II) se presentan las radiaciones solares registradas en 5 localidades, Rincón de Ramírez, Costas de San Francisco, Paso de la Laguna (próxima a las localizaciones de la $7^{\text {a }}$ Sección de Treinta y Tres y Vuelta Grande en Rocha), Cebollatí e India Muerta, a partir de enero de 2017.

En general se puede apreciar una tendencia general similar, con valores superiores a comienzos de año, intermedios en el mes de febrero y principios de marzo, para descender en forma importante sobre fines de dicho mes. No obstante, se observa que en Paso de la Laguna en las 2 primeras décadas de enero y en India Muerta en la primera de febrero, se registraron valores inferiores respecto al promedio de todas las situaciones, de más de $2 \mathrm{MJ} / \mathrm{m}^{2} /$ día. Cinco de 6 observaciones en Paso de la Laguna y 3 de 6 en India Muerta en los 2 primeros 
meses del año, son menores que las registradas en la otras 3 localidades.

Dado que no se dispuso de registros de radiación solar en cada uno de los sitios en la etapa de investigación parcelaria, como marco general de referencia de los ambientes disponibles en las 3 zafras 2014-2015, 2016-2017 y 2017-2018, en la figura 29 se puede observar los valores registrados en la Estación Agroclimática de Paso de la Laguna, ubicada aproximadamente en un lugar central, distante no más de 60-70 km de los 14 sitios de evaluación utilizados. No por ello, se deja de reconocer la posibilidad que pueden haber existido pequeños desvíos propios de cada localización, como el mencionado en el párrafo anterior.

A primer golpe de vista se destacan las condiciones existentes en la zafra 20152016 con muy buena y estable disponibilidad, superior o igual a los $18 \mathrm{MJ} / \mathrm{m}^{2} /$ día desde comienzos de año hasta fines de febrero, con un pico máximo de 24 a mediados de enero. A comienzos de abril, se invirtieron las condiciones, pasando a ser la zafra de peor disponibilidad. Estos registros están acordes con las productividades obtenidas en la investigación parcelaria en las distintas localidades en 2015-2016, reafirmando una vez más la incidencia de la radia- ción solar en el logro de altas productividades, utilizando la misma tecnología. En Rincón de Ramírez en esta zafra el tratamiento $\mathrm{N}^{\circ} 1$ (testigo tecnológico) rindió 13,5 t/ha SL contra 12,234 t/ha SL obtenidas en el año anterior (10,3\% superior). En Costas de San Francisco (2015-2016) el tratamiento 1 rindió $12,336 \mathrm{t} / \mathrm{ha} \mathrm{SL}$, cuando había rendido 11,324 t/ha SL el año anterior en la $7^{\text {a }}$ Sección de Treinta y Tres (8,9 \% más). En Cebollatí 2015-2016, se cosecharon 11,723 t/ha SL con el tratamiento 1 , cuando se habían logrado 9,023 t/ha SL en 2014-2015 (29,9\% más) y por último en India Muerta, fue el lugar donde se encontró la diferencia menor, $11,149 \mathrm{t} /$ ha SL en la primera zafra y $11,604 \mathrm{t} / \mathrm{ha} \mathrm{SL}$ en la segunda $(4,1 \%)$.

Si bien en el primer año también ocurrieron picos de alta disponibilidad de radiación, su ocurrencia fue más variable, pudiendo quizás favorecer la expresión del rendimiento de algunos tratamientos de acuerdo a cuando ocurrieron sus eventos fenológicos más importantes en la construcción de su productividad. Como posible ejemplo de tal razonamiento, en la zafra 2014-2015 el tratamiento $\mathrm{N}^{\circ} 9$ de $\mathrm{CH}$ Quebracho en Rincón de Ramírez, máxima productividad alcanzada en la toda la serie de trabajos, alcanzó su mayor valor individual en una

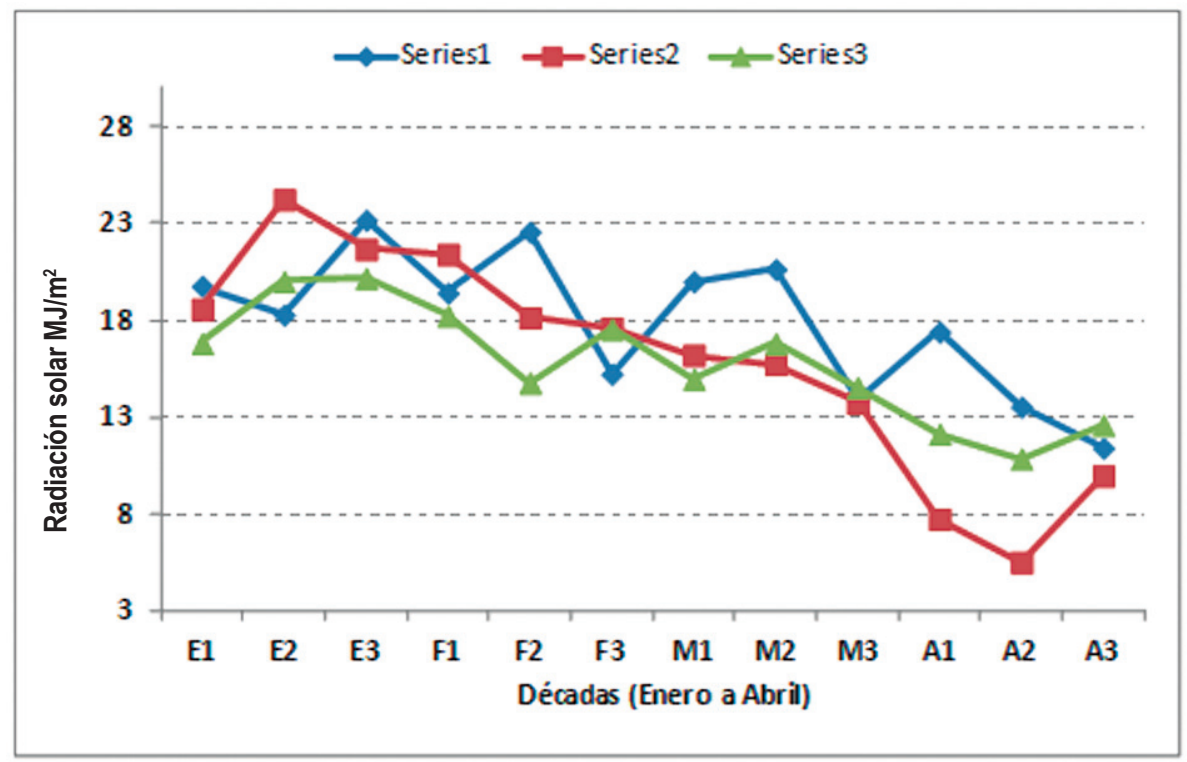

Figura 29. Radiaciones solares registradas en Paso de la Laguna en las zafras 2014-2015, 2015-2016 y 2016-2017 (series 1, 2 y 3 respectivamente). 
repetición (de las 3 conducidas) donde se registró el inicio de floración antes de que ocurrieran en sus pares.

En la figura anterior, se puede observar que la zafra 2016-2017 donde fueron conducidos los trabajos de validación fue la que en general ofreció menor oferta solar desde comienzos mediados de enero hasta fines de marzo.

\subsection{Resultados obtenidos}

\subsubsection{Productividad de grano/ha}

En la etapa de investigación parcelaria, zafras 2014-2015 y 2015-2016, en ensayos localizados en 4 sitios de producción de la zona este del país se contrastaron la tecnología base correspondiente a los productores integrantes del quintil superior de rendimientos con 11 tratamientos alternativos. En períodos de cultivo donde en general no ocurrieron temperaturas bajas que pudieran afectar la productividad se cosecharon en promedio de los 2 años 11,624 t/ha de arroz seco y limpio (SL) con $13 \%$ de humedad y $11,972 \mathrm{t} /$ ha sano, seco y limpio (SSL) con la tecnología testigo y $12,491 \mathrm{t} / \mathrm{ha}(\mathrm{SL})$ y $12,796 \mathrm{t} / \mathrm{ha}$ (SSL) con los mejores tratamientos seleccionados en cada localización $\left(\mathrm{N}^{\circ}\right.$ 9 en Rincón de Ramírez, $7^{a}$ Sección. de Treinta y Tres - Costas de San Francisco, e India Muerta y $\mathrm{N}^{\circ} 12$ en Cebollatí). Los incrementos promedio obtenidos con las propuestas alternativas fueron de $7,5 \%$ en arroz seco y limpio (SL) y de $6,9 \%$ en sano, seco y limpio (SSL).

\section{Análisis de contrastes}

Como una opción diferente y complementaria a la información generada en el análisis tradicional de tratamientos dispuestos en bloques al azar utilizado en la investigación parcelaria, se realizaron contrastes ortogonales. En ellos se compararon los efectos de cada uno de los factores o subfactores elegidos (cultivar, instalación del cultivo, fertilización 1, fertilización plus, protección de enfermedades) en 2 escenarios posibles, resultantes de la puesta en ejecución simultánea del resto de las prácticas de manejo correspondientes a una u otra de las tecnologías de producción utilizadas (testigo tecnológico, TT; propuestas alternativas, PA). Del conjunto de análisis realizados se puede considerar que:

- en general existió incidencia de las condiciones climáticas existentes en cada zafra en la expresión de efectos de las prácticas comparadas;

- las variedades alternativas superaron o igualaron en rendimiento a las utilizadas por los mejores productores cuando se aplicaron las prácticas PA; EI Paso 144 en el ambiente "Cebollatí» rindió muy bien con la tecnología PA en las 2 zafras, repitiendo el nivel de productividad (217 bolsas promedio);

- solamente en una situación de 8 posibles, la alternativa de «instalación del cultivo» resultó superior a la comúnmente usada por los productores, usando el resto de prácticas TT. Nuevamente Cebollatí, en la zafra 2014-2015 fue el ambiente, donde se observó la diferencia;

- utilizando la tecnología PA, en 6 de las 8 situaciones (2 zafras) no hubo diferencias por usar la práctica alternativa de instalación y en las 2 restantes, se logró mayor rendimiento con la normalmente utilizada por los productores;

- la estrategia de fertilización alternativa incluida en el paquete de manejo TT, solamente permitió incrementar el rendimiento en una ocasión (Costas de San Francisco 2015-2016). Usando en su totalidad las prácticas del manejo PA, la alternativa propuesta elevó el rendimiento en 2 oportunidades (Rincón de Ramírez y $7^{\text {a }}$ de Treinta y Tres en 2014-2015);

- no se detectaron efectos importantes del factor denominado "Fertilización Plus» en el rendimiento. Solamente en una de las 16 comparaciones realizadas (incluyendo TT y PA) se encontró una tendencia a disminuir el rendimiento por su inclusión ( $7^{\mathrm{a}}$ de Treinta y Tres 2014-2015; (p: 0,008);

- en 2 de las 8 condiciones ambientales donde se realizaron las evaluaciones se pudieron observar síntomas de Brusone 
en cultivos próximos a los experimentos (India Muerta 2014-2015 y Cebollatí 2015-2016). Sólo en Cebollatí 2015-2016 se encontraron diferencias significativas en rendimiento por realizar una doble aplicación de fungicidas, tanto en la comparación de prácticas TT como PA.

Los altos rendimientos fueron obtenidos mediante la combinación de distintas prácticas de manejo seleccionadas, cultivares apropiados para la zona, estrategias de fertilización $(\mathrm{N}, \mathrm{P}, \mathrm{K})$, aplicación de un fertilizante foliar al macollaje, suministro de $\mathrm{Si}$ en 2 épocas, macollaje y comienzo de floración. Ello fue acompañado en el caso del tratamiento $\mathrm{N}^{\circ} 9$ con la práctica de instalación comúnmente utilizada por el productor (tratado de semilla con tebuconazol más thiametoxan; densidades de siembra 130 kg/ha en Treinta y Tres y 170 kg/ha en India Muerta). Al utilizar variedades resistentes o tolerantes a Brusone, el manejo preventivo de enfermedades en el tratamiento 9 se realizó con una sola aplicación de un fungicida junto a sílice y fosfito de potasio, a comienzos de floración. En el caso de Cebollatí donde se seleccionó el tratamiento 12, en el tratamiento de semillas además de los 2 productos ya nombrados se usó zinc y la semilla fue posteriormente inoculada con Endorice (Herbaspirillum sp.); en el manejo de enfermedades se usó la práctica testigo de hacer una aplicación preventiva de fungicida, a comienzos de floración y de aparecer síntomas de Brusone realizar una segunda pulverización a los 15-20 días.

Se encontró interacción estadísticamente significativa en los análisis realizados entre efectos de tratamientos con el año de ejecución, mostrando la importancia del marco ambiental en la expresión de los mismos.

Los trabajos de validación fueron un gran desafío para el comité técnico del proyecto. Por un lado, por la responsabilidad asumida en la selección de la alternativa que se consideró más adecuada para cada localidad. Por otro, por el riesgo que implicaba que las condiciones ambientales disponibles en la zafra 2016-2017, fueran muy diferentes a las registradas en los 2 años anterio- res. Por último, porque se trabajó con una superficie mucho mayor donde es esperable que exista mayor desuniformidad de condiciones y por tanto mayor variabilidad en la posible expresión de efectos de los factores, ya sean simples, así como de sus interacciones.

La etapa de validación realizada en predios de 6 productores en Treinta y Tres y Rocha confirmó la validez de las propuestas tecnológicas alternativas. Con ellas se lograron los siguientes rendimientos: Rincón de Ramírez 10,555 t/ha SL y 10,576 t/ha SSL; Costas de San Francisco 11,979 t/ha SL, 12,234 t/ha SSL; $7^{\text {a }}$ Sección de Treinta y Tres 10,901 t/ha SL, 10,945 t/ha SSL; Cebollatí 8,759 t/ha SL, 9,254 t/ha SSL; Vuelta Grande 9,235 t/ha SL, 9,330 t/ha SSL; India Muerta 10,685 t/ha SL, 10,816 t/ha SSL. Utilizando la media de los seis sitios, 10,352 t/ha SL, 10,526 t/ha SSL en las propuestas alternativas y $9,029 \mathrm{t} / \mathrm{ha} \mathrm{SL}, 9,189 \mathrm{t} / \mathrm{ha} \mathrm{SSL}$ en los TT, el aumento fue de $14,5 \%$ SL y $14,7 \%$ SSL. Se destaca que tampoco en esta zafra ocurrieron temperaturas bajas durante el período reproductivo del arroz, que pudiera afectar su producción.

\subsubsection{Rendimientos obtenidos en la validación vs la investigación parcelaria}

En el cuadro 66 se pueden apreciar los rendimientos obtenidos en los tratamientos 1 y 9 en general (o 12 en Cebollatí), correspondientes a los testigos tecnológicos y a las propuestas alternativas en los 14 ambientes manejados en las 3 zafras, 4 por año en la primera fase y los 6 correspondientes al tercer año. Por un lado, se presenta la productividad obtenida en los trabajos expresada en cantidad de grano, seco y limpio, expresado en $13 \%$ de humedad, de manera de poder ser comparada con las producciones generadas en otras regiones o sistemas de producción. El país es exportador y la calidad del producto es una característica que lo distingue en el concierto internacional y una de las preocupaciones permanentes que los mejoradores genéticos tienen en consideración al momento de seleccionar sus materiales. Por tal 
motivo, como estaba expresado en la redacción del proyecto los rendimientos obtenidos también son presentados en grano sano, seco y limpio, la forma por la que el productor en Uruguay recibe el pago cuando entrega su arroz en la industria.

En el resumen general, se observa que en la investigación parcelaria la propuesta alternativa supera en rendimiento al obtenido con la tecnología testigo en un $7,5 \%$ en arroz SL y un 6,9\% en SSL. En los trabajos de validación, esas diferencias se incrementaron al doble, en promedio 14,7 y $14,6 \%$ respectivamente, mostrando lo contrario a lo que se piensa habitualmente, que las ventajas demostradas por el uso de nuevas tecnologías generadas en pequeñas o medianas parcelas es difícil de reproducir cuando se traslada la operativa a superficies mayores. La excepción en el concepto expresado, lo constituye la localización Cebollatí; allí en el trabajo de validación no se encontraron diferencias entre las 2 tecnologías puestas en ejecución, cuando en la etapa de in- vestigación la alternativa en promedio rindió en promedio un $7,3 \%$ más. Cabe recordar que allí en el tratamiento 12 se utilizó en la siembra semilla de Parao de calidad y vigor subóptimos, se logró una implantación inferior en número al tratamiento 1 (158 vs 322 plantas $/ \mathrm{m}^{2}$ ) y más lenta, lo que incidió en el ciclo del cultivo, floreciendo más tarde que El Paso 144. Según los muestreos de componentes de rendimiento, también fue diferente cómo las plantas de Parao utilizaron la energía y los nutrientes absorbidos para llegar a la cosecha con un número similar de panojas por unidad de superficie (590-584 panojas $/ \mathrm{m}^{2}$ ), más granos llenos (54.073-40.753/ $\mathrm{m}^{2}$ ) y menor peso de granos (PMG $=26-27,7$ gramos). Quizás ello haya tenido incidencia en una performance diferente a la esperada del tratamiento 12.

En el cuadro 67 se observa que con la tecnología testigo usada por los productores integrantes del quintil superior, el rendimiento relativo obtenido en las validaciones respecto al logrado en las parcelas pequeñas

Cuadro 66. Rendimientos SL y SSL obtenidos en 14 ambientes en las zafras 2014-2015, 2015-2016 (investigación parcelaria) y 2016-2017 (validaciones)*

\begin{tabular}{|c|c|c|c|c|c|c|c|c|}
\hline \multirow[t]{3}{*}{$\bar{G}$} & \multirow[t]{3}{*}{ Loc } & \multirow[t]{3}{*}{ Zafra } & \multicolumn{3}{|c|}{ Rendimiento SLt/ha } & \multicolumn{3}{|c|}{ Rendimiento SSL t/ha } \\
\hline & & & \multicolumn{2}{|c|}{ Tecnología } & \multirow{2}{*}{$\begin{array}{l}\text { Ren Rel } \\
\text { PAIT \% }\end{array}$} & \multicolumn{2}{|c|}{ Tecnología } & \multirow{2}{*}{$\begin{array}{l}\text { Ren Rel } \\
\text { PAVT \% }\end{array}$} \\
\hline & & & TT & $\mathrm{PA}$ & & TT & $\mathrm{PA}$ & \\
\hline \multirow{9}{*}{1} & \multirow{4}{*}{$\mathrm{RR}$} & $2014-15$ & 12,334 & 14,301 & 115,9 & 12,803 & 14,899 & 116,4 \\
\hline & & $2015-16$ & 13,500 & 12,985 & 96,2 & 13,886 & 13,135 & 94,6 \\
\hline & & prom & 12917 & 13,643 & 105,6 & 13,345 & 14,017 & 105,0 \\
\hline & & $2016-17$ & 9,700 & 10,555 & 108,8 & 9,908 & 10,576 & 106,7 \\
\hline & \multirow{3}{*}{$\begin{array}{c}7^{\mathrm{a}} \mathrm{STT} \\
\mathrm{CSF}\end{array}$} & $2014-15$ & 11,324 & 11,996 & 105,9 & 11,491 & 12,205 & 106,2 \\
\hline & & $2015-16$ & 12,336 & 13,369 & 108,4 & 12,336 & 12,957 & 105,0 \\
\hline & & prom & 11,830 & 12,683 & 107,2 & 11,914 & 12,581 & 105,6 \\
\hline & \multirow{3}{*}{$\begin{array}{c}7^{\mathrm{a}} \mathrm{STT} \\
\mathrm{CSF} \\
\end{array}$} & $2016-17$ & 8,683 & 10,901 & 125,5 & 8,631 & 10,945 & 126,8 \\
\hline & & $2016-17$ & 9,461 & 11,979 & 126,6 & 9,507 & 12,234 & 128,7 \\
\hline \multirow{4}{*}{2} & & $2014-15$ & 9,023 & 9,944 & 110,2 & 9,397 & 10,311 & 109,7 \\
\hline & \multirow{3}{*}{ CE } & $2015-16$ & 11,723 & 12,310 & 105,0 & 12,092 & 12,949 & 107,1 \\
\hline & & prom & 10,373 & 11,127 & 107,3 & 10,745 & 11,630 & 108,2 \\
\hline & & $2016-17$ & 8.780 & 8.759 & 99.8 & 9.077 & 9.254 & 1019 \\
\hline \multirow{5}{*}{3} & \multirow[t]{3}{*}{$\mathrm{IM}$} & 2014-15 & 11,149 & 12,174 & 109,2 & 11,561 & 12,636 & 109,3 \\
\hline & & $2015-16$ & 11,604 & 12,845 & 110,7 & 12,208 & 13,272 & 108,7 \\
\hline & & prom & 11,377 & 12,510 & 110,0 & 11,885 & 12,954 & 109,0 \\
\hline & \multirow{2}{*}{$\begin{array}{l}V G \\
I M\end{array}$} & $2016-17$ & 7,924 & 9,235 & 116,5 & 7,919 & 9,330 & 117,8 \\
\hline & & $2016-17$ & 9,629 & 10,685 & 1110 & 10,095 & 10,816 & 1071 \\
\hline \multirow{2}{*}{\multicolumn{2}{|c|}{$\begin{array}{l}\text { Todos } \\
\text { promedios }\end{array}$}} & Irw.parc. & 11,624 & 12,491 & 107,5 & 11,972 & 12,796 & 106,9 \\
\hline & & Validación & 9,029 & 10,352 & 114,7 & 9.189 & 10,526 & 114,6 \\
\hline
\end{tabular}

${ }^{*} \mathrm{Gr}=$ Grupo de productores; Loc= localización; $\mathrm{SL}=$ seco y limpio; SSL= sano, seco y limpio; TT= testigo tecnológico; PA= propuesta alternativa; Ren Rel= rendimiento relativo; RR= Rincón de Ramírez; $7^{\text {a }} \mathrm{STT}=7^{\mathrm{a}}$ Sección de Treinta y Tres; CSF= Costas de San Francisco; CE= Cebollatí; IM= India Muerta; VG= Vuelta Grande; Inv. parc. = investigación parcelaria. 
Cuadro 67. Relaciones entre resultados obtenidos en rendimiento SL y SSL entre la investigación parcelaria y la validación y entre las tecnologías testigo y alternativa

\begin{tabular}{lcccc}
\hline Fuente de información & \multicolumn{4}{c}{ Rendimientos t/ha } \\
\cline { 2 - 5 } & $\mathrm{SL}$ & $\mathrm{SL}$ & $\mathrm{SSL}$ & $\mathrm{SSL}$ \\
& Testigo & $\begin{array}{c}\text { Propuesta. } \\
\text { Tecnológico }\end{array}$ & $\begin{array}{c}\text { Alternativa } \\
\text { Tecnológico }\end{array}$ & $\begin{array}{c}\text { Propuesta } \\
\text { Alternativa }\end{array}$ \\
\hline Irw estiqación parcelaria & 11,624 & 12,491 & 11,972 & 12,786 \\
Validación & 9,029 & 10,352 & 9,189 & 10,526 \\
\hline Porcentajes (\%) entre generado & 77,7 & 82,9 & 76,7 & 82,3 \\
en Validación / I $\mathrm{m}$. Parcelaria & & & \\
\hline
\end{tabular}

es del orden del $77,7 \%$ SL y $76,7 \%$, SSL mientras que, con el ajuste de algunas prácticas introducidas en las propuestas alternativas, disminuyen las diferencias entre los resultados generados por las distintas evaluaciones (82,9\% SL; 82,3\% SSL).

\subsubsection{Construcción de los rendimientos y su potencial}

¿En base a qué elementos se construyeron los altos rendimientos obtenidos en los trabajos conducidos en las 4 localidades en 3 años de ejecución? ¿Tienen puntos de encuentro, o se edificaron en distinta forma de acuerdo a las condiciones en que se generaron?

En el cuadro 68 se presentan los componentes del rendimiento de algunos tratamientos que fueron seleccionados subjetivamente por su productividad en cada una de las situaciones manejadas, su promedio y rangos de variación. Se incluyen promedios de tratamientos donde se sembró El Paso 144 y CH Quebracho en Rincón de Ramírez (tratamiento 9 en zafra
2014-2015 y general de todos los tratamientos en 2015-2016), El Paso 144 e INIA Merín en $7^{\text {a }}$ Sección de Treinta y Tres (tratamientos 4, 9, 11 y 12 en zafra 2014-2015) y Costas de San Francisco (tratamientos 7, 9 y 11 en zafra 2015-2016), EI Paso 144 y Parao en Cebollatí (tratamientos 8, 9 y 12 en zafra 2014-2015 y tratamiento 12 en 1015-2016) y solamente Parao en India Muerta (tratamientos 2 y 9 en 2014-2015 y tratamientos 9 y 11 en 2015-2016) . La productividad promedio de los tratamientos seleccionados fue de 12,9 t/ha con un rango de variación de $+/-9,7 \%$. Los altos rendimientos fueron obtenidos con la producción promedio de 47.500 granos llenos $/ \mathrm{m}^{2}$, logrados con la formación de 547 panojas $/ \mathrm{m}^{2}$ de 98 granos de los cuales se llenaron el $89 \%$. En India Muerta se formó la cantidad potencial más alta de granos a llenar (61.152), basada en la producción de 624 panojas $/ \mathrm{m}^{2}$. El rango de variación porcentual más alto se encontró en el número de granos vacíos, dado por el bajo promedio registrado (10 granos por panoja).

Cuadro 68. Componentes del rendimiento promedio en tratamientos de alta productividad en 4 localizaciones, zafras 2014-2015 y 2015-2016*.

\begin{tabular}{|c|c|c|c|c|c|c|c|}
\hline Localización & $\begin{array}{c}\text { Rend. SSL } \\
\text { tha }\end{array}$ & Pan $/ \mathrm{m}^{2}$ & $\mathrm{G} \| / \mathrm{p}$ & GT/p & $\mathrm{GV} / \mathrm{p}$ & $\mathrm{G}\|-\mathrm{s}\| / \mathrm{m}^{2}$ & PMG \\
\hline Rincón de Ramírez & 14,224 & 535 & 82 & 90 & 8 & 43.748 & 31,58 \\
\hline $7^{a}$ T. Tres- San Francisco & 12,592 & 511 & 96 & 105 & 9 & 49.151 & 28,47 \\
\hline Cebollatí & 11,731 & 519 & 85 & 97 & 11 & 44.913 & 28,44 \\
\hline India Muerta & 13,007 & 624 & 84 & 98 & 13 & 52.433 & 28,02 \\
\hline Promedio general & 12,889 & 547 & 87 & 98 & 10 & 47.562 & 29,12 \\
\hline Variación $\%+i$ - promedio & 9,7 & 10,3 & 8,1 & 7,7 & 25 & 9,1 & 12,6 \\
\hline
\end{tabular}

* Rend. SSL = rendimiento de arroz, sano, seco y limpio; Pan $/ \mathrm{m}^{2}=$ panojas por metro cuadrado; GII/p= granos Ilenos por panoja; GT/p= total de granos por panoja; GV/p= granos vacíos por panoja; $\mathrm{G} \|-\mathrm{sll} / \mathrm{m}^{2}=$ granos llenos más semillenos por metro cuadrado; $P M G=$ peso de mil granos. 
En el cuadro 69 se observan los promedios de componentes del rendimiento obtenidos en 10 muestreos realizados en cada tecnología (testigo y alternativa) y su dispersión en referencia a los mismos (DE) en las validaciones instaladas en la zafra 20162017. En Rincón de Ramírez no se presentan las cantidades de granos, dado que se produjo desgrane en las muestras respectivas antes de realizarse los conteos correspondientes; por el mismo motivo no se incluye esta localización en el promedio de valores de cada columna presentados al pie.

Es de destacar que los muestreos son en su conjunto una estimación de lo que sucede en una superficie mucho mayor (en las validaciones en promedio 87.500 veces) y como consecuencia sus números pueden sobrestimar las cantidades reales. En general se logró una alta producción de panojas en todas las localidades con las 2 tecnologías (promedio 559, rango de variación $13,1 \%$ ), similar a los tratamientos de máxima productividad seleccionados en los experimentos (551 sin considerar Rincón de Ramírez en el Cuadro 74). En San Francisco, $7^{\mathrm{a}}$ de Treinta y Tres e India Muerta con la propuesta alternativa se logró un número mayor de panojas $/ \mathrm{m}^{2}$ (595 PA vs 542 TT), mientras que fueron de un nivel similar en Cebollatí y Vuelta Grande (544 PA vs 547 TT). El número total de granos a llenar por panoja, fue mayor con la alternativa en $7^{\text {a }}$ de Treinta y Tres y Cebollatí (113 PA vs 90 TT), similar en San Francisco $(90,87)$ y mayor en la tecnología testigo (PA 114 vs 143 TT) en Vuelta Grande e India Muerta donde se sembró la variedad INIA Tacuarí, que se caracteriza por formar panojas más grandes y granos más livianos.

Considerando en conjunto la información obtenida en los tratamientos de alta productividad en la etapa de investigación y los correspondientes a las 2 tecnologías (TT y $\mathrm{PA}$ ) en las validaciones, se realizó una comparación de potenciales de rendimiento (Cuadro 70). Se presenta el rendimiento real obtenido (SSL), los componentes en forma individual y un cálculo teórico del potencial basado en el producto de los números de granos llenos y el peso de granos en cada una de las 3 situaciones (alta productividad, TT, PA). En la primera columna se muestra que los rendimientos de las propuestas alternativas en

Cuadro 69. Componentes del rendimiento promedio en parcelas de las validaciones, zafra 2016-2017*.

\begin{tabular}{|c|c|c|c|c|c|c|c|c|c|c|c|c|c|c|}
\hline LOC & Tec & $\begin{array}{c}\text { Ren. SSL } \\
\text { tha }\end{array}$ & Panimt & $\mathrm{DE}$ & Gllp & $\mathrm{DE}$ & GTip & $\mathrm{DE}$ & GVip & $\mathrm{DE}$ & G $\| \mathrm{lim}^{2}$ & $\mathrm{DE}$ & PMG g & $\mathrm{DE}$ \\
\hline $\begin{array}{l}\mathrm{RR} \\
\approx\end{array}$ & $\begin{array}{l}\text { TT } \\
\text { PA }\end{array}$ & $\begin{array}{r}9,908 \\
10,576\end{array}$ & $\begin{array}{l}622 \\
624\end{array}$ & $\begin{array}{l}127 \\
132\end{array}$ & - & $\cdot$ & - & - & - & $\cdot$ & - & - & $\begin{array}{l}28,90 \\
31,81\end{array}$ & $\begin{array}{l}0,44 \\
0,70\end{array}$ \\
\hline$\overline{S F}$ & $\begin{array}{l}\text { TT } \\
\text { PA }\end{array}$ & $\begin{array}{r}9,507 \\
12,234\end{array}$ & $\begin{array}{l}614 \\
661\end{array}$ & $\begin{array}{l}118 \\
104\end{array}$ & $\begin{array}{l}79 \\
81\end{array}$ & $\begin{array}{l}14 \\
10\end{array}$ & $\begin{array}{l}90 \\
87\end{array}$ & $\begin{array}{l}14 \\
10\end{array}$ & $\begin{array}{r}12 \\
5\end{array}$ & $\begin{array}{l}2 \\
1\end{array}$ & $\begin{array}{l}47729 \\
52473\end{array}$ & $\begin{array}{l}10217 \\
7110\end{array}$ & $\begin{array}{l}28,45 \\
28,35\end{array}$ & $\begin{array}{l}0,75 \\
0,58\end{array}$ \\
\hline $7^{a}$ & $\mathrm{TT}$ & 8,631 & 502 & 98 & 88 & 9 & 102 & 10 & 13 & 3 & 44234 & 10380 & 27,09 & 0,68 \\
\hline TT & $\mathrm{PA}$ & 10,945 & 565 & 109 & 98 & 11 & 117 & 7 & 19 & 8 & 54744 & 10849 & 26,39 & 0,53 \\
\hline CB & $\begin{array}{l}\mathrm{TT} \\
\mathrm{PA}\end{array}$ & $\begin{array}{l}9,077 \\
9,254\end{array}$ & $\begin{array}{l}586 \\
590\end{array}$ & $\begin{array}{l}165 \\
128 \\
\end{array}$ & $\begin{array}{l}72 \\
92\end{array}$ & $\begin{array}{l}16 \\
10\end{array}$ & $\begin{array}{r}78 \\
109\end{array}$ & $\begin{array}{l}17 \\
15\end{array}$ & $\begin{array}{r}6 \\
14 \\
\end{array}$ & $\begin{array}{l}3 \\
8\end{array}$ & $\begin{array}{l}40753 \\
54073\end{array}$ & $\begin{array}{c}9690 \\
10205\end{array}$ & $\begin{array}{l}27,69 \\
25,98\end{array}$ & $\begin{array}{l}1,44 \\
1,09\end{array}$ \\
\hline VG & $\begin{array}{l}\text { TT } \\
\text { PA }\end{array}$ & $\begin{array}{l}7,919 \\
9,330\end{array}$ & $\begin{array}{l}508 \\
498\end{array}$ & $\begin{array}{l}109 \\
111\end{array}$ & $\begin{array}{r}107 \\
80 \\
\end{array}$ & $\begin{array}{l}24 \\
10 \\
\end{array}$ & $\begin{array}{r}123 \\
91 \\
\end{array}$ & $\begin{array}{l}25 \\
12\end{array}$ & $\begin{array}{l}15 \\
10\end{array}$ & $\begin{array}{l}6 \\
5 \\
\end{array}$ & $\begin{array}{l}53208 \\
39834 \\
\end{array}$ & $\begin{array}{l}12134 \\
10732\end{array}$ & $\begin{array}{l}21,53 \\
25.86\end{array}$ & $\begin{array}{l}1,29 \\
1,10\end{array}$ \\
\hline IM & $\begin{array}{l}\text { TT } \\
\text { PA }\end{array}$ & $\begin{array}{l}10,096 \\
10,816\end{array}$ & $\begin{array}{l}510 \\
569\end{array}$ & $\begin{array}{l}105 \\
111\end{array}$ & $\begin{array}{l}128 \\
107\end{array}$ & $\begin{array}{l}27 \\
18\end{array}$ & $\begin{array}{l}162 \\
136\end{array}$ & $\begin{array}{l}23 \\
19\end{array}$ & $\begin{array}{l}32 \\
27\end{array}$ & $\begin{array}{l}8 \\
7\end{array}$ & $\begin{array}{l}59269 \\
63398\end{array}$ & $\begin{array}{l}7846 \\
8428\end{array}$ & $\begin{array}{l}20,12 \\
25,46\end{array}$ & $\begin{array}{l}0,67 \\
0,50\end{array}$ \\
\hline Pr. & $\begin{array}{l}\text { TT } \\
\mathrm{PA}\end{array}$ & $\begin{array}{r}9,046 \\
10,516 \\
\end{array}$ & $\begin{array}{l}544 \\
555 \\
\end{array}$ & & $\begin{array}{l}95 \\
92 \\
\end{array}$ & & $\begin{array}{l}111 \\
108 \\
\end{array}$ & & $\begin{array}{l}16 \\
15 \\
\end{array}$ & & $\begin{array}{l}49864 \\
52079 \\
\end{array}$ & & $\begin{array}{l}24,98 \\
26,41 \\
\end{array}$ & \\
\hline $\begin{array}{l}\text { Rang } \\
\text { Vari } \\
\text { Pron }\end{array}$ & $\%$ & $\begin{array}{l}12,0 \\
14,2\end{array}$ & $\begin{array}{l}10,3 \\
13,3\end{array}$ & & $\begin{array}{l}25,8 \\
14,7\end{array}$ & & $\begin{array}{l}37,8 \\
22,7\end{array}$ & & $\begin{array}{l}81,3 \\
73,3\end{array}$ & & $\begin{array}{l}18,9 \\
22,3\end{array}$ & & $\begin{array}{c}16,7 \\
5,5\end{array}$ & \\
\hline
\end{tabular}

* Loc= localización; Tec= tecnología; Ren. SSL = rendimiento de arroz, sano, seco y limpio; pan $/ \mathrm{m}^{2}=$ panojas por metro cuadrado; GII/p= granos llenos por panoja; GT/p= total de granos por panoja; $\mathrm{GV} / \mathrm{p}=$ granos vacíos por panoja; G Ilen/m²= granos llenos por metro cuadrado; $P M G=$ peso de mil granos; $D E$ = desvío estándar; $\mathrm{RR}=$ Rincón de Ramírez; SF= San Francisco; $7^{\text {a }}$ TT= Séptima Sección de Treinta y Tres; VG= Vuelta Grande; $\mathrm{IM}=$ India Muerta; TT= tecnología testigo; PA= propuesta alternativa; ${ }^{* *}$ no se presenta la cantidad de granos en RR porque se produjo desgrane en las muestras de componentes; $\mathrm{Pr}^{* * *}=$ promedio de 5 localizaciones (no se considera RR); Rango +/- Variación \% Promedio = rango de variación porcentual más o menos el promedio. 
Cuadro 70. Registros promedio de componentes del rendimiento en tratamientos seleccionados por alta productividad en la etapa de investigación y de las 2 tecnologías en las validaciones*.

\begin{tabular}{lcccccccc}
\hline Tratamientos & $\begin{array}{c}\text { R SSL } \\
\text { t/ha }\end{array}$ & Par/m & G Ilen/p & G tot/p & G vac/p & G llen/m ${ }^{2}$ & $\begin{array}{c}\text { PMG } \\
\text { g }\end{array}$ & $\begin{array}{c}\text { Rend. pot. } \\
\text { t/ha }\end{array}$ \\
\hline Alta Productividad & 12,443 & 551 & 88,7 & 100 & 11,0 & 48874 & 28,31 & 13,823 \\
TT validaciones & 9,046 & 544 & 94,8 & 111 & 15,6 & 49864 & 24,98 & 12,454 \\
$\%$ TT val. /Alta Pr. & 73 & 99 & 107 & 111 & 142 & 102 & 88 & 90 \\
\hline PAvalidaciones & 10,516 & 575 & 91,6 & 108 & 15,0 & 52079 & 26,41 & 13,753 \\
$\%$ PAval. /Alta & 85 & 104 & 103 & 108 & 136 & 107 & 93 & 99 \\
Pr. & & & & & & & &
\end{tabular}

* Sin considerar Rincón de Ramírez; R SSL= rendimiento sano, seco y limpio obtenido; pan $/ \mathrm{m}^{2}=$ panojas por metro cuadrado; $G$ Ilen/p= granos llenos por panoja; $G$ tot $/ p=$ total de granos por panoja; $G$ vac/p= granos vacíos por panoja; G Ilen $/ \mathrm{m}^{2}=$ granos llenos por metro cuadrado; $P M G$ g= peso de mil granos en gramos; Rend. pot. $\mathrm{t} / \mathrm{ha}=$ rendimiento potencial basado en el número de granos llenos y su peso; TT= tecnología testigo; $\mathrm{PA}=$ propuesta alternativa; Alta $\mathrm{Pr} .=$ alta productividad.

promedio se aproximaron más en las validaciones a los obtenidos en los tratamientos de mayor productividad seleccionados en la etapa de investigación parcelaria, que los correspondientes a TT (85 y $73 \%$ ).

Si bien con la tecnología testigo de los mejores se obtuvo en las validaciones una cantidad de panojas similar y de mayor tamaño $(11 \%)$, presentaron mayor esterilidad y un peso de granos menor (12\%), resultando en un rendimiento potencial $10 \%$ menor que los de alta productividad. Con las prácticas alternativas, en base a una mayor producción de panojas y una esterilidad algo menor, se llegó a formar y llenar una cantidad mayor de granos, que a su vez resultaron más pesados y permitieron alcanzar el mismo nivel de rendimiento potencial logrado con los componentes en la etapa experimental (99\%).

\section{Rendimiento alcanzable $\left(R_{2}\right)$ vs potencial $\left(R_{p}\right)$}

Utilizando el modelo de simulación OryzaV3 para cultivares indica, Carracelas et al. (2016) reportaron que el rendimiento potencial $\left(R_{p}\right)$ del país es de $14 \mathrm{t} / \mathrm{ha}(\mathrm{SL}$, $14 \%$ humedad.); en particular, el potencial para Rocha se estimó en 14,7 t/ha y para Treinta y Tres en 13,7 t/ha (SL 14\% humedad). La media de rendimiento de los tratamientos alternativos en los 6 sitios de validación fue de 10,352 t/ha, con un máximo logrado en San Francisco $(11,979 \mathrm{t} / \mathrm{ha})$, lo que equivale a un $74 \%$ y un $86 \%$ respectivamente, del potencial promedio de ambos departamentos corregido a $13 \%$ de humedad (14 t/ha). Cassman et al. (2003), consideran que los rendimientos de chacra se estabilizan al alcanzar el $75-85 \%$ del $\left(R_{p}\right)$. Esto indica que las propuestas tecnológicas que surgen de este proyecto, están obteniendo rendimientos muy cercanos al potencial alcanzable por los productores. Se debe mencionar que el modelo ajustado por Carracelas et al. utilizó como base la información de la variedad El Paso 144 para la zona este y que las nuevas variedades evaluadas en el proyecto elevan sustancialmente los rendimientos en relación a esa variedad. Sería importante chequear si el utilizar coeficientes tecnológicos generados con los nuevos materiales genéticos disponibles, puede incidir en los resultados reportados por el modelo.

\subsubsection{Requerimientos nutricionales y su eficiencia}

Como complemento de la información referida a componentes del rendimiento, en el cuadro 71 se presentan los contenidos de nutrientes N-P-K de los mismos tratamientos seleccionados por alta productividad y de las tecnologías testigo y alternativa manejadas en las validaciones, de manera de visualizar con qué objetivos debemos utilizar las herramientas tecnológicas disponibles para satisfacer las demandas necesarias para alcanzarlos (los análisis de componentes de rendimiento y de contenidos de nutrientes no son presentados en esta publicación). A su vez, junto a las 
Cuadro 71. Contenidos promedio de nitrógeno, fósforo y potasio en grano y paja en tratamientos seleccionados por alta productividad en la etapa de investigación y de las 2 tecnologías en las validaciones*.

\begin{tabular}{|c|c|c|c|c|c|c|c|}
\hline \multirow[t]{2}{*}{ Localización } & \multirow[t]{2}{*}{ Tratamientos } & \multicolumn{2}{|c|}{$N \%$} & \multicolumn{2}{|c|}{$\mathrm{Pmg} / \mathrm{g}$} & \multicolumn{2}{|c|}{$\mathrm{K} \%$} \\
\hline & & grano & paja & grano & paja & grano & paja \\
\hline \multirow[t]{3}{*}{ Rincón de Ramírez } & Alta Productividad & 1,10 & 0,70 & 2,45 & 1,26 & 0,23 & 1,78 \\
\hline & TT validaciones & 103 & 054 & 257 & 1,67 & 0,23 & 1,11 \\
\hline & PAvalidaciones & 107 & 0,68 & 297 & 2,00 & 0,17 & 1,39 \\
\hline $\begin{array}{l}\text { San Francisco }-7^{3} \mathrm{~T} . \\
\text { Tres }\end{array}$ & Alta Productividad & 108 & 0,68 & 2,52 & 1,41 & 0,21 & 1,56 \\
\hline San Francisco & $\begin{array}{l}\text { TT validaciones } \\
\text { PA validaciones }\end{array}$ & $\begin{array}{l}1,06 \\
1,10\end{array}$ & $\begin{array}{l}0.61 \\
0.67\end{array}$ & $\begin{array}{l}2,86 \\
3,06\end{array}$ & $\begin{array}{l}0,93 \\
1,48\end{array}$ & $\begin{array}{l}0,20 \\
0,23\end{array}$ & $\begin{array}{l}0,88 \\
1,04\end{array}$ \\
\hline \multirow[t]{2}{*}{$7^{d}$ Sec. de Treinta y Tres } & TT validaciones & 1,19 & 0,63 & 224 & 1,23 & 0,21 & 1,33 \\
\hline & PAvalidaciones & 1.16 & 0.66 & 246 & 1.49 & 0.25 & 1.90 \\
\hline \multirow[t]{3}{*}{ Cebollatí } & Alta Productividad & 104 & 057 & 223 & 0,89 & 0,22 & 1,08 \\
\hline & TT validaciones & 121 & 0,65 & 286 & 0,85 & 0,19 & 1,03 \\
\hline & PAvalidaciones & 129 & 0,77 & 2,42 & 1,09 & 0,18 & 0,97 \\
\hline India Muerta & Alta Productividad & 109 & 0,66 & 2,44 & 1,17 & 0,22 & $1, \mathbb{0 3}$ \\
\hline \multirow[t]{2}{*}{ Vuelta Grande } & TT validaciones & 1,05 & 0,59 & 3,10 & 0,88 & 0,23 & 1,10 \\
\hline & PAvalidaciones & 100 & 0,52 & 2,85 & 0,90 & 0,21 & 1,11 \\
\hline \multirow[t]{2}{*}{ India Muerta } & TT validaciones & 1,17 & 0,67 & 2,73 & 1,10 & 0,22 & 1,26 \\
\hline & PAvalidaciones & 121 & 0,72 & 2,67 & 1,31 & 0,22 & 1,48 \\
\hline
\end{tabular}

* $\mathrm{N}=$ nitrógeno; $\mathrm{P}=$ fósforo; $\mathrm{K}=$ potasio; Alta productividad= seleccionados en la etapa de investigación parcelaria; $\mathrm{TT}=$ tecnología testigo; $\mathrm{PA}=$ propuesta alternativa.

producciones de materia seca, nos permiten conocer las cantidades absorbidas por las plantas y su eficiencia de conversión en grano.

Según Witt y Dobermann (2002) el balance de nutrientes óptimo se logra con una absorción de aproximadamente $15 \mathrm{~kg}$ de $\mathrm{N}$, 2,6 kg de P y $15 \mathrm{~kg}$ de $\mathrm{K}$ por tonelada de rendimiento de grano. Estas tasas de absorción de nutrientes son válidas para los objetivos de rendimiento que alcanzan del 70 al 80 por ciento del rendimiento potencial (máximo). A partir de entonces, opinan que la cantidad de nutrientes requeridos para producir una tonelada adicional de rendimiento de grano aumenta debido a la disminución de la eficiencia interna del uso de nutrientes.

En el cuadro 72 se presentan los valores promedio de cantidad de nutrientes $\mathrm{N}$ $\mathrm{P}-\mathrm{K}$ movilizados en las validaciones por tonelada de arroz producido, comparado con los reportados en otros sistemas de producción de arroz en Asia y Argentina.

En el caso de Asia, la información aparece discriminada con 2 niveles de disponibilidad de nutrientes, óptima y limitante. Según Witt et al. (1999) se asume que la absorción de un nutriente particular resulta ser más eficiente en una situación de bajo suministro del mismo, siempre que los otros nutrientes no sean limitantes en el crecimiento de la planta. Ello se puede observar en las menores cantidades de nutrientes necesarias por tonelada de grano, en el nivel limitante.

Los valores reportados por Quintero (2009) en Entre Ríos, Argentina, con respecto a los de Asia, se ubican en el extremo superior del intervalo limitante de $\mathrm{N}$, intermedio del mismo en $\mathrm{K}$ y se requiere algo más que el rango de nivel óptimo de $\mathrm{P}$ para producir una tonelada de grano. En los trabajos del proyecto, los requerimientos de $\mathrm{N}$ (media 14,4 kg; mediana 14,8 kg) están dentro del rango óptimo de disponibilidad de $\mathrm{N}$ presentado por Dobermann y Fairshurst en Asia; al igual que en Argentina e incluso un poco mayores son las cantidades de $P$ necesarias $3,2 \mathrm{~kg} / \mathrm{t}$ de grano (indicando un exceso) y en el caso de potasio (media 10,4 $\mathrm{kg}$; mediana $10,1 \mathrm{~kg}$ ) los valores se ubican próximos al extremo menor del rango limitante (o sea que se estaría absorbiendo con alta eficiencia).

El modelo QUEFTS de simulación (Quantitative Evaluation of the Fertility of 
Cuadro 72. Cantidad de nutrientes (N-P-K) movilizados por tonelada de grano en distintos sistemas de producción*

\begin{tabular}{|c|c|c|c|c|}
\hline Fuente & Disponibilidad & $\frac{N}{\mathrm{~kg} / \mathrm{t} \text { grano }}$ & $\begin{array}{c}P \\
\text { kg/tgrano }\end{array}$ & $\begin{array}{c}\mathrm{K} \\
\mathrm{kg} / \mathrm{tgrano}\end{array}$ \\
\hline $\begin{array}{l}\text { Asia-Dobermann } \\
\text { y Fairshurs }(2000)\end{array}$ & $\begin{array}{l}\text { Optima } \\
\text { Limitante }\end{array}$ & $\begin{array}{l}14-16 \\
11-13 \\
\end{array}$ & $\begin{array}{l}2,4-2,8 \\
1,7-2,3 \\
\end{array}$ & $\begin{array}{l}14-16 \\
10-13 \\
\end{array}$ \\
\hline $\begin{array}{l}\text { Argentina - } \\
\text { Quintero (2009) }\end{array}$ & media & 13 & 3 & 12 \\
\hline \multirow{2}{*}{$\begin{array}{l}\text { RTR } \\
\text { validaciones }\end{array}$} & $\begin{array}{l}\text { media general } \\
\text { (trt1 - trt } 9 / 12)\end{array}$ & $\begin{array}{c}14,4 \\
(14,3-14,5)\end{array}$ & $\begin{array}{c}3,2 \\
(3,2-3,3)\end{array}$ & $\begin{array}{c}10,4 \\
(9,9-10,8)\end{array}$ \\
\hline & $\begin{array}{l}\text { mediana general } \\
(\operatorname{trt} 1-\operatorname{trt} 9 / 12)\end{array}$ & $\begin{array}{c}148 \\
(14,5-14,9)\end{array}$ & $\begin{array}{c}3,2 \\
(3,2-3,2)\end{array}$ & $\begin{array}{c}10,1 \\
(9,8-10,1)\end{array}$ \\
\hline
\end{tabular}

${ }^{*} \mathrm{~kg}$ de nutrientes absorbidos en partes aéreas por tonelada de grano producido; trt= tratamientos.

Tropical Soils, Janssen et al., 1990), utilizado en los cálculos de cantidades de nutrientes a suministrar en Asia, considera rendimientos máximos menores que los obtenidos en el RTR y estima una disminución en las eficiencias internas de nutrientes cuando los rendimientos objetivo están cerca del potencial de rendimiento.

En el cuadro 73 se pueden observar las productividades parciales (PPFN), kg arrozl $\mathrm{kg} \mathrm{N}$ aplicado, e internas (EIN), kg arroz/kg $\mathrm{N}$ absorbido, promedio obtenidas en los trabajos de validación en los tratamientos $\mathrm{N}^{\circ}$ 1 y 9/12, tecnologías testigo y/o alternativas respectivamente.

La productividad parcial promedio de nitrógeno (PPFN) en la opción alternativa (tratamientos 9 y/o 12) de los trabajos de validación, duplica a la reportada como de nivel de disponibilidad óptimo por Witt et al. (2009); no obstante, al ser lograda en general con mayor aplicación del nutriente, resultó $26 \%$ menor al promedio obtenido con la tecnología testigo.

La eficiencia interna (EIN) alcanzada con la tecnología alternativa con la obtención de productividades más altas (análisis no presentados en esta publicación), también se ubica en valores de disponibilidad óptimo según Witt et al. (2009).

En el proyecto se utilizó una estrategia de fertilización combinada, por un lado considerando estimaciones de $\mathrm{N}, \mathrm{P}, \mathrm{K}$ en el suelo previo a la siembra y niveles críticos determinados por el sistema de investigación nacional y por otro las necesidades del cultivo de arroz para la obtención de un rendimiento de 12 t/ha. Además, se tuvo en cuenta no sólo un enfoque de suficiencia, sino también de mantenimiento de fósforo y potasio en el suelo. Este último aspecto, puede haber incidido en la obtención de menores valores de PPF (productividad parcial) de $\mathrm{P}$ y $\mathrm{K}$ que solamente consideran la

Cuadro 73. Productividad parcial y eficiencia interna de nitrógeno obtenidas en las validaciones 2016-2017 en comparación con otro sistema de producción*

\begin{tabular}{|c|c|c|c|}
\hline Fuente & Disponibilidad & $\begin{array}{c}P P F N \\
\mathrm{~kg} \text { arrozkgN apl. }\end{array}$ & $\begin{array}{c}\text { EIN } \\
\mathrm{kg} \text { arroz } / \mathrm{kg} \mathrm{N} \text { abs. }\end{array}$ \\
\hline \multirow{2}{*}{$\begin{array}{l}\text { Asia - } \\
\text { Witt et al. (2009) }\end{array}$} & Mediana & 44 & 58 \\
\hline & Óptima & $>=50$ & 68 \\
\hline \multirow{2}{*}{$\begin{array}{l}\text { RTR } \\
\text { validaciones }\end{array}$} & $\begin{array}{c}\text { media general } \\
\text { (trt1 - trt } 9 / 12 \text { ) }\end{array}$ & $\begin{array}{c}116 \\
(133-99)\end{array}$ & $\begin{array}{c}703 \\
(70.8-698)\end{array}$ \\
\hline & $\begin{array}{c}\text { mediana general } \\
\text { (trt1 - trt 9/12) }\end{array}$ & $\begin{array}{c}120 \\
(134-92)\end{array}$ & $\begin{array}{c}67,5 \\
(69,1-67,1)\end{array}$ \\
\hline
\end{tabular}

* PPFN = productividad parcial de $\mathrm{N}$; EIN = eficiencia interna de $\mathrm{N}$; apl. = aplicados; abs. = absorbidos; trt= tratamientos; mediana= cantidad de una serie de valores crecientes que la divide en dos partes iguales, superiores e inferiores a ella. 
producción de partes aéreas de plantas en la estación de crecimiento del cultivo, ignorando su residualidad en el suelo. La baja de la PPFN con el uso de mayores dosis de fertilizante, aún con aumentos importantes de rendimientos ejemplifica el difícil camino que tiene la intensificación sostenible, entendida como el camino de incrementar rendimientos manteniendo o mejorando los indicadores de sustentabilidad. Asociado a esto, otro tema a considerar será el destino final del $\mathrm{N}$ no adquirido por las plantas, que se puede perder en la atmósfera como gas de efecto invernadero, filtrarse a través del perfil del suelo para contaminar el agua subterránea, o por escorrentía contaminando los cursos de agua superficiales (Fisher, 1998).

Con la disponibilidad cada vez mayor de información meteorológica a través de Internet, es posible ajustar el manejo de nitrógeno según las condiciones ambientales existentes y probables de ocurrir en los días siguientes, haciendo un uso más eficiente de las aplicaciones en cobertura. 


\section{5 - CONCLUSIONES}

Se identificó y regionalizó un conjunto de prácticas de manejo del cultivo que son las que utilizan los productores de mayor rendimiento en la zona este del país. Se conformaron tres subregiones: 1 . Treinta y Tres; 2. Norte de Lavalleja, Lascano y Cebollatí; 3. India Muerta, San Luis, 18 de Julio.

Los resultados de dos años de ensayos y uno de validación en campos de productores mostraron que existen oportunidades de mejora en la productividad, a pesar de los ya altos rendimientos que obtiene el sector arrocero uruguayo, particularmente los productores de punta. Esta confirmación rebate la hipótesis que dio origen a este proyecto en 2011 y 2012, en la cual se pensó que se estaba llegando al techo de rendimientos posibles y había poco margen de mejora.

La utilización de cultivares resistentes y/ o tolerantes a las enfermedades, junto con un adecuado suministro de nutrientes considerando expectativas de altos rendimientos y buenos manejos del cultivo, permitió obtener incrementos superiores $(14,5 \%$ en promedio) a las metas iniciales de este trabajo. Se reafirma el concepto de integración de las medidas de manejo con los nuevos cultivares para mejorar resultados, ya que ni las variedades existentes con el nuevo paquete de manejo, ni las variedades modernas con el manejo convencional lograron el salto productivo. Es posible que pequeños ajustes en las prácticas, en especial en referencia a épocas de realización, permitan obtener aún mejores resultados.

Con las alternativas propuestas se movilizaron en promedio $14,5 \mathrm{~kg} \mathrm{~N}, 3,3 \mathrm{~kg} \mathrm{P}, \mathrm{y}$ $10,8 \mathrm{~kg} \mathrm{~K}$ por tonelada de grano producido en los trabajos de validación. La productividad parcial (PPFN) fue de $113 \mathrm{~kg}$ arroz/kg $\mathrm{N}$ aplicado y la eficiencia interna (EIN) de $69,8 \mathrm{~kg}$ arroz/kg N absorbido promedio. Se consideran muy aceptables el balance de nutrientes, así como la PPFN y la EIN logradas, dado el nivel de productividad alcanzado y que la cantidad de nutrientes requeridos para producir una tonelada adicional de grano por encima del $70-80 \%$ del potencial $\left(R_{p}\right)$ aumenta, debido a la disminución de la eficiencia interna del uso de los mismos.

Se destaca la experiencia de estos tres años de trabajo conjunto entre los investigadores, los técnicos de las industrias y los productores, que fueron copartícipes desde las etapas de formulación del proyecto. Este involucramiento integral aseguró la pertenencia y el compromiso de todas las partes en los resultados del mismo y en la difusión hacia el resto del sector. A su vez, permitió valorar la eficacia de un abordaje integral, conjunto y participativo de los distintos aspectos clave del manejo del cultivo cuando el objetivo es mayor, en este caso intentar rendimientos significativamente superiores a los de los mejores productores de la región.

Hubo una valoración altamente positiva de los trabajos de validación en campos de productores, conducidos por ellos mismos. Estas parcelas de validación de escala comercial dan confianza y credibilidad a otros productores en los resultados generados, son un escenario ideal para difusión y transferencia y en definitiva facilitan el proceso de adopción masiva de nuevas tecnologías.

Para los ambientes y condiciones climáticas predominantes en la región este del Uruguay existen combinaciones de practicas de manejo y nuevos cultivares que permiten explorar rendimientos mayores a los alcanzables con las tecnologías predominantes utilizadas por los productores de punta (hace 5 años). 



\section{8 - BIBLIOGRAFÍA}

Abal G., D’Angelo M., Cataldo J., Gutiérrez A., 2011. Mapa solar del Uruguay versión 1.0. Memoria Técnica. Montevideo, Ediciones Universitarias. 58 p. (Biblioteca Plural).

Aggarwal P.K., Hebbar K.B., Venugopalan M.V., Rani S., Bala A., Biswal A., Wani S.P., 2008. Quantification of yield gaps in rainfed rice, wheat, cotton and mustard in India. Global Theme on Agroecosystems, Report No 43.

Below F., Gentry L., 2011. Producing 300 bushels corn sustainably. Crop Physiology Laboratory Department of Crop Sciences, University of Illinois in Urbana Champaign. In: Fluid fertilizer Foundation Forum Proceedings. Scottsdale, AZ February 2011.

Blanco P., Roel A., Deambrosi E., Bonilla C., Cantou G., Molina F., 2010. Closing the yield gap in rice production in Uruguay: Impact of Technological changes. [Expanded abstract]. In: International Rice Research Conference $\left(28^{\circ}, 2010\right.$, Hanoi, Vietnam). CGIAR, IRRI.

Cassman K.G., 1999. Ecological intensification of cereal production systems: yield potential, soil quality, and precision agriculture. Proceedings of the National Academy of Sciences USA, 96:11 p 59525959.

Cassman K.G., Dobermann A.D., Walters D., Yang H., 2003. Meeting cereal demand while protecting natural resources and improving environmental quality. Ann. Rev. Environ. Res. 28: 315-358.

Carracelas G., Guilpart N., Grassini P., Cassman K. 2016. Determinación del potencial y de la brecha de rendimiento en los sistemas de arroz en Uruguay. In: INIA Treinta y Tres, ed. Arroz: Resultados Experimentales 2015-2016. Cap. 2, p.58. (Actividades de Difusión, 765).

Deambrosi E., Méndez R., Roel A., 1997. Estrategia en la producción de arroz. Para un mejor aprovechamiento de las principales variables climáticas. Montevideo, INIA. 16 p. (Serie Técnica, 89).
Deambrosi E., Méndez R., 2007. Respuesta de cultivares de arroz de tipo índica a densidades de siembra y aplicaciones de nitrógeno en la zona Este de Uruguay. Montevideo: INIA. 36 p. (Serie Técnica, 167).

Dobermann A., Fairhurst T., 2000. Rice Nutrient disorders and nutrient management. Potash \& Phosphate Institute, Phosphate Institute of Canada, International Rice Research Institute. 191 p.

Evans L.T., 1993. Crop evolution, adaptation and yield. Cambridge, Cambridge University Press. 500 p.

Fisher K.S., 1998. Toward increasing nutrientuse efficiency in rice cropping systems: the next generation of technology. Field Crops Research, 56(1-2): 1-6.

Groth, D. E., Sanders D. E., 1996. Etiology and control of the delayed phytotoxicity syndrome [Abstract]. In: Proceedings of the Rice Technical Working Group, $\left(26^{\circ}\right.$, San Antonio, Texas, Feb. 25-28.), p. 203204.

Groth, D. E., Sanders D. E., Rich G., 1999. Delayed phytotoxicity syndrome of rice. Louisiana Agriculture, 42:13-14.

Janssen B. H., 1998. Efficient use of nutrients: an art of balancing. Field Crops Research, 56:197-201.

Janssen B.H., Guiking F.C.T., van der Eijk, D., Smaling, E.M.A., Wolf, J., van Reuler, H., 1990. A system for quantitative evaluation of the fertility of tropical soils (QUEFTS). Geoderma 46: 229-318

Khush, G.S., Peng, S., 1996. Breaking the yield frontier of rice. In: Reynolds MP, Rajaram $S$, McNab A, eds. Increasing yield potential in wheat: breaking the barriers. Proceedings of a Workshop held (1996, Obregón, Sonora, March26-28). El Batán (Mexico): International Maize and Wheat Improvement Center. p 36-51.

Kropff, M.J., Williams, R.L., Horie, T., Angus, J.F., Singh, U., Centeno, H.G., Cassman, K.G., 1994. Predicting yield potential of rice in different environments. In: Proceedings of the Temperate Rice - Achievements 
and Potential, v.2. Yanco, Agricultural Research Institute, NSW, Australia.

Laborte, A.G., De Bie, C.A.J.M., Smailing, E.M.A., Moya, P.F., Boiling, A.A., van Ittersum, M.K, 2012. Rice yields and yield gaps in Southeast Asia: past trends and future outlook. Eur. J. Agron. 36: 9-20.

Matsushima S. 1966. Crop science in rice: theory of yield determination and its application. Japan: Fuji Publ. Co. Ltd. p 1-365.

Méndez R., Deambrosi E., 2009. Coberturas nitrogenadas para la producción de arroz. Parte I, Eficiencia de aplicación. Montevideo: INIA. 38 p. (Serie Técnica; 179).

Mitchell P.L., Sheehy J.E., Woodward F.I., 1998. Potential yields and the efficiency of radiation use in rice. Makati City, Philippines: IRRI. (Discussion Paper Series $N^{\circ} 32$ ).

Pérez de Vida F., Molina F., 2011. Exploración del potencial de rendimiento. En: Arroz Resultados Experimentales 2010-2011. INIA Treinta y Tres. Cap. 7, p.9-14. (Actividades de difusión; 651).

Quintero C., 2009. Factores limitantes para el crecimiento y productividad del arroz en Entre Ríos, Argentina. Tesis doctoral Universidade da Coruña. Paraná: Fundagro-Fundación para el desarrollo agropecuario.

Siband P., Wey J., Oliver R., Letourmy P., Manichon H., 1999. Analysis of the yield of two groups of tropical maize cultivars: varietal characteristics, yield potentials, optimum densities. Agronomie, 18:545561.
Siband P., Witt Gines H.C., Simbahan G.C., Cruz R.T., 2004. Yield formation analysis of irrigated rice: characteristics of cultivars and on-farm crop diagnosis. In: Dobermann A, Witt C, Dawe D, eds.Increasing productivity of intensive rice systems through site-specific nutrient management. Enfield, N.H. (USA) y Los Baños (Filipinas): Science Publishers and IRRI. p-289-306.

SOSBAI, 2016. Arroz irrigado: recomendações técnicas da pesquisa para o sul do Brasil. Reunião técnica da cultura do arroz

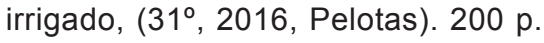

Uraga, R., 2011. Seminario Taller Brecha de rendimiento en arroz. INIA Treinta y Tres 20 de julio 2011

Wey J., Oliver R., Mandal R, Siband P., 1999. Analysis of local limitations to maize yield under tropical conditions. Agronomie, 18:545-561.

Witt C., Dobermann A., Abdulrachman S., Gines H.C., Wang G.H., Nagajaran R., Satawathananont S., Son T.T., Tan P.S., Tiem L.V., Simbahan G.C., Olk D.C., 1999. Internal nutrient efficiencies of irrigated lowland rice in tropical and subtropical Asia. Field Crops Research, 63:113-138.

Yoshida S., Parao F.T., 1976. Climatic influence on yield and yield components of lowland rice in the tropics. In: Climate and rice. Manila (Filipinas): IRRI. p. 471-494.

Yoshida S. 1981. Fundamentals of rice crop science. Los Baños (Filipinas): IRRI. 269 p. 


\section{Pautas de la entrevista a productorespertenecientes al quintil superior de rendimientos}

Edad: $20-30$; 30-40; 40-50; 50-60; >60 años

Nivel de educación: primaria; secundaria; técnico agropecuario o similar; terciaria

Localización: ¿En qué zona siembra? ¿Por qué razones siembra en la zona y no en otra?

Tamaño: ¿Qué superficies promedio sembró en los últimos 3-4 años?

Antecedentes de uso del suelo: ¿Qué usos anteriores del suelo dispuso para sembrar? ¿Retornos (con / sin pradera), rastrojos (1, 2, 3, 4... años); arrozbarbecho-arroz; arroz, verdeo, arroz? varias de esas situaciones en un mismo año?

$¿$ Trata de elegir o disponer de esas opciones (y/o proporciones), o siembra lo que se le presente en cada zafra?

Uso de insumos: ¿En general, planifica todos los insumos que va a utilizar antes de sembrar?

Uso de glifosato: ¿Aplica glifosato? ¿1 vez en primavera previo a la siembra; 1 ó a veces 2 , en primavera? ¿otoño y primavera? ¿más de 2 veces?

Cultivares: ¿Qué variedades siembra? ¿Por qué razones usa esa (s) variedad (es)?

Época de siembra: ¿Si le es posible, entre qué fechas trata de ubicar la siembra de sus cultivos? ¿25/9 al 15/10; $1 / 10$ al 20/ $10 ; 5 / 10$ al $25 / 10 ; 10 / 10$ al $30 / 10$ ?

Laboreo de verano: ¿Utiliza el laboreo de verano? ¿En toda el área; en parte del área? ¿En particular en los retornos?; ¿En general, no utiliza el LV?

Tipo de siembra: ¿Utiliza la siembra directa? ¿En la mayoría del área, o en parte? ¿Utiliza el laboreo reducido? ¿en la mayoría o en parte del área? ¿laboreo convencional?

¿En alguna oportunidad, utiliza la siembra al voleo?
Densidad de siembra ¿Qué densidad de siembra utiliza en general? ¿75; 100; 125; 150; 175; 200 kg/ha ; ¿depende del cultivar?

Tratamiento de semillas: ¿En la siembra, utiliza semilla tratada? ¿No; sí; siempre; a veces (en siembra más tempranas; de acuerdo a la preparación del suelo; de acuerdo a los antecedentes de la chacra; para reducir la densidad de siembra; otra razón).

Si trata la semilla, con qué tipo de producto? ¿Fungicida; insecticida; fungicida + insecticida; zinc; otro tipo (micronutrientes); promotores del crecimiento?

\section{Fertilización}

\section{Criterios utilizados para fertilizar}

¿Utiliza el análisis de suelo? ¿No; sí; a veces, no siempre? - criterio o niveles críticos manejados ( $N, P, K)$.

Tiene en cuenta: ¿El uso anterior de la chacra? ¿La variedad sembrada? ¿La época de siembra? ¿Las condiciones climáticas previstas? ¿La disponibilidad de riego? ¿Los precios del fertilizante (por fórmula)? ¿Otra razón?

Épocas de aplicación del fertilizante basal: ¿Aplica el fertilizante basal en forma anticipada, antes de la siembra? ¿Sí; no?

Si lo hace en forma anticipada: ¿Cree que es mejor por mayor eficiencia de absorción del fertilizante?; ¿por logística, para disponer de más tiempo de siembra en la época adecuada?

¿Qué nutrientes aplica en forma anticipada a la siembra? ¿Sólo P; N y P; P y K; $\mathrm{N}, \mathrm{P}, \mathrm{K}$; azufre, Zinc; Otros?

¿Qué nutrientes aplica en forma simultánea a la siembra? sólo $\mathrm{P}$; $\mathrm{N}$ y $\mathrm{P}$; $\mathrm{P}$ y K; N,P,K; azufre, Zinc; Otros?

Fuente de fertilizante basal: ¿Mezcla física; formulación química? ¿Qué formula 
de fertilizante utiliza? ¿Qué cantidades de fertilizante basal aplica normalmente?

Uso anterior: ¿Fertiliza de igual manera sin distinguir el uso inmediato anterior, retorno/rastrojo? ¿Fertiliza en forma diferente los rastrojos? Si los fertiliza en forma diferente, ¿cómo lo hace?

Retornos: $\mathrm{P}_{2} \mathrm{O}_{5}, \mathrm{~N}, \mathrm{~K}_{2} \mathrm{O} ; \mathrm{S}, \mathrm{Zn}$; otros

Rastrojos: $\mathrm{P}_{2} \mathrm{O}_{5}, \mathrm{~N}, \mathrm{~K}_{2} \mathrm{O} ; \mathrm{S}, \mathrm{Zn}$; otros

Si lo hace igual: $\mathrm{P}_{2} \mathrm{O}_{5}, \mathrm{~N}, \mathrm{~K}_{2} \mathrm{O} ; \mathrm{S}, \mathrm{Zn}$; otros

\section{Fertilización en cobertura Nitrógeno}

Fuentes utilizadas: Urea común; Verde urea; Novatec; $\mathrm{N}_{3} \mathrm{O}$ plus; otro?

Épocas y cantidades aplicadas: antes de macollaje; macollaje; primordio; antes de macollaje y primordio; macordio; macollaje y primordio: otra época

\section{Potasio}

¿Aplica K en cobertura? ¿Sí; no; a veces?

Tipo de aplicación: ¿terrestre; aérea?

Forma de aplicación: en conjunto con el nitrógeno; sólo

Foliares

¿Utiliza fertilizantes foliares? ¿Sí; no; a veces?

¿Los aplica al macollaje? ¿N; N+otros macronutrientes?; macro+micro?

¿Los aplica más tarde? ¿N; N+macro; macro+micro?

Tipo de aplicación de la $1^{\text {a }}$ cobertura de $\mathrm{Ni}$ trógeno;

¿terrestre antes de la inundación; aérea antes de la inundación; a veces aérea, a veces terrestre, pero siempre antes de la inundación? ¿en barro, o después de un baño?

¿Hace más de una cobertura nitrogenada, o no?

¿En qué se basa para dividir el $\mathrm{N}$ en distintas proporciones en las diferentes épocas de aplicación? ¿Experiencia personal; recomendación técnica del técnico del molino; recomendación del asesor privado? ¿Practicidad o economía / poder usar una aplicación terrestre vs aérea? ¿Para que cierre antes la entrefila? ¿macolle mejor? ¿porque no aplica basal? ¿por calidad de aplicación de la terrestre? ¿otra razón?

¿Conoce resultados de la investigación nacional, sobre posibles efectos de los manejos del $\mathrm{N}$ sobre la sanidad del cultivo? ¿Sí; no tiene conocimiento concreto?

\section{Manejo de malezas Aplicación de herbicidas}

¿Generalmente aplica el o los mismos herbicidas?

¿Aplica el o los productos, de acuerdo a: las malezas presentes? ¿A las malezas presentes y a la variedad sembrada? ¿A la variedad sembrada? ¿Otra razón?

¿Qué productos utiliza normalmente?

¿Un producto sólo, aunque sea esporádicamente o en situaciones puntuales? ¿Clomazone, quinclorac, penoxsulam, bispiribac, propanil, cyhalofop?

¿Mezclas dobles de productos: glifosatoclomazone; propanil-clomazone; bispiribac-clomazone; penoxsulamclomazone;cyhalofop-quinclorac; bispiribac-quinclorac; cyhalofoppenoxsulam; quinclorac-clomazone; quinclorac-penoxsulam?

¿Mezclas triples de productos: clomazonequinclorac-propanil; clomazonecyhalofop-quinclorac?

¿Secuencias de varios productos: glifosato+clomazone y ... ; otras?

¿Cypericidas y/o ...para malezas de hoja ancha: pyrazosulfuron; metsulfuron; triclopir; dicamba; otro? ¿Sólos, o en mezclas?

¿En alguna oportunidad, ha observado fitotoxicidad en el cultivo de arroz, atribuible a la aplicación de herbicidas? ¿Con un producto determinado?; ¿con el uso de mezclas determinadas?; ¿con alguna variedad en especial? ¿Otra razón?

Si observó fitotoxicidad, ¿recuerda qué condiciones climáticas existieron en el período pré o pos inmediato a la aplicación? 
¿Días fríos en el período previo? ¿Fríos en el período pos? ¿Lluvia en días previo a la aplicación?; ¿lluvia en días pos?; ¿frío y lluvia en días previos?; ¿frío y lluvia en días pos?; ¿otra razón? ¿en pozos?

¿Observó fitotoxicidad debidas a solapamientos de aplicaciones? ¿Sí; no?

¿Utiliza surfactantes, adjuvantes, humectantes, cuando aplica herbicidas?

sí - Usa uno que le anduvo bien, y le tiene confianza?; tiene en cuenta las recomendaciones del fabricante, para cada producto en particular? Otra razón

No: ¿porque considera que anda igual; antes de ocuparse de definir su agregado, prefiere agregarle una dosis un poco mayor; porque al usar mezcla de herbicidas, considero que no es necesario?

¿Tiene en cuenta la fuente de agua, para asegurar la calidad de la aplicación? ¿pH; dureza; sedimentos?. No: ¿utiliza la que tiene; comenzaron a traer las empresas aplicadoras; otro comentario?

¿Qué tipo de aplicación prefiere utilizar con los herbicidas? ¿terrestre; aérea? ¿Ajusta la dosis de herbicida, de acuerdo al tipo de aplicación? ¿Sí; no?

Si reduce la dosis de producto en la aplicación terrestre en relación a la aérea, ¿en qué proporción lo hace? ¿15\%; $20-30 \%$; $30-40 \% ; 40-50 \%$ ?

¿Qué volumen de aplicación utiliza con los herbicidas?

Terrestres: ¿30-50; 60; 75; 80-100?

Aéreas: ¿ 5-10; 20; 30; 40?

Aprovecha la aplicación de herbicidas, ¿para aplicar otro tipo de productos?

¿Fertilizante; insecticida; fungicida?

Si lo hace, ¿ve un efecto diferente de los productos? ¿antagonista; sinérgico

\section{Manejo del riego \\ Construcción de taipas}

¿Qué intervalo vertical utiliza en la nivelación? ¿3-4 cm; 5-6 cm; 7-8 cm; > $8 \mathrm{~cm}$ ?

Época de construcción: ¿Antes de la siembra? ¿sin resiembra de las mismas; des- pués de la siembra? ¿con resiembra de las taipas después de la siembra? ¿con resiembra y refertilización de las mismas

Tipo de taipa - ¿Alta; baja; mediana?

Momento de ingreso del agua

¿Ha necesitado bañar para promover la emergencia y/o uniformizarla?

¿Qué criterios utiliza para tomar la decisión?

¿Cuando dio baños para emergencia, en general precisó dar más baños a continuación?

¿Cómo maneja el riego?

¿En general, da un baño y trata de dejar con cierto nivel de agua cuanto antes, o prefiere llevar el cultivo a baños hasta cierta época?

En promedio, ¿con cuántos días después de la emergencia calza el cultivo? ¿20 dde (días después de la emergencia?; 25 dde; 30; 40 dde; 50 dde; más de 50 dde

¿Qué nivel de agua utiliza para regar? ¿Profundo hasta que dé la taipa?; ¿bajo?; ¿primero bajo y lo va subiendo gradualmente hasta primordio? ¿Otro?

¿Le gusta renovar el agua? ¿Sí, periódicamente; cuando veo algas, musgo...; no?

¿Cómo maneja el agua dentro de la chacra? ¿Llena el cuadro de más abajo, y va de abajo hacia arriba? ¿de arriba, va cortando hacia abajo?; ¿usa auxiliares, y maneja áreas de no más 25-30 ha?

\section{Manejo de enfermedades}

Sin entrar a considerar el uso de fungicidas, ¿cree que existen y utiliza manejos que pueden contribuir a no tener problemas más serios con las enfermedades?

¿Usar una variedad resistente y/o tolerante; tener en consideración el uso anterior de los suelos; el manejo de la fertilización nitrogenada; reducir la densidad de siembra de los rastrojos; otras opciones?

\section{Fungicidas}

¿Qué estrategia de uso utiliza?

¿Una aplicación en forma preventiva; una preventiva, y si aparecen síntomas 
decide una segunda aplicación curativa; dos aplicaciones preventivas; cuantas sean necesarias, 3 o más; si no hay síntomas, prefiere no aplicar?

En caso de considerarlo, diferenciar la estrategia, ya sea para enfermedades del tallo y/o para Brusone

¿Qué tipo de productos ha utilizado (si no hay problemas, qué marcas comerciales) ¿Preventiva (s) / Curativa (s)?

Cuando decide utilizar fungicidas, ¿considera importante las condiciones climáticas existentes al momento de la aplicación? Sí; no; indiferente

Si le es posible, ¿prefiere la aplicación se realice: en la mañana temprano (1) si no hay mucho rocío 2 ) haya o no haya mucho rocío); en la tardecita, sin alta temperatura, ni viento?

¿Qué volumen de aplicación utiliza? ¿5-10; $15 ; 20 ; 30 ; 40$ ?

\section{Manejo de insectos}

¿Utiliza insecticidas? ¿No; a veces; siempre?

Si aplica insectida, ¿qué utiliza? ¿cipermetrina; alfa-ciper metrina; lambda cihalotrina; imidacloprid; tiametoxam; lambda + imidacloprid; lamba + tiametoxam?

\section{Cosecha}

\section{Retiro de agua}

¿Prefiere en lo posible mantener la chacra con un nivel de agua hasta la cosecha?

¿Prefiere dejar de regar unos días antes de la cosecha, pero no corta hacia afuera? ¿25-30 d; 20-25 d; 15-20d?
¿Prefiere dejar de regar unos días antes de la cosecha, y también corta hacia afuera unos días después? 25-30 d; 20-25 d; $15-20 d$ / y después...

Dentro del alto nivel de rendimientos que obtiene en una zafra, en los últimos años, ¿qué variación encuentra entre los valores máximos y los mínimos? $i<10$ bolsas/ha; 10-15b/ha; 15-20 b/ha; 20-25 b/ ha; más de $20 \mathrm{~b} / \mathrm{ha}$ ?

¿A qué posibles factores atribuye las diferencias mencionadas?

¿Qué prácticas de manejo ha utilizado y le parece que podría modificar para incrementar los rendimientos?

¿Qué prácticas de manejo no ha utilizado y le parece podría contribuir a incrementar los rendimientos?

\section{Productividad}

A su criterio, ¿cuáles serían los 6-7 factores (más o menos, los que les parezca) más importantes que contribuyen a lograr una productividad alta?

Luego de seleccionarlos, ¿qué porcentaje de contribución al rendimiento le otorgaría a cada uno de ellos, de forma de cuantificar su importancia; dicho de otra manera darle a cada uno un número (\%), de forma que sumen 100 entre ellos. 


\section{ANEXO II}
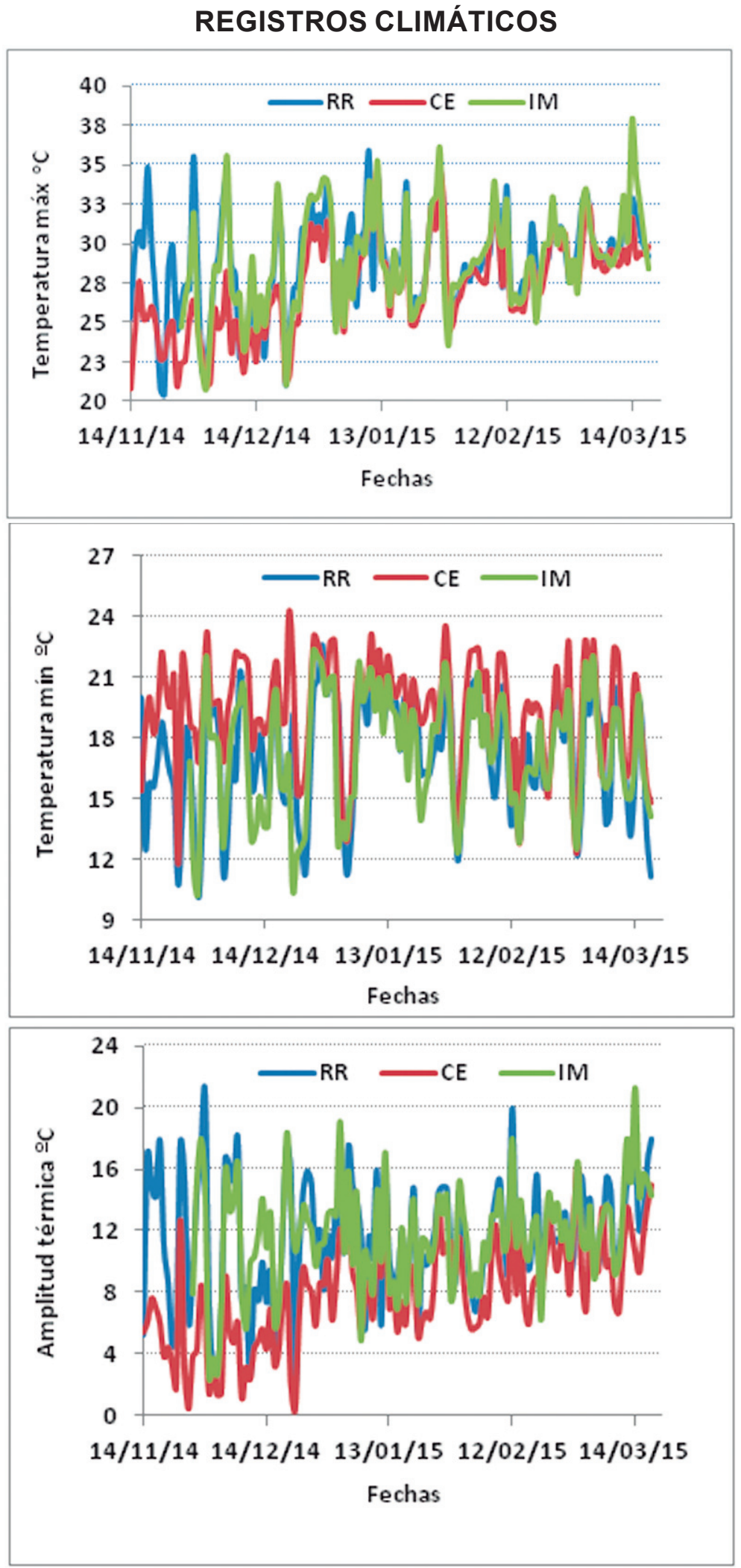

Figura 1. Temperaturas máximas, mínimas y amplitud térmica en Rincón de Ramírez (RR), Cebollatí (CE) e India Muerta (IM). Zafra 2014-2015. 


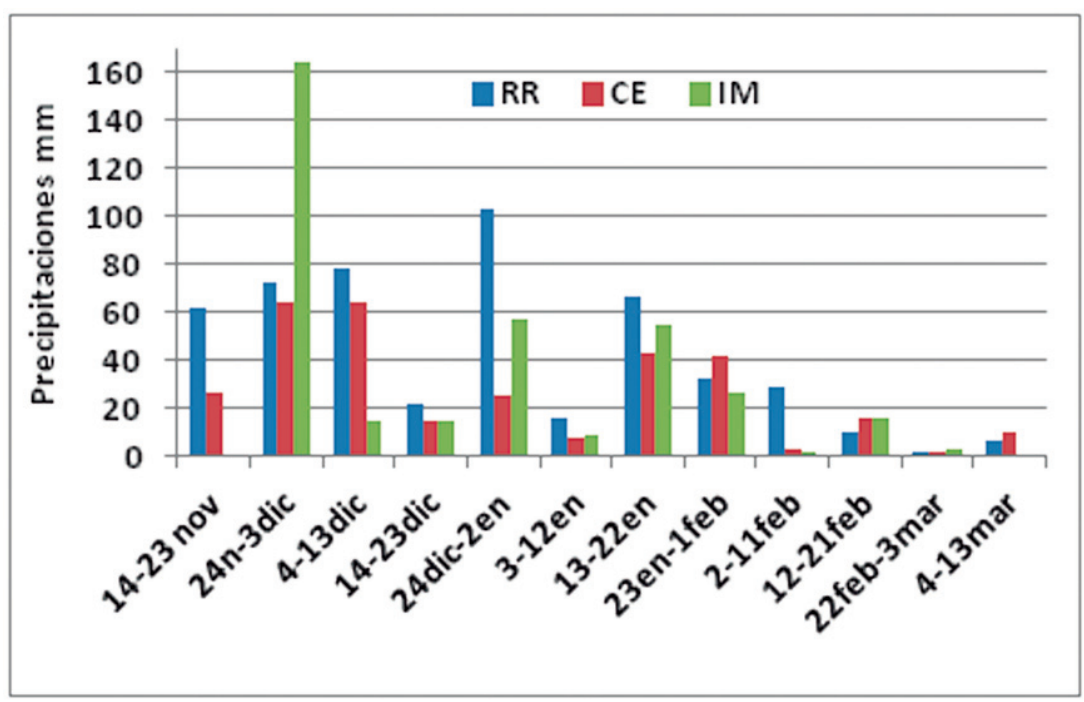

Figura 2. Precipitaciones desde el 14 de noviembre 2014 al 13 de marzo 2015 en Rincón de Ramírez (RR), Cebollatí (CE) e India Muerta (IM).

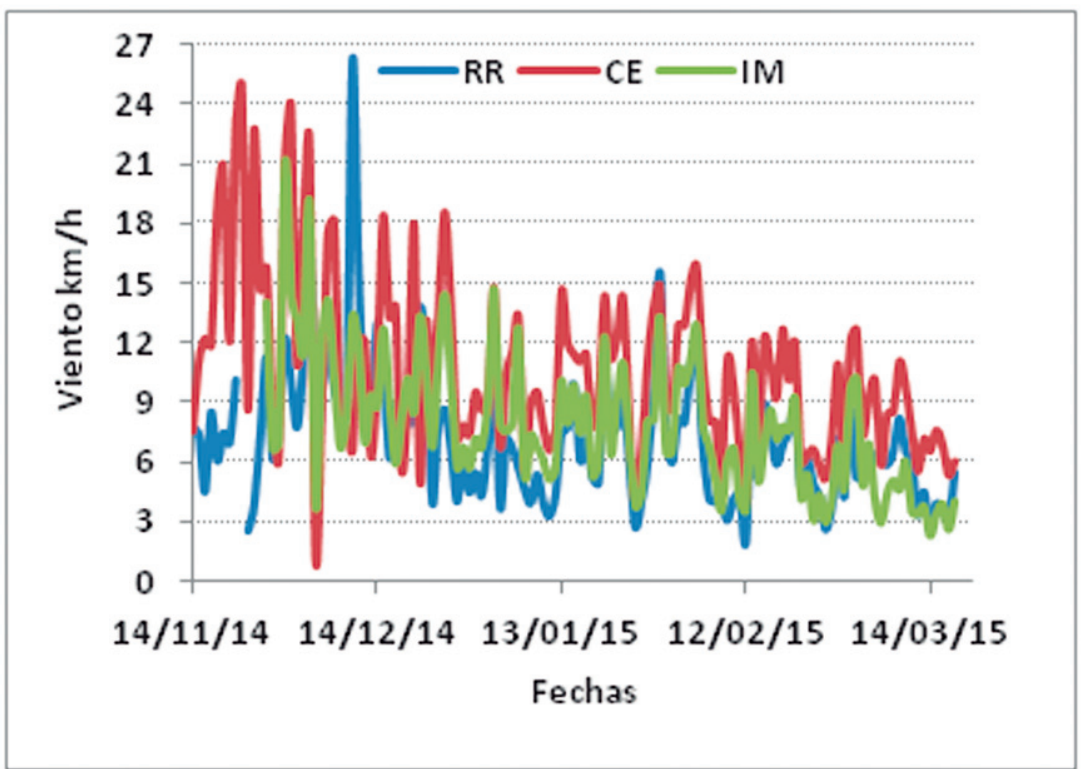

Figura 3. Viento en Rincón de Ramírez (RR), Cebollatí (CE) e India Muerta (IM). Zafra 2014-2015. 

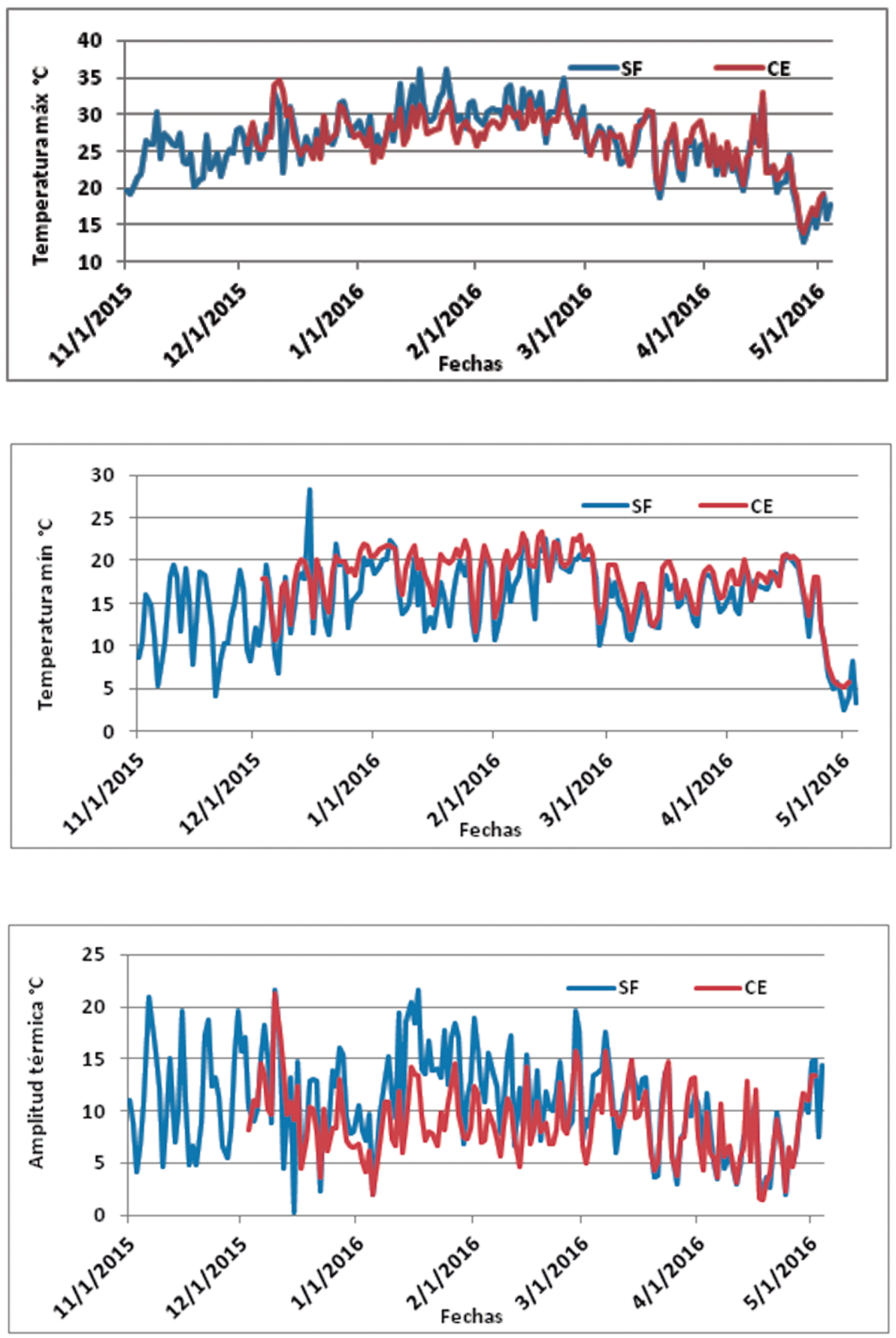

Figura 4. Temperaturas máximas, mínimas y amplitud térmica en Costas de San Francisco (SF) y Cebollatí (CE). Zafra 2015-2016. 


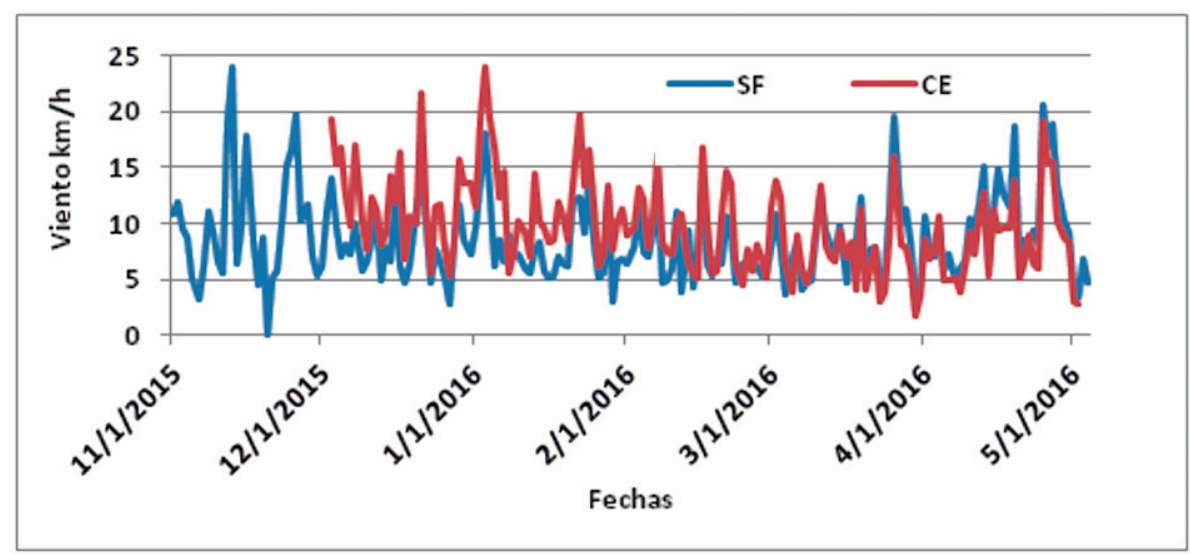

Figura 5. Viento en Costas de San Francisco (SF) y Cebollatí (CE). Zafra 2015-2016 

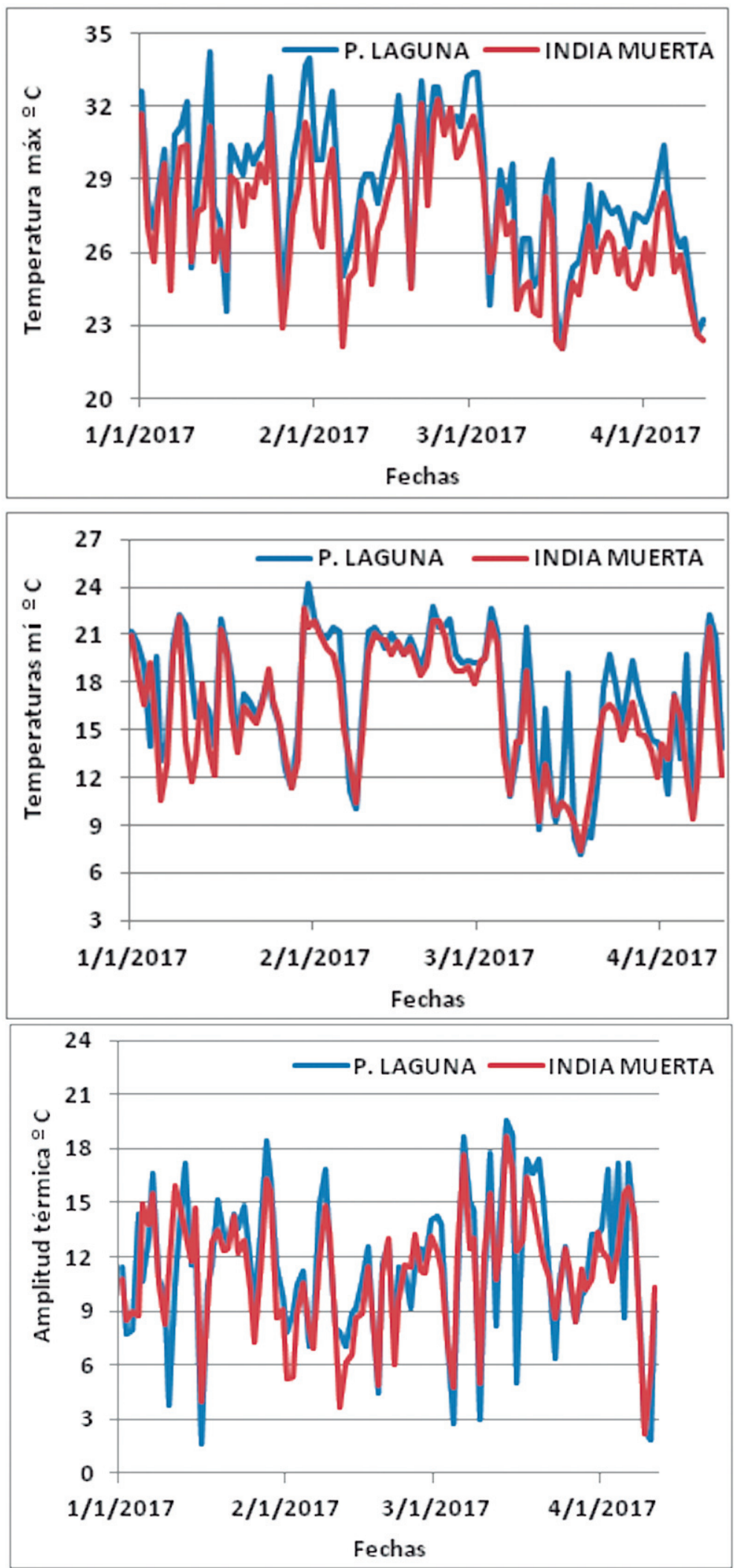

Figuras 6 Temperaturas máximas, mínimas y amplitud térmica, registradas en Paso de la Laguna (Treinta y Tres) e India Muerta (Rocha) respectivamente, desde el 1 de enero al 11 de abril 2017 


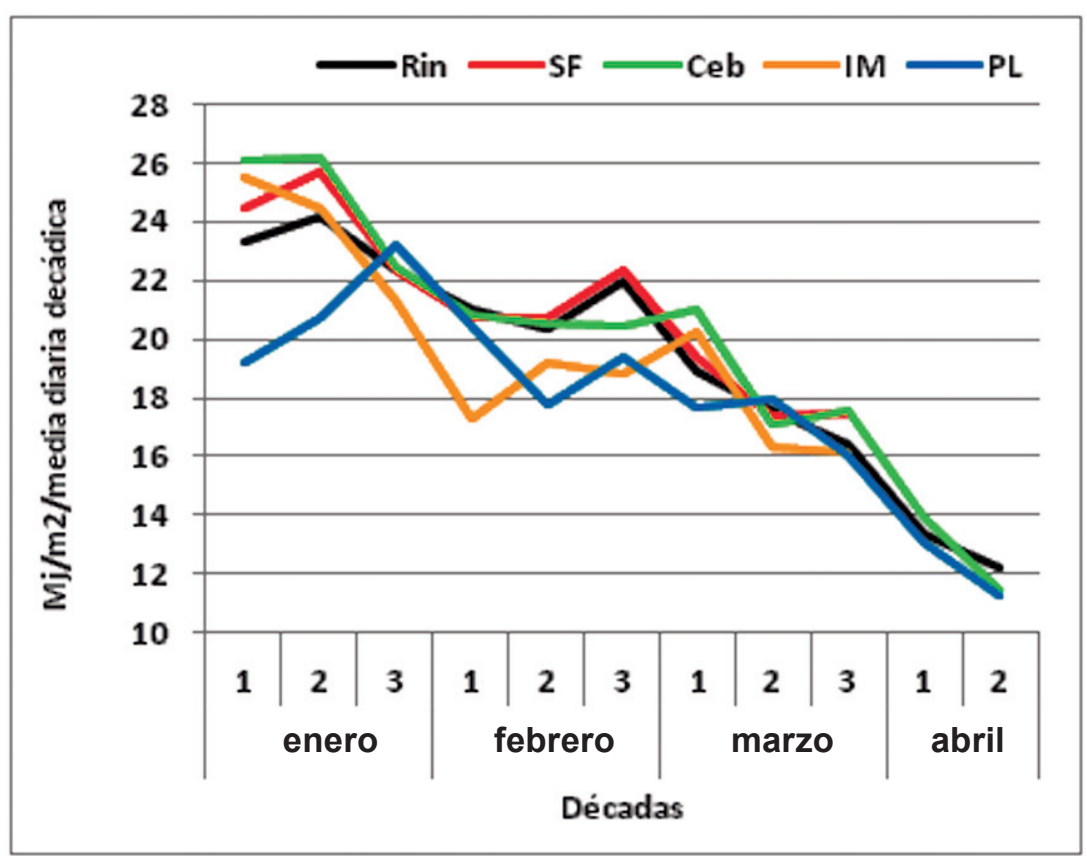

Figura 7. Radiación solar registrada en Rincón de Ramírez, Costas de San Francisco, Paso de la Laguna, Cebollatí e India Muerta, a partir de enero 2017 (promedios diarios según décadas)

Cuadro 1. Acumulaciones térmicas en India Muerta y Paso de la Laguna, zafra 2016-2017*.

\begin{tabular}{lccccc}
\hline Localización & \multicolumn{3}{c}{ Promedio acumulaciones diarias (GD $\left.\mathrm{G}_{10}\right)$} & Acumulación total $\left(\mathrm{GD}_{10}\right)$ \\
& enero & febrem & marzo & 1 al 10 abril & desde el 1/1 - 10/4 2017 \\
\hline India Muerta & 12,2 & 13,3 & 9,7 & 10,4 & 1156,7 \\
P. de Ia Laguna & 13,4 & 14,7 & 11,0 & 11,4 & 1282,5 \\
Relación \% IM & $-8,9$ & $-9,5$ & $-11,8$ & $-8,8$ & $-9,2$ \\
\hline
\end{tabular}

* $\left(\mathrm{GD}_{10}\right)=$ grados día, base $10{ }^{\circ} \mathrm{C}$. 
Depósito Legal: $373.883 / 19$

IMPRESO EN LA R. O. DEL URUGUAY

Editorial Agropecuaria Hemisferio Sur S.R.L.

Cassinoni 1629/804 - Teléfono 24022010

Montevideo - Uruguay

Email: libreriaperi@hemisferiosur.com.uy

http://www.hemisferiosur.com.uy

Facebook: Libreria Peri 
INIA Dirección Nacional

Andes 1365, P. 12

Montevideo

Tel.: 59829020550

Fax: 59829023633

iniadn@dn.inia.org.uy

INIA La Estanzuela Ruta 50, Km 11

Colonia

Tel.: 59845748000

Fax: 59845748012 iniale@le.inia.org.uy

INIA Las Brujas

Ruta 48, Km 10

Canelones

Tel.: 59823677641

Fax: 59823677609

inia_lb@lb.inia.org.uy

INIA Salto Grande

Camino al Terrible

Salto

Tel.: 59847335156

Fax: 59847329624

inia_sg@sg.inia.org.uy

INIA Tacuarembó

Ruta 5, Km 386

Tacuarembó

Tel.: 59846322407

Fax: 59846323969

iniatbo@tb.inia.org.uy

INIA Treinta y Tres Ruta 8, Km 281 Treinta y Tres Tel.: 59844522023 Fax: 59844525701 iniatt@tyt.inia.org.uy

www.inia.uy 